INSTITUTO DE PESQUISAS ENERGÉTICAS E NUCLEARES

Autarquia associada à Universidade de São Paulo

EFEITO DA IRRADIAÇÃO NA TOXICIDADE DE FÁRMACOS EM SOLUÇÃO AQUOSA: CLORIDRATO DE FLUOXETINA, DICLOFENACO DE SÓDIO E MISTURA DE AMBOS

FLÁVIO KIYOSHI TOMINAGA

Dissertação apresentada como parte dos requisitos para obtenção de Grau de Mestre em Ciências na Área de Tecnologia Nuclear - Aplicações

Orientadora: Dra. Sueli Ivone Borrely 
A minha família e amigos, em especial aos meus avós Xinzi e Tizuko, aos meus pais Milton e Marli e a irmã Andressa 
'Num intervalo de tempo suficientemente longo, o impossível se torna possível, o possível, provável, e o provável, virtualmente certo. Basta esperar: o tempo, por si só, realiza milagres." 


\section{AGRADECIMENTOS}

Primeiramente agradeço a Deus pela oportunidade de aprendizado e crescimento até o presente momento,

Á Dra Sueli Ivone Borrely pela orientação, ensinamentos, dedicação, confiança e simplicidade e por ter me concebido a oportunidade de realização deste trabalho.

Ao Dr Antônio Carlos e ao Dr Roque, pela parceria pelo apoio e dedicação.

Á Dra Ana Paula Batista e ao Dr Fábio Campos pelo apoio, profissionalismo, dedicação e atenção, doando parte do seu tempo para auxiliar nos experimentos.

Aos meus queridos pais, Milton e Marli, pela paciência compreensão e amor. Agradeço pelo apoio, confiança e esforços para auxiliar meus sonhos a se tornarem realidade.

À minha irmã Andressa, que sempre me incentivou e esteve ao meu lado, me apoiando e partilhando das conquistas da minha vida.

Aos meus avós, Xinzi (in memorian) e Tizuko, que cuidaram e me apoiaram por toda a vida, ajudando a concretizar meus projetos de vida.

Às grandes amigas de trabalho Stephanie e Nathalia, que sempre me auxiliaram no laboratório, dividindo momentos de boas conversas e aprendizados.

Ao técnico Reginaldo, que me auxiliava nos laboratório, pela ajuda prestada nos tempos de dificuldades, pelo companheirismo e confiança.

Aos engenheiros Carlos e Beth pela irradiação das amostras e pelo aprendizado.

Aos amigos Milson, Sara, Raquel que me auxiliaram nessa jornada e estiveram me prestando ajuda nos momentos de dificuldades e alegrias.

A todos os professores, funcionários da biblioteca e do Ensino do IPEN por terem sido prestativos e ter contribuído com meus conhecimentos. Ao pessoal da segurança e da faxina por tornarem o ambiente mais agradável.

Aos colegas de trabalho Aline, Haynne, Neildes, Fábio, Djalma, Edmilson, Vanessa, que dividiram momentos durante esse período.

Ao IPEN/CNEN pela concessão da bolsa e oportunidades de realizar o mestrado.

E a todos que deram a sua contribuição. Muito obrigado! 


\title{
EFEITO DA IRRADIAÇÃO NA TOXICIDADE DE FÁRMACOS EM SOLUÇÃO AQUOSA: CLORIDRATO DE FLUOXETINA, DICLOFENACO DE SÓDIO E MISTURA DE AMBOS
}

\section{FLÁVIO KIYOSHI TOMINAGA}

\begin{abstract}
RESUMO
As evidências da contaminação das águas por resíduos de medicamentos e seus subprodutos levou esse grupo de resíduos a compor a lista de poluentes orgânicos emergentes, como consequência da expansão do uso de medicamentos, como o antidepressivo cloridrato de fluoxetina e o anti-inflamatório diclofenaco. Diversos Processos Oxidativos Avançados vêm sendo aplicados para a degradação destes compostos. Dentre eles, o processo de irradiação com feixe elétrons obteve bons resultados na remoção de toxicidade e degradação de fármacos. O presente estudo consistiu em aplicar radiação ionizante como uma possível tecnologia para degradar os fármacos em águas. A irradiação de solução aquosa contendo os fármacos foi aplicada usando acelerador de elétrons, cuja eficiência foi discutida mediante análises químicas (Cromatografia Líquida Ultra Rápida e Carbono Orgânico Total (COT)), ecotoxicológicas (ensaios de toxicidade com Vibrio fischeri e Daphnia similis) e biológicas (Ensaios Respirométricos). Os resultados de COT indicaram mineralização não significativa dos compostos, mesmo sendo observada degradação máxima de 99,9\% para o diclofenaco e $55 \%$ para o cloridrato de fluoxetina na mistura (1:1) em 5.0 kGy. Foi observada toxicidade aguda dos fármacos, sendo mais acentuada para a fluoxetina, seguido do diclofenaco e, finalmente, da mistura para $V$. fischeri. Quando $D$. similis foram empregadas nessa avaliação, a ordem de toxicidade foi de fluoxetina, a mistura de ambos os medicamentos e do diclofenaco. Além disso, foi observada remoção de toxicidade nas amostras irradiadas em todas as doses aplicadas para a bactéria $V$. fischeri, com maior eficiência de remoção de toxicidade de $55 \%$, em 5 kGy, na mistura dos dois fármacos. Para a $D$. similis, foi observada remoção significativa de toxicidade da mistura apenas na dose 2,5 kGy. Os ensaios respiroétricos não indicaram biodegradabilidade após o tratamento.
\end{abstract}

Palavras-chave: diclofenaco, fluoxetina, mistura de fármacos, radiação ionizante, toxicidade. 


\title{
RADIATION EFFECTS ONTO TOXICITY OF PHARMACEUTICALS SOLUTION: HYDROCHLORIDE FLUOXETINE, SODIUM DICLOFENAC AND
}

\section{THEIR MIXTURE}

\section{FLÁVIO KIYOSHI TOMINAGA}

\begin{abstract}
The evidence of water contamination by pharmaceuticals and byproducts residues took them to the list of wastewater emerging organic pollutants, as a result of expansion in drug usage. Fluoxetine hydrochloride antidepressant and diclofenac anti-inflammatory are good examplex. Several Advanced Oxidation Processes have been applied for degradation of these compounds. Among them, the electron beam irradiation process obtained good results in the removal of toxicity and degradation of pharmaceutical. The present study aimed to apply ionizing radiation as a possible technology to degrade the pharmaceutical in water. Irradiation of aqueous solution containing the pharmaceutical was applied using electron accelerator, whose efficiency was discussed through Chemical Analysis, COT, ecotoxicological (Toxicity Testing using Vibrio fischeri and Daphnia similis) and biological measurements (respirometric tests). The COT results indicated not significant mineralization of the compounds. It was observed maximum degradation of $99.9 \%$ for diclofenac and $55 \%$ for fluoxetine hydrochloride in a mixture solution (1:1) at 5.0 kGy. Regarding ecotoxicity, acute effects were more pronounced for fluoxetine, followed by diclofenac and finally the mixture, to Vibrio fischeri. When Daphnia similis were exposed fluoxetine was more toxic, followed by the mixture of both products and the third was diclofenac. Furthermore, radiation effects for removing toxicity was more effective with $V$. fischeri bacterium, all applied doses and $>55 \%$ removal of toxicity at $5 \mathrm{kGy}$ (in the mixture). To $D$. similis, toxicity removal was effective when treated with 2.5 kGy (mixture). No improvements in biodegradability was obtained by radiation ( respirometric tests).
\end{abstract}

Keywords: diclofenac, fluoxetine, ionizing radiation, pharmaceuticals mixture, toxicity. 


\section{SUMÁRIO}

Página

1. INTRODUÇÃO

2. OBJETIVOS

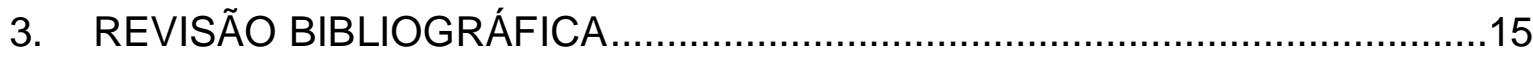

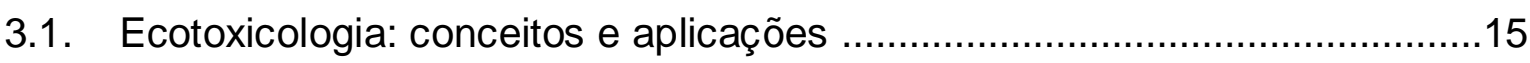

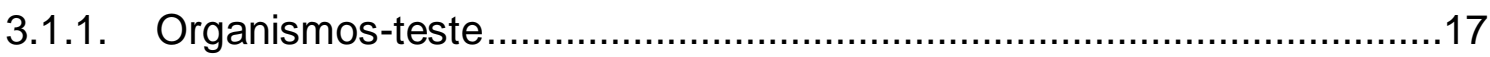

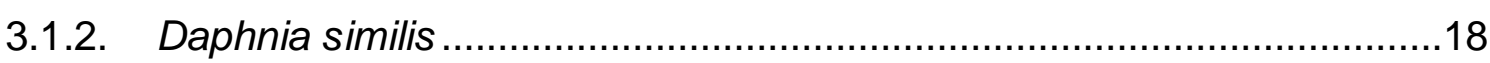

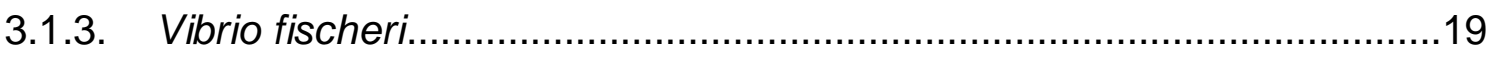

3.2. Poluição e a presença de fármacos no meio ambiente ................................21

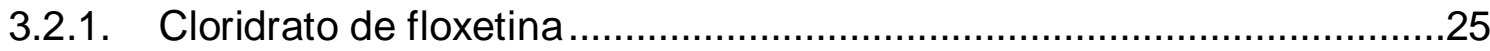

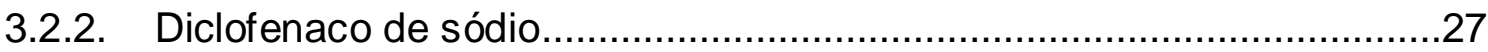

3.3. Riscos ambientais associados à presença de fármacos e seus resíduos ...28

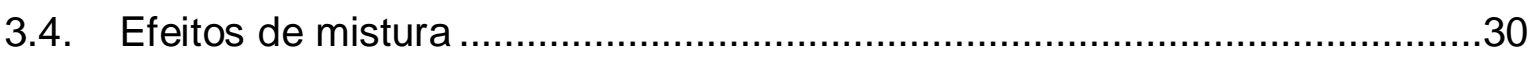

3.5. Principais processos de tratamento de efluentes ........................................31

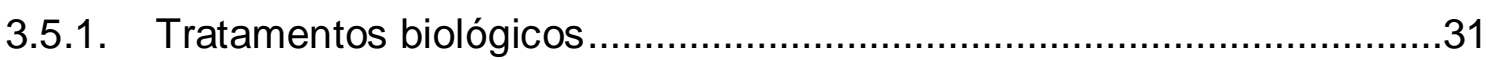

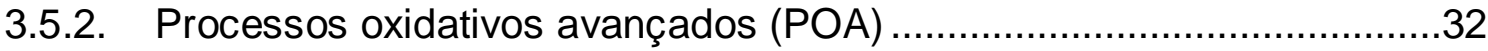

3.5.2.1. Aplicações da Radiação ionizante para o tratamento de águas .........33

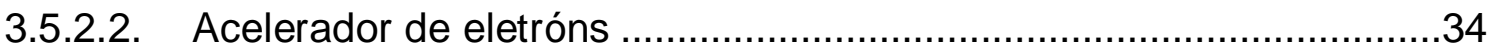

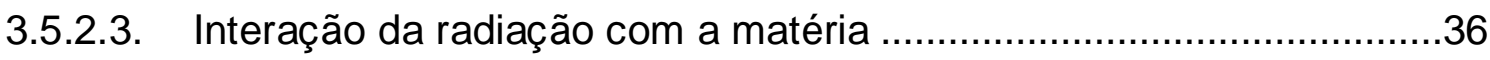

3.5.2.4. Associação de processos oxidativos avançados com tratamentos

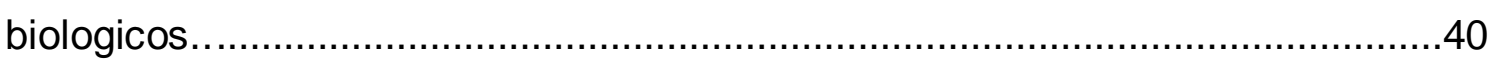

3.6. Análise de carbono orgânico total (COT) ……........................................... 41

3.7. Cromatografia líquida ultra rápida .............................................................. 41

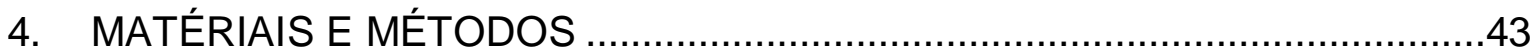

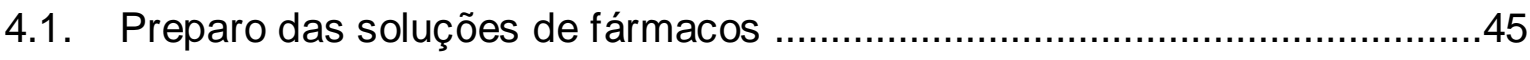

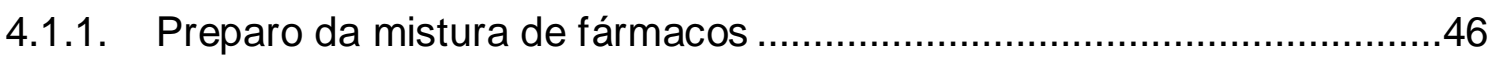

4.2. Irradiação das amostras (fármacos em solução aquosa) ...............................46

4.3. Análises químicas empregadas ...........................................................4

4.3.1. Análises de carbono orgânico total (COT) ………………................47

4.3.2. Análises de cromatografia líquida ultra rápida......................................48

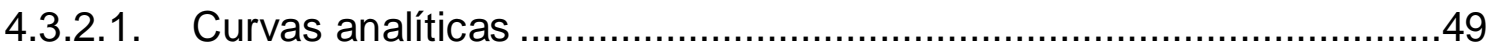

4.4. Aplicação de ensaios de ecotoxicológicos ................................................50 


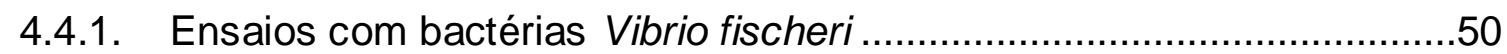

4.4.2. Ensaios com microcrustáceos Daphnia similis....................................51

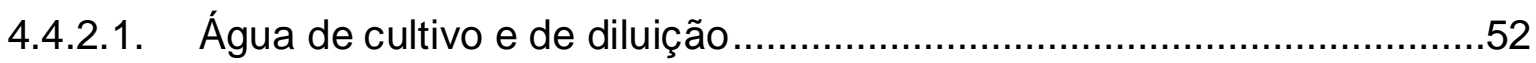

4.4.2.2. Manutenção do cultivo de Daphnia similis ........................................53

4.4.2.3. Ensaios de toxicidade aguda com Daphnia similis ............................55

4.5. Unidades tóxicas (UT) e eficiência de remoção de toxicidade .....................55

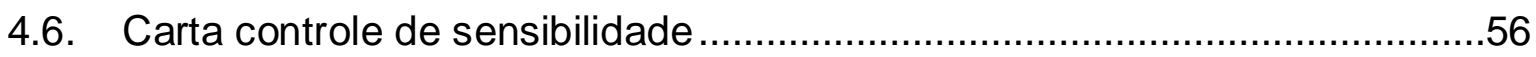

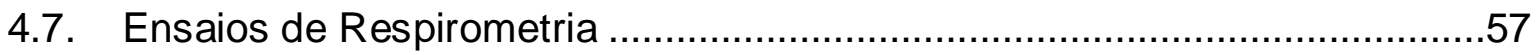

4.8. Análise estatística (ensaios ecotoxicológicos) …….......................................59

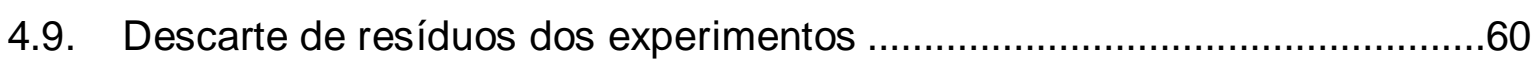

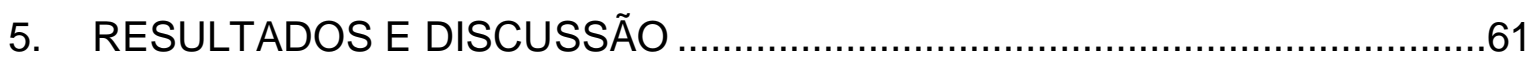

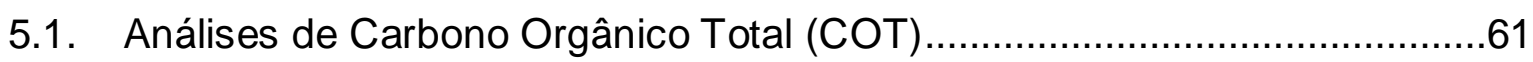

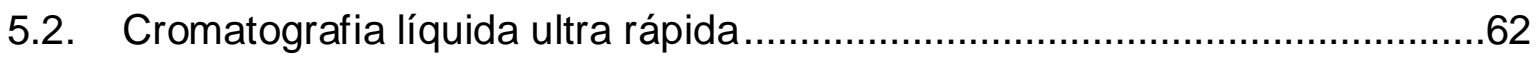

5.2.1. Curva de calibração das soluções cloridrato de fluoxetina e diclofenaco

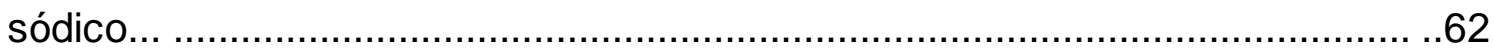

5.2.2. Efeito da irradiação nas amostras estudadas .......................................64

5.3. Ensaios ecotoxicológicos empregados …………...................................

5.3.1. Ensaios de Toxicidade aguda com Vibrio fischeri ................................71

5.3.2. Ensaios de Toxicidade aguda com Daphnia similis .............................75

5.3.3. Comparações entre a toxicidade dos fármacos .....................................80

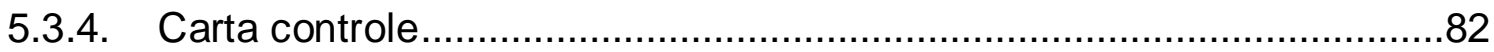

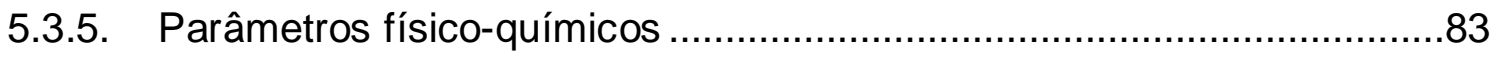

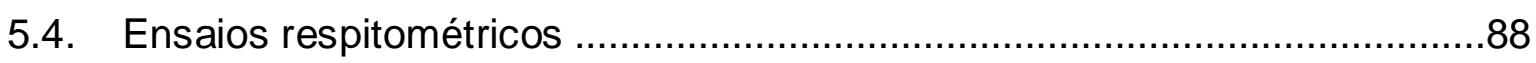

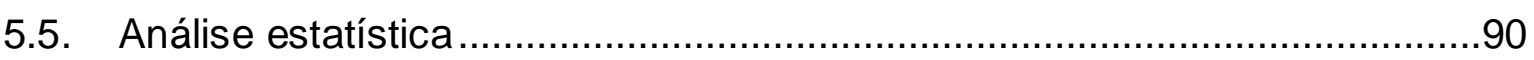

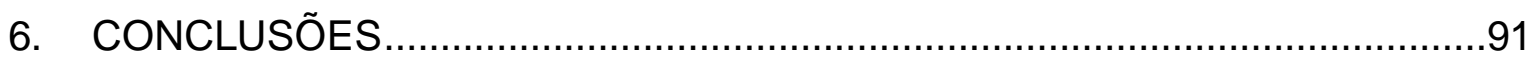

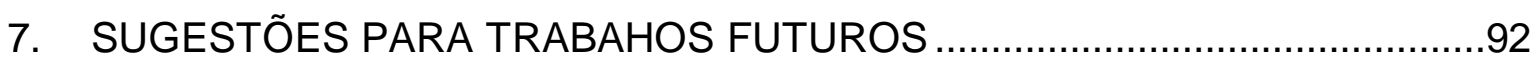

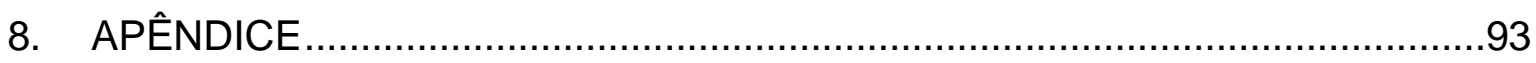

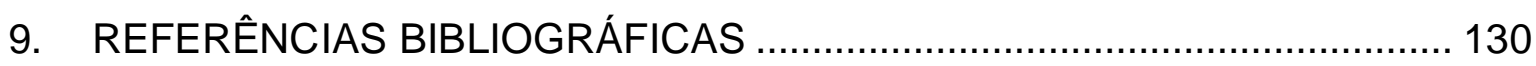




\section{LISTA DE TABELAS}

Tabela 1 - Detecção de fármacos em diferentes matrizes ambientais, incluindo águas para o consumo da população.

Tabela 2 - Parâmetros de toxicidade de diferentes organismos expostos à fluoxetina e diclofenaco. ...............................................................................29

Tabela 3 - Possíveis efeitos de uma mistura binária............................................31

Tabela 4 - Variação da constituição da fase móvel de acordo com o tempo, nas análises cromatográficas para a detecção dos fármacos cloridrato de fluoxetina e diclofenaco sódico.

Tabela 5 - Valores de Carbono Orgânico Total (COT) e eficiência de remoção de COT das misturas de fármacos (cloridrato de fluoxetina e diclofenaco sódico) após a irradiação por feixe de elétrons em diferentes doses.

Tabela 6 - Limites de Detecção (LD) e Limites de Quantificação (LQ) para os curvas anaíticas obtidas pela cromatigrafia ultra rápida.

Tabela 7 - Valores de concentrações dos fármacos cloridrato de fluoxetina e diclofenaco sódico, bem como valores de eficiência de remoção para estes compostos utilizando a radiação por feixe de elétrons.

Tabela 8 - Concentrações dos fármacos cloridrato de fluoxetina e diclofenaco sódico na mistura mais concentrada (A), bem como eficiência de degradação dos compostos em diferentes doses de radiação.

Tabela 9 - Concentração dos fármacos cloridrato de fluoxetina e diclofenaco sódico na mistura diluída 1:10 (B), bem como eficiência de degradação destes compostos em diferentes doses de radiação (kGy).

Tabela 10 - Valores de $C E 50_{15 m i n}$ para os fármacos cloridrato de fluoxetina e diclofenaco sódico para a bactéria marinha $V$. fischeri........................................71 Tabela 11 - Valores de CE5015 min e Unidades Tóxicas para a mistura mais concentrada (A) (Diclofenaco sódico e Cloridrato de Fluoxetina)..........................72 Tabela 12 - Valores de CE50 ${ }_{15 m i n}$ e Unidades Tóxicas (UT) para o diclofenaco sódico. .73

Tabela 13 - Valores de CE50 15min, Unidades Tóxicas e Eficiência de Remoção de Toxicidade para a mistura mais concentrada (A) dos fármacos cloridrato de fluoxetina e diclofenaco sódico para $V$. fischeri.

Tabela 14 - Valores de CE50 para os fármacos cloridrato de fluoxetina e diclofenaco sódico.

Tabela 15 - Valores de Unidades Tóxicas para a mistura mais concentrada (A) (Diclofenaco sódico e Cloridrato de Fluoxetina).

Tabela 16 - Valores de CE50 ${ }_{48 \mathrm{~h}}$ e Unidades Tóxicas (UT) para os fármacos cloridrato de fluoxetina e diclofenaco sódico.

Tabela 17 - Valores de CE50 48h, Unidades Tóxicas e Eficiência de Remoção de Toxicidade para a mistura mais concentrada $(A)$ dos fármacos cloridrato de fluoxetina e diclofenaco sódico para $D$. similis.

Tabela 18 - Valores de CE50 48h, Unidades Tóxicas e Eficiência de Remoção de Toxicidade para a Diluição 1:10 dos fármacos cloridrato de fluoxetina e diclofenaco sódico para $D$. similis.

Tabela 19 - Valores de CE50 (mg. $\mathrm{L}^{-1}$ ) dos fármacos cloridrato de fluoxetina e diclofenaco sódico para os organismos $V$. fischeri e $D$. similis.

Tabela 20 - Valores de $\mathrm{pH}$ da mistura de cloridrato de fluoxetina e diclofenaco sódico (misturas concentrada (A) e diluida 1:10 (B)) utilizadas nos ensaios de toxicidade. 
Tabela 21 - Valores de Oxigênio Dissolvidos da mistura de cloridrato de fluoxetina e diclofenaco sódico utilizados nos ensaios de toxicidade.

Tabela 22 - Valores de condutividade da mistura de cloridrato de fluoxetina e diclofenaco sódico utilizados nos ensaios de toxicidade.

Tabela 23 - Dados calculados pelo teste de Turkey para verificar a variação significa entre as médias de CE50. 


\section{LISTA DE FIGURAS}

Figura 1 - Daphnia similis. Fonte: MORAIS, 2015........................................18 Figura 2 - (a) Microcrustaceo Daphnia similis com efípio. (b) Efipio. Fonte Alves,

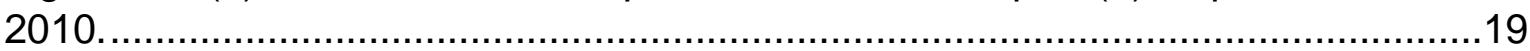

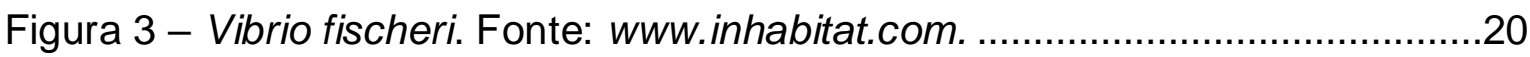
Figura 4 - Receita do mercado farmacêutico mundial 2001-2014. Fonte:

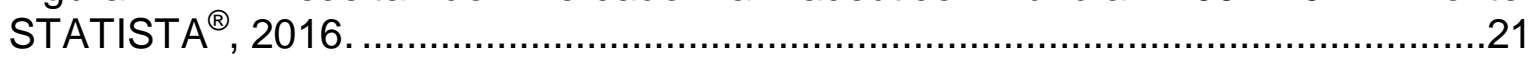

Figura 5 - Formula estrutural do cloridrato de fluoxetina. Fonte: Silva, 2014 ........26

Figura 6 - Estrutura química do diclofenaco de sódio. Fonte: PUBCHEM. .............28

Figura 7 - Comparação entre acelerador de elétrons e um tubo de televisão. Fonte: BORRELY, 2001.......................................................................

Figura 8 - Formas de interação da radiação ionizante - ação direta e indireta.

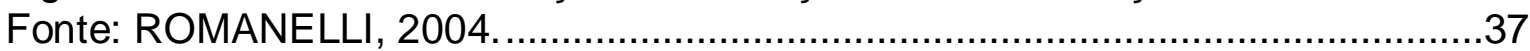

Figura 9 - Fluxograma das etapas desenvolvidas no pres ente estudo. .................44 Figura 10 - Embalagens de fármacos comerciais utilizados no preparo das soluções estoques, em estudo. ………....................................................... 46 Figura 11 - (a) Amostras das soluções de fármacos, contidas em vidro Pirex ${ }^{\circledR}$, passando sob o feixe de elétrons, durante o tratamento no acelerador ................47

Figura 12 - Analisador de Carbono Orgânico Total (COT). ..................................48 Figura 13 - Equipamento utilizado nas análises cromatográficas (Cromatógrafo Modelo UFLC 20 AD, Shimadzu)...............................................................48 Figura 14 - Bactéria bioluminescente Vibrio fischeri (Biolux ${ }^{\circledR}$ ) adquiridas em lotes

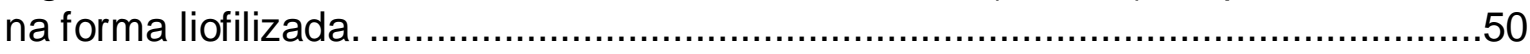
Figura 15 - Sistema analisador (Micotox® 500) empregado no ensaio com a bactéria bioluminescente Vibrio fischeri...............................................................51 Figura 16 - Equipamentos utilizados para medir os valores de $\mathrm{pH}$, condutividade e Oxigênio Dissolvido (OD). ............................................................................53 Figura 17 - Câmara de germinação com temperatura e fotoperíodo controlados. 53 Figura 18 - (a) Cultivo de microalga Pseudokirchneriella subcaptada sob aeração e iluminação constantes (b) Fermentação da ração líquida para a manutenção dos organismos. . .54 Figura 19 - Sistema utilizado para incubação de amostras durante os ensaios com Daphnia similis. ............................................................................................5 Figura 20 - Esquema operacional para realização de testes respirométricos. ......58 Figura 21 - Equipamentos utilizados para a realização dos ensaios respirométricos, EPUSP .59 Figura 22 - Curva analítica obtida utilizando espectrometria de emissão de fluorescência com leitura no comprimento de onda de excitação $=230 \mathrm{~nm}$ e emissão $=290 \mathrm{~nm}$ para a fluoxetina, com intervalos de detecção de (a) 0,01142 a $0,9856 \mathrm{mgL}^{-1}$ e (b) 1,0234 a $35,982 \mathrm{mgL}^{-1}$.

Figura 23 - Curva analítica obtida por espectrofotometria de absorção no UV/VIS no comprimento de onda de $276 \mathrm{~nm}$ para o diclofenaco, com intervalos de detecção de (a) 0,00524 a 0,7548 mgL $\mathrm{m}^{-1}$ e (b) 3,5744 a 40,257 mg.L $\mathrm{L}^{-1} \ldots \ldots \ldots \ldots \ldots . .63$ Figura 24 - Degradação dos fármacos cloridrato de fluoxetina e diclofenaco de sódio irradiados em doses de 1.0 e 5.0 kGy (kGy). Figura 25 - Cromatograma das amostras da irradiadas (mistura mais concentrada (A)) em diferentes doses - Cromatografia Líquida Ultra Rápida para o cloridrato de fluoxetina com o detector de fluorescência. 
Figura 26 - Cromatograma das amostras da irradiadas (mistura mais concentrada (A)) em diferentes doses - Cromatografia Líquida Ultra Rápida para o diclofenaco sódico com o detector UV/VIS.

Figura 27 - Degradação da mistura mais concentrada (A) $\left(50 \mathrm{mg} \cdot \mathrm{L}^{-1}\right.$ de DIC e 5 mg. $\mathrm{L}^{-1} \mathrm{FXT}$ ) versus dose (kGy)............................................................68 Figura 28 - Degradação da mistura diluída 1:10 (B) (cloridrato de fluoxetina e diclofenaco sódico) em diferentes doses de radiação (kGy). 70 Figura 29 - Variação de CE50 ${ }_{15 m i n}$ do Cloridrato de Fluoxetina, Diclofenaco sódico e Mistura mais concentrada (A). .72 Figura 30 - Variação das Unidades Tóxicas da mistura de fármacos, cloridrato de fluoxetina e diclofenaco sódico (mistura mais concentrada (A)), em diferentes doses de radiação aplicadas para a bactéria marinha $V$. fischeri. .74 Figura 31 - Variação de CE50 48 h do Cloridrato de Fluoxetina, Diclofenaco sódico e mistura mais concentrada (A). .77 Figura 32 - Variação das Unidades Tóxicas dos fármacos separados (cloridrato de fluoxetina e diclofenaco sódico) para as amostras brutas e irradiadas em 5.0 kGy, com o microcrustáceo $D$. similis.

Figura 33 - Unidades Tóxicas de uma mistura de fármacos concentrada (A) (cloridrato de fluoxetina e diclofenaco sódico), submetidas a um processo de irradiação por feixe de elétrons nas doses de 2,5 e 5,0 kGy para a Daphnia similis (48 h). .79 Figura 34 - Carta controle de sensibilidade do organismo $D$. similis em relação ao cloreto de potássio. ................................................................................... 82 Figura 35 - Carta controle de sensibilidade da bactéria $V$. fischeri em relação ao fenol. 83

Figura 36 - Média com desvios-padrão dos valores de pH das amostras irradiadas e não irradiadas utilizadas nos ensaios de toxicidade. 84 Figura 37 - Médias com desvios-padrão dos valores de condutividade das amostras irradiadas e não irradiadas utilizadas nos ensaios de toxicidade. 87 Figura 38 - Respirograma de uma mistura de fármacos (diclofenaco de sódio + cloridrato de fluoxetina) de uma solução bruta e irradiada a 5.0 kGy. .88 


\section{INTRODUÇÃO}

As evidências da contaminação das águas por medicamentos e seus subprodutos levou esse grupo de resíduos a compor a lista de poluentes orgânicos emergentes, como consequência da expansão do uso de medicamentos. O consumo de produtos farmacêuticos cresceu nos últimos anos no Brasil, notando-se o aumento de produtos controlados como o cloridrato de fluoxetina (ANVISA, 2009).

Outro fármaco bastante consumido é o diclofenaco, medicamento prescrito como analgésico, antipirético e anti-inflamatório. De acordo com o levantamento realizado por ACUÑA e coautores, em 2015, o consumo anual de diclofenaco no período de 2010 a 2013 foi superior a 60 toneladas no Brasil. Desta forma, o consumo destes compostos farmacológicos pode resultar em contaminação do meio ambiente, uma vez que, quando consumidos para usos terapêuticos, os fármacos e os metabólitos dos produtos são normalmente eliminados pelas vias excretoras, atingindo os sistemas de esgotos.

A presença de contaminantes emergentes em águas superficiais, águas subterrâneas, sedimentos e estações de tratamento de esgoto tem sido demonstrada, em quantidade bastante variada. Concentrações superiores a 160 ng. $\mathrm{L}^{-1}$ de diclofenaco foram reportadas em águas superficiais (SILVA, 2014). Todavia já foram demonstradas contaminações em organismos aquáticos, a exemplo o estudo de Costa Junior e colaboradores (2014), quando detetectaram o cloridrato de fluoxetina na faixa de $\mathrm{ng} \cdot \mathrm{L}^{-1} \mathrm{em}$ tecido de peixes.

A deteção de produtos quimícos no meio ambiente aumenta a probabilidade dos riscos ambientais, levando a uma crescente redução na disponibilidade da água com qualidade compatível com as necessidades do ser humano e também com características que mantenham a biodeversidade natural da fauna e flora aquática (MASSARO, 2011). Esse entendimento levou ao controle legal e parcial de emissões para efluentes, que visam à proteção da vida 
no ambiente aquático, uma vez que há a necessidade do aprimoramento do saneamento básico no país.

Diante disso, devem ocorrer tanto o controle ambiental como o desenvolvimento industrial gerenciados, de modo a garantir uma produção adequada com o desenvolvimento sustentável. Da mesma forma, buscam-se alternativas tecnológicas que possam auxiliar nessa produção com uso racional de água, energia, disposição e tratamento adequados de resíduos.

Tanto a ecotoxicologia quanto a legislação ambiental vem sendo aplicadas para atender essa finalidade. Diferentes grupos de pesquisa têm buscado tratamentos alternativos de efluentes e a associação de processos de tratamento. A irradiação de efluentes pode ser utilizada para a degradação de medicamentos contidos em efluentes.

O presente estudo consistiu em aplicar a radiação ionizante como uma possível tecnologia para degradar fármacos em águas. Foram empregadas ferramentas da ecotoxicologia a fim de availiar a toxicidade dos fármacos, diclofenaco de sódio e cloridrato de fluoxetina e da mistura de ambos, para diferentes organismos aquáticos. A irradiação da solução aquosa contendo os fármacos foi aplicada em acelerador de elétrons, cuja eficiência de tratamento será discutida mediante análises químicas, ecotoxicológicas e biológicas. 


\section{OBJETIVOS}

O presente trabalho teve como objetivo aplicar a irradiação com feixe de elétrons em soluções aquosas de fármacos visando a redução da toxicidade e a degradação dos produtos. Também foi elaborada uma revisão sobre os potenciais dessa tecnologia. As seguintes etapas foram desenvolvidas:

- Estudar os possíveis efeitos tóxicos das soluções de fármacos e da mistura dos produtos ( a. Cloridrato de fluoxetina, b. Diclofenaco sódico e c. A mistura de ambos), verificando possíveis sinergias;

- Determinar a eficiência de remoção de toxicidade dessa mistura após o processamento por radiação;

- Determinar os efeitos da irradiação na redução da toxicidade das soluções estudadas, determinando a melhor dose de radiação para a melhora das soluções aqui consideradas como efluentes. 


\section{REVISÃO BIBLIOGRÁFICA}

\subsection{Ecotoxicologia: conceitos e aplicações}

A Ecotoxicologia começou a ser desenvolvida na década de 70 por meio de toxicologistas que possuíam grande interesse no meio ambiente (TRUHAUT, 1977). Essa ciência permite avaliar os danos ocorridos nos diversos ecossistemas após contaminação, além de prever possíveis impactos futuros, considerando a interação destes poluentes com o meio ambiente e seus organismos residentes (ZAGATTO e BERTOLETTI, 2008). Desta forma, a Ecotoxicologia pode ser definida como a ciência em que são abordados os efeitos de compostos químicos sobre os ecossistemas e seus componentes não humanos (FERNICOLA, 2004).

Os testes ecotoxicológicos são ensaios em que organismos indicadores são expostos a determinadas substâncias (compostos químicos, amostras de efluentes ou água bruta) em diferentes concentrações de acordo com sua tolerância ecológica a determinadas substâncias químicas. Quando expostos a determinados poluentes, estes organismos apresentam alguma alteração fisiológica, morfológica ou comportamental (MAGALHÃES e FERRÃO FILHO, 2008).

Os ensaios de toxicidade podem ser realizados por meio de diluições seriadas de uma amostra (efluente/solução) ou por meio de amostras ambientais coletadas em campo (NIPPER, 2002). A análises dos ensaios pode ser feito por meio de observações de efeitos letais ou sub-letais (alteração de comportamento, crescimento, reprodução, anomalias ou incidência de tumores, alterações fisilógicas, densidade e diversidade de espécies) numa determinada comunidade biológica, de modo estatisticamente significativo aos organismos, durante o tempo de exposição. Desta forma, o objetivo dos ensaios de toxicidade é determinar a concentração do agente químico que causa efeito sobre uma população de organismos testes (ZAGATTO e BERTOLETTI, 2008). 
Para a avaliação dos efeitos, alguns conceitos são adotados, tais como a Concentração de Efeito Não Observado (CENO), a Concentração de Efeito Observado (CEO) e a Concentração de Inibição (CI50). A Concentração de Efeito Não Observado (CENO) pode ser definida como a maior concentração da amostra que não causa efeito letal. A Concentração de Efeito Observado (CEO) é a menor concentração da amostra que causa efeito deletério. Por fim, a Concentração de Inibição (Cl50) é a concentração que causa efeito na reprodução, crescimento ou desenvolvimento embriolarval a $50 \%$ dos organismos. Os ensaios devem ser realizados em paralelo a um grupo controle, sendo este o grupo padrão de referência de qualidade a ser comparado com o experimento (NIPPER, 2002).

Os ensaios de toxicidade podem ser analisados de forma temporal, podendo ser classificados em ensaios agudos ou ensaios crônicos (ZAGATTO e BERTOLETTI, 2006). Os ensaios de toxicidade aguda avaliam efeitos agudos que ocorrem como resultado em uma exposição de curto período. Uma substância terá toxicidade aguda, caso $50 \%$ ou mais de indivíduos de uma população exposta morrer por ação direta da substância (RAND, 1995). Ensaios de toxicidade crônica permitem avaliar os efeitos adversos mais sutis, a exposição do organismo ao agente químico, em níveis subletais, causando ao organismos distúrbios fisiológicos e/ou comportamentais ao longo do prazo (ZAGATTO e BERTOLETTI, 2006).

Os ensaios ecotoxicógicos também podem ser classificados de acordo com a renovação das amostras, sendo classificados em teste estático (amostra não é trocada), semi-estático (a solução teste é substituída em intervalos definidos) ou dinâmico (os organismos são expostos a um fluxo contínuo da amostra). Alguns fatores como as caractéristicas da amostras (volatilidade, solubilidade, estabilidade, etc) e o tipo de ensaio (agudo ou crônico) influenciam na escolha do ensaio aplicado (KNIE \& LOPES, 2004).

A principal ferramenta legal no Brasil que regulamenta o controle do lançamento de efluentes e qualidade da água nos corpos hídricos é a resolução CONAMA 357/05, que dispõe sobre a classificação e diretrizes ambientais para o enquadramento dos corpos de água superficiais, bem como estabelece as 
condições e padrões de lançamento de efluentes nestes corpos hídricos (CONAMA, 2005). Mais recentemente, esta resolução foi complementada e alterada pela CONAMA 430/2011, que dispõem sobre as condições e padrões de lançamento de efluentes (CONAMA, 2011).

O artigo $2^{\circ}$ do Capítulo I, parágrafos XVII e XVIII abordam o efeito tóxico agudo e efeito tóxico crônico (CONAMA, 2005). Segundo a CONAMA 430/2011, no artigo 4º parágrafo XIII, define os testes de toxicidade como métodos utilizados para detectar e avaliar a capacidade de um agente tóxico provocar efeito nocivo, utilizando bioindicadores dos grandes grupos de uma cadeia ecológica (CONAMA, 2011).

\subsubsection{Organismos-teste}

A escolha das espécies, manutenção e cultivo de organismos aquáticos possuem a mesma importância que a avaliação da toxicidade dos organismos, uma vez que podem influenciar na confiabilidade dos resultados analíticos. Desta forma, a seleção das espécies devem se basear em critérios como: apresentar seletividade constante e sensibilidade aos contaminantes; elevada disponibilidade e abundância; uniformidade e estabilidade genética das populações; representatividade de seu nível trófico; significado ambiental em relação à área de estudo; ampla distribuição e importância comercial e facilidade de cultivo e adaptação às condições de trabalho. Além disso, deve-se ter o conhecimento sobre a reprodução, alimentação, fisiologia e comportamento do organismo a ser utilizado (ZAGATTO e BERTOLETTI, 2008).

Outra premissa básica é que os organismos aquáticos devem pertencer a certos grupos taxonômicos representativos dos ecossistemas aquáticos, visto que estão inseridos em uma cadeia trófica ou alimentar cuja transferência de energia se dá de um organismo a outro. Para a avaliação do efeito tóxico de uma amostra é recomendável a utilização de mais de uma espécie representativa da biota aquática, preferencialmente de espécies de diferentes níveis tróficos, visto que diferentes espécies de organismos apresentam diferentes sensibilidades às substâncias químicas. Desta forma, não é possível extrapolar os efeitos tóxicos de uma espécie para outra espécie (ZAGATTO e BERTOLETTI, 2006). 
Entre os organismos difundidos e que a apresentam metodologia padronizada pela ABNT - Associação Brasileira de Normas Técnicas estão os microcrustáceos Daphnia similis e a bactéria Vibrio fischeri.

\subsubsection{Daphnia similis}

A Daphnia similis, também conhecida como pulga d'água, pertence ao Subfilo Crustacea, sendo um microcrustáceo. Seu comprimento varia entre 0,5 a $5,0 \mathrm{~mm}$, possuindo uma carapaça bivalve transparente que recobre todo o corpo, exceto a cabeça e as antenas. São organismos filtradores com pernas torácica, compostas por cedas que agem como peneiras, retendo algas, bactérias e pequenas partículas de material orgânico da água. $O$ alimento é transferido pela boca, em que é moído pelas mandíbulas e direcionado para o trato digestivo (ALMEIDA et al, 2002; BARNES e RUPPERT, 1996; BUIKEMA e SHERBERGER, 1977 apud SILVA, 2014) (Figura 1).

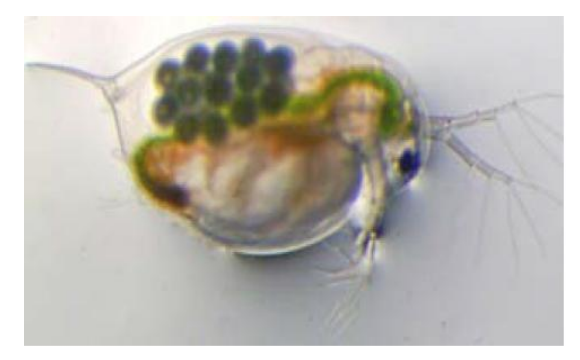

Figura 1 - Daphnia similis. Fonte: MORAIS, 2015.

A reprodução normalmente ocorre de maneira assexuada, por partenogênese. As fêmeas produzem células diplóides que dão origem a uma população constituída inteiramente por fêmeas. Caso ocorra estresse ambiental ou qualquer alteração, tais como superpopulação, falta de alimento, alterações das condições de cultivo, temperatura, isso acarretará no surgimento de machos, conhecidos por efípios, além de fêmeas com dois ovos haplóides que são fecundados pelos machos (Figura 2).

A presença de efípios deve ser evitada no cultvo de Daphnia similis para a utilização de testes ecotoxicológicos, mantendo em condições ideiais e controladas. Se dois ou mais efípios surgirem numa cultura, esta deve ser descartada, iniciando-se uma nova cultura (ZAGATTO \& BERTOLETTI, 2006). 

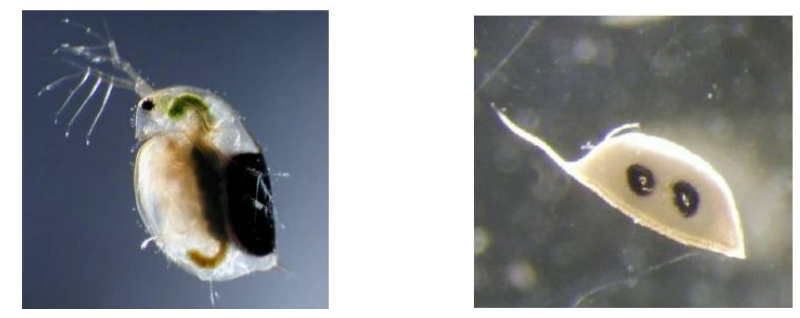

Figura 2 - (a) Microcrustaceo Daphnia similis com efípio. (b) Efipio. Fonte Alves, 2010.

A Daphnia torna-se reprodutiva de cinco a dez dias após o nascimento. Em condições favoráveis as crias possuem de 4 a 65 jovens, dependendo da idade dos organismos (ZAGATTO \& BERTOLETTI, 2006).

Os ensaios de toxicidade aguda com esses organismos são muito utilizados em laborátorio. Os cultivos e ensaios são simples, de fácil manutenção e apresentam boa repetibilidade, são bastante aceitos em publicações científicas, e estão incluídos em relatórios ambientais de qualidade de água e exigidos em monitoramentos por órgãos ambientais e fiscalizadores (COSTA e OLIVI, 2008).

\subsubsection{Vibrio fischeri}

A Vibrio fischeri pertence a familía Vibrionaceae, sendo bactéria marinha, gram-negativa, anaeróbia facultativa e emite luz naturalmente, sob condições ambientais favoráveis e concentrações de oxigênio superiores a $0,5 \mathrm{mg} \cdot \mathrm{L}^{-1}$ (SOARES, 2012; KNIE e LOPES, 2004). Pode ser encontrada em várias espécies de lulas e peixes, na qual vive em colônias dentro desses animais, estabelecendo relações de simbiose. A Vibrio também pode ser encontrada como patógeno de invertebrados ou saprófito de vida livre, desenvolvendo-se sobre matéria orgânica dissolvida ou particulada no mar (GRINEVICUS, 2006; RUBY et al, 2004) (Figura 3). 


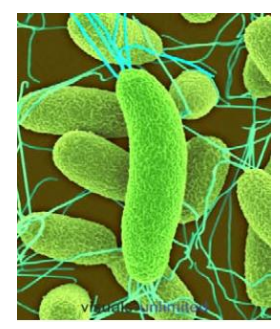

Figura 3 - Vibrio fischeri. Fonte: www.inhabitat.com.

Esta bactéria é normalmente utilizada na forma liofilizada, sendo empregada como microrganismo-teste em diversos ensaios de toxicidade aguda de amostras ambientais em diferentes partes do mundo. Durante os ensaios, também conhecidos como Microtox ${ }^{\circledR}$, a perda de luminescência, emitida naturalmente pelo organismo ao ser exposto ao agente tóxico, é o parâmetro biológico avaliado.

Os ensaios apresentam simplicidade, sensibilidade, rapidez, além de necessitar de um pequeno volume de amostra. A desvantagem do ensaio é a necessidade de ajuste de salinidade, uma vez que a adição de cloreto de sódio ou sacarose podem causar variações na toxicidade de alguns compostos, dificultando a comparação dos resutados obtidos em organismos de água doce (SOARES, 2012). Outra desvatagem é a critica recebida devido ao baixo significado ecológico. Ademais, existem controvérsias do emprego deste organismo de ambiente marinho em águas doces. Todavia esta bactéria tem apresentado resultados similares a outros ensaios de toxicidade aguda em ambos os ambientes (COSTA e OLIVI, 2008).

A luminescência está diretamente associada ao metabolismo bacteriano, ocorrendo durante o ciclo de Krebs. A energia produzida é emitida na luz verdeazulada, podendo ser lida em $490 \mathrm{~nm}$. Durante a exposição da bactéria às substâncias tóxicas ocorre a interferência na produção de energia, acarretando na redução da intensidade da luz (SOARES, 2012). 


\subsection{Poluição e a presença de fármacos no meio ambiente}

A água é o recurso natural comum mais importante para a vida no planeta Terra. Todavia, se apresenta cada vez mais escasso e em condições inapropriadas para uso, devido às diversas formas de poluição geradas pela população ao decorrer de seu desenvolvimento (BARROS e AMIN, 2008).

A poluição pode afetar o ser humano de forma direta, por meio do consumo de água imprópria, ou de forma indireta, por meio da ingestão de alimentos contaminados por depósito cumulativo de substâncias químicas altamente prejudiciais (SOUZA, 2008). Os poluentes podem atingir ecossistemas aquáticos na forma de despejos de diversos materiais através de processos naturais ou antropogênicos, como dejetos de animais, substâncias farmacêuticas, agrotóxicos, sedimentos, despejos industriais, entre outros. Estes contaminantes podem resultar em riscos à saúde da população, principalmente por se tratarem muitas vezes de compostos recalcitrantes (ALMEIDA, 2013).

Dentre alguns poluentes orgânicos, destacam-se os compostos farmacêuticos presentes em diversas matrizes ambientais, devido ao elevado crescimento do consumo destes produtos. Segundo dados do "STATISTA ${ }^{\circledR}$ ", a receita mundial do mercado passou de 390,2 bilhões de dólares (U\$) em 2001 para U\$ 1.057,2 trilhões em 2014. A evolução anual desse mercado foi apresentada na Figura 4.

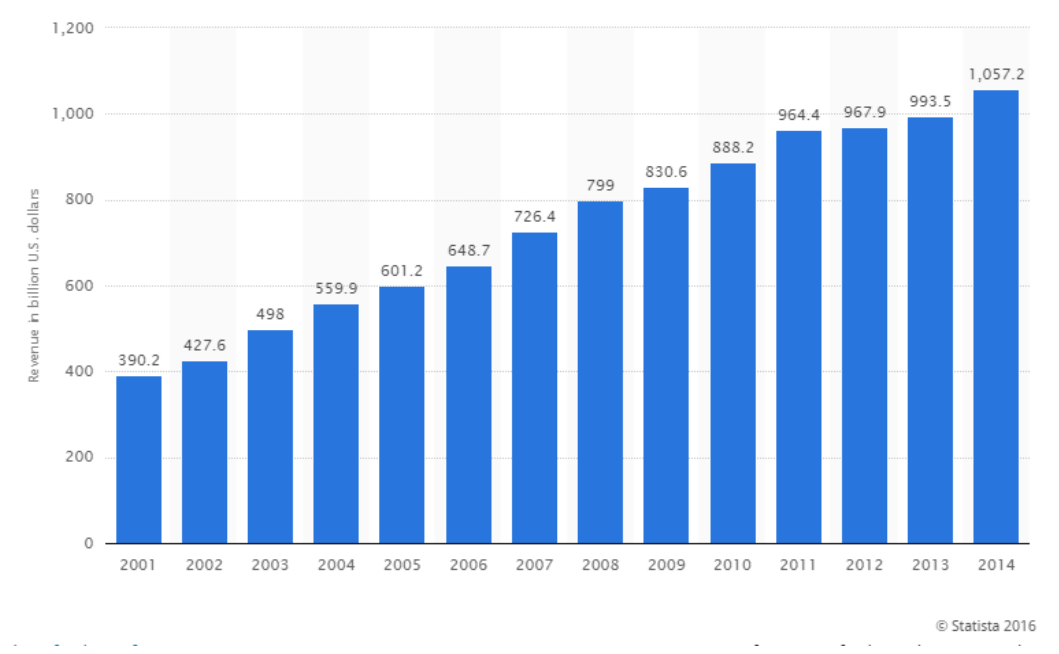

Figura 4 - Receita do mercado farmacêutico mundial 2001-2014. Fonte: STATISTA $^{\circledR}, 2016$. 
Em relação à produção nacional, segundo dados da "IMS Health", o mercado farmacêutico teve um salto de faturamento de $R$ \$28,7 bilhões em 2010 para $R \$ 41,8$ bilhões em 2014 , representando um crescimento de $45,6 \%$ no Brasil (FRIAS, 2015). Segundo HORA e colaboradores (2015), um dos motivos para esse aumento está associado a fatores econômicos, políticos e culturais que têm contribuído para o crescimento e a difusão da automedicação, o que pode ser um problema na saúde pública.

Houve também crescimento em relação aos medicamentos controlados, com aumento de $161 \%$ no fornecimento entre os períodos de 2009 a 2015 (AGÊNCIA SENADO, 2015). No município de São Paulo esse crescimento foi de 47\%, entre 2010 e 2014, destacando-se a demanda de antidepressivos consumidos por meio milhão de pessoas em 2014. A comercialização do fármaco fluoxetina atingiu 39.825.888 comprimidos em 2014 (CAMBRICOLI et al, 2015).

Outro fármaco frequentemente adquirido é o diclofenaco, medicamento prescrito como analgésico, antipirético e anti-inflamatório. Segundo um levantamento realizado por ACUÑA e colaboradores (2015), o consumo nacional pode chegar a valores superiores a 60 toneladas por ano.

Alguns estudos destacaram a presença destes contaminantes emergentes em ambientes aquáticos em diversos países, representados na Tabela 1 (ANDREU et al, 2016; GAFFNEY et al, 2014; LI, 2014; BILA e DEZOTTI, 2003). 
Tabela 1 - Detecção de fármacos em diferentes matrizes ambientais, incluindo águas para o consumo da população.

\begin{tabular}{|c|c|c|c|c|}
\hline Substância & Classe & $\begin{array}{c}\text { Concentrações no } \\
\text { Meio Ambiente }\end{array}$ & Condições & Referência \\
\hline \multirow{2}{*}{ Ibuprofeno } & \multirow{2}{*}{$\begin{array}{l}\text { Anti-inflamatório / } \\
\text { analgésico / } \\
\text { antipirético }\end{array}$} & $10,0-78,2 \mathrm{ng} \cdot \mathrm{L}^{-1}$ & $\begin{array}{c}\text { Água } \\
\text { superficial (SP } \\
\text { - Brasil) }\end{array}$ & $\begin{array}{l}\text { ALMEIDA et } \\
\text { al, } 2005\end{array}$ \\
\hline & & $117 \mathrm{ng} \cdot \mathrm{L}^{-1}$ & $\begin{array}{c}\text { Água } \\
\text { superficial } \\
\text { (Espanha) }\end{array}$ & $\begin{array}{l}\text { ANDREU et } \\
\text { al } 2016\end{array}$ \\
\hline \multirow{2}{*}{ Diazepam } & \multirow{2}{*}{$\begin{array}{c}\text { Ansiolítico/ uso } \\
\text { psiquiátrico }\end{array}$} & $0,2-4,8 \mathrm{ng} \cdot \mathrm{L}^{-1}$ & $\begin{array}{c}\text { Água } \\
\text { superficial (SP } \\
\text { - Brasil) }\end{array}$ & $\begin{array}{l}\text { ALMEIDA et } \\
\text { al, } 2005\end{array}$ \\
\hline & & $23,5 \mathrm{ng} \cdot \mathrm{L}^{-1}$ & $\begin{array}{l}\text { Água para } \\
\text { consumo } \\
\text { (Itália) }\end{array}$ & $\begin{array}{c}\text { GAFFNEY et } \\
\text { al, } 2014\end{array}$ \\
\hline \multirow{2}{*}{ Diclofenaco } & \multirow{2}{*}{ Anti-inflamatório } & $0,55 \mu g \mathrm{~L}^{-1}$ & $\begin{array}{c}\text { Efluente } \\
\text { tratado (SP - } \\
\text { Brasil) }\end{array}$ & $\begin{array}{c}\text { BORRELY et } \\
\text { al, } 2012\end{array}$ \\
\hline & & $6-35 \mathrm{ng} \cdot \mathrm{L}^{-1}$ & $\begin{array}{l}\text { Água para } \\
\text { consumo } \\
\text { (Alemanha) }\end{array}$ & $\begin{array}{c}\text { GAFFNEY et } \\
\text { al, } 2014\end{array}$ \\
\hline Piroxicam & $\begin{array}{l}\text { Anti-inflamatório / } \\
\text { analgésico / }\end{array}$ & $0,331 \mu g \mathrm{~L}^{-1}$ & $\begin{array}{c}\text { Efluente } \\
\text { tratado (MS - } \\
\text { Brasil) }\end{array}$ & $\begin{array}{c}\text { AMERICO et } \\
\text { al, } 2012\end{array}$ \\
\hline Ciprofloxacina & Antibiótico & $0,09-5,524 \mu \mathrm{g} \mathrm{L}^{-1}$ & $\begin{array}{c}\text { Afluente } \\
\text { tratado (SP - } \\
\text { Brasil) }\end{array}$ & $\begin{array}{l}\text { BORRELY et } \\
\text { al, } 2012\end{array}$ \\
\hline Propranolol & Betabloqueador & $0,036-0,51 \mu g \mathrm{~L}^{-1}$ & $\begin{array}{c}\text { Afluente } \\
\text { tratado (SP - } \\
\text { Brasil) }\end{array}$ & $\begin{array}{c}\text { BORRELY et } \\
\text { al, } 2012\end{array}$ \\
\hline Fluoxetina & $\begin{array}{l}\text { Antidepressores, } \\
\text { Ansiolíticos }\end{array}$ & $0,82 \mathrm{ng} \cdot \mathrm{L}^{-1}$ & $\begin{array}{l}\text { Água para } \\
\text { consumo ( } \\
\text { EUA) }\end{array}$ & $\begin{array}{c}\text { GAFFNEY et } \\
\text { al, } 2014\end{array}$ \\
\hline Naproxeno & Anti-inflamatório & $4,603 \mu g \mathrm{~L}^{-1}$ & $\begin{array}{l}\text { Esgoto Bruto } \\
\text { (MS - Brasil) }\end{array}$ & $\begin{array}{l}\text { AMERICO et } \\
\text { al, } 2012\end{array}$ \\
\hline
\end{tabular}

A contaminação do meio ambiente por estes compostos pode ocorrer durante todo o processo, desde a produção até o descarte. Quando consumidos para usos terapêuticos, os restos dos metabolitos dos produtos são normalmente eliminados pelas vias excretoras, atingindo os sistemas de esgotos. Por outro lado, os medicamentos com validade vencida são descartados na maioria das vezes de forma inadequada, podendo atingir o meio ambiente (ARAUJO et al, 2010). 
Outras vias de contaminação que podem ser descritas são: a remoção incompleta em estações de tratamento, a lixiviação, lançamentos de esgotos domésticos em cursos de água, lançamentos de efluentes farmacêuticos (AMÉRICO et al, 2012; GROS et al, 2009; KUMAR et al, 2009; FARRÉ et al, 2008). Além disso, a eliminação de antibióticos e hormônios utilizados em medicina veterinária é outra via de contaminação que pode ser considerada significativa (TORRES et al, 2012).

A absorção de compostos farmacêuticos não ocorre totalmente, podendo ser eliminados pela excreção (AMERICO et al, 2012). Estes compostos farmacêuticos são excretados pela urinas e fezes como substância inalterada ativa, metabólitos ou ainda sobre a forma de conjugado glucorônico ou ácido sulfúrico (TORRES et al, 2012). De modo geral, a excreção de uma dose de fármacos pode ocorrer entre 50 a 90\% na forma inalterada, podendo persistir no meio ambiente (MULROY, 2001).

A presença dos contaminantes no meio ambiente pode estar sujeita a diversas combinações de processos que podem afetar o seu destino e comportamento, como a hidrólise, a fotólise, a complexação e a biodegradação. Desta forma, processos bióticos e abióticos podem ser responsáveis pela degradação de substâncias potencialmente tóxicas na natureza. No entanto, algumas delas são recalcitrantes, podendo persistir no meio ambiente por longos períodos de tempo (COSTA e OLIVI, 2008).

Os meios de degradação e os efeitos dos fármacos dependem de suas propriedades físico-químicas. A mobilidade dos compostos depende da solubilidade em água e do coeficiente de partição octanol-água (DíAZCRUZ et al, 2003). De modo geral, fármacos apresentam propriedades físico-químicas persistentes, sendo lipofílicos e bioacumulativos, além de apresentarem baixa pressão de vapor, que facilita a sua dispersão no meio ambiente (TORRES et al, 2012).

Além das características dos produtos,a taxa de remoção de fármacos em estações de tratamento de efluentes (ETEs) está relacionada a diversos fatores como o tipo de tratamento aplicado, a idade do lodo ativado, o tempo de retenção 
hidráulica e a temperatura no processo conforme a estação do ano (LÓPEZSERNA et al, 2010; VERLICCHI et al, 2010; GROS et al, 2007).

GURKE e colaboradores (2015) estudaram a eficiência de uma estação de tratamento de esgoto equipada com tratamento secundário para a remoção biológica para fósforo e nitrogênio, observando que, embora a taxa de remoção fosse maior que 50\%, a concentração de fármacos e subprodutos detectados no efluente ainda era maior que $1 \mu \mathrm{g} \cdot \mathrm{L}^{-1}$.

AMÉRICO e colaboradores (2012) avaliaram a presença de compostos farmacológicos em amostras de afluentes e efluentes de uma ETE equipada com um reator anaeróbio de leito fluidizado (RALF), determinando concentrações de diclofenaco em ambas as condições com concentrações de $2,47 \mu \mathrm{g} . \mathrm{L}^{-1}$ em esgoto bruto e $0,27 \mu \mathrm{g} \cdot \mathrm{L}^{-1}$ em efluente tratado.

\subsubsection{Cloridrato de floxetina}

A fluoxetina atua como um potente inibidor específico, seletivo, da captação da serotonina nos neurônios pré-sinápticos, elevando, assim, os níveis de serotonina nas áreas sinápticas cerebrais (Eli Lilly \& Company, 2013).

Este medicamento é indicado para o tratamento da depressão, associada ou não à ansiedade, ao tratamento de bulimia nervosa, do transtorno obsessivocompulsivo (TOC) e do transtorno disfórico pré-menstrual (TDPM), incluindo tensão pré-menstrual (TPM), irritabilidade e disforia (mal-estar provocado pela ansiedade).

O cloridrato de fluoxetina (cloridrato de $( \pm)-N-m e t i l-3-f e n i l-3-[(\alpha, \alpha, \alpha-t r i f l u o r o-$ p-tolil)-oxi]propilamina), com a fórmula molecular $\mathrm{C}_{17} \mathrm{H}_{18} \mathrm{~F}_{3} \mathrm{NO} \cdot \mathrm{HCl}$ e peso de $345,79 \mathrm{~g} \cdot \mathrm{mol}^{-1}$, se apresenta na forma de pó branco a quase branco, solúvel em água em concentração de $14 \mathrm{mg} \cdot \mathrm{mL}^{-1}$ (Eli Lilly \& Company, 2013) (Figura 5). 


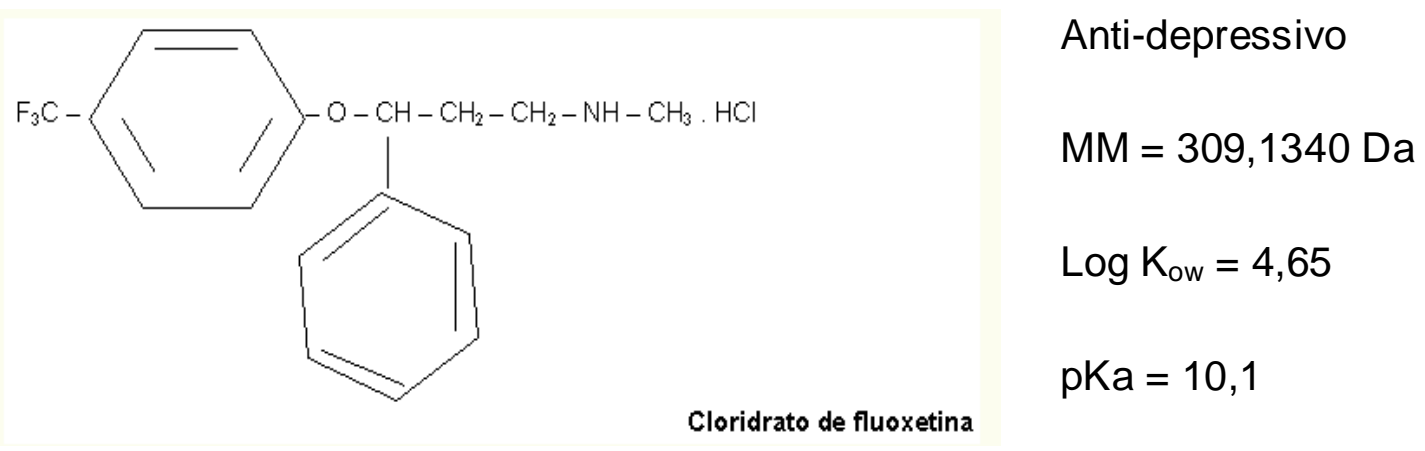

Figura 5 - Formula estrutural do cloridrato de fluoxetina. Fonte: Silva, 2014.

A serotonina, 5-hydroxytryptamine (5HT), é o hormônio e o neurotransmissor envolvido principalmente na excitação de órgãos e constrição de vasos sanguíneos. Esta substância também é encontrada em paredes sanguíneas, localizada no hipotálamo e parte central do cérebro. Dentre algumas funções destacam-se o estímulo dos batimentos cardíacos, início do sono e a luta contra a depressão. A atuação de medicamentos que trata a depressão tende a elevar os níveis deste hormônio no cérebro. Ademais, este hormônio regula a luz durante o sono, uma vez que é o precursor do hormônio melatonina (regulador do relógio natural) (ANDRADE et al, 2003). Outras funções deste neurotransmissor também estão relacionadas à ingestão de alimentos e ao comportamento sexual (FENT et al, 2006).

A comercialização deste medicamento ocorre de maneira controlada pela Portaria ํo. 344/1998, podendo ser encontrada na lista C1. Segundo o relatório apresentado pela ANVISA em 2009, uma das possíveis reações adversas observadas durante $\mathrm{o}$ tratamento dos sintomas depressivos com a fluoxetina seria a perda de peso. Desta forma, a utilização deste fármaco estaria sofrendo um desvio de seu uso, sendo administrada para a perda de peso, muitas vezes ocorrendo sem a avaliação do risco/benefício.

De acordo com um caso reportado no relatório, a fluoxetina foi prescrita em associação com um grande número de outras substâncias ativas. Esse tipo de 
prescrição múltipla ocorria principalmente para mulheres, sugerindo a utilização do medicamento com finalidades estéticas.

A fluoxetina é extensivamente metabolizada no fígado à norfluoxetina e em outros metabólitos não identificados, que são excretados na urina. A meia-vida de eliminação da fluoxetina é de 4 a 6 dias e a de seu metabólito ativo é de 4 a 16 dias (Medley ${ }^{\circledR}$ Indústria Farmacêutica Ltda). A excreção dos metabólitos ocorre pela urina (65\%) e nas fezes (15\%) por mais de 30 dias (SOARES, 2005). Cerca de 2,5 a $5 \%$ da fluoxetina e $10 \%$ do metabolito ativo norfluoxetina são excretados na forma inalterada na urina (TELLES-CORREIA et al, 2009).

\subsubsection{Diclofenaco de sódio}

O diclofenaco de sódio (2-(2,6-dicloroanilina)fenil)acetato de sódio), com a fórmula $\mathrm{C}_{14} \mathrm{H}_{10} \mathrm{Cl}_{2} \mathrm{NNaO}_{2}$ e peso de $318,14 \mathrm{~g} \cdot \mathrm{mol}^{-1}$, se apresenta na forma de pó cristalino, levemente higroscópico (ROCHA, 2010). Possui solubilidade de 19 $\mathrm{mg} \cdot \mathrm{mL}^{-1}$ em água (RISSI , 2013).

Esse medicamento é classificado como anti-inflamatório não esteroidal (AINE). De modo geral, é bastante indicado como analgésico, antipirético e antiinflamatório, sendo largamente prescrito e adquirido livremente (ROCHA, 2010). Em alguns casos este medicamento pode ser utilizado para tratamento de doenças reumáticas, com uso prolongado (FENT et al, 2006). Outras utilizações para o diclofenaco sódico são o tratamento de formas degenerativas e inflamatórias de reumatismo (artrite reumatoide), espondilite anquilosante, osteoartrite e espondilartrite, síndromes dolorosas da coluna vertebral, reumatismo não-articular, dores pós-traumáticas e pós-operatórias, inflamação e edema, condições inflamatórias e/ou dolorosas em ginecologia (dismenorréia primária ou anexite) (NOVARTIS). A estrutura molecular do composto foi apresentada na Figura 6. 


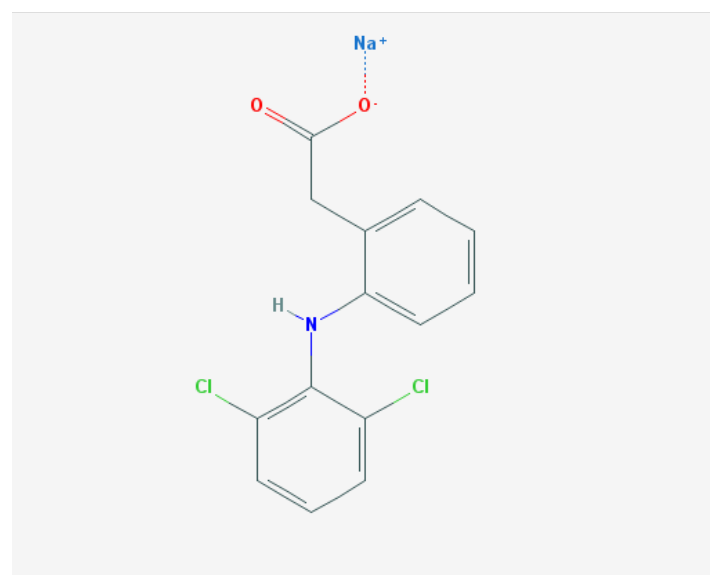

\author{
Anti-inflamatório \\ $\mathrm{MM}=319,19 \mathrm{~g} \cdot \mathrm{mol}^{-1}$ \\ $\log \mathrm{K}_{\mathrm{ow}}=4,02$ \\ $\mathrm{pKa}=4,1$
}

Figura 6 - Estrutura química do diclofenaco de sódio. Fonte: PUBCHEM.

O diclofenaco é um composto rapidamente metabolizado por diversos mamíferos (EMEA, 2004). O composto sofre biotransformação pelo citrocromomo P450, gerando metabólitos como o 4-hidroxi e 5-hidroxi-diclofenaco e outros metabólitos em menor concentração como o 3-hidróxi-4-metoxi e 4,5-di-hidroxi diclofenaco. Os metabólitos do diclofenaco são excretados na urina (65\%) e na bile (35\%), sendo pouco eliminado sem alteração (AGUIAR, 2009).

A ação farmacológica compreende na inibição da atividade da enzima cicloxigenase (COX), resultando no decréscimo da conversão do ácido araquidônico em precursores de prostaglandinas e tromboxanos, responsáveis pelos processos inflamatórios, dores e febre. As prostangladinas desempenham diversas funções fisiológicas de acordo com as células fontes e moléculas-alvo. Estão envolvidas em processos inflamatórios e dores, regulação da corrente sanguínea nos rins, processos de coagulação e síntese de mucosa gástrica protetora (ROCHA, 2010; FENT, 2006).

\title{
3.3. Riscos ambientais associados à presença de fármacos e seus resíduos
}

De modo geral, os fármacos são classificados como contaminantes emergentes, sendo, essencialmente, compostos que interferem no funcionamento do sistema endócrino dos organismos, resultando em resposta não naturais. Estes contaminantes podem ser obtidos de forma natural ou sintética e, 
juntamente com outros produtos, tais como, produtos para cuidado pessoal, esteródies hormonais sexuais, drogas ilícitas, dentre outros e podem ser considerados desreguladores endócrinos (OLLER et al, 2011).

Deste modo, os efeitos tóxicos nesses ecossistemas de medicamentos não se restrigem apenas aos desequílibrios ecológicos provocados nos corpos d'águas receptores, mas também podem afetar a saúde humana, em decorrência dos fenômenos de bioacumulação ao longo da cadeia alimentar e da persistência dos poluentes tóxicos na água que será utilizada (MASSARO, 2011).

Segundo as categorias de toxicidade baseadas pela legislação europeia, baseadas em valores de CE50, o potencial tóxico pode ser classificado em: muito tóxico (CE50 $\left.\leq 1 \mathrm{mg} \cdot \mathrm{L}^{-1}\right)$; tóxico $\left(1 \leq \mathrm{CE} 50 \leq 10 \mathrm{mg} \cdot \mathrm{L}^{-1}\right)$ e perigoso $(10 \leq \mathrm{CE} 50 \leq$ $100 \mathrm{mg} \cdot \mathrm{L}^{-1}$ ) (Commission of the European Communities, 1996). A toxicidade do cloridrato de fluoxetina e diclofenaco sódico para diferentes organismos aquáticos vêm sendo objeto de estudos, conforme consta da Tabela 2.

Tabela 2 - Parâmetros de toxicidade de diferentes organismos expostos à fluoxetina e diclofenaco.

\begin{tabular}{|c|c|c|c|c|}
\hline Fármaco & Organismo & $\begin{array}{c}\text { Tempo } \\
\text { exposição }\end{array}$ & CE50/LC50/IC50 & Referência \\
\hline \multirow{5}{*}{ Fluoxetina } & Vibrio fischeri & $15 \mathrm{~min}$ & $1,15 \mathrm{mg} \cdot \mathrm{L}^{-1}$ & SILVA (2014) \\
\hline & Daphnia similis & $48 \mathrm{~h}$ & $1,31 \mathrm{mg} \cdot \mathrm{L}^{-1}$ & SILVA (2014) \\
\hline & $\begin{array}{c}\text { Pseudokirchneriella } \\
\text { subcapitata }\end{array}$ & $48 \mathrm{~h}$ & $0 ; 024 \mathrm{mg} \cdot \mathrm{L}^{-1}$ & $\begin{array}{l}\text { BROOKS et al } \\
(2003)\end{array}$ \\
\hline & $\begin{array}{l}\text { Chironomus } \\
\text { tentans }\end{array}$ & $10 \mathrm{~d}$ & $15,2 \mathrm{mg} \cdot \mathrm{kg}^{-1}$ & $\begin{array}{l}\text { BROOKS et al } \\
(2003)\end{array}$ \\
\hline & Hyalella azteca & $10 d$ & $43 \mathrm{mg} \cdot \mathrm{kg}^{-1}$ & $\begin{array}{c}\text { BROOKS et al } \\
(2003)\end{array}$ \\
\hline \multirow{4}{*}{ Diclofenaco } & Vibrio fischeri & $30 \mathrm{~min}$ & $4,17 \mathrm{mg} \cdot \mathrm{L}^{-1}$ & $\begin{array}{l}\text { HOMLOK et al } \\
(2011)\end{array}$ \\
\hline & Daphnia similis & $48 \mathrm{~h}$ & $46 \mathrm{mg} \cdot \mathrm{L}^{-1}$ & $\begin{array}{c}\text { MENDES et al } \\
(2010)\end{array}$ \\
\hline & $\begin{array}{c}\text { Pseudokirchneriella } \\
\text { subcapitata }\end{array}$ & $72 \mathrm{~h}$ & $64,8 \mathrm{mg} \cdot \mathrm{L}^{-1}$ & $\begin{array}{l}\text { QUINN et al } \\
(2011)\end{array}$ \\
\hline & Lemna minor & $7 \mathrm{~d}$ & $47,6 \mathrm{mg} \cdot \mathrm{L}^{-1}$ & $\begin{array}{l}\text { QUINN et al } \\
(2011)\end{array}$ \\
\hline
\end{tabular}

Alguns estudos reportam diversos efeitos causados por resíduos de fármacos. WEINBERGER II e KLAPER (2013) demonstraram que concentrações ambientais da fluoxetina causaram impactos no comportamento de peixes 
Pimephales promelas, em que principalmente os machos se tornaram antissociais e agressivos. BROOKS e colaboradores (2003) verificaram que houve aumento significativo da prole de Ceriodaphnia dubia exposta em $56 \mu \mathrm{g} \cdot \mathrm{L}^{-1}$ de fluoxetina.

Em relação ao diclofenaco, TAGGART e colaboradores (2007) verificaram um catastrófico declino de abutres Gyps no norte da Índia. As aves se alimentavam das carcaças de gado morto, tratados com o composto pouco após a morte, sendo verificado em outro estudo que aves morriam de insuficiência renal causada após a ingestão da carcaça de animais contaminados com diclofenaco (FENT et al, 2006).

HONG e colaboradores (2007) verificaram alterações na saúde dos peixes em uma exposição prolongada a concentrações ambientalmente relevante de diclofenaco. Foram dectadas alterações em genes de expressão genética utilizados como biomarcadores de peixes da espécie Oryzias latipes. SCHWAIGER e colaboradores (2004) observaram induções a lesões renais e alterações nas brânquias, a partir de concentrações de $5 \mu \mathrm{g} \cdot \mathrm{L}^{-1}$.

Ademais, outros componentes podem ser adicionados aos produtos fármacêuticos visando proporcionar propriedades aos princípios ativos, como estabilidade, volume, coloração, gosto, taxa de absorção. Estas substâncias são conhecidas como excipientes, destacando-se: solventes, surfactantes, lubrificantes, emusificantes, conservantes antimicrobianos (CARLSSON et al, 2006). CAMINADA (2008) concluiu que a toxicidade dos fármacos testados variava de acordo com a formulação estudada, sugerindo que a toxicidade apresentada dependia do excipiente utilizado.

\subsection{Efeitos de mistura}

No momento em que estes contaminantes se dispõem no meio ambiente, torna-se comum a mistura com diferentes compostos. A exposição da biota aquática a essa mistura pode resultar em interações toxicológicas diferentes da ação esperada pela ação do contaminante sozinho (RAND et al, 1995). Os possíveis efeitos podem ser classificados como sinergético, aditivo, potencial e antôgonico (ZAGATTO e BERTOLETTI, 2006). Na tabela 3 constam os possíveis efeitos que podem ocorrer durante a combinação binária de duas substâncias. 
Tabela 3 - Possíveis efeitos de uma mistura binária. Fonte: Zagatto e Bertoletti, 2006.

\begin{tabular}{|c|c|}
\hline Efeito de mistura & Somatório \\
\hline Aditivo & $1+1=2$ \\
\hline Sinergético & $1+1=5$ \\
\hline Antagônico & $2+3=4$ \\
\hline Potencial & $0+1=4$ \\
\hline
\end{tabular}

O modo de interação entre os constituintes da mistura, bem como o sítio alvo no organismo afetam na toxicidade, podendo acarretar em diferentes efeitos. Estes podem ser divididos basicamente em quatro tipos: os constituintes da mistura podem afetar a mesma função fisiológica; pode haver uma interação química entre os constituintes da mistura afetando a toxicidade de um dos compostos; a absorção, o metabolismo, a distribuição ou a excreção de um constituinte sofre alteração provocada pelos demais constituintes da mistura, podendo haver, ainda, competição entre os constituintes da mistura pelo mesmo tecido receptor (COSTA e OLIVI, 2008).

\subsection{Principais processos de tratamento de efluentes}

\subsubsection{Tratamentos biológicos}

O tratamento biológico de esgotos e efluentes representa um mecanismo natural, onde a matéria orgânica biodegradável é decomposta por microrganismos, à medida que é consumida utilizando o carbono como fonte de energia, além de aproveitar o oxigênio dissolvido na água para otimizar a mineralização dos contaminantes (BORRELY, 1998).

Estes processos são considerados os mais representativos por sua grande utilidade, eficiência e simplicidade, sendo que qualquer tecnologia pode ser associada ao tratamento biológico, uma vez que estes processos podem tornar os compostos mais susceptíveis ao ataque microbiano. No entanto, à medida que as atividades industriais geram produtos sintéticos recalcitrantes e o conjunto de efluentes lançados pelas indústrias representam matrizes complexas de efluentes, a biodegradabilidade fica prejudicada devido à carga demasiadamente tóxica aos processos metabólicos (BORRELY, 2001). 
O potencial de ensaios de biodegradação tem sido bastante crítico para o desenvolvimento sequencial de processos. Os ensaios de respirometria fornecem respostas que estimam a biodegradabilidade aeróbica em intervalos de tempo curtos (30 min). Estes ensaios são bastante úteis para prever a dinâmica de resposta de curto-tempo sob condições transitórias, uma vez que não sofrem 0 processo de aclimatação. Desta forma, não há o risco considerável de subestimar o verdadeiro potencial do tratamento biológico, sendo estes ensaios bastante adequados para o controle de processos (GUIEYSSE e NORVILL, 2014).

O princípio dos métodos respirométricos para a determinação taxa de consumo de oxigênio (TCO) leva em consideração as variações na taxa de respiração do lodo em consequência do tipo de substrato acrescentado e a velocidade de degradação de parte da biomassa, sendo que este parâmetro é um dos principais componentes a serem quantificados no procedimento de projetos e/ou gestão de tratamentos de águas residuais (ANDREOTTOLA et al, 2004).

\subsubsection{Processos oxidativos avançados (POA)}

Os Processos Oxidativos Avançados (POAs) podem ser caracterizados pela produção in situ de espécies transitórias oxidativas altamente reativas e pouco seletivas, tais como radical hidroxila $\left(\mathrm{OH}^{\cdot}\right)$. Estes radicais são capazes de degradar diversos compostos orgânicos e poluentes inorgânicos (RIZZO, 2011). Estes processos têm sido descritos como uma alternativa eficiente para remoção de poluentes persistentes e efluentes com elevada carga orgânica (AMORIM et al, 2009).

A pesquisa e desenvolvimento de POAs tem-se tornado pertinente nas últimas décadas, devido ao grande potencial de aplicações e a diversidade de tecnologias que podem ser envolvidas (KLAVARIOTI et al, 2009). Dentre os processos de POAs destacam-se diversos processos de fotocatálise heterogêneos e homogêneos, tais como processo ultravioleta (UV), radiação solar, eletrólise, ozonização $\left(\mathrm{O}_{3}\right.$ ou $\left.\mathrm{O}_{3} / \mathrm{H}_{2} \mathrm{O}_{2}\right)$, processo Fenton $\left(\mathrm{H}_{2} \mathrm{O}_{2} / \mathrm{Fe}^{+2}\right.$ ou $\mathrm{H}_{2} \mathrm{O}_{2} / \mathrm{O}_{3} / \mathrm{Fe}^{+2}$ ), ultrassom, processos de radiação ionizante (Radiação utilizando elétrons acelerados, raios $\mathrm{y}$ e raios $\mathrm{X}$ ), fotocatálise, utilização de catalisadores, dentre outros (PINHEIRO, 2011). 
A associação dos POAs vem sendo empregada na forma de prétratamento para processos biológicos, visando aumentar a biodegradabilidade e reduzir a toxicidade (KLAVARIOTI et al, 2008). Estes processos podem ser utilizados em sistemas de tratamento para esgoto e de efluentes, sistemas de reuso de águas residuais, estações de tratamento de água potável para consumo, desinfeção biológica de efluentes e lodo, dentre outros (RIZZO, 2011).

\subsubsection{Aplicações da Radiação ionizante para o tratamento de águas}

A radiação ionizante possui energia suficiente para a remoção de elétrons de suas orbitais em torno do átomo, perturbando, assim, o equilíbrio destas moléculas, modificando-as e ionizando-as. Este tipo de radiação ocorre de maneira natural no Universo, podendo também ser provocada pelo homem através de materiais radioativos. Dentre os diversos tipos de radiação, podem-se destacar as radiações $\alpha, \beta, \gamma$, Raio-X e radiação de nêutrons (CNSC, 2012). As aplicações da radiação ionizante tem-se expandido em diversas áreas como saúde, indústria, agricultura e meio ambiente.

Nas áreas industriais, sua aplicação estende-se a esterilização de produtos médicos, produção de polímeros com melhores características, gamagrafia industrial, traçadores radioativos, coloração em pedras preciosas, dentre outros. $\mathrm{Na}$ área da saúde, existem aplicações em tratamento médicos como a braquiterapia, a produção de diversos radio-fármacos utilizados na medicina nuclear, a produção de hidrogel para fins médicos, além do desenvolvimento de novos aparelhos para diagnósticos médicos como a tomografia, a tomografia por emissão de pósitrons (PET), Raios-X. Na agricultura, a radiação ionizante é bastante utilizada para a redução de carga microbiana em alimentos.

$\mathrm{Na}$ área ambiental, esta tecnologia pode ser utilizada para o tratamento de gases tóxicos e de efluentes líquidos. Neste último caso, visando aumentar a biodegradabilidade e/ou reduzir a toxicidade dos efluentes finais, além de poder ser utilizado para a desinfecção de lodo de esgoto e remediação do solo (MORAIS, 2015; IAEA, 2007; IAEA, 2004; BORRELY, 2001, BORRELY, 1998).

O processo de irradiação com feixe elétrons obteve bons resultados na remoção de toxicidade e degradação de fármacos (SILVA, 2014; SANTOS, 2011). 
A degradação de contaminantes orgânicos complexos quando submetidos a processos oxidativos avançados produzem produtos de oxidação intermediários que podem ser mais tóxicos do que os compostos parentais (RIZZO, 2011). Desta forma, ensaios de toxicidade para as misturas são necessárias a fim de avaliar o comportamento das amostras após o tratamento.

\subsubsection{Acelerador de eletróns}

A aplicação da radiação ionizante tem-se mostrado eficiente para a remoção de matéria orgânica, compostos orgânicos persistentes e contaminantes ambientais de esgotos, lodos e efluentes industriais, além de melhorias em aspectos ecotoxicológicos (ROMANELLI et al, 2004). A utilização torna-se viável para aplicação industrial em razão do custo e do tempo (SELAMBAKKANNU et al, 2011). Ademais, os aceleradores de elétrons apresentam outras vantagens como taxa de dose alta, rendimento maior de energia, licenciamento similar às máquinas de Raios- $X$ e o sistema liga-desliga que cessa a emissão da radiação ionizante (DUARTE, 1999).

Os aceleradores de elétrons são dispositivos capazes de acelerar partículas subatômicas de valores muito baixos até valores entre alguns bilhões de elétrons-volt (eV) e altas energias cinéticas, pela combinação entre campos elétricos e magnéticos. A dinâmica de funcionamento constitui-se na formação de um potencial de alta voltagem que é estabelecido entre o cátodo e o ânodo, no vácuo. A partir de alterações na variação do potencial aplicado a aceleração de elétrons, é possível variar a energia cinética, e consequentemente, o seu poder de penetração (SANTOS, 2011).

Estes equipamentos são constituídos por tubos de acelerador em vácuo, canhões de elétrons, câmara de irradiação, painel de controle e sistemas de segurança. Seus componentes possuem blindagem visando barrar a passagem dos raios $X$ que podem ser gerados pelo fretamento dos elétrons ao penetrar na matéria (BORRELY, 2001). Desta forma, o princípio de funcionamento do acelerador de elétrons pode ser comparada ao funcionamento de um tubo de televisão que utiliza cerca de milhões de volts de energia (Figura 7) (RELA, 2006). 


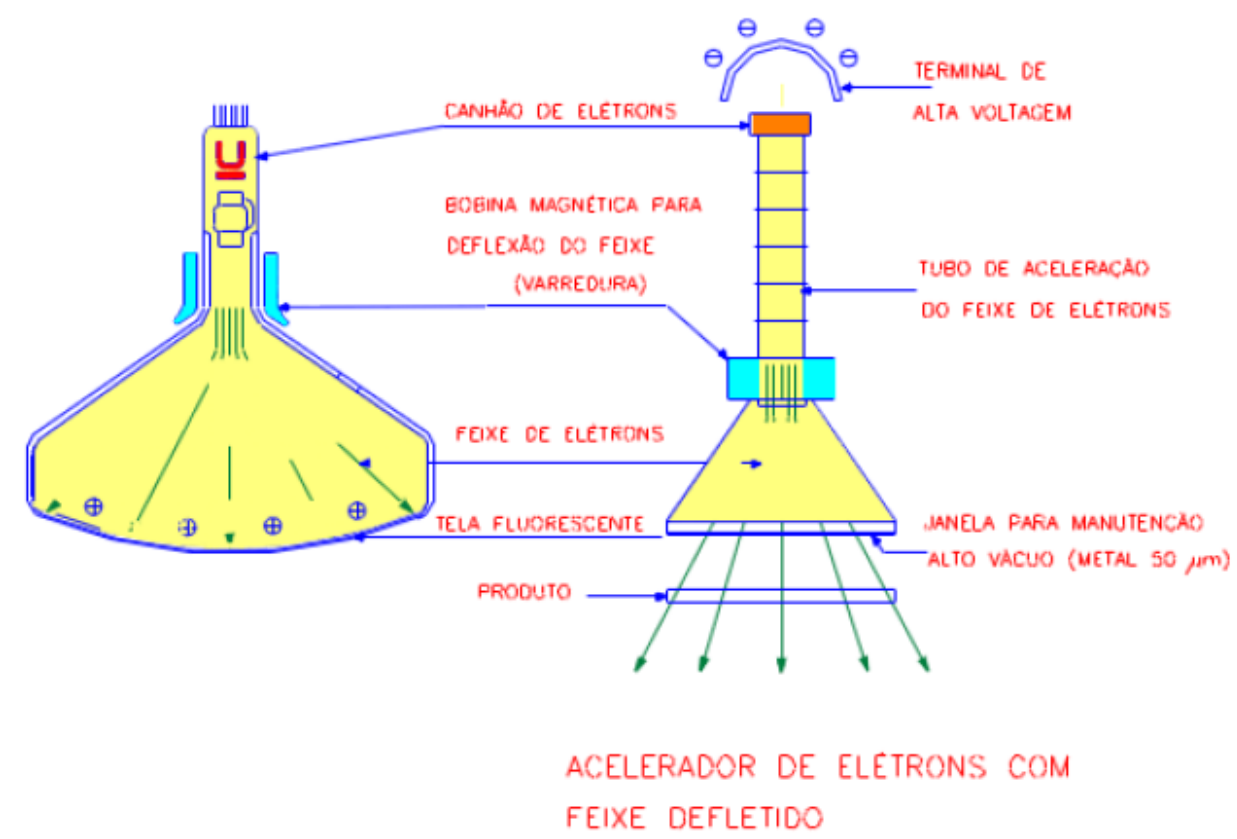

Figura 7 - Comparação entre acelerador de elétrons e um tubo de televisão. Fonte: BORRELY, 2001.

Os aceleradores de partículas começaram a ser desenvolvidos em 1927 baseando-se nas pesquisas do físico Enerst Lawarence, sendo que o primeiro acelerador de partículas foi construído na Universidade de Cambridge, na Inglaterra, pelos físicos Cockroft e Walton (HARVEY, 1969). Em 1950, os primeiros estudos por tratamento com radiação ionizante foram realizados, voltando-se principalmente, para trabalhos de desinfecção de esgotos. Nos anos 60 , os estudos voltaram para trabalhos de purificação de água e tratamento de águas residuais. Entre os anos de 1970 e 1980, algumas pesquisas voltaram-se aos estudos em águas residuais industriais e em águas subterrâneas poluídas. A partir dos anos 90, diversas plantas pilotos foram construídas a fim de desenvolver novas pesquisas (MORAIS, 2015).

A implantação de plantas pilotos tem ocorrido em diversos países tais como Austria, Brasil, Japão, República da Coréia, Federação Russa, Estados Unidos, dentre outros. O processo de radiação ionizante tem-se mostrado efetivo para o tratamento (decomposição de compostos orgânicos e persistentes) e desinfecçcão de efluentes. $O$ processo tem obtido alta eficiência com um custo relativamente baixo, utilizando-se de baixas doses (IAEA, 2007). 
Um destaque é a planta completa de Daegu, localizada em um complexo têxtil industrial na República da Coréia, em 2005. Este projeto foi baseado em uma instalação de uma planta piloto, com o funcionamento desde 1988. O sistema utiliza da combinação de um acelerador de eletróns associado a um tratamento biológico. O complexo tem a capacidade de tratar cerca de $10.000 \mathrm{~m}^{3}$ por dia de águas residuais, utlizando-se de um acelerador de eletróns de 1 Mev, 400 kW. A planta pode operar a doses de 1 kGy, obtendo eficiência na remoção de águas residuais, favorecendo a redução do tempo de retenção em biotratamentos. O custo da implementação da planta operacional foi estimado em U\$D 4 milhões, sendo o custo de operação obtido em torno de U\$D 0.3 por $\mathrm{m}^{3}$ de efluente (HAN, 2012).

No Brasil, o Centro de Tecnologia das Radiações (CTR) localizado no Instituto de Pesquisas Energéticas e Nucleares (IPEN) possui uma planta piloto. O acelerador de elétrons de 1,5 MeV e 3,7kW foi construído em 1993, possuindo capacidade de tratar $3 \mathrm{~m}^{3}$ por hora de efluentes (PINHEIRO, 2011). Esta planta vêm sendo utilizada para o estudo em diversos trabalhos (MORAIS, 2015; SILVA, 2014; SANTOS, 2011; PINHEIRO, 2011; HIGA, 2008; BORRELY,2001).

Atualmente, foi apresentado o "Projeto da Unidade Móvel com Acelerador Industrial de Eletróns", com a parcerias do IPEN, SENAI-SP, Truckvan Indústria e Comércio e a empresa coreana EB-Tech Co Ltd. Este projeto tem como um dos objetivos o tratamento de efluentes líquidos, estimado no valor de 1,2 milhão de euros (INSTITUTO DE PESQUISAS ENERGETICAS E NUCLEARES, 2015). Estudos prévios já demostraram a viabilização técnica da construção de unidades móveis no país (RELA, 2006).

\subsubsection{Interação da radiação com a matéria}

A irradiação por feixe de elétrons é fundamentado na interação da radiação ionizante produzida por um acelerador de elétrons com o substrato (soluções aquosas, efluentes industriais, águas residuais) (PINHEIRO, 2011). Durante a irradiação, o substrato sofre diversas modificações induzidas pelas espécies químicas que são formadas a partir da interação da radiação com a água e seus componentes. Estas espécies são altamente reativas, e desencadeiam outras 
séries de reações, cujo entendimento torna-se fundamental para o desenvolvimento da aplicação da tecnologia das radiações para fins ambientais (BORRELY, 2001).

No processo os elétrons interagem com as moléculas e átomos presentes na amostra irradiada pela transferência de energia (SILVA, 2014). Na primeira fase do processo, ocorre um efeito físico, em intervalos muito curtos da ordem de $10^{-13} \mathrm{~s}$ a $10^{-12} \mathrm{~s}$, nos quais os átomos sofrem ionização e/ou excitação. $\mathrm{Na}$ segunda fase, ocorrem efeitos químicos, processados em intervalos de tempos estimados de $10^{-9} \mathrm{~s}$, nas quais as moléculas podem sofrer rupturas em suas ligações, gerando radicais livres (DUARTE, 1999).

Os efeitos químicos da interação da radiação com a matéria podem ocorrer por dois mecanismos: o modo direito e o indireto (Figura 8). Na ação direta, a radiação interage diretamente com a molécula de interesse, sendo que este modo de ação ocorre de maneira insignificante, mesmo em altas concentrações dos compostos orgânicos. Na ação indireta, conhecida como radiólise da água, a radiação interage com a molécula de água, gerando espécies químicas muito reativas e difusíveis que irão interagir no material de estudo (ROMANELLI, 2004).

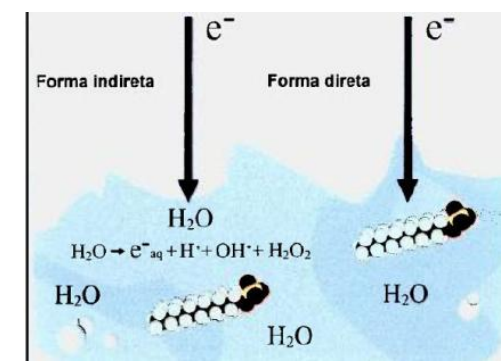

Figura 8 - Formas de interação da radiação ionizante - ação direta e indireta. Fonte: ROMANELLI, 2004.

$\mathrm{Na}$ ação indireta da radiação, as moléculas da água sofrem ionização e excitação pela radiação, levando a formação de espécies intermediárias reativas redutoras $\left(\mathrm{e}_{\text {aq }}^{-} \mathrm{e} \mathrm{H} \cdot\right)$ e oxidantes $(\mathrm{OH} \cdot)$. Esses radicais são formados em intervalos de tempo curtos (10 ${ }^{-14}$ a $10^{-9}$ segundos) e interagem com os compostos orgânicos e inorgânicos (BORRELY, 2001).

A química das radiações é uma ciência bem estabelecida. Desta forma, os principais produtos intermediários e moleculares são determinados pela Equação 
1, em que são demonstradas as principais espécies formadas e acompanhadas de seus respectivos rendimentos para $100 \mathrm{eV}$ de energia absorvida (valor de $\mathrm{G}$ ). O valor $\mathrm{G}$ indica o numero de moléculas "produzidas ou reagidas" para uma dada energia da radiação, sendo estes valores expressos em mol J-1 e são dependentes do pH da solução (BORRELY, 2001).

$\mathrm{H}_{2} \mathrm{O} \rightarrow[2,6] \mathrm{e}_{\mathrm{aq}}^{-}+[0,6] \mathrm{H} \cdot+[2,7] \mathrm{OH} \cdot+[0,7] \mathrm{H}_{2} \mathrm{O}_{2}+[2,6] \mathrm{H}_{3} \mathrm{O}^{+}+[0,45] \mathrm{H}_{2}$ Equação 1

Em meio ácido o $e^{-}$aq é convertido em átomo de hidrogênio, de acordo com a Equação 2:

$$
\mathrm{e}_{\mathrm{aq}}^{-}+\mathrm{H}^{+}{ }_{\mathrm{aq}} \rightarrow \mathrm{H} \cdot \quad \text { Equação } 2
$$

Em meio básico os átomos de hidrogênio são transferidos em $\mathrm{e}_{\mathrm{aq}}^{-} \mathrm{e}$ os radicais $\mathrm{OH}$. dissociam-se, conforme as Equação 3 e Equação 4, respectivamente:

$$
\begin{array}{ll}
\mathrm{H} \cdot+\mathrm{OH} \cdot \rightarrow \mathrm{e}^{-} \text {aq } & \text { Equação 3 } \\
\mathrm{OH} \cdot \rightarrow \mathrm{O}_{\mathrm{aq}}+\mathrm{H}^{+}{ }_{\text {aq }} & \text { Equação 4 }
\end{array}
$$

A aplicação da tecnologia da radiação ionizante com feixes de elétrons nos processos de tratamento de efluentes deve ser realizada respeitando a espessura da camada de água de acordo com a energia do equipamento utilizado a fim de fornecer elétrons acelerados na integridade na amostra (BORRELY, 2001).

A quantidade de energia que é transferida da radiação ionizante para a matéria é definida como dose absorvida, sendo a unidade definida pelo Sistema Internacional de Unidade para dose absorvida como Joule por quilograma $\left({\mathrm{J} . \mathrm{kg}^{-1}}^{-1}\right.$, a qual é dada o nome especial de Gray (Gy), previamente chamado de rad. A relação entre essas unidades por ser definida por $1 \mathrm{~Gy}=1 \mathrm{~J} \mathrm{~kg}^{-1}=100 \mathrm{rad}$ (INMETRO, 2007).

A interação dos radicais livres formados com as moléculas de poluentes induzem reações de oxidação, redução, dissociação ou degradação. Estes tipos de interações são responsáveis pela decomposição de compostos orgânicos, que 
ocorrem de maneira não seletiva, sendo necessária a determinação da dose e a taxa de radiação de modo experimental (SILVA, 2014).

Exemplos de aplicação que obtiveram bons resultados, tem-se:

Duarte (1999) obteve reduções significativas na remoção de compostos orgânicos presentes em efluentes industriais, bem como a remoção, de corantes e o clareamento das amostras. Mais de $90 \%$ dos compostos orgânicos foram removidos na dose de 20 kGy. No entanto, alguns parâmetros convencionais desses efluentes industriais não foram melhorados durante o processo de radiação, porém este processo é visto como promissor em pré-tratamento, visto que durante o processo de radiação são originados ácidos orgânicos que podem ser facilmente biodegradados.

Borrely (2001) obteve redução significativa da toxicidade de mistura de esgoto domésticos e industriais provenientes da Estação de Esgoto de Suzano em São Paulo, após o processo de radiação. Os percentuais obtidos de remoção de toxicidade para os organismos $V$. fischeri e $D$. similis foram superiores a $85 \%$. Para os peixes $P$. reticula, a eficiência se manteve entre 40 e 60\%. Para a aplicação real dos processos, as doses de radiação sugeridas foram de 50, 20 e doses entre 5-10 kGy, de acordo com os pontos estudados.

Higa (2008) avaliou a toxicidade para organismos aquáticos e a aplicação do tratamento com irradiação e adsorção em zeólita. A radiação obteve eficiência de $60 \%$ para efluentes da indústria química a partir de doses de $40 \mathrm{kGy}$, enquanto que para efluentes de industrias têxteis as doses variaram entre 0,5 e 3,0 kGy. Tanto o processo de radiação ionizante quanto a adsorção em zeólitas foram considerados eficientes para a redução da coloração e toxicidade em efluentes que apresentavam corantes.

Pinheiro (2011) avaliou a redução de toxicidade e a degradação dos corantes Remazol Black B (RB5) e Remazol Orange (RO3R). Para doses de 10 kGy obteve resultados eficientes na remoção de cor superiores a 97\%, enquanto que para essa mesma dose foi observada uma redução de toxicidade de aproximadamente $60 \%$ para a bactéria Vibrio fischeri. 
Desta forma, é possível observar que doses baixas (entre 0.5 e 5.0 kGy) se apresentam adequadas para o tratamento destes poluentes recalcitrantes, melhorando o benefício em termos de custo de produção.

Segundo Han et al (2007), o fator econômico é o ponto mais importante para a instalação de uma planta de acelerador de eletróns, sendo que os aceleradores originam elétrons acelerados com energia que alcançam entre 50 a 400 kW. Para o tratamento de gás, a energia necessária é aproximadamente de 0,7 a 1,0 MeV, enquanto que para tratamentos de águas residuais e higinenização de esgoto, a energia deve ser superior a 1,0 MeV, o que torna este processo mais caro. Entretanto, a utilização de doses baixas de radiação pode ser suficiente para a penetração de elétrons, auxiliando na degradação dos compostos.

\subsubsection{Associação de processos oxidativos avançados com tratamentos biologicos}

A eficiência das técnicas de oxidação biológica é normalmente dificultada pela presença de materiais biorefratários, embora sejam os mais usados convencionalmente e utilizados em estratégia de tratamentos econômicos. A utilização de POAs isolados como procedimento de tratamento não se apresenta de forma lucrativa. No entanto, a combinação deste processo pode favorecer a redução de toxicidade ate um nível desejado e combinando-se com processos de oxidação biológicos (GOGATE e PANDIT, 2004).

A combinação dos POAs tem sido estudada na forma de pré-tratamento para processos biológicos, visando aumentar a biodegradabilidade e reduzir a toxicidade (KLAVARIOTI et al, 2009).

SIRTORI e colaboradores (2009) caracterizaram a degradação dos compostos de uma mistura complexa de um efluente de uma indústria farmacêutica utilizando-se do processo Fenton seguido de processos biológicos. A água residual tóxica, da qual continha compostos biorecalcitrantes, tais como, o ácido nalidixico, que após o tratamento foi obtida eficiência de remoção de 95\% do carbono orgânico dissolvido inicial, uma vez que foi verificado o aumento de biodegradabilidade do efluente após o processo Fenton. 
LESTER e colaboradores (2013) utilizaram a combinação de processos biológicos seguidos de ozonização de uma instalação de formulação farmacêutica (TEvaKs, Israel) com o objetivo de reduzir a concentração dos fármacos carbamamazepina e venlafaxina. A associação dos tratamentos resultou de forma eficiente para remoção dos fármacos, ademais foi verificado o aumento de biodegradabilidade após o processo de ozonização.

A questão chave para a escolha desses processos deve se basear no processo com a melhor economia global e melhor desempenho ecológico. Durante a combinação dos processos químicos, físicos e biológicos para o tratamento de águas tornam-se necessários alguns conhecimentos prévios tais quais: a característica específica do efluente para a escolha dos oxidantes, a capacidade de oxidação dos compostos químicos utilizados, o potencial para a formação de compostos tóxicos intermediários, mudanças de comportamento do poluente, escolha de agentes biológicos. Além disso, a eficiência de combinação dos processos vai depender da finalidade do tratamento (OLLER et al, 2011).

\subsection{Análise de carbono orgânico total (COT)}

O carbono orgânico total de uma determinada solução é a concentração de carbono orgânico oxidado a $\mathrm{CO}_{2}$, em um forno de alta temperatura, e quantificado por meio de um analisador infravermelho. Esta análise considera as parcelas biodegradáveis e não biodegradáveis da matéria orgânica, não sofrendo interferência de outros átomos que estejam ligados à estrutura orgânica, quantificando apenas o carbono presente na amostra (CETESB, 2014).

\subsection{Cromatografia líquida ultra rápida}

Segundo a Internacional Union of Pure and Applied Chemistry (IUPAC, 1993), a cromatografia pode ser definida como um método de separação física em que os componentes a serem separados são distribuídos em duas fases, na qual se tem a fase estacionária e a fase móvel.

A cromatografia líquida (CL) começou a ser desenvolvida desde 1950 e até os dias atuais, graças ao impulso pelo desenvolvimento contínuo de novas partículas de fases estacionárias (FE), foi possível alcançar avanços, gerando-se 
colunas mais seletivas, eficientes e estáveis química e mecanicamente (MALDANER e JARDIM, 2009).

Um tipo de técnica de separação desenvolvido é a Cromatografia Líquida de Alta Eficiência (CLAE), também conhecida como High Performance Liquid Cromatography (HPLC). Esta cromatografia consiste em separação física realizada na fase líquida. A amostra é separada em seus componentes ou analitos, distribuindo-os entre a fase móvel e a fase estacionária (FAVARIN, 2012). Associado ao desenvolvimento das técnicas cromatográficas na última década, o desenvolvimento da CLAE tem sido direcionado à necessidade de análises mais rápidas, porém sem o comprometimento do desempenho cromatográfico (MALDANER e JARDIM, 2009).

Outro método cromatográfico desenvolvido foi o Ultra Fast Liquid Cromatography (UFLC), também conhecido como Cromatografia Líquida Ultra Rápida, que torna as análises dez vezes mais rápidas e três vezes melhor que a separação por sistema HPLC convencional (SHIMADZU, 2013).

Parte da avaliação da tecnologia em estudo empregou as análises cromatográficas no presente estudo. 


\section{MATÉRIAIS E MÉTODOS}

A metodologia do presente trabalho consistiu na avaliação dos efeitos tóxicos dos fármacos, cloridrato de fluoxetina (Prozac ${ }^{\circledR}$ ) e diclofenaco sódico (Voltaren ${ }^{\circledR}$ ) e da mistura de ambos os medicamentos. Para as análises foram empregados ensaios de toxicidade aguda com os organismos Vibrio fischeri e Daphnia similis. Ademais, a irradiação com feixe de elétrons foi estudada como uma possibilidade de tratamento de água contaminada, visando à diminuição de toxicidade e a possível degradação dos mesmos. Algumas análises químicas e biológicas também foram empregadas a fim de compreender os resultados de toxicidade com os efeitos da irradiação nas soluções em estudo.

Os experimentos foram realizados no Laboratório de Ensaios Biológicos e Ambientais (LEBA) do Instituto de Pesquisas Energéticas e Nucleares. Houve colaboração com o Centro de Engenharia de Sistemas Químicos (CESQ/PQIEPUSP), do Departamento de Engenharia Química da Escola Politécnica da Universidade de São Paulo e com o Laboratório de Hidráulica da Escola Politécnica, também da EPUSP. O fluxograma, representado na Figura 9, demonstra um esquema dos experimentos realizados ao longo do trabalho. 


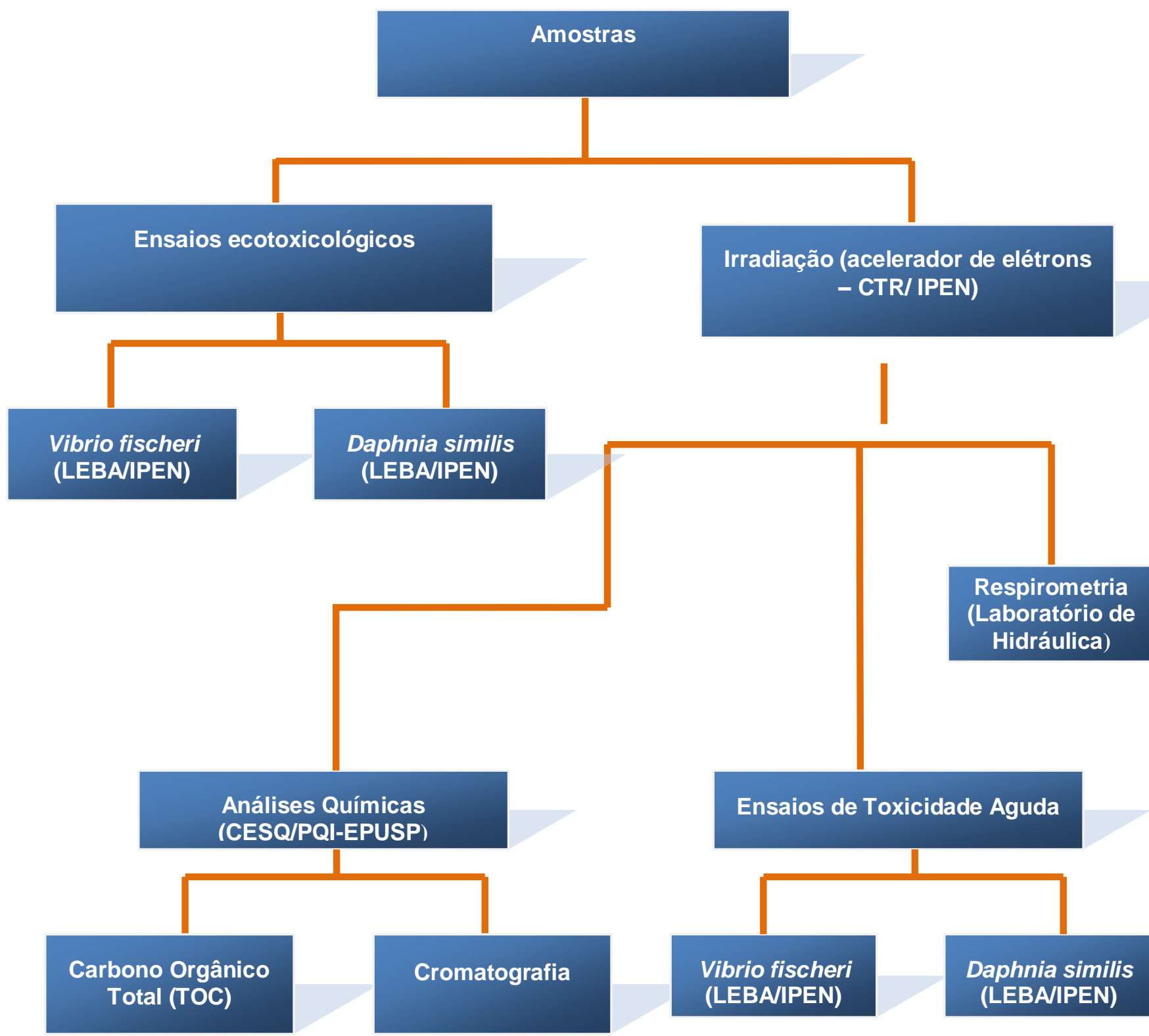

Legenda:

CTR/IPEN (Centro de Tecnologia das Radiações, Instituto de Pesquisas Energéticas e Nucleares) LEBA (Laboratório de Ensaios Biológicos e Ambientais)

CESQ/PQI-EPUSP (Centro de Engenharia de Sistemas Químicos, Escola Politécnica da Universidade de São Paulo)

Figura 9 - Fluxograma das etapas desenvolvidas no presente estudo. 


\subsection{Preparo das soluções de fármacos}

Os fármacos utilizados no presente estudo foram obtidos na forma de comprimidos, com marcas comerciais, conforme consta na Figura 10.

As cápsulas do cloridrato de fluoxetina foram adquiridas da marca Prozac $^{\circledR}$ (Fabricante: Lilly), contendo $22,4 \mathrm{mg}$ de cloridrato de fluoxetina (equivalente a $20 \mathrm{mg}$ de fluoxetina). Dentre os excipientes encontram-se o amido em pó e amido em pó com $5 \%$ de silicone q.s.p, conforme informado pelo fabricante. A solubilidade do cloridrato de fluoxetina é de $14000 \mathrm{mg} \cdot \mathrm{L}^{-1} \mathrm{em}$ água (SANTOS, 2011).

Os comprimidos de diclofenaco sódico foram obtidos da marca Voltaren ${ }^{\circledR}$ (Fabricante: Novartis). Cada cápsula do medicamento contém $50 \mathrm{mg}$ de diclofenaco de sódio em sua formulação, além de alguns excipientes (dióxido de silício, celulose microcristalina, lactose, estearato de magnésio, amido de milho, povidona, macrogol, polissorbato 80 , talco, óxido de ferro amarelo e óxido férrico vermelho, amidoglicolato de sódio, polímero metacrilato, dióxido de titânio e hipromelose). A solubilidade diclofenaco é de $19000 \mathrm{mg} \cdot \mathrm{L}^{-1}$ em água (RISSI , 2013).

Para o preparo das soluções-estoque, os comprimidos foram diluídos em água destilada, sendo estes submetidos à agitação, com o uso de agitadores magnéticos, por um período de 4 horas, a fim de garantir melhor homogeinização das soluções. O preparo das soluções estoque de $\operatorname{Prozac}^{\circledR}$ foi realizado a partir da diliuição de 1 comprimido em balão volumétrico de $2 \mathrm{~L}$, ao passo que as soluções estoques de Voltaren $^{\circledR}$ foram preparadas com a diluição de 2 comprimidos em balão volumétrico de $1 \mathrm{~L}$. 


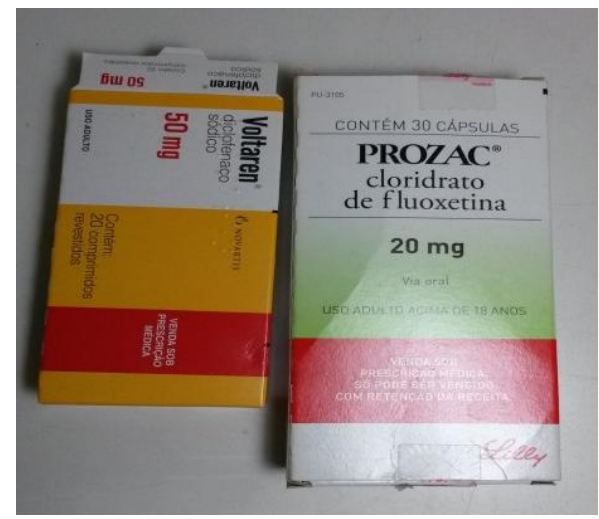

Figura 10 - Embalagens de fármacos comerciais utilizados no preparo das soluções estoques, em estudo.

\subsubsection{Preparo da mistura de fármacos}

As misturas foram preparadas em duas diluições, visando avaliar o comportamento dos fármacos em mistura. Com bases em estudos anteriores, foram utilizadas concentrações próximas aos valores de efeitos observados (CE50) para os organismos previamente reportados pela literatura (SILVA, 2014; HOMLOK et al, 2011; MENDES et al, 2010). Os ensaios foram preparados na diluição1:1, em que foi realizada a mistura na proporção 50/50 (\%v/v) dos fármacos (Mistura mais concentrada $(\mathrm{A})$ ). Em alguns casos, foi utilizado a diluição 1:10, em que foram misturados 50\% (v/v) de fluoxetina e 10\% (v/v) de diclofenaco, completando-se o balão com água destilada (40\% v/v) (Mistura diluída 1:10(B)).

\subsection{Irradiação das amostras (fármacos em solução aquosa)}

As amostras líquidas contendo os fármacos foram irradiadas no Acelerador Industrial de Elétrons do IPEN, tipo Dynamitron ${ }^{\circledR}$, com potência de $37,5 \mathrm{~kW}$. A energia do feixe de eletróns pode variar entre 0,5 a 1,5 MeV e a corrente elétrica de 0,3 até 25,0 mA. Durante os experimentos, a energia da máquina foi fixada em 1,4 MeV, variando-se apenas a corrente elétrica para que as irradiações atingissem as doses estabelecidas.

Durante a irradiação, as amostras foram mantidas em recipiente de vidro $\left(\right.$ Pyrex $^{\circledR}$ ), com volume de $246 \mathrm{~mL}$, de modo a assegurar o máximo de $4 \mathrm{~mm}$ de espessura para a irradiação, respeitando-se, assim, a baixa penetrabilidade dos eletróns em soluções aquosas. Os recipientes foram recobertos com filme 
plástico, a fim de evitar possíveis contaminações das amostras durante 0 processo de irradiação, bem como perdas. A velocidade de $6,72 \mathrm{~m} \cdot \mathrm{min}^{-1}$ foi utilizada durante o transporte das amostras até a área de irradiação, com auxílio de esteira automática, sendo que estas passaram duas vezes sob o feixe de eletróns, recebendo metade da dose de radiação aplicada em cada passada da amostra nos feixes de elétrons (Figura 11).

(a)

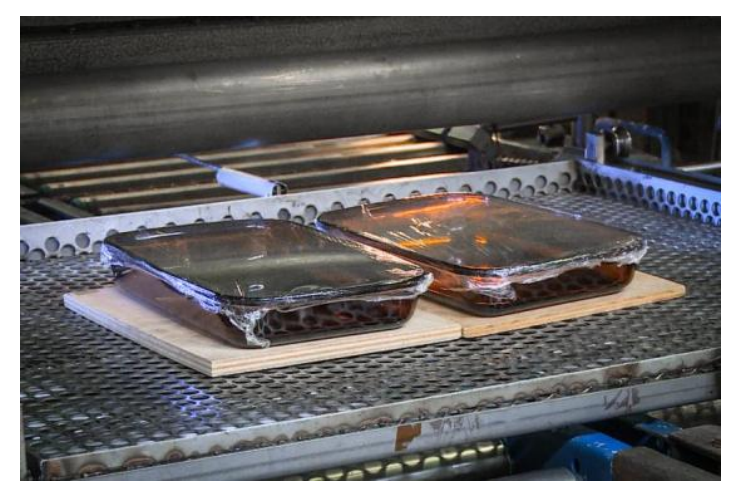

(b)

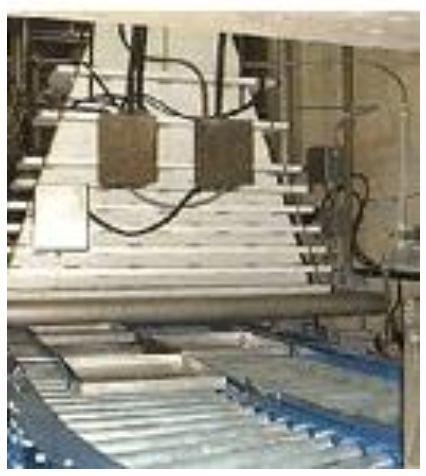

Figura 11 - (a) Amostras das soluções de fármacos, contidas em vidro Pirex ${ }^{\circledR}$, passando sob o feixe de elétrons, durante o tratamento no acelerador

(b) acelerador industrial de elétrons.

As doses de radiação aplicadas foram de 2.5, 5.0, 7.5 e 10 kGy. Com base em estudos anteriores, alguns ensaios foram realizados apenas na dose de $5.0 \mathrm{kGy}$, visto que esta foi a mais eficiente para remoção da toxicidade (SILVA, 2014; SANTOS, 2011). O limite máximo estabelecido foi de 10 kGy, visando trabalhar com doses mais baixas para viabilizar o custo de operação e minimizar a energia do processo.

\subsection{Análises químicas empregadas}

\subsubsection{Análises de carbono orgânico total (COT)}

Para as análises de Carbono, foi utilizado o analisador de TOC-LCPH/CPN Shimadzu (Figura 12). O carbono orgânico total foi obtido a partir da diferença de carbono total (CT) e do carbono inorgânico (IC). A quantificação do CT foi obtida pela oxidação catalítica da amostra a $680^{\circ} \mathrm{C}$, ao passo que o $\mathrm{Cl}$ ocorreu pela injeção da amostra em uma solução de ácido fosfórico a 25\%. O equipamento 
quantifica o $\mathrm{CO}_{2}$ formado em ambos os casos por absorção no infravermelho não dispersivo (SHIMADZU CORPORATION, 2014).

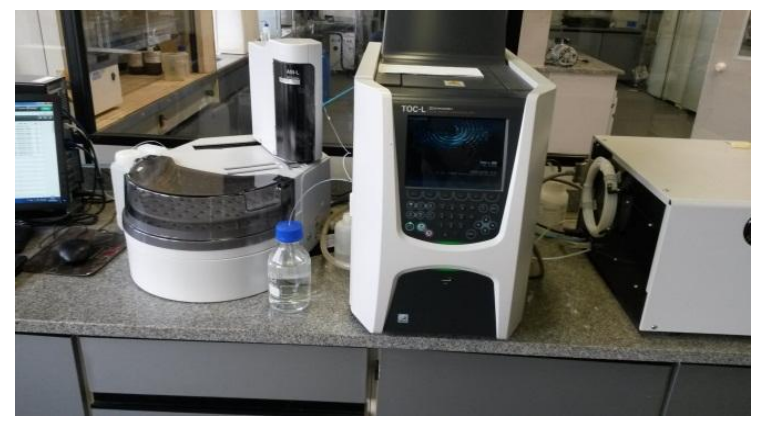

Figura 12 - Analisador de Carbono Orgânico Total (COT).

\subsubsection{Análises de cromatografia líquida ultra rápida}

A cromatografia líquida ultrarrápida (ultra-fast liquid chromatography, UFLC) foi utilizada para quantificar os fármacos em solução aquosa. O equipamento utilizado para as análises cromatográficas foi da marca Shimadzu, modelo UFLC 20 AD equipado com detector UV/VIS (SPD 20A) e com o detector de fluorescência $\left(\mathrm{RF}-10 \mathrm{Axl}\right.$ ). A coluna empregada foi a $\mathrm{C}_{18}$ (Kinetex $5 \mu \mathrm{m}$ Phenomenex®, $150 \times 4,60 \mathrm{~mm}$ ) a uma temperatura de $40^{\circ} \mathrm{C}$ e vazão de 1,8 $\mathrm{ml} \cdot \mathrm{min}^{-1}$ (Figura 13).

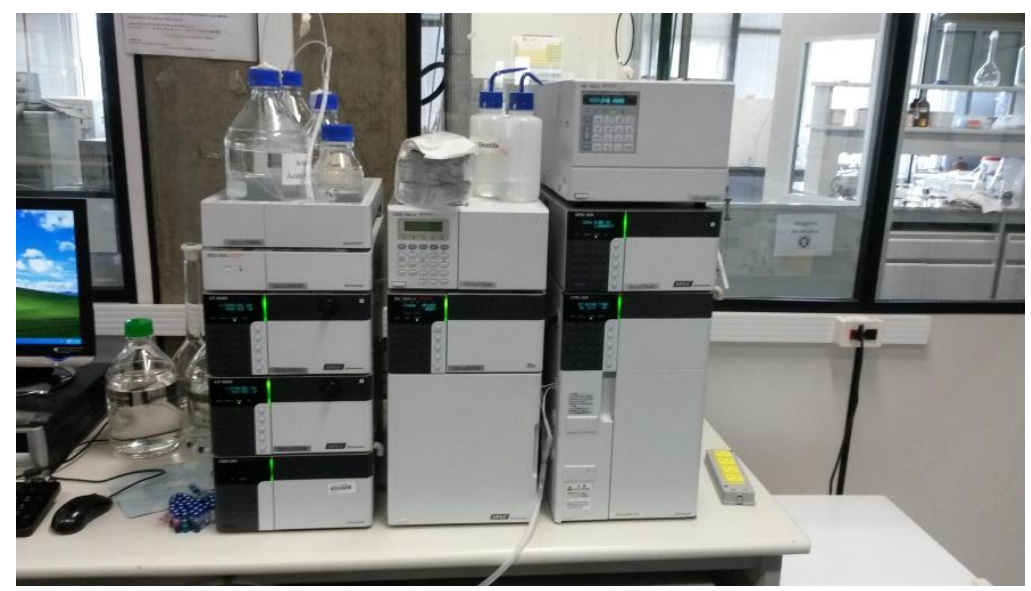

Figura 13 - Equipamento utilizado nas análises cromatográficas (Cromatógrafo - Modelo UFLC 20 AD, Shimadzu).

Para detectar os fármacos presentes na mistura, foi utilizado detector de fluorescência para o cloridrato de fluoxetina e o detector UV/VIS para o diclofenaco sódico. Devido à baixa detecção da fluoxetina por UV/Vis, a detecção do cloridrato de fluoxetina foi realizada com detecção por fluorescência com 
leitura nos comprimentos de onda de excitação e emissão, sendo $\lambda_{\text {excitação }}=230$ $\mathrm{nm}$ e $\lambda_{\text {emissão }}=290 \mathrm{~nm}$ (SILVA, 2014). A leitura do pico de absorção do diclofenaco foi realizada no comprimento de onda de $276 \mathrm{~nm}$, em que ocorre a máxima absorção do composto (RIZZO et al, 2009). Os tempos de retenção para a identificação dos fármacos foram de 5,9 min para o cloridrato de fluoxetina e 9,9 min para o diclofenaco sódico.

O volume de injeção para as amostras dependeu da faixa de concentração dos fármacos. Para amostras com concentrações entre 1 e $40 \mathrm{mg} \cdot \mathrm{L}^{-1}$, foram injetados de $10 \mu \mathrm{L}$ de amostras, enquanto que para as amostras com faixas inferiores a $1 \mathrm{mg} . \mathrm{L}^{-1}$, o volume injetado foi de $70 \mu \mathrm{L}$. O método de eluição utilizado foi o modo de eluição por gradiente, variando-se a constituição da fase móvel, representado na Tabela 4.

Tabela 4 - Variação da constituição da fase móvel de acordo com o tempo, nas análises cromatográficas para a detecção dos fármacos cloridrato de fluoxetina e diclofenaco sódico.

\begin{tabular}{|c|c|c|}
\hline \multirow{2}{*}{ Tempo (min) } & Fase móvel A & Fase móvel B \\
\hline 0,01 & $\mathrm{H}_{2} \mathrm{O} 1 \%$ ácido acético & $29 \%$ acetonitrila \\
\hline 7,00 & $\mathrm{H}_{2} \mathrm{O} 1 \%$ ácido acético & $29 \%$ acetonitrila \\
\hline 7,01 & $\mathrm{H}_{2} \mathrm{O} 1 \%$ ácido acético & $52 \%$ acetonitrila \\
\hline 11,01 & $\mathrm{H}_{2} \mathrm{O} 1 \%$ ácido acético & $29 \%$ acetonitrila \\
\hline 14,0 & $\mathrm{H}_{2} \mathrm{O} 1 \%$ ácido acético & $29 \%$ acetonitrila \\
\hline
\end{tabular}

\subsubsection{Curvas analíticas}

Para a construção das curvas analíticas foram utilizados os compostos farmacológicos obtidos na forma pura, adquiridos em farmácia de manipulação.

O preparo das soluções-padrão foi realizado nas concentrações de 50 $\mathrm{mg} \cdot \mathrm{L}^{-1}$ para o cloridrato de fluoxetina e $50 \mathrm{mg} \mathrm{L}^{-1}$ para diclofenaco sódico, sendo ambos diluídos em metanol. A partir destas soluções-padrão, foram preparadas as diluições necessárias em água Mili- $Q^{\circledR}$.

Os valores do Limite de Detecção (LD) e do Limite de Quantificação (LQ) podem ser expressos pelas fórmulas:

$$
\mathrm{LD}=3,3 \times \mathrm{s} / \mathrm{S} \quad \text { Equação } 5
$$




$$
\mathrm{LQ}=10 \times \mathrm{s} / \mathrm{S} \quad \text { Equação } 6
$$

Onde $s$ é o coeficiente linear e o $S$ é o coeficiente angular da curva analítica (RIBANI et al, 2004).

\subsection{Aplicação de ensaios de ecotoxicológicos}

O cultivo dos organismos-teste, bem como os ensaios de toxicidade empregados, foram realizados conforme as metodologias normatizadas, seguindo as recomendações da Associação Brasileira de Normas Técnicas (ABNT-NBR). Foram empregados organismos de duas classes biológicas, a bactéria Vibrio fischeri com exposção de 15 min e o microcrustáceo Daphnia similis com exposição de $48 \mathrm{~h}$.

A validação dos ensaios de toxicidade foi baseada em resultados obtidos com substâncias de referências. Para a bactéria Vibrio fischeri, foi utilizado o fenol e para o microcrustáceo Daphnia similis, o cloreto de potássio.

\subsubsection{Ensaios com bactérias Vibrio fischeri}

Os testes de toxicidade aguda com a bactéria luminescente Vibrio fischeri seguiram as recomendações da normativa ABNT NBR 15411/2012, utilizando bactérias liofilizadas. Estas foram adquiridas do mercado nacional, da marca Biolux $^{\circledR}$ (Figura 14), ficando estocadas sob refrigeração em freezer. $O$ equipamento empregado foi o analisador de fotoluminescência Microbics ${ }^{\circledR}$ (M500 Toxicity Analyzer).

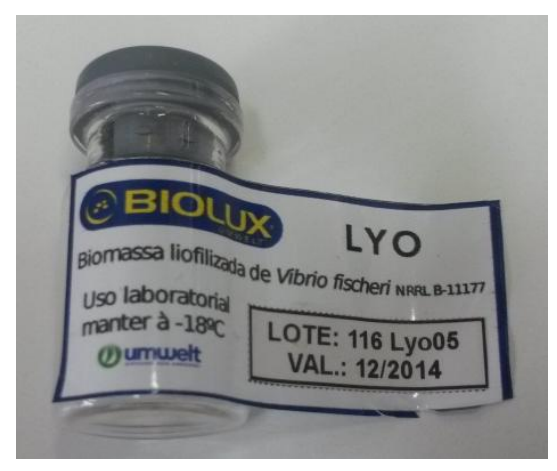

Figura 14 - Bactéria bioluminescente Vibrio fischeri (Biolux ${ }^{\circledR}$ ) adquiridas em lotes na forma liofilizada. 
Para os ensaios primeiramente realizou-se a reativação das bactérias com $1000 \mu \mathrm{L}$ solução de tampão de reativação. Em seguida foi preparada a devida série de diluição das amostras. As cubetas de leitura receberam $100 \mu \mathrm{L}$ da solução que continha a bactéria. A diluição da amostra foi realizada com a solução diluente (1:10 - solução Biolux, que contém sal) juntamente com os controles. As concentrações utilizadas para os testes de toxicidade aguda foram equivalentes a $5,11 \% ; 10,23 \% ; 20,47 \% ; 40,95 \%$. Em alguns casos, para amostras mais tóxicas a diluição de $2,56 \%$ foi utilizada, enquanto que a diluição de $81,90 \%$ foi usada para amostras menos tóxicas.

Duas sequências de cubetas foram dispostas no analisador Microbics ${ }^{\circledR}$ : na primeira as amostras já com o ajuste osmótico adequado. A segunda fileira de cubetas já continha as bactérias. A partir desta sequência foram obtidos os valores de luminescência, a fim de calibrar o analisador. Na sequência foram obtidas as medidas de $I_{0}$ (luminescência inicial, sem a amostra). Após a transferência das respectivas frações de amostra para as cubetas de leitura e transcorridos os 15 minutos de exposição, os valores de $I_{15}$ foram obtidos (Figura 15).

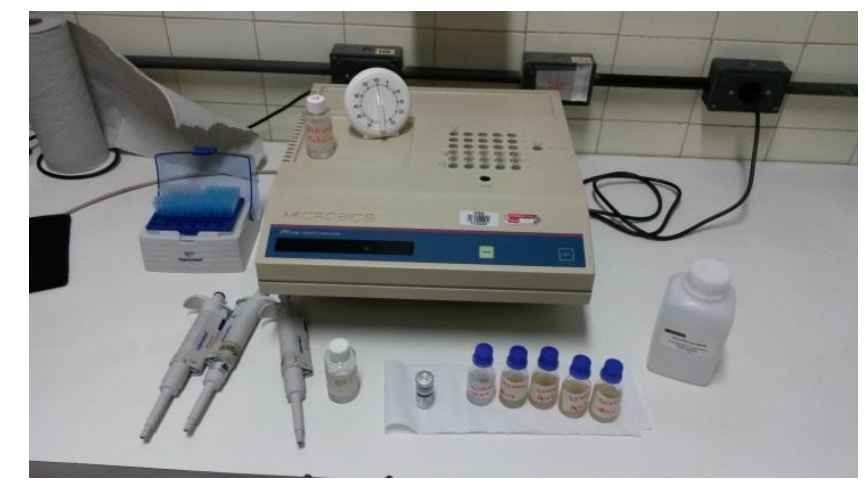

Figura 15 - Sistema analisador (Micotox® 500) empregado no ensaio com a bactéria bioluminescente Vibrio fischeri.

\subsubsection{Ensaios com microcrustáceos Daphnia similis}

O laboratório LEBA mantém um cultivo regular de Daphnia similis. A manutenção dos organismos e os ensaios de toxicidade aguda empregado com esses microcrustáceos serão discutidos nos itens a seguir. 


\subsubsection{1. Água de cultivo e de diluição}

A água utilizada para a manutenção do cultivo dos organismos Daphnia similis, bem como para a diluição das soluções-estoque da mistura de fármacos foi procedente de uma adutora no município de Salto/SP.

Após a coleta de cada de lote de água, foram realizados testes de viabilidade com o organismo-teste por meio de exposição de 10 organismos. Os ensaios foram realizados com $24 \mathrm{~h}$ duração sem adição de alimentos aos organismos. Todos os lotes de água coletados no período de estudo foram considerados satisfatórios, visto que a imobilidade dos organismos não ultrapassou $10 \%$.

Os parâmetros físico-químicos também foram avaliados após as coletas. Os parâmetros analisados foram $0 \mathrm{pH}, \quad$ o oxigênio dissolvido (OD), a condutividade eléltrica e dureza da água, sendo esta corrigida quando necessário para aproximadamente $45 \pm 2 \mathrm{mg} \mathrm{CaCO}_{3} / \mathrm{L}$, conforme a norma ABNT 12713/2009. Embora a norma recomende que o cultivo do $\mathrm{pH}$ seja mantido entre 7.0 e 7.6, por práticas e procedimentos do Laboratório de Ensaios Biologicos e Ambientais (LEBA), não ocorreu ajuste de pH em água natural.

As medições de $\mathrm{pH}$ foram efetuadas no $\mathrm{pHmetro}$ de bancada da marca Micronal $^{\circledR}$, modelo B474. As análises de OD e condutividade foram realizadas pelo analisador multiparâmetros medidor da marca $\mathrm{HACH}^{\circledast}$, modelo $\mathrm{HQ40d}$ (Figura 16). A medição da dureza foi realizada pelo método titulométrico do EDTA (CETESB, 1992). 


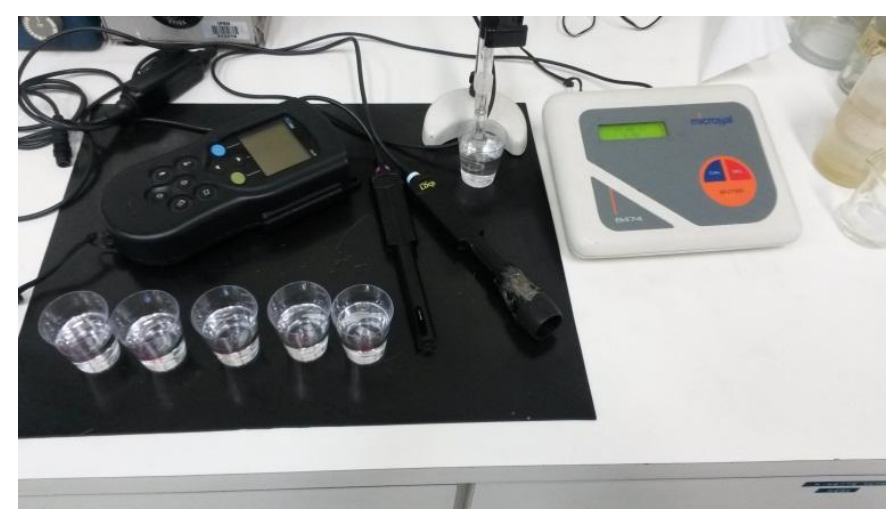

Figura 16 - Equipamentos utilizados para medir os valores de $\mathrm{pH}$, condutividade e Oxigênio Dissolvido (OD).

A fim de garantir uma saturação de oxigênio adequada e uma melhor homogeinização das soluções inseridas para o ajuste de dureza na água, foi mantida aeração constante na água por um período de no mímino 24 horas para a realização dos ensaios e trocas de água dos cultivos.

\subsubsection{Manutenção do cultivo de Daphnia similis}

Os cultivos do organismos foram mantidos em uma câmara de germinação em temperatura de $20 \circ \mathrm{C} \pm 1 \stackrel{\circ}{ } \mathrm{C}$, com fotoperíodo de 16 horas luz e 8 horas escuro. As culturas foram mantidas em cristalizadores com capacidade de aproximadamente 2 litros, em que foram mantidos entre 30 a 40 organismos em água de cultivo, sendo esta renovada uma vez por semana (Figura 17).

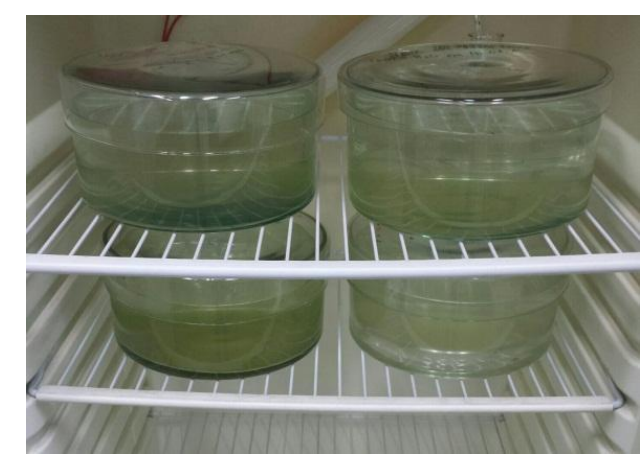

Figura 17 - Câmara de germinação com temperatura e fotoperíodo controlados.

A alimentação dos organismo foi feita diariamente com a microalga Pseudokirchneriella subcaptada na concentração de 1 a $5 \times 10^{6}$ células por organismo, sendo complementada com a ração para peixes da marca Alcon 
Basic $^{\circledR}$ MEP Complex com adição de leveduras a ração líquida (RL) (Figura 18). A proporção de alimentos foi de $100 \mu \mathrm{L}$ de microalga e $50 \mu \mathrm{L}$ de ração para cada indivíduo. A microalga foi cultivada no laboratório LEBA, por uma semana com o meio de cultura L.C. Oligo, preparado conforme ABNT 12648/2011, sob aeração e iluminação constante.

Semanalmente, para atingir uma concentração ideal da microalga a suspensão algacea foi centrifugada por 5 minutos em uma centrifuga da marca Quimis $^{\circledR}$, modelo Q222T. O sobrenadante foi descartado e a microalga foi concentrada e ressuspensa em cerca de $1,0 \mathrm{~mL}$ de água de cultivo no agitador de tudos tipo vortex da marca Phoenix ${ }^{\circledR}$, modelo AP56.

A ração líquida foi preparada através da fermentação da ração para peixes em flocos da marca Alcon Basic ${ }^{\circledR}$ MEP Complex. A fermentação foi realizada em um balão de destilação contendo $5,0 \mathrm{~g}$ de ração em 1,0 litro de água destilada. Essa mistura foi mantida sob forte aeração constante por sete dias. Posteriormente, $50 \mathrm{ml}$ dessa ração fermentada foi misturada $0,5 \mathrm{~g}$ de fermento biológico (levedura) e $75 \mathrm{~mL}$ de água destilada (Figura 18).
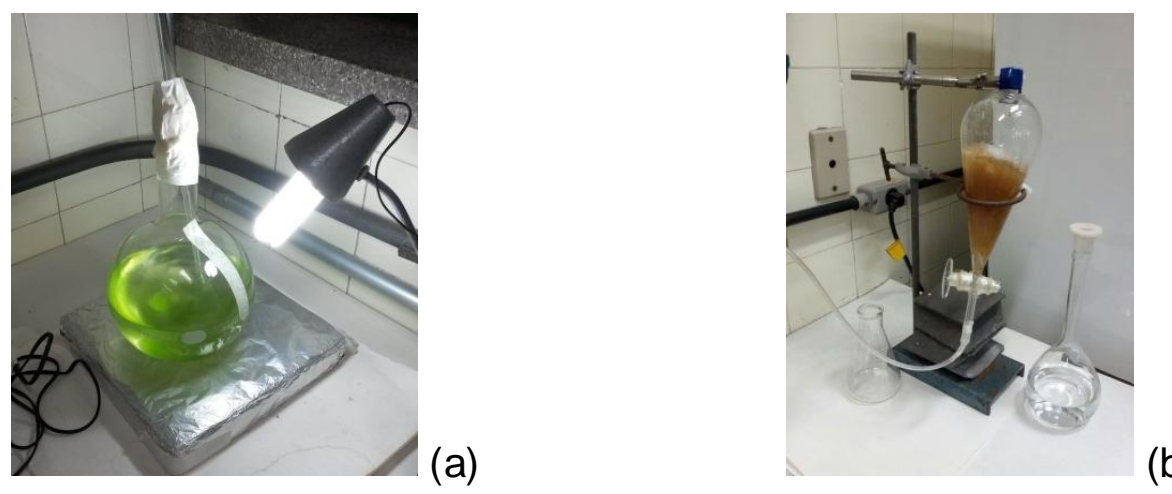

Figura 18 - (a) Cultivo de microalga Pseudokirchneriella subcaptada sob aeração e iluminação constantes (b) Fermentação da ração líquida para a manutenção dos organismos.

A manutenção do cultivo foi realizado diariamente, alimentando os organismos e retirando-se as neonatas e as carapaças liberadas durantes as mudas. Cada cultivo foi mantido por um período de 28 dias. 


\subsubsection{Ensaios de toxicidade aguda com Daphnia similis}

Os ensaios de toxicidade aguda foram realizados conforme a norma ABNT NBR 12713/2009, empregando organismos jovens, chamados de neonatos, com idade entre 6 a 24 horas. Os testes foram feitos a partir da diluição das amostra (soluções-estoque de fármacos) com o uso de água de cultivo, com no mínimo cinco concentrações por amostra e os respectivos controles.

Cada concentração foi distribuída em quatro tubos de ensaios contendo $10,0 \mathrm{~mL}$ da amostra, sendo estes levados a um período de aclimatação em incubadora. Posteriormente, em cada tubo de ensaio foram adicionados 5 organismos, totalizando 20 por concentração. Após esses procedimentos, os tubos de ensaio foram protegidos com filme plástico escuros, a fim de isolar as amostras da interação com o ambiente e inibir o deslocamentos dos organismos para regiões mais claras. Em seguida, foram levados a uma incubadora a $20^{\circ} \mathrm{C}$, por um período de 48 horas (Figura 19).

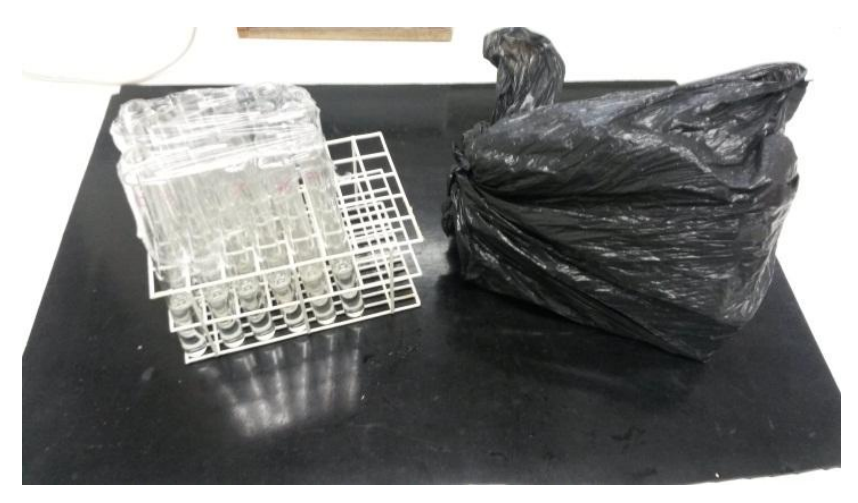

Figura 19 - Sistema utilizado para incubação de amostras durante os ensaios com Daphnia similis.

Cada ensaio foi acompanhado de um controle, que baseou-se em um grupo de organismos expostos as mesmas condições do ensaio, entretanto, mantidos em água de cultivo. Após o período de 48 horas, foi avaliada a imobilidade/mortalidade dos organismos em cada concentração.

\subsection{Unidades tóxicas (UT) e eficiência de remoção de toxicidade}

A Concentração Efetiva 50 (CE50) pode ser definida como a concentração que causa efeitos agudos a 50\% dos organismos expostos, em um determinado período de exposição, nas condições de ensaio. 
Esses valores apresentam uma relação inversamente proporcional de concentração-efeito, ou seja, quanto menor o valor de CE50 maior a toxicidade. Assim, para trabalhar com grandezas diretamentes proporcinais, estes valores podem ser transformados em Unidades Tóxicas, seguindo a Equação 7:

$$
\text { UT }=100 / \text { CE50 } \quad \text { Equação } 7
$$

Além disso, a partir das Unidades Tóxicas, é possivel obter valores de eficiência de remoção de toxicidade de uma amostra, conforme Equação 4:

Eficiência de remoção de toxicidade $=\left(\left(U T_{\text {bruto }}-U T_{\text {amostra irradiada }}\right) \times 100\right) / U T_{\text {bruto }}$ Equação 8

Sendo:

$\mathrm{UT}_{\text {bruto }}$ : Unidade tóxica da amostra antes do tratamento.

UT amostra irradiada : Unidade Tóxica da amostra irradiada em determinada dose de radiação.

\subsection{Carta controle de sensibilidade}

O controle da sensiblidade dos organismos é um procedimento que permite maior precisão e confibilidade nos resultados obtidos, sendo realizado por meio de ensaios periódicos com substâncias referência. De acordo com os procedimentos descritos na Norma NBR 12713/2004 da ABNT, mensalmente a sensibilidade do organismo-teste deve ser avaliada por meio de ensaios com uma substância referência. Os ensaios foram realizados nas mesmas condições dos ensaios definitivos. Para o organismo Daphnia similis foi utilizado o cloreto de potássio $(\mathrm{KCl})$, para a a Vibrio fischeri, o fenol.

O uso de substâncias de referência em laboratórios de Ecotoxicolgia é um procedimento rotineiro em programas de garantia da qualidade analítica, de estudos que utilizam testes de toxicidade aguda e crônica (ZAGATTO e BERTOLETTI, 2006). Para que a garantia da qualidade analítica do estudo seja aprovadas, os valores de CE50 obtidos para a substância referência precisam estar dentro de um intervalo de confiança. A variabilidade dos resultados que pode ser analisada através do coeficiente de variação $(\mathrm{CV})$, dado pela equação Equação 5): 
$C V=(S / X) \times 100$

Equação 9

Sendo:

$S=$ desvio padrão

$\mathrm{X}=$ média dos resultados

De modo geral, um método ecotoxicógico é considerado bom quando a variação dos resultados, expressa pelo valor de CV seja inferior ou igual a $30 \%$. Caso a sensibilidade dos organismos-teste esteja fora da faixa definida por alguma norma, para uma determinada substância referência, é sinal de que ocorreu alguma alteração em algum fator no meio ambiente do sistema do teste, pela qual este deve ser submetido a uma nova avaliação completa (ZAGATTO e BERTOLETTI, 2006).

\subsection{Ensaios de Respirometria}

Os ensaios de respirometria foram realizados no Laboratório de Hidráulica da Escola Politécnica, EPUSP. O modelo de respirômetro utilizado foi um equipamento do modelo Beluga S32c, do tipo semiaberto contínuo.

A metodologia dos ensaios segiu o princípio do método para determinação da taxa de consumo de oxigênio (TCO) que considera as variações na taxa de respiração do lodo em consequência do tipo de substrato acrescentado e da velocidade de degradação de parte da biomassa (ANDREOTTOLA, 2005).

O consumo de oxigênio se desenvolve em duas fases principais:

- Respiração endógena do lodo: quantidade de oxigênio necessário para que a as células tenham energia suficiente para manter as funções das células;

- Respiração exógena do lodo: consumo de oxigênio dos microrganismos para a degradação dos substratos presentes no meio líquido.

Durante a fase exógena, a taxa de absorção de oxigênio pode ser influenciado pelo tipo de substrato presente no esgoto, tendo-se desta forma: 
- Substratos rapidamente biodegradáveis - possuem uma elevada velocidade de consumo de oxigênio;

- Substratos lentamente biodegradáveis - possuem uma velocidade inferior de consumo de oxigênio que os substratos biodegradáveis, entretanto, uma velocidade superior a fase endógena.

Para a obtenção da TCO são utilizados equipamentos denomidos Respirômetros, os quais são constituidos por um medidor de OD acoplado a um computador, onde os dados da concentração de oxigênio em função do tempo são armazenados (Figura 20).

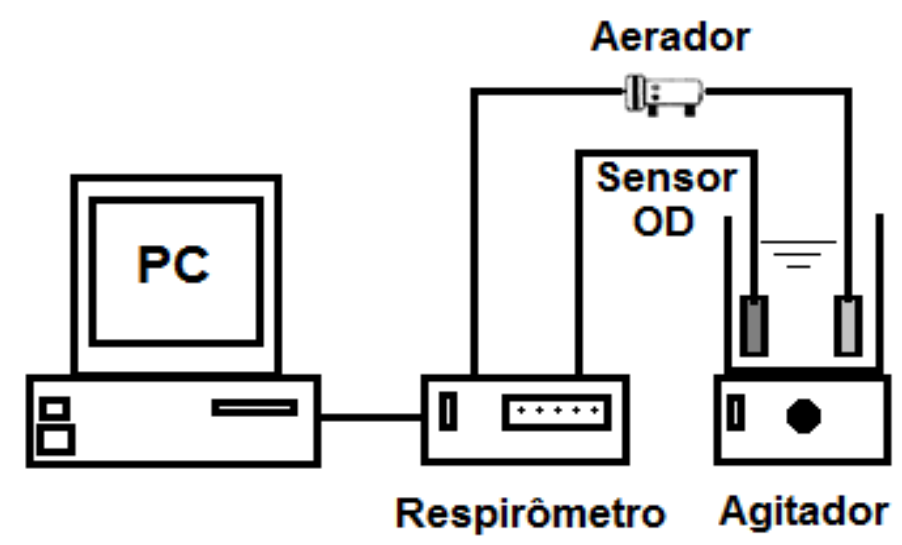

Figura 20 - Esquema operacional para realização de testes respirométricos.

Os dados obtidos são posteriormente tratados estatísticamente por um software, e assim, são apresentados na forma de diagramas da TCO em função do tempo. Os valores de TCO de forma semi-contínua podem ser obtidos através da variação da OD medidos ao computador de modo periódico (Equação 10).

$$
T C O=\frac{d O}{d t}=\frac{O D \max -O D \min }{t 1-t 0} \quad \text { Equação } 10
$$

Para a realização dos ensaios respirométricos, coletou-se lodo biológico proveniente da estação de tratamento biológico do CRUSP/USP. Visando minimizar a influência de possíveis transferências do gás oxigênio atmosférico 
para a massa líquida, foi empregado no teste um pequeno reator com tampa, que possuia abertura para a introdução da sonda, hélice de agitação e aeradores.

O lodo biológico foi introduzido nos reatores juntamente com os agitadores e a sonda para medir o oxigênio dissolvido na amostra (OD). De acordo com VAN HAANDEL e MARAIS (1999), é necessário o consumo de oxigênio de 2 a 3 $\mathrm{mgO}_{2} \cdot \mathrm{L}^{-1}$ para se ter dados confiáveis. Desta forma, após o período da fase endógena, foram adicionados $30 \mathrm{~mL}$ de acetato visando verificar a viabilidade do lodo biológico. Após o lodo ter retornado a fase endógena, foram introduzidos 30 $\mathrm{mL}$ do substrato observando a biodegradabilidade das amostras. Ao final dos ensaios foram adicionados, novamente, mais $30 \mathrm{~mL}$ de acetato de modo a verificar a atividade do lodo. Ao longo do procedimento, os aeradores foram ligados e desligados, de acordo com a concentração de oxigênio na fase líquida, para garantir uma concentração de oxigênio suficiente aos microrganismos (Figura 21).

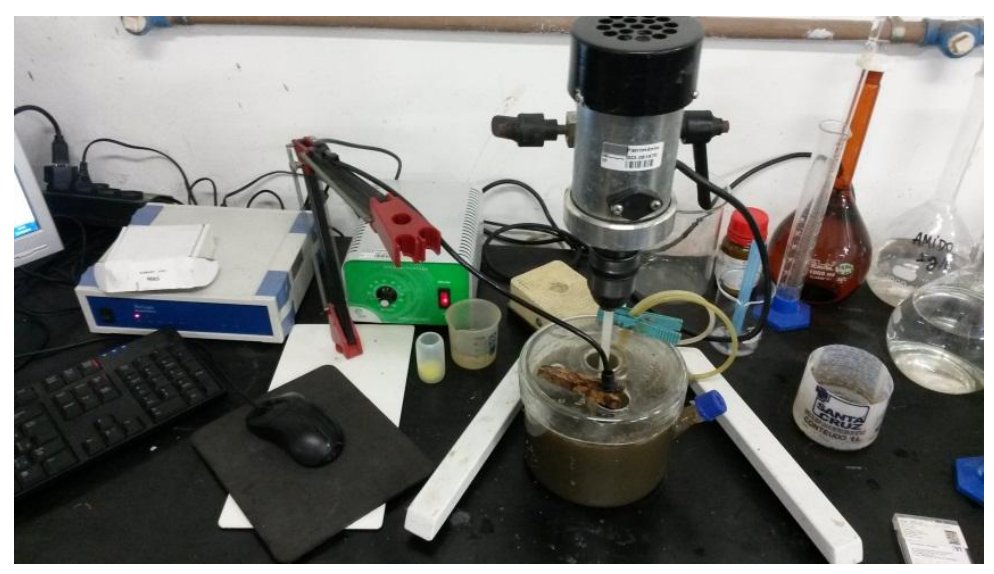

Figura 21 - Equipamentos utilizados para a realização dos ensaios respirométricos, EPUSP

\subsection{Análise estatística (ensaios ecotoxicológicos)}

Os resultados de CE50 foram calculados a partir de testes estatísticos conforme previsto nas respectivas normas técnicas.

Ensaios com Vibrio fischeri basearam-se no valor de efeito gama (relação entre a luz perdida e a luz remanescente) para numa determinada concentração da amostra. Aplicando-se uma análise de regressão linear com esses valores 
foram determinadas as CE50, com base na perda da bioluminescência da bactéria $V$.fischeri.

A análise de dados brutos da imobilidade da dafnia em função das concentrações de amostra foi realizada com o método Trimmed SpearmanKarber, com auxílio de programa computacional (HAMILTON et al, 1977).

A avaliação estatistica de significância entre os dados coletados foram realizados por meio do método estatítisco Análise de Variância (ANOVA) com o Teste de Tukey. Este procedimento é utilizado para comparar três ou mais condições impostas ou objetos em que se desejam medir ou avaliar num experimento (UFPR, 2009).

Após verificar que há variação significativa pela ANOVA, o procedimento seguinte é o de comparar as médias das condições utilizando algum teste de comparação de média ou constrastes para identificar quais condições são diferentes, sendo o Teste de Tukey que permite testar qualquer constraste entre duas médias de condições (UFPR, 2009).

\subsection{Descarte de resíduos dos experimentos}

As soluções utilizadas nos ensaios foram armazenadas em bombonas de $20 \mathrm{~L}$ corretamente identificadas e entregues ao setor responsável pela coleta e destinação final do IPEN. 


\section{RESULTADOS E DISCUSSÃO}

\subsection{Análises de Carbono Orgânico Total (COT)}

Com o objetivo de verificar a mineralização da mistura de fármacos (cloridrato de fluoxetina e diclofenaco sódico) após a irradiação por feixe de elétrons, foram realizadas análises de Carbono Orgânico Total (COT). Na Tabela 5 foram apresentados os COT (mg. $\left.\mathrm{L}^{-1}\right)$ das amostras brutas e irradiadas em diferentes doses e concentrações.

Tabela 5 - Valores de Carbono Orgânico Total (COT) e eficiência de remoção de COT das misturas de fármacos (cloridrato de fluoxetina e diclofenaco sódico) após a irradiação por feixe de elétrons em diferentes doses.

\begin{tabular}{|c|c|c|c|c|c|}
\hline \multirow[t]{2}{*}{$\begin{array}{l}\text { Dose } \\
\text { (kGy) }\end{array}$} & & \multicolumn{2}{|c|}{ Mistura mais concentrada $(\mathrm{A})$} & \multicolumn{2}{|c|}{ Mistura diluída 1:10 (B) } \\
\hline & Ensaio & $\begin{array}{c}\text { COT } \\
\left(\mathrm{mg}^{-1} \mathrm{~L}^{-1}\right)\end{array}$ & $\begin{array}{c}\text { Eficiência } \\
\text { de } \\
\text { Remoção } \\
(\%)\end{array}$ & $\begin{array}{c}\text { COT } \\
\left(m g \cdot L^{-1}\right)\end{array}$ & $\begin{array}{l}\text { Eficiência de } \\
\text { Remoção (\%) }\end{array}$ \\
\hline & 1 & 54,22 & - & 15,04 & - \\
\hline & 2 & 53,71 & - & 16,94 & - \\
\hline & 3 & 53,92 & - & - & - \\
\hline & $X \pm S$ & $53,95 \pm 0,26$ & - & $15,99 \pm 1,34$ & - \\
\hline \multirow{4}{*}{2.5} & 1 & 53,76 & 0,35 & 17,35 & - \\
\hline & 2 & 53,47 & 0,89 & 16,68 & - \\
\hline & 3 & 53,67 & 0,52 & - & - \\
\hline & $X \pm S$ & $53,63 \pm 0,15$ & $0,59 \pm 0,28$ & $17,02 \pm 0,47$ & - \\
\hline \multirow{4}{*}{5.0} & 1 & 54,45 & - & 12,67 & 20,8 \\
\hline & 2 & 54,99 & - & 13,72 & 14,2 \\
\hline & 3 & 55,20 & - & - & - \\
\hline & $X \pm S$ & $54,88 \pm 0,39$ & - & $13,20 \pm 0,74$ & $17,5 \pm 4,64$ \\
\hline \multirow{4}{*}{7.5} & 1 & 52,51 & 2,67 & 11,05 & 30,9 \\
\hline & 2 & 53,33 & 1,15 & 10,40 & 35,0 \\
\hline & 3 & 52,30 & 3,06 & - & - \\
\hline & $X \pm S$ & $52,71 \pm 0,54$ & $2,29 \pm 1,01$ & $10,73 \pm 0,46$ & $33,0 \pm 2,87$ \\
\hline \multirow{4}{*}{10.0} & 1 & 53,26 & 1,28 & 11,51 & 28,0 \\
\hline & 2 & 53,38 & 1,06 & 11,71 & 26,8 \\
\hline & 3 & 53,59 & 0,67 & - & - \\
\hline & $X \pm S$ & $53,41 \pm 0,17$ & $1,00 \pm 0,31$ & $11,61 \pm 0,14$ & $27,4 \pm 0,88$ \\
\hline
\end{tabular}

$X \pm S$ : Média com desvio-padrão Mistura mais concentrada (A): $50 \mathrm{mg} \cdot \mathrm{L}^{-1}$ de DIC e $5 \mathrm{mg} \cdot \mathrm{L}^{-1} \mathrm{FXT}$ Mistura diluída 1:10 (B): 5 mg. $\mathrm{L}^{-1}$ de DIC e $5 \mathrm{mg} \cdot \mathrm{L}^{-1}$ de FXT 
Os resultados de COT para a mistura de fármacos mais concentrada $(A)$ indicaram valores de 53,95 \pm 0,26 mg. $\mathrm{L}^{-1}$ de carbono orgânico em solução aquosa. Após a irradiação das amostras, os valores de COT permanecerem praticamente constantes. Foram observadas eficiências na remoção de carbono orgânico total inferiores a 2,29\%, indicando que não houve mineralização significativa das amostras irradiadas (Tabela 5).

Quando a mistura de fármacos diluída 1:10 (B) foi irradiada, foi obtida baixa mineralização da mistura a partir de 5,0 kGy, com remoção de carbono orgânico máximo de 33,0\% em 7,5 kGy. Desta forma, foi possível verificar que a concentração dos fármacos interferiu na remoção de carbono orgânico total das amostras.

SILVA (2014) verificou baixa mineralização para o cloridrato de fluoxetina, apresentando valores de remoção de COT de $22 \%$ com 20 kGy a partir de concentrações iniciais de $20,0 \mathrm{mg} \cdot \mathrm{L}^{-1}$.

Segundo RIZZO (2011) os Processos Oxidativos Avançados (POAs), normalmente podem promover a mineralização incompleta dos poluentes orgânicos complexos, com formação de dióxido de carbono e espécies inorgânicas, mas em produtos de oxidação intermediários. DUARTE (1999) estudou a degradação de diversos compostos aromáticos pelo processo de radiação com feixe de elétrons, verificando a formação de ácidos orgânicos após o tratamento dos poluentes orgânicos.

\subsection{Cromatografia líquida ultra rápida}

\subsubsection{Curva de calibração das soluções cloridrato de fluoxetina e diclofenaco sódico.}

As leituras dos comprimentos de onda de excitação e emissão da fluoxetina permitiram obter as curvas analíticas com análises em triplicatas, para a determinação da concentração dos fármacos (Figura 22). Foram obtidas duas curvas, uma para um limite de detecção para faixas de concentrações de 1,0234 a $35,982 \mathrm{mg} \cdot \mathrm{L}^{-1}$ e outra para faixas de 0,01142 a $0,9856 \mathrm{mg} \cdot \mathrm{L}^{-1}$. 
(a)

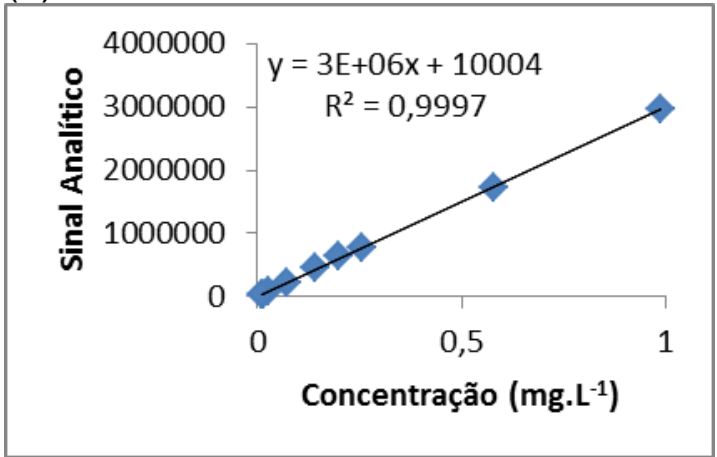

(b)

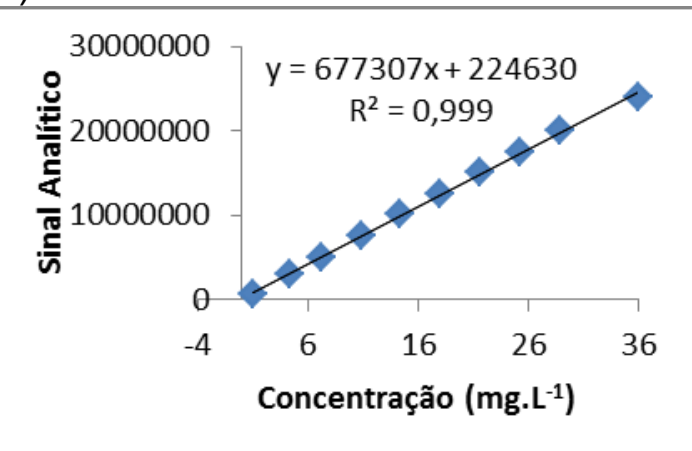

Figura 22 - Curva analítica obtida utilizando espectrometria de emissão de fluorescência com leitura no comprimento de onda de excitação $=230 \mathrm{~nm}$ e emissão $=290 \mathrm{~nm}$ para a fluoxetina, com intervalos de detecção de (a) 0,01142 a $0,9856 \mathrm{mgL}^{-1}$ e (b) 1,0234 a $35,982 \mathrm{mgL}^{-1}$.

Para a obtenção das curvas analíticas do diclofenaco, foram realizadas leituras nos comprimentos de absorção do composto utilizando detector UV/Vis, sendo obtidas duas curvas, um para limite de detecção para faixas de concentrações de 0,00524 a $0,7548 \mathrm{mg} \cdot \mathrm{L}^{-1}$ e outra para faixas de 3,5744 a 40,257 mg.L $L^{-1}$ (Figura 23).

(a)

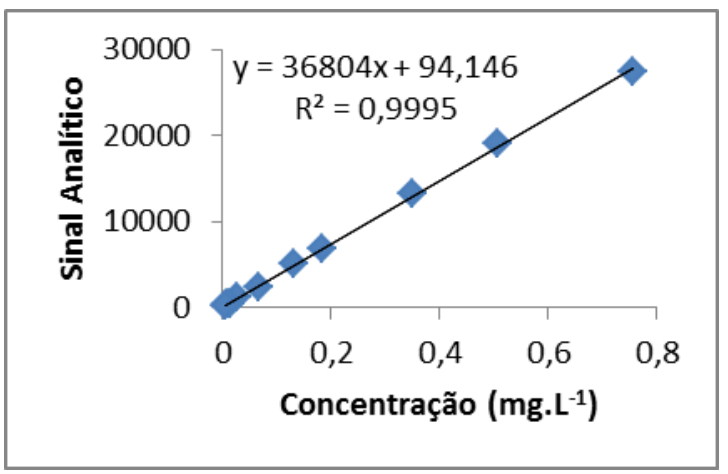

(b)

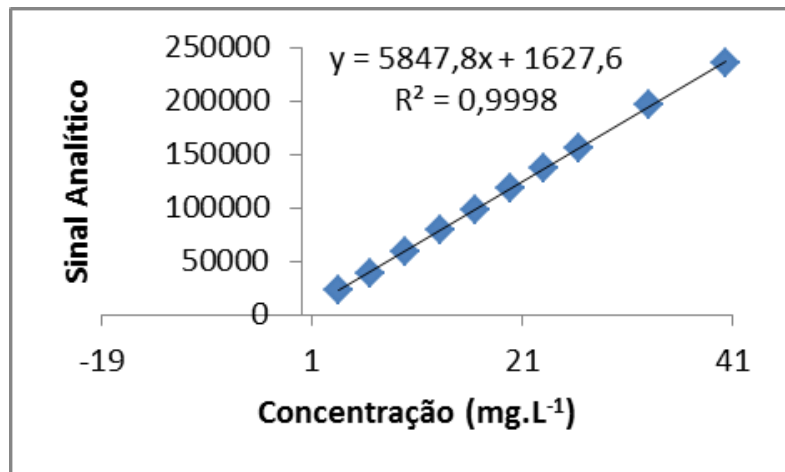

Figura 23 - Curva analítica obtida por espectrofotometria de absorção no UV/VIS no comprimento de onda de $276 \mathrm{~nm}$ para o diclofenaco, com intervalos de detecção de (a) 0,00524 a 0,7548 $\mathrm{mgL}^{-1}$ e (b) 3,5744 a 40,257 mg. $\mathrm{L}^{-1}$.

As bandas de absorção de energia de uma substância na faixa de comprimento de onda de 190 a $300 \mathrm{~nm}$ representam $\pi \rightarrow \pi^{*}$ ou $\mathrm{n} \rightarrow \pi^{*}$ (Holler et al, 2009), assim, a presença de ligações $\pi$ nos anéis aromáticos na estrutura molecular da fluoxetina e diclofenaco é responsável pela absorção de energia na região do ultravioleta (UV). 
Os valores dos Limites de Detecção (LD) e dos Limites de Quantificação (LQ) foram apresentados na Tabela 6. Para intervalos de concentração de 0,011 a $0,986 \mathrm{mg} \cdot \mathrm{L}^{-1}$ de fluoxetina foi valores de $L D$ e $L Q$ foram $11 \mathrm{ng} \cdot \mathrm{L}^{-1}$ e $33,3 \mathrm{ng} \cdot \mathrm{L}^{-1}$, enquanto que para faixas de concentração de 0,052 a $0,755 \mathrm{mg} \cdot \mathrm{L}^{-1}$ de diclofenaco sódico, foi possível obter limites de detecção de $8,4 \mathrm{ngL}^{-1}$ e quantificação de 25,6 $\eta \mathrm{nL}^{-1}$.

Tabela 6 - Limites de Detecção (LD) e Limites de Quantificação (LQ) para os curvas anaíticas obtidas pela cromatigrafia ultra rápida.

\begin{tabular}{|c|c|c|c|c|}
\hline Fármaco & Curva analítica & $\begin{array}{c}\text { Faixa de } \\
\text { concentração } \\
\left(\mathrm{mgL}^{-1}\right)\end{array}$ & $\begin{array}{c}\text { Limites de } \\
\text { Detecção } \\
\left(\text { LD) }\left(\mathrm{mgL}^{-1}\right)\right.\end{array}$ & $\begin{array}{c}\text { Limites de } \\
\text { Quantificação } \\
(\mathrm{LQ})\left(\mathrm{mgL}^{-1}\right)\end{array}$ \\
\hline \multirow{2}{*}{ Diclofenaco } & $\mathrm{y}=36804 \mathrm{x}+94,146$ & $0,052-0,755$ & 0,00844 & 0,0256 \\
\cline { 2 - 5 } Fluoxetina & $\mathrm{y}=5847,8 \mathrm{x}+1627,6$ & $6,5-40,26$ & 0,918 & 2,78 \\
\cline { 2 - 5 } & $\mathrm{y}=3.10^{6} \mathrm{x}+10004$ & $0,011-0,986$ & 0,0110 & 0,0333 \\
\hline
\end{tabular}

Os valores obtidos neste estudo estão em concordância com aqueles determinados por outros autores. SILVA (2014) obteve limites de detecção e quantificação de $15 \mu \mathrm{g} \cdot \mathrm{L}^{-1}$ e $48 \mu \mathrm{g} \cdot \mathrm{L}^{-1}$, respectivamente, por espectroscopia de fluorescência para o cloridrato de fluoxetina. Para o diclofenaco sódico, COELHO (2008) determinou limites de detecção do método (LDM) de 38 ng. $\mathrm{L}^{-1}$ e limite de quantificação de $108 \mathrm{ng} \cdot \mathrm{L}^{-1}$.

\subsubsection{Efeito da irradiação nas amostras estudadas}

$\mathrm{Na}$ Tabela 7 foram apresentadas as áreas determinadas para cada fármaco e na Figura 24 pode ser visualisada a degradação dos fármacos após a irradiação utilizando as doses de 1.0 e 5.0 kGy. 
Tabela 7 - Valores de concentrações dos fármacos cloridrato de fluoxetina e diclofenaco sódico, bem como valores de eficiência de remoção para estes compostos utilizando a radiação por feixe de elétrons.

\begin{tabular}{|c|c|c|c|c|c|c|c|}
\hline & \multicolumn{6}{|c|}{ Fármacos } \\
\hline & & \multicolumn{3}{|c|}{ Cloridrato de Fluxetina } & \multicolumn{3}{|c|}{ Diclofenaco sódico } \\
\hline $\begin{array}{c}\text { Doses } \\
\text { (kGy) }\end{array}$ & Ensaios & Área & $\begin{array}{l}\text { Concentração } \\
\text { Cloridrato de } \\
\text { Fluoxetina } \\
\left(\mathrm{mg} . \mathrm{L}^{-1}\right)\end{array}$ & $\begin{array}{c}\text { Eficiência de } \\
\text { Remoção } \\
(\%)\end{array}$ & Área & $\begin{array}{c}\text { Concentração } \\
\text { Diclofenaco } \\
\text { sódico } \\
\left(\mathrm{mg} \cdot \mathrm{L}^{-1}\right)\end{array}$ & $\begin{array}{c}\text { Eficiência } \\
\text { de } \\
\text { Remoção } \\
(\%)\end{array}$ \\
\hline \multirow{4}{*}{0} & 1 & 2770759 & 3,97 & - & 155270 & 55,99 & - \\
\hline & 2 & 2811844 & 4,03 & - & 154564 & 54,74 & - \\
\hline & 3 & 2852229 & 4,09 & - & 152220 & 54,88 & - \\
\hline & $X \pm S$ & & $4,03 \pm 0,06$ & & & $55,54 \pm 0,58$ & \\
\hline \multirow{4}{*}{1} & 1 & 1114900 & 1,61 & 60,1 & 225573 & 40,81 & 26,5 \\
\hline & 2 & 1088696 & 1,57 & 61,1 & 225959 & 40,88 & 26,4 \\
\hline & 3 & 1106546 & 1,60 & 60,4 & 227246 & 41,11 & 26,0 \\
\hline & $X \pm S$ & & $1,59 \pm 0,02$ & $60,5 \pm 0,47$ & & $40,93 \pm 0,16$ & $\begin{array}{c}26,3 \pm \\
0,29\end{array}$ \\
\hline \multirow{4}{*}{5} & 1 & 161667 & 0,051 & 98,8 & 3284 & 0,09 & 99,8 \\
\hline & 2 & 169226 & 0,053 & 98,7 & 2888 & 0,08 & 99,9 \\
\hline & 3 & 159433 & 0,050 & 98,8 & 3047 & 0,08 & 99,9 \\
\hline & $X \pm S$ & & $0,051 \pm 0,002$ & $98,7 \pm 0,042$ & & $0,08 \pm 0,01$ & $\begin{array}{c}99,8 \pm \\
0,01\end{array}$ \\
\hline
\end{tabular}

$\mathrm{X} \pm \mathrm{S}$ : Média com desvio-padrão

(a)

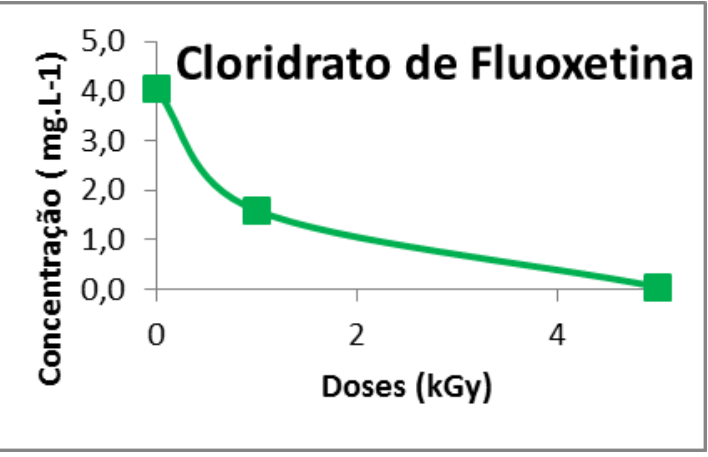

(b)

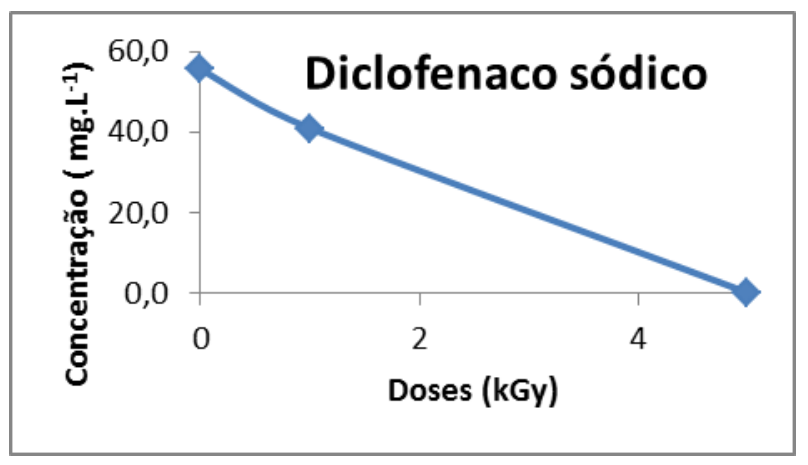

Figura 24 - Degradação dos fármacos cloridrato de fluoxetina e diclofenaco de sódio irradiados em doses de 1.0 e 5.0 kGy (kGy).

Quando as amostras dos compostos foram irradiadas separadamente, foi obtida importante porcentagem de degradação dos fármacos irradiados. Mais de $98,0 \%$ de ambos os fármacos foram degradados com 5.0 kGy, indicando alta eficiência do processo de degradação de ambos os fármacos utilizando radiação com feixe de elétrons ( Tabela 7). 
Em relação à irradiação da mistura dos fármacos mais concentrada $(A)$, os cromatogramas para a mistura de fármacos irradiados em diferentes doses foram apresentados nas Figuras 25 e 26.

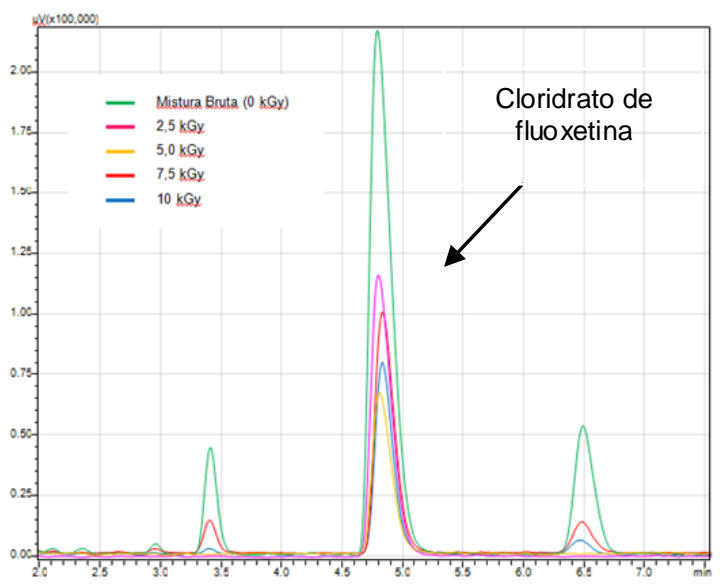

Figura 25 - Cromatograma das amostras da irradiadas (mistura mais concentrada $(\mathrm{A})$ ) em diferentes doses - Cromatografia Líquida Ultra Rápida para o cloridrato de fluoxetina com o detector de fluorescência.

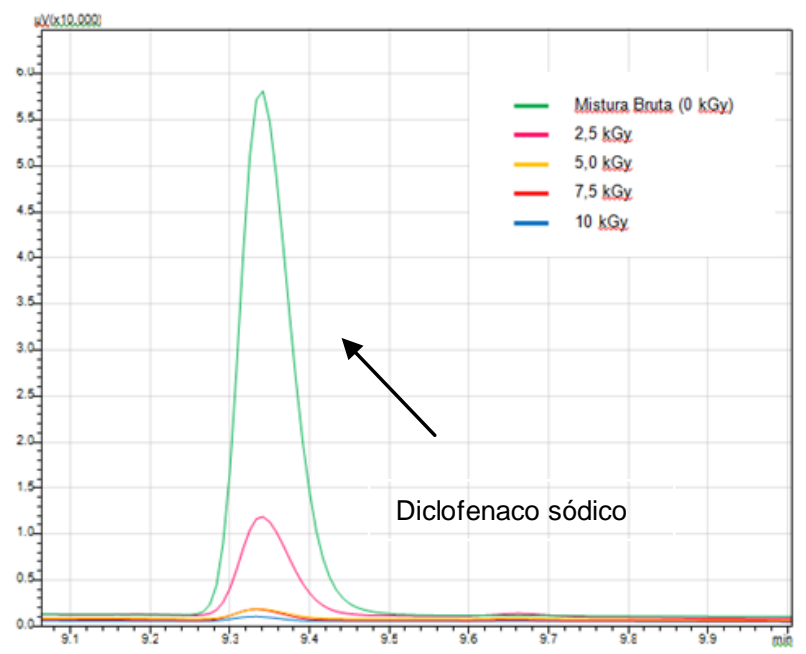

Figura 26 - Cromatograma das amostras da irradiadas (mistura mais concentrada $(\mathrm{A})$ ) em diferentes doses - Cromatografia Líquida Ultra Rápida para o diclofenaco sódico com o detector UV/VIS.

Foi possível observar degradação dos compostos conforme as doses aplicadas. Além disso, houve a formação de produtos de degradação, decorrente da oxidação, que correspondem aos demais picos que não são os picos dos fármacos de interesse. 
$\mathrm{Na}$ Tabela 8, foram apresentadas as áreas determinadas para cada fármaco, a concentração e a eficiência de remoção do cloridrato de fluoxetina e diclofenaco sódico na mistura mais concentrada (A). Na Figura 27 foi representada a degradação da mistura conforme as doses de irradiação.

Tabela 8 - Concentrações dos fármacos cloridrato de fluoxetina e diclofenaco sódico na mistura mais concentrada (A), bem como eficiência de degradação dos compostos em diferentes doses de radiação.

\begin{tabular}{|c|c|c|c|c|c|c|c|}
\hline & \multicolumn{6}{|c|}{ Fármacos } \\
\hline & & \multicolumn{3}{|c|}{ Cloridrato de Fluxetina } & \multicolumn{3}{|c|}{ Diclofenaco sódico } \\
\hline & Ensaios & Área & $\begin{array}{l}\text { Concentração } \\
\text { Cloridrato de } \\
\text { Fluoxetina } \\
\left(\mathrm{mg}_{\mathrm{L}}^{-1}\right)\end{array}$ & $\begin{array}{c}\text { Eficiência } \\
\text { de } \\
\text { Remoção } \\
(\%)\end{array}$ & Área & $\begin{array}{c}\text { Concentração } \\
\text { Diclofenaco } \\
\text { sódico } \\
\left(\mathrm{mg} \cdot \mathrm{L}^{-1}\right)\end{array}$ & $\begin{array}{l}\text { Eficiência } \\
\text { de } \\
\text { Remoção } \\
(\%)\end{array}$ \\
\hline \multirow{4}{*}{0} & 1 & 1444183 & 3,60 & - & 154418 & 52,26 & - \\
\hline & 2 & 1428307 & 3,55 & - & 149477 & 50,57 & - \\
\hline & 3 & 1920694 & 5,01 & - & 155565 & 52,65 & - \\
\hline & $x \pm S$ & & $4,05 \pm 0,83$ & & & $51,82 \pm 1,11$ & \\
\hline \multirow{4}{*}{2,5} & 1 & 2835403 & 3,85 & 4,93 & 49863 & 8,25 & 84,1 \\
\hline & 2 & 2746292 & 3,72 & 8,18 & 49874 & 8,25 & 84,1 \\
\hline & 3 & 2307829 & 3,08 & 24,1 & 49748 & 8,23 & 84,1 \\
\hline & $x \pm S$ & & $3,55 \pm 0,42$ & $\begin{array}{l}12,4 \pm \\
10,28\end{array}$ & & $8,24 \pm 0,01$ & $\begin{array}{c}84,1 \pm \\
0.02\end{array}$ \\
\hline \multirow{4}{*}{5,0} & 1 & 1466960 & 1,83 & 54,8 & 24080 & 0,65 & 98,7 \\
\hline & 2 & 1471713 & 1,84 & 54,6 & 22756 & 0,62 & 98,8 \\
\hline & 3 & 1458618 & 1,82 & 55,1 & 22709 & 0,61 & 98,8 \\
\hline & $X \pm S$ & & $1,83 \pm 0,01$ & $\begin{array}{c}54,8 \pm \\
0,24\end{array}$ & & $0,63 \pm 0,02$ & $\begin{array}{c}99,8 \pm \\
0,04\end{array}$ \\
\hline \multirow{4}{*}{7,5} & 1 & 2013375 & 2,64 & 34,9 & 5640 & 0,15 & 99,7 \\
\hline & 2 & 2473059 & 3,32 & 1831 & 5679 & 0,15 & 99,7 \\
\hline & 3 & 2013375 & 2,64 & 34,9 & 4713 & 0,13 & 99,8 \\
\hline & $X \pm S$ & & $2,87 \pm 0,39$ & $\begin{array}{c}29,3 \pm \\
9,66\end{array}$ & & $0,14 \pm 0,01$ & $\begin{array}{c}99,7 \pm \\
0,03\end{array}$ \\
\hline \multirow{4}{*}{10,0} & 1 & 2772813 & 3,76 & 7,21 & 5550 & 0,15 & 99,7 \\
\hline & 2 & 2392534 & 3,20 & 21,1 & 5359 & 0,14 & 99,7 \\
\hline & 3 & 1985733 & 2,60 & 35,9 & 4928 & 0,13 & 99,8 \\
\hline & $x \pm S$ & & $3,19 \pm 0,58$ & $\begin{array}{c}21,4 \pm \\
14,3\end{array}$ & & $0,14 \pm 0,01$ & $\begin{array}{c}99,7 \pm \\
0,02\end{array}$ \\
\hline
\end{tabular}

$X \pm S$ : Média com desvio-padrão

Mistura mais concentrada (A): $50 \mathrm{mg} \cdot \mathrm{L}^{-1}$ de DIC e $5 \mathrm{mg} \cdot \mathrm{L}^{-1} \mathrm{FXT}$ 


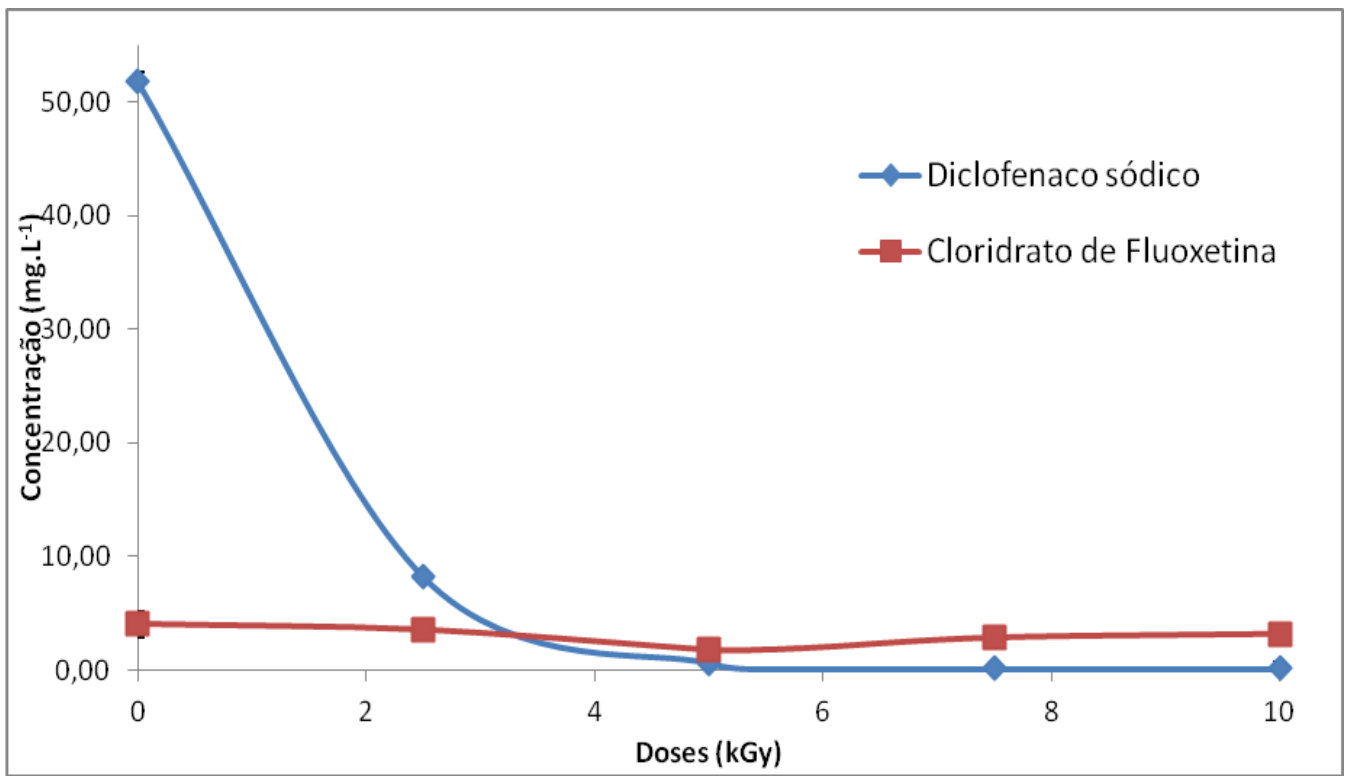

Figura 27 - Degradação da mistura mais concentrada (A) $\left(50 \mathrm{mg} \cdot \mathrm{L}^{-1}\right.$ de DIC e $5 \mathrm{mg} \cdot \mathrm{L}^{-1} \mathrm{FXT}$ ) versus dose (kGy).

A irradiação da mistura mais concentrada (A) resultou em degradações superiores a 99,0\% para o diclofenaco sódico a partir de $5.0 \mathrm{kGy}$. Para o cloridrato de fluoxetina, foram obtidas degradações máximas de 54,8\% em 5.0 kGy. Por meio da avaliação da degradação dos fármacos na mistura, foi possível verificar que a estrutura molecular do diclofenaco de sódio foi reagiu preferencialmente pelas espécies oxidativas formadas durante irradiação, proporcionando melhor porcentagem de degradação do diclofenaco, quando comparado com a fluoxetina, uma vez que, ambos os compostos são degradados com eficiências superiores a $98 \%$ quando foram irradiados em separado.

KWON e ARMBRUST (2006) verificaram que o cloridrato de fluoxetina não hidrolisa na água e é resistente aos processos de de hidrólise, fotólise e a degradação microbiana. Para o diclofenaco, BUSER e colaboradores (1998) verificaram que este composto é fotodegradado quando exposto à radiação solar, sendo obtidas taxas de fotodegradação de até $90 \%$ em água superficial.

HOMLOK e colaboradores (2013) analisaram a degradação de diferentes compostos orgânicos por processos oxidativos avançados. Foi concluído que a oxidação de fenóis, ácidos maleico e fumárico iniciada por radicais hidroxilas apresenta maior eficiência de degradação. Os grupos amina, acetonamina e hidrazo, quando ligados ao anel fenol, apresentam taxas de degradação menores, 
em provável consequência aos radicais intermediários formados (fenoxi, anilino, semi-iniquinone, hidrazil).

Em relação à mistura diluída 1:10 (B), na Tabela 9 foram apresentadas as áreas relativas aos picos cromatográficos para cada fármaco, bem como a eficiência de remoção.

Tabela 9 - Concentração dos fármacos cloridrato de fluoxetina e diclofenaco sódico na mistura diluída 1:10 (B), bem como eficiência de degradação destes compostos em diferentes doses de radiação (kGy).

\begin{tabular}{|c|c|c|c|c|c|c|c|}
\hline & \multicolumn{6}{|c|}{ Fármacos } \\
\hline & & \multicolumn{3}{|c|}{ Cloridrato de Fluxetina } & \multicolumn{3}{|c|}{ Diclofenaco sódico } \\
\hline $\begin{array}{l}\text { Doses } \\
\text { (kGy) }\end{array}$ & Ensaios & Área & $\begin{array}{c}\text { Concentração } \\
\text { Cloridrato de } \\
\text { Fluoxetina } \\
\left(\mathrm{mg} \cdot \mathrm{L}^{-1}\right)\end{array}$ & $\begin{array}{c}\text { Eficiência } \\
\text { de } \\
\text { Remoção } \\
(\%)\end{array}$ & Área & $\begin{array}{c}\text { Concentração } \\
\text { Diclofenaco } \\
\text { sódico } \\
\left(\mathrm{mg} \cdot \mathrm{L}^{-1}\right)\end{array}$ & $\begin{array}{c}\text { Eficiência } \\
\text { de } \\
\text { Remoção } \\
(\%)\end{array}$ \\
\hline \multirow{4}{*}{0} & 1 & 2860446 & 3,89 & - & 29468 & 4,76 & - \\
\hline & 2 & 2843202 & 3,87 & - & 29386 & 4,75 & - \\
\hline & 3 & 2739693 & 3,71 & - & 29321 & 4,74 & - \\
\hline & $X \pm S$ & & $3,82 \pm 0,10$ & & & $4,75 \pm 0,01$ & \\
\hline \multirow{4}{*}{2,5} & 1 & 487451 & 0,159 & 95,8 & $<L^{*}$ & $<\mathrm{LD}^{*}$ & $>99,8$ \\
\hline & 2 & 477887 & 0,156 & 95,9 & $<L^{*}$ & $<\mathrm{LD}^{*}$ & $>99,8$ \\
\hline & 3 & 490280 & 0,160 & 95,8 & $<\mathrm{LD}^{*}$ & $<$ LD* $^{*}$ & $>99,8$ \\
\hline & $X \pm S$ & & $0,16 \pm 0,002$ & $\begin{array}{c}95,9 \pm \\
0,06\end{array}$ & & & $>99,8$ \\
\hline \multirow{4}{*}{5,0} & 1 & 341525 & 0,111 & 97,1 & $<L^{*}$ & $<\mathrm{LD}^{*}$ & $>99,8$ \\
\hline & 2 & 347017 & 0,1012 & 97,1 & $<\mathrm{LD}^{*}$ & $<\mathrm{LD}^{*}$ & $>99,8$ \\
\hline & 3 & 334985 & 0,108 & 97,2 & $<\mathrm{LD}^{*}$ & $<\mathrm{LD}^{*}$ & $>99,8$ \\
\hline & $X \pm S$ & & $0,110 \pm 0,002$ & $\begin{array}{c}97,1 \pm \\
0,05\end{array}$ & & - & $>99,8$ \\
\hline \multirow{4}{*}{7,5} & 1 & 329289 & 0,106 & 97,2 & 1150 & 0,03 & 99,4 \\
\hline & 2 & 310481 & 0,100 & 97,4 & 1291 & 0,03 & 99,3 \\
\hline & 3 & 309881 & 0,100 & 97,4 & 1108 & 0,03 & 99,4 \\
\hline & $X \pm S$ & & $0,102 \pm 0,004$ & $\begin{array}{c}97,3 \pm \\
0,10\end{array}$ & & $0,03 \pm 0,00$ & $\begin{array}{c}99,4 \pm \\
0,05\end{array}$ \\
\hline \multirow{4}{*}{10,0} & 1 & 214949 & 0,068 & 98,2 & $<\mathrm{LD}^{*}$ & $<\mathrm{LD}^{*}$ & $>99,8$ \\
\hline & 2 & 223041 & 0,071 & 98,1 & $<\mathrm{LD}^{*}$ & $<\mathrm{LD}^{*}$ & $>99,8$ \\
\hline & 3 & 215008 & 0,068 & 98,2 & $<\mathrm{LD}^{*}$ & $<\mathrm{LD}^{*}$ & $>99,8$ \\
\hline & $X \pm S$ & & $0,069 \pm 0,002$ & $\begin{array}{c}98,2 \pm \\
0,04\end{array}$ & & & $>99,8$ \\
\hline
\end{tabular}

$<D^{*}$ : Amostras que apresentaram concentração do diclofenaco sódico menor que o limite de detecção $\left(0,003094 \mathrm{mg} \cdot \mathrm{L}^{-1}\right)$

$\mathrm{X} \pm \mathrm{S}$ : Média com desvio-padrão

Mistura mais concentrada (A): $50 \mathrm{mg} \cdot \mathrm{L}^{-1}$ de DIC e $5 \mathrm{mg} \cdot \mathrm{L}^{-1} \mathrm{FXT}$

Mistura diluída 1:10 (B): $5 \mathrm{mg} \cdot \mathrm{L}^{-1}$ de DIC e $5 \mathrm{mg} \cdot \mathrm{L}^{-1}$ de FXT 


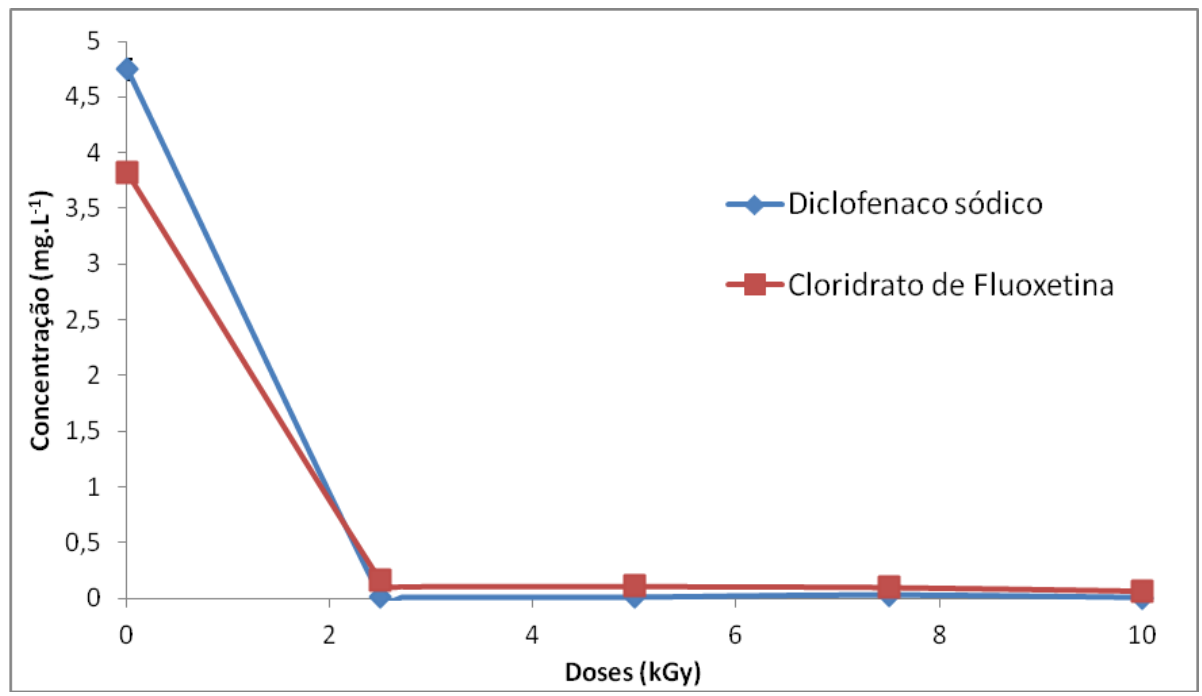

Figura 28 - Degradação da mistura diluída 1:10 (B) (cloridrato de fluoxetina e diclofenaco sódico) em diferentes doses de radiação (kGy).

Foram obtidas eficiências superiores a 95,0\% para ambos os fármacos em todas as doses aplicadas. Para o diclofenaco sódico foram determinadas concentrações abaixo do limite de detecção (8 ng. $\left.\mathrm{L}^{-1}\right)$, representadas na Tabela 9. Desse modo, foi possível verificar que o processo de irradiação por feixe de elétrons apresentou eficiência na degradação da mistura dos fármacos em concentrações mais baixas (Figura 28).

Silva (2014) demonstrou que doses mais baixas como a de 0,5 kGy promoveram boa eficiência de degradação do cloridrato de fluoxetina.

\subsection{Ensaios ecotoxicológicos empregados}

A utilização de ensaios de toxicidade é uma importante ferramenta de avaliação da remoção de toxicidade de tratamentos de efluentes, tais como, os Processos Oxidativos Avançados (POAs) (RIZZO, 2011). Desta forma, neste item foram discutidos os resultados de ensaios ecotoxicológicos, visando demostrar o potencial tóxico dos fármacos do presente estudo para diferentes organismos, bem como a remoção de toxicidade das soluções submetidas ao processo de irradiação por feixe de elétrons. 


\subsubsection{Ensaios de Toxicidade aguda com Vibrio fischeri}

Os resultados de CE50 dos fármacos cloridrato de fluoxetina e diclofenaco sódico separados foram obtidos a partir das soluções-estoque preparadas. No presente estudo foram observados CE50 de 4,59 $\pm 0,17 \mathrm{mg} \cdot \mathrm{L}^{-1}$ para o cloridrato de fluoxetina e 5,12 $\pm 0,41 \mathrm{mg} \cdot \mathrm{L}^{-1}$ para o diclofenaco sódico (Tabela 10).

Tabela 10 - Valores de $C E 50_{15 \text { min }}$ para os fármacos cloridrato de fluoxetina e diclofenaco sódico para a bactéria marinha $V$. fischeri.

\begin{tabular}{|c|c|c|c|c|}
\hline & \multicolumn{4}{|c|}{ Fármacos } \\
\hline & \multicolumn{2}{|c|}{ Cloridrato de Fluxetina } & \multicolumn{2}{|c|}{ Diclofenaco sódico } \\
\hline Ensaios & CE50 (\%) & $\begin{array}{c}\text { CE50 } \\
\left(\mathrm{mg}^{-L^{-1}}\right)\end{array}$ & CE50 (\%) & $\begin{array}{l}\text { CE50 } \\
\left(m g \cdot L^{-1}\right)\end{array}$ \\
\hline 1 & $47,25(40,65-54,91)$ & 4,73 & $5,48(2,64-11,34)$ & 5,48 \\
\hline 2 & $46,47(41,17-52,45)$ & 4,65 & $4,68(1,83-11,97)$ & 4,68 \\
\hline 3 & $44,03(30,46-63,66)$ & 4,40 & $5,21(2,61-10,38)$ & 5,21 \\
\hline$X \pm S$ & $45,92 \pm 1,68$ & $4,59 \pm 0,17$ & $5,12 \pm 0,41$ & $5,12 \pm 0,41$ \\
\hline
\end{tabular}

SILVA (2014) e HOMLOK e colaboradores (2011) obtiveram CE50 para a bactéria $V$. fischeri de $1,15 \mathrm{mg} \cdot \mathrm{L}^{-1}$ para o cloridrato de fluoxetina e 4,17 mg. $\mathrm{L}^{-1}$; para o diclofenaco sódico, respectivamente. Logo, foi possível verificar que os resultados de toxicidade obtidos corroboram com a literatura apresentada.

De acordo as categorias de toxicidade baseadas pela legislação européia, a toxicidade de ambos os fármacos pode ser classificada como tóxica (Intervalos de 1 a $10 \mathrm{mg}^{-1} \mathrm{~L}^{-1}$ ) para a bactéria bioluminescente (Comission of the European Communities, 1996).

Em relação à mistura mais concentrada $(A)$, na Tabela 11, foram apresentados os valores de CE50 15min e Unidades Tóxicas (UT) dos ensaios agudos de toxicidade, a partir da exposição de $15 \mathrm{~min}$ da bactéria bioluminescente $V$. fischeri. Foram obtidos valores médios de CE50 $15 \mathrm{~min}$ de 15,0\% para a mistura e UT de 6,76. 
Tabela 11 - Valores de CE5015 min e Unidades Tóxicas para a mistura mais concentrada $(A)$ (Diclofenaco sódico e Cloridrato de Fluoxetina).

\begin{tabular}{|c|c|c|}
\hline & \multicolumn{3}{|c|}{ Mistura mais concentrada (A) } \\
\hline Ensaio & CE50 $15 \min (\%)$ & UT \\
\hline 1 & $17,1(12,75-22,83)$ & 5,86 \\
\hline 2 & $13,3(10,16-17,28)$ & 7,55 \\
\hline 3 & $14,5(10,21-20,72)$ & 6,88 \\
\hline $\mathbf{X} \pm \mathbf{S}$ & $\mathbf{1 5 , 0 \pm 1 , 9 4}$ & $\mathbf{6 , 7 6} \pm \mathbf{0 , 8 5}$ \\
\hline
\end{tabular}

$X \pm$ S: Média com desvio-padrão

IC: intervalo de confiança

Mistura mais concentrada (A): $50 \mathrm{mg}^{-\mathrm{L}^{-1}}$ de DIC e $5 \mathrm{mg} \cdot \mathrm{L}^{-1} \mathrm{FXT}$

Na Figura 29 foi apresentada a comparação entre as CE50 dos fármacos cloridrato de fluoxetina, diclofenaco sódico e mistura mais concentrada $(A)$ com as respectivas médias e desvio-padrão obtidas no presente estudo, com $V$. fischeri.

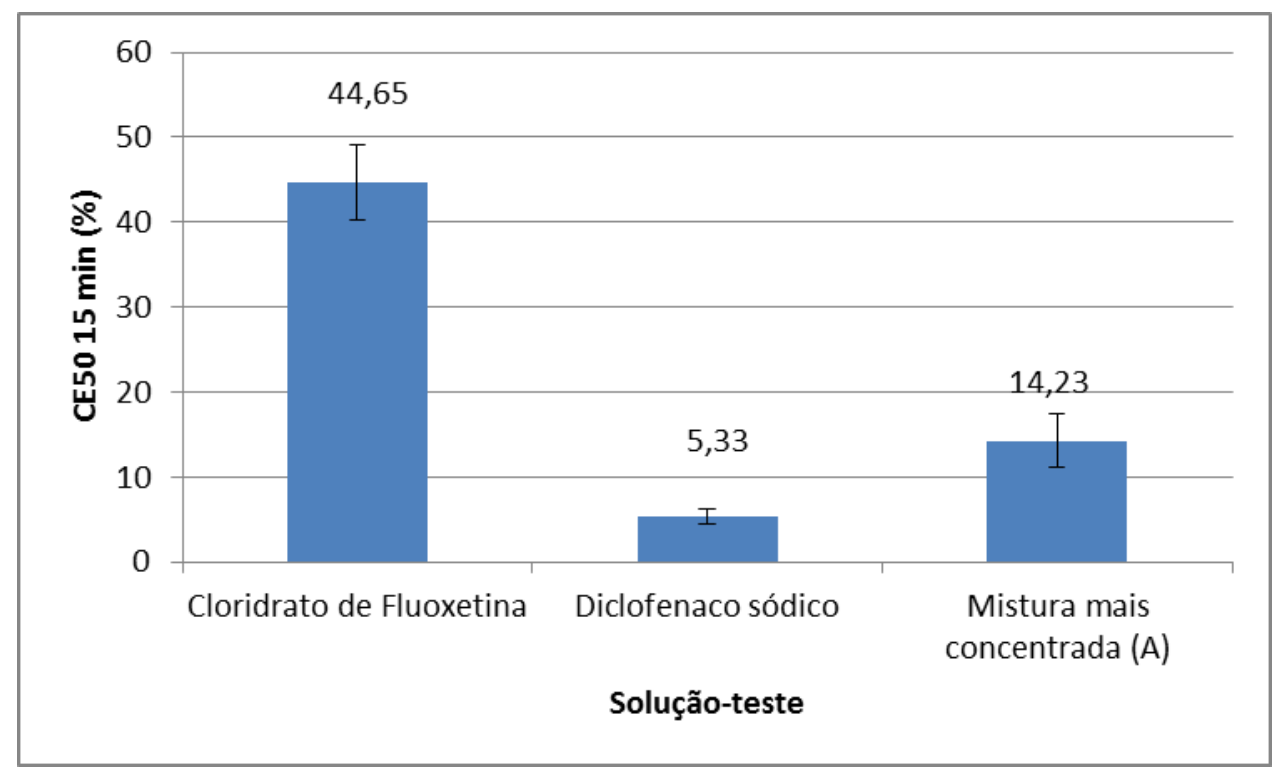

Figura 29 - Variação de CE50 ${ }_{15 \mathrm{~min}}$ do Cloridrato de Fluoxetina, Diclofenaco sódico e Mistura mais concentrada (A).

Quando comparados os valores médios de CE50 $15 \mathrm{~min}$ da fluoxetina, diclofenaco e a mistura, foi possível observar maior toxicidade para o diclofenaco sódico, seguida da mistura e cloridrato de fluoxetina. Estes resultados demonstraram que não houve potencialização dos efeitos dessas substâncias, quando presentes na mesma solução, para a bactéria $V$. fischeri (Figura 29).

SANTOS (2011) observou um aumento aparente de toxicidade para a mistura do fármaco cloridrato de fluoxetina e surfactante dodecil sulfato de sódio 
para a bactéria marinha $V$. fischeri, com um aumento de toxicidade de aproximadamente 2 vezes para a mistura dos compostos.

A avaliação da remoção de toxidade das amostras, empregando a irradiação por feixe de elétrons, foi realizada para o diclofenaco sódico em 5.0 kGy e para a mistura mais concentrada (A) nas doses de 2.5; 5.0; 7.5 e 10.0 kGy para a bactéria luminescente $V$. fischeri, com exposição de 15 min.

Foi observada diminuição de toxicidade de 19,60 \pm 1,60 para 6,22 \pm 2,31 da solução de diclofenaco sódico, correspondendo a eficiência de remoção de toxicidade de $68,29 \%$ (Tabela 12)

Tabela 12 - Valores de CE50 ${ }_{15 \text { min }}$ e Unidades Tóxicas (UT) para o diclofenaco sódico.

\begin{tabular}{|c|c|c|c|}
\hline \multicolumn{2}{|c|}{} & \multicolumn{2}{|c|}{ Diclofenaco sódico } \\
\hline Doses (kGy) & Ensaios & CE50 15min (\%) & UT \\
\hline \multirow{4}{*}{0} & 1 & $5,48(2,64-11,34)$ & 18,25 \\
\cline { 2 - 4 } & 2 & $4,68(1,83-11,97)$ & 21,37 \\
\cline { 2 - 4 } & 3 & $5,21(2,61-10,38)$ & 19,19 \\
\cline { 2 - 4 } & $\mathbf{X} \pm \mathbf{S}$ & $\mathbf{5 , 1 2 \pm 0 , 4 1}$ & $\mathbf{1 9 , 6 0 \pm 1 , 6 0}$ \\
\hline \multirow{5}{*}{5,0} & 1 & $11,26(7,93-16,00)$ & 8,88 \\
\cline { 2 - 4 } & 2 & $21,10(20,15-22,10)$ & 4,74 \\
\cline { 2 - 4 } & 3 & $19,89(16,56-23,88)$ & 5,03 \\
\cline { 2 - 4 } & $\mathbf{X} \pm \mathbf{S}$ & $\mathbf{1 7 , 4 2} \pm \mathbf{5 , 3 7}$ & $\mathbf{6 , 2 2} \pm \mathbf{2 , 3 1}$ \\
\hline
\end{tabular}

$\mathrm{X} \pm \mathrm{S}$ : Média com desvio-padrão

IC: intervalo de confiança

Em relação à mistura mais concentrada $(A)$, os valores de CE50 $15 \mathrm{mi}(\%)$, Unidades Tóxicas (UT) e Eficiência de Remoção de Toxicidade, nos ensaios de exposição de 15 min da bactéria bioluminescente $V$. fischeri estão representados na Tabela 13. 
Tabela 13 - Valores de CE50 15min, Unidades Tóxicas e Eficiência de Remoção de Toxicidade para a mistura mais concentrada (A) dos fármacos cloridrato de fluoxetina e diclofenaco sódico para $V$. fischeri.

\begin{tabular}{|c|c|c|c|c|}
\hline \multicolumn{5}{|c|}{ Mistura mais concentrada $(\mathrm{A})$} \\
\hline $\begin{array}{l}\text { Doses } \\
\text { (kGy) }\end{array}$ & Ensaio & CE50 $48 \mathrm{~h}(\%)$ & UT & Eficiência (\%) \\
\hline 0 & & $14,95 \pm 1,94$ & $6,76 \pm 0,85$ & - \\
\hline \multirow{4}{*}{2,5} & 1 & $29,51(22,06-39,47)$ & 3,39 & 54,1 \\
\hline & 2 & $23,02(18,86-31,41)$ & 4,34 & 41,2 \\
\hline & 3 & $20,16(11,55-35,20)$ & 4,96 & 32,9 \\
\hline & $X \pm S$ & $24,23 \pm 4,79$ & $4,23 \pm 0,79$ & $37,4 \pm 11,7$ \\
\hline \multirow{4}{*}{5,0} & 1 & $31,45(8,65-114,25)$ & 3,18 & 57,0 \\
\hline & 2 & $30,32(18,81-48,87)$ & 3,30 & 55,4 \\
\hline & 3 & $34,77(20,61-58,64)$ & 2,88 & 61,1 \\
\hline & $X \pm S$ & $32,42 \pm 2,31$ & $3,12 \pm 0,22$ & $53,9 \pm 3,22$ \\
\hline \multirow{4}{*}{7,5} & 1 & $37,98(22,54-64,01)$ & 2,63 & 64,4 \\
\hline & 2 & $32,6(23,85-44,57)$ & 3,07 & 58,5 \\
\hline & 3 & $32,68(28,11-38,00)$ & 3,06 & 58,6 \\
\hline & $X \pm S$ & $34,42 \pm 3,08$ & $2,92 \pm 0,25$ & $56,8 \pm 3,68$ \\
\hline \multirow{4}{*}{10} & 1 & $33,86(18,66-61,45)$ & 2,95 & 60,0 \\
\hline & 2 & $21,03(7,85-56,37)$ & 4,76 & 35,7 \\
\hline & 3 & $21,82(8,82-53,96)$ & 4,58 & 38,0 \\
\hline & $X \pm S$ & $25,57 \pm 7,19$ & $4,10 \pm 0,99$ & $39,4 \pm 14,7$ \\
\hline
\end{tabular}

$X \pm S$ : Média com desvio-padrão

IC: intervalo de confiança

Mistura mais concentrada (A): $50 \mathrm{mg}^{-\mathrm{L}^{-1}}$ de DIC e $5 \mathrm{mg} \cdot \mathrm{L}^{-1} \mathrm{FXT}$

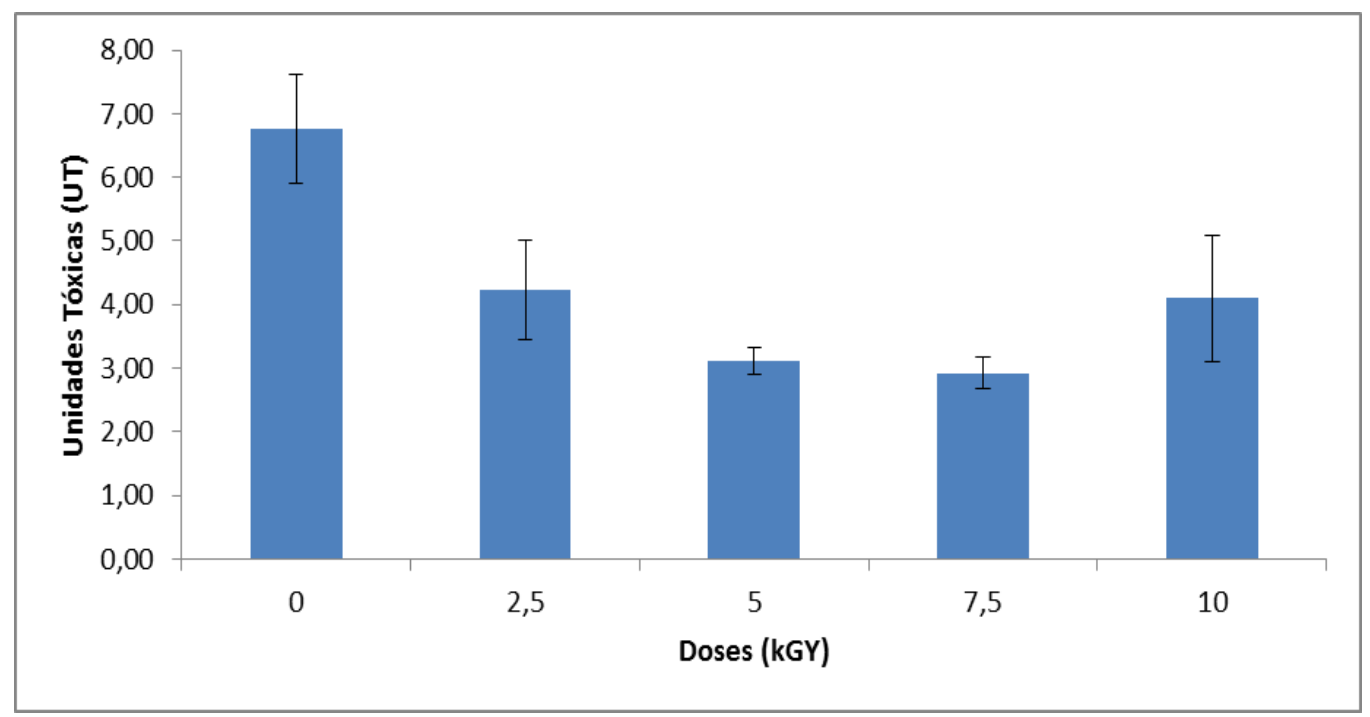

Figura 30 - Variação das Unidades Tóxicas da mistura de fármacos, cloridrato de fluoxetina e diclofenaco sódico (mistura mais concentrada (A)), em diferentes doses de radiação aplicadas para a bactéria marinha $V$. fischeri. 
Para a mistura, foi obtida remoção de toxicidade em todas as doses aplicadas. Os valores de UT diminuíram de 6,76 \pm 0,85 para valores entre 3,12 \pm 0,22 a $4,23 \pm 0,79$. Além disso, foi verificada remoção máxima de toxicidade na dose de $7.5 \mathrm{kGy}$, com aumento de toxicidade em $10 \mathrm{kGy}$, sugerindo a formação de subprodutos mais tóxicos (Figura 30).

Para o cloridrato de fluoxetina, SILVA (2014) demonstrou remoção significativa da toxicidade do fármaco após o processo de irradiação na dose de 5.0 kGy, obtendo valores de $17,26 \%$ de eficiência de remoção de toxicidade para a $V$. fischeri, a partir de soluções iniciais de $20,0 \mathrm{mg} \cdot \mathrm{L}^{-1}$ de cloridrato de fluoxetina.

As eficiências médias de remoção de toxicidade foram obtidas entre $37,43 \%$ a $56,82 \%$, sendo as melhores doses, a de 5.0 e $7.5 \mathrm{kGy}$, com valores médios de $53,89 \%$ e $56,82 \%$, respectivamente.

\subsubsection{Ensaios de Toxicidade aguda com Daphnia similis}

Os ensaios de toxicidade foram realizados para as soluções-estoque de ambos os fármacos (cloridrato de fluoxetina e diclofenaco sódico) e para as misturas destes compostos com diferentes concentrações (mistura mais concentrada (A) e diluída 1:10 (B)). No presente estudo foram observadas CE50 de $1,09 \pm 0,11 \mathrm{mg} \cdot \mathrm{L}^{-1}$ para o cloridrato de fluoxetina e $24,86 \pm 4,28 \mathrm{mg} \cdot \mathrm{L}^{-1}$ para o diclofenaco sódico (Tabela 14).

Tabela 14 - Valores de CE50 para os fármacos cloridrato de fluoxetina e diclofenaco sódico.

\begin{tabular}{|c|c|c|c|c|}
\hline & \multicolumn{4}{|c|}{ Fármacos } \\
\hline & \multicolumn{2}{|c|}{ Cloridrato de Fluxetina } & \multicolumn{2}{|c|}{ Diclofenaco sódico } \\
\hline Ensaios & CE50 (\%) & CE50 (mg.t $\left.{ }^{-1}\right)$ & CE50 (\%) & CE50 (mg. $\left.\mathrm{L}^{-1}\right)$ \\
\hline 1 & $15,38(12,36-19,13)$ & 1,54 & $26,34(24,16-28,72)$ & 26,34 \\
\hline 2 & $9,47(8,68-10,42)$ & 0,95 & $28,2(25,83-30,78)$ & 28,2 \\
\hline 3 & $7,76(6,44-9,36)$ & 0,76 & $20,04(17,87-22,47)$ & 20,04 \\
\hline$X \pm S$ & $10,87 \pm 1,09$ & $1,09 \pm 0,11$ & $24,86 \pm 4,28$ & $24,86 \pm 4,28$ \\
\hline
\end{tabular}

$\mathrm{X} \pm \mathrm{S}$ : Média com desvio-padrão

IC: intervalo de confiança

SILVA (2014) analisou a toxicidade do cloridrato de fluoxetina, obtendo CE50 de 1,31 mg. $L^{-1}$ para $D$. similis, assim, foi verificado que a média dos valores obtidos corroborou com a literatura. 
*Para o diclofenaco, MENDES e colaboradores (2010) observaram CE50 de $46,00 \mathrm{mg} \cdot \mathrm{L}^{-1}$, demonstrando maior sensibilidade do organismo $D$. similis para os mesmos fármacos testados. Este fato pode ser explicado pela presença de excipientes (corantes, óles minerais, emulsificantes, surfactantes, dentre outros) na formulação, visto que, estes apresentaram efeitos tóxicos em vários organismos (CAMINADA, 2008; CARLSOON et al, 2005).

De acordo com as categorias de toxicidade baseadas pela legislação europeia, as toxicidades dos fármacos para a $D$. similis podem ser classificados como tóxico para o cloridrato de fluoxetina $\left(1 \mathrm{mg} \cdot \mathrm{L}^{-1} \leq \mathrm{CE} 50 \leq 10 \mathrm{mg} \cdot \mathrm{L}^{-1}\right)$ ao passo que o diclofenaco sódico foi classificado como perigoso $\left(10 \leq \mathrm{CE} 50 \leq 100 \mathrm{mg} \cdot \mathrm{L}^{-1}\right)$ (Comission of the European Communities, 1996).

Para a mistura mais concentrada (A), foram apresentados os valores de CE50 48h e Unidades Tóxicas (UT) na Tabela 15. O valores de CE50 obtidos foram de $24,2 \%$ e as UT foram de 4,13 .

Tabela 15 - Valores de Unidades Tóxicas para a mistura mais concentrada (A) (Diclofenaco sódico e Cloridrato de Fluoxetina).

\begin{tabular}{|c|c|c|}
\hline & \multicolumn{2}{|c|}{ Mistura mais concentrada $(\mathrm{A})$} \\
\hline Ensaio & CE50 48h (\%) & UT \\
\hline 1 & $23,63(19,53-28,58)$ & 4,23 \\
\hline 2 & $24,44(22,70-26,32)$ & 4,09 \\
\hline 3 & $24,63(21,54-28,15)$ & 4,06 \\
\hline$X \pm S$ & $24,23 \pm 0,53$ & $4,13 \pm 0,09$ \\
\hline
\end{tabular}

Na Figura 31 foi apresentada a comparação entre as CE50 dos fármacos cloridrato de fluoxetina, diclofenaco sódico e mistura mais concentrada $(A)$ com as respectivas médias e desvio-padrão obtidas no presente estudo. 


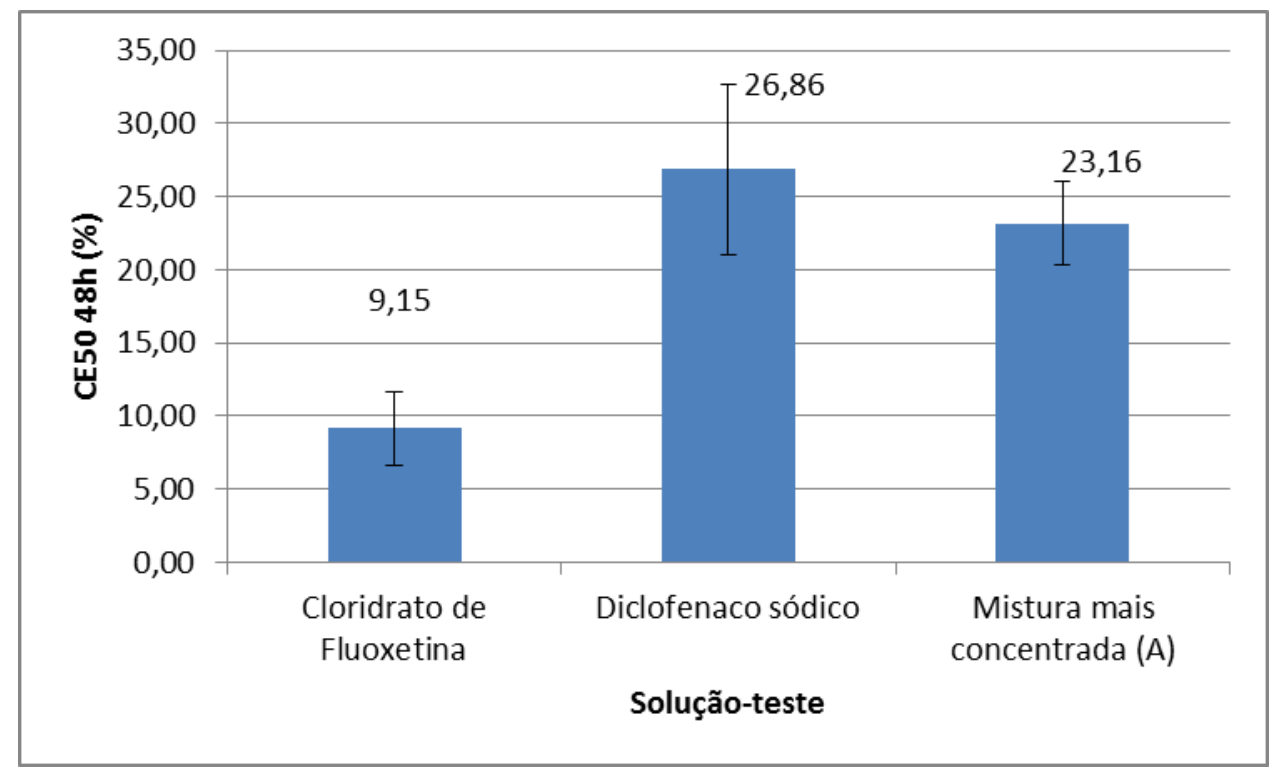

Figura 31 - Variação de CE50 48h do Cloridrato de Fluoxetina, Diclofenaco sódico e mistura mais concentrada $(A)$.

Quando comparados os valores médios de CE50 $48 \mathrm{~h}$ de todas as amostras foi possível observar maior toxicidade para o cloridrato de fluoxetina, seguida da mistura e diclofenaco sódico. Estes resultados demonstraram que não houve potencialização dos efeitos tóxicos dessas substâncias, quando presentes na mesma solução, para o microcrustáceo D. similis (Figura 31).

SANTOS (2011) não observou potencialização no efeito da mistura de cloridrato de fluoxetina e surfactante dodecil sulfalto de sódico para o organismo D. similis.

Em relação a irradiação das amostras, o cloridrato de fluoxetina, diclofenaco sódico e a mistura diluída 1:10 (B) foram irradiados apenas na dose de 5.0 kGy. Já a mistura mais concentrada $(A)$ foi irradiada nas doses de 2.5 e 5.0 kGy.

$\mathrm{Na}$ Tabela 16, foram representadas as CE50 $48 \mathrm{~h}$ e Unidades Tóxicas (UT) dos ensaios de toxicidade realizados para os fármacos cloridrato de fluoxetina e diclofenaco sódico, de ambos os brutos e irradiados na dose de 5,0 kGy. 
Tabela 16 - Valores de CE50 48 e Unidades Tóxicas (UT) para os fármacos cloridrato de fluoxetina e diclofenaco sódico.

\begin{tabular}{|c|c|c|c|c|c|}
\hline \multicolumn{2}{|c|}{} & \multicolumn{5}{c|}{ Cloridrato de Fluxetina } & \multicolumn{2}{c|}{ Diclofenaco sódico } \\
\cline { 3 - 7 } $\begin{array}{c}\text { Doses } \\
\text { (kGy) }\end{array}$ & Ensaios & CE50 48h (\%) & UT & CE50 48h (\%) & UT \\
\hline \multirow{4}{*}{5,0} & 1 & $36,2(29,6-44,3)$ & 2,76 & $25,6(23,4-28,0)$ & 3,91 \\
\cline { 2 - 7 } & 2 & $30,8(25,3-37,4)$ & 3,25 & $28,2(25,8-30,8)$ & 3,55 \\
\cline { 2 - 7 } & 3 & $37,9(31,8-45,2)$ & 2,64 & $30,3(28,5-32,3)$ & 3,30 \\
\cline { 2 - 7 } & $\mathbf{X} \pm \mathbf{S}$ & $\mathbf{3 5 , 0 \pm 3 , 7 2}$ & $\mathbf{2 , 8 8} \pm \mathbf{0 , 3 2}$ & $\mathbf{2 8 , 0} \pm \mathbf{2 , 3 7}$ & $\mathbf{3 , 5 9} \mathbf{0 , 3 1}$ \\
\hline
\end{tabular}

$X \pm S$ : Média com desvio-padrão

IC: intervalo de confiança

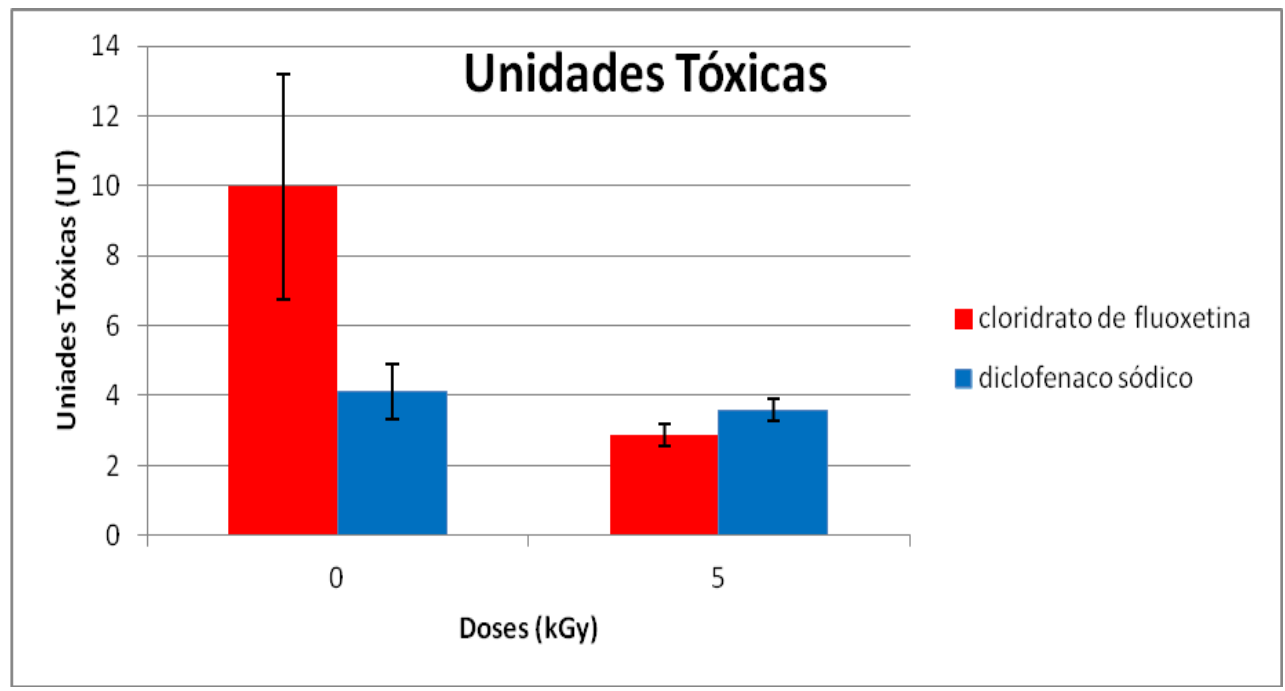

Figura 32 - Variação das Unidades Tóxicas dos fármacos separados (cloridrato de fluoxetina e diclofenaco sódico) para as amostras brutas e irradiadas em 5.0 kGy, com o microcrustáceo $D$. similis.

Os resultados obtidos quanto à toxicidade das soluções de fármacos separados demonstraram boa eficiência de remoção de toxicidade para o cloridrato de fluoxetina na dose de 5,0 kGy (Figura 32). Foi verificada diminuição das unidades tóxicas iniciais de 9,98 $\pm 3,23$ para valores de 2,88 $\pm 0,32$, representando uma eficiência de remoção de toxicidade de $71,1 \%$, indicando remoção de toxicidade para o cloridrato de fluoxetina quando irradiado nesta dose.

Para o fármaco diclofenaco sódico, os valores variaram de 4,11 $\pm 0,77$ para a amostra bruta para 3,59 $\pm 0,31$ em 5,0 kGy, representando eficiência de 
remoção de toxicidade de 12,8\%. Desta forma, foi possível verificar que há toxicidade nos produtos gerados pela degradação do composto (Tabela 16).

Em relação à mistura mais concentrada $(\mathrm{A})$, os resultados de CE50, UT e eficiência de remoção de toxicidade foram apresentados na Tabela 17. Na Figura 33 foi representado o comportamento das Unidades Tóxicas em relação as doses de radiação aplicadas.

Tabela 17 - Valores de CE50 48h, Unidades Tóxicas e Eficiência de Remoção de Toxicidade para a mistura mais concentrada $(A)$ dos fármacos cloridrato de fluoxetina e diclofenaco sódico para $D$. similis.

\begin{tabular}{|c|c|c|c|c|}
\hline \multicolumn{5}{|c|}{ Mistura mais concentrada $(\mathrm{A})$} \\
\hline $\begin{array}{l}\text { Doses } \\
\text { (kGy) }\end{array}$ & Ensaio & CE50 48h $(\%)$ & UT & Eficiência \\
\hline 0 & $X \pm S$ & $23,2 \pm 2,86$ & $4,38 \pm 0,56$ & - \\
\hline \multirow{4}{*}{2.5} & 1 & $46,3(39,5-54,2)$ & 2,16 & 50,7 \\
\hline & 2 & $35,9(31,6-40,8)$ & 2,79 & 36,4 \\
\hline & 3 & $31,9(29,0-35,0)$ & 3,14 & 28,3 \\
\hline & $X \pm S$ & $38,0 \pm 7,44$ & $2,70 \pm 0,50$ & $34,7 \pm 12,0$ \\
\hline \multirow{4}{*}{5.0} & 1 & $29,7(27,1-32,5)$ & 3,37 & 23,1 \\
\hline & 2 & $31,0(27,1-35,6)$ & 3,22 & 26,4 \\
\hline & 3 & $32,3(29,7-35,0)$ & 3,10 & 29,2 \\
\hline & $X \pm S$ & $31,0 \pm 1,28$ & $3,23 \pm 0,13$ & $21,8 \pm 3,20$ \\
\hline
\end{tabular}

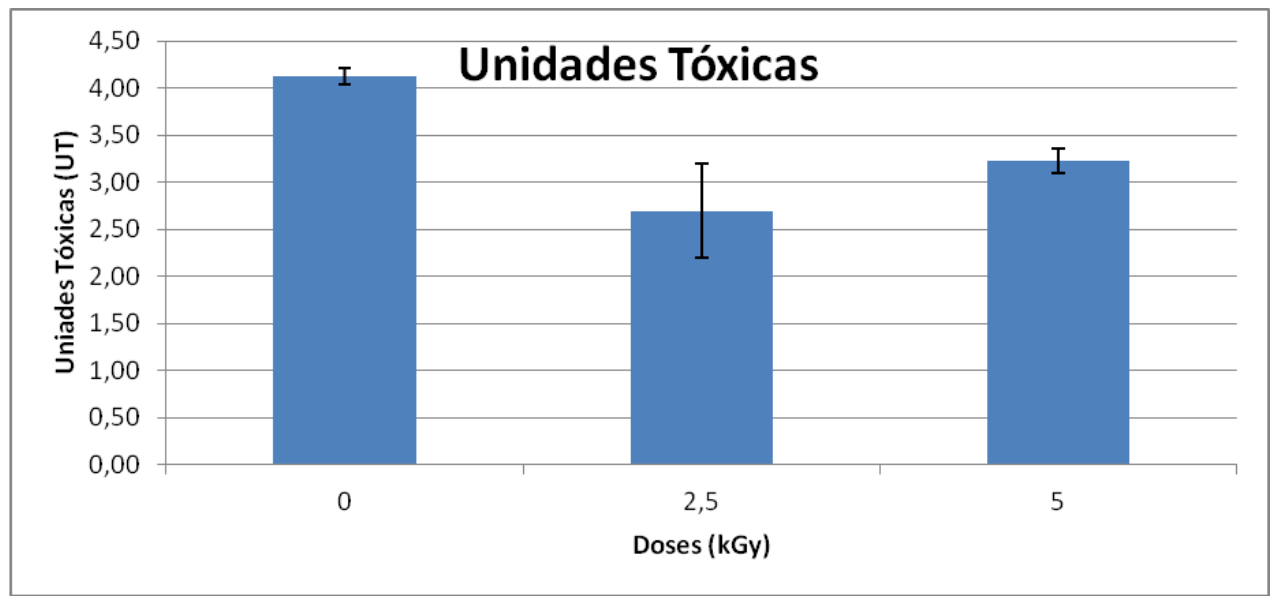

Figura 33 - Unidades Tóxicas de uma mistura de fármacos concentrada $(A)$ (cloridrato de fluoxetina e diclofenaco sódico), submetidas a um processo de irradiação por feixe de elétrons nas doses de 2,5 e 5,0 kGy para a Daphnia similis (48 h). 
Foram obtidas baixas eficiências de remoção de toxicidade com valores máximos de 34,7\% na dose de $2,5 \mathrm{kGy}$, (Tabela 17). A baixa remoção de toxicidade pode estar associada, principalmente, aos produtos de degradação do diclofenaco sódico, e também a presença de cloridrato de fluoxetina que não foi degradada durante o processo de irradiação.

Para a mistura diluída 1:10 (B), os valores de eficiência de remoção de toxicidade foram de 66,9\% em 5.0 kGy, demonstrando eficiência de remoção de toxicidade da mistura nesta dose (Tabela 18). Desta forma, foi possível verificar que, embora ambos os fármacos tenham sido degradados, a toxicidade foi proveniente dos produtos de degradação da amostra irradiada.

Tabela 18 - Valores de CE50 48h, Unidades Tóxicas e Eficiência de Remoção de Toxicidade para a Diluição 1:10 dos fármacos cloridrato de fluoxetina e diclofenaco sódico para $D$. similis.

\begin{tabular}{|c|c|c|c|c|}
\hline \multicolumn{5}{|c|}{ Diluição 1:10 } \\
\hline $\begin{array}{l}\text { Doses } \\
\text { (kGy) }\end{array}$ & Ensaio & CE50 48h (\%)/ IC & UT & $\begin{array}{l}\text { Eficiência de } \\
\text { remoção de } \\
\text { toxicidade (\%) }\end{array}$ \\
\hline \multirow{4}{*}{0} & 1 & $28,17(23,69-33,50)$ & 3,55 & - \\
\hline & 2 & $29,69(24,93-35,35)$ & 3,37 & - \\
\hline & 3 & $21,76(18,21-26,01)$ & 4,60 & - \\
\hline & $X \pm S$ & $26,54 \pm 4,21$ & $3,84 \pm 0,66$ & - \\
\hline \multirow{4}{*}{5.0} & 1 & $68,73(60,78-77,72)$ & 1,45 & 65,4 \\
\hline & 2 & $89,1(83,77-94,77)$ & 1,12 & 73,3 \\
\hline & 3 & $81,07(77,47-84,85)$ & 1,23 & 70,7 \\
\hline & $X \pm S$ & $79,63 \pm 10,26$ & $1,27 \pm 0,17$ & $66,9 \pm 4,41$ \\
\hline
\end{tabular}

$\mathrm{X} \pm \mathrm{S}$ : Média com desvio-padrão

IC: intervalo de confiança

\subsubsection{Comparações entre a toxicidade dos fármacos}

$\mathrm{Na}$ Tabela 19, foram apresentados as CE50 $\left(\mathrm{mg}^{-\mathrm{L}^{-1}}\right)$ dos ensaios de toxicidade realizados para os fármacos cloridrato de fluoxetina e diclofenaco sódico. Foi possível observar que a bactéria $V$. fischeri apresentou sensibilidade a ambos os fármacos em estudos, ao passo que apenas o cloridrato de fluoxetina se apresentou com toxicidade elevada para o organismo $D$. similis. 
Tabela 19 - Valores de CE50 (mg. $\left.\mathrm{L}^{-1}\right)$ dos fármacos cloridrato de fluoxetina e diclofenaco sódico para os organismos $V$. fischeri e $D$. similis

\begin{tabular}{|c|c|c|}
\hline \multirow{2}{*}{ Fármacos } & \multicolumn{2}{|c|}{ CE50 $\left(\mathrm{mg} \cdot \mathrm{L}^{-1}\right)$} \\
\cline { 2 - 3 } & Vibrio fischeri & Daphnia similis \\
\hline Cloridrato de Fluoxetina & $4,59 \pm 1,68$ & $1,09 \pm 0,40$ \\
\hline Diclofenaco sódico & $5,12 \pm 0,41$ & $24,86 \pm 4,86$ \\
\hline
\end{tabular}

O potencial tóxico, bem como efeitos destes fármacos sobre organismos unicelulares já vem sendo foco em diversos trabalhos. NEUWOEHNER e colaboradores (2009) avaliaram o modo de ação fisiológica da fluoxetina em Pseudokirchneriella subcapitata. Foi observado que a fluoxetina não apresentou efeitos na fotossíntese após o período de $2 \mathrm{~h}$. No entanto, foi verificado que a fluoxetina apresentou efeitos no crescimento, sendo concluído que o composto apresenta efeitos no balanço de energia das células das algas.

DASTIDAR e colaboradores (2000) verificaram alto potencial bactericida do diclofenaco tanto para bactérias gram-positivas quanto para gram-negativas, verificando, também, a degradação das moléculas de DNA das bactérias E. coli. Desta forma, visto que o crescimento das células das bactérias depende da síntese de DNA e RNA, a interferência na síntese destas moléculas pode interromper o crescimento das bactérias. Sendo assim, o tóxico do diclofenaco sódico para a bactéria marinha $V$. fischeri, pode ser explicado devido ao potencial tóxico deste fármaco.

Em relação aos invertebrados, a exposição destes organismos em concentrações baixas de fluoxetina $\left(\mu \mathrm{g} \cdot \mathrm{L}^{-1}\right)$ pode estimular a reprodução (BROOKS et al, 2003; FONG, 1998). FLAHERTY e DODSON (2005) estudaram o efeito crônico da exposição de Daphnia magna a baixas concentrações de fluoxetina $\left(36 \mu \mathrm{g} \cdot \mathrm{L}^{-1}\right)$. Durante o estudo não foram observados efeitos sobre a sobrevivência e a morfologia dos adultos e recém-nascidos, no entanto foi observado um aumento significativo no número total de Daphnia prole produzida. No entanto, PERY e colaboradores (2008) observaram efeitos significativos na mortalidade de $D$. magna em concentração mais elevadas $\left(121 \mu \mathrm{g} \cdot \mathrm{L}^{-1}\right)$. Após 21 dias de exposição, foram verificadas $40 \%$ nas mortalidades dos organismos.

OLIVEIRA (2014), ao expor o microcrustáceo D. magna em diferentes concentrações de diclofenaco, verificou alterações significativas nas respostas 
bioquímica, indicando estresse oxidativo dos organismo. GÓMEZ-OLIVÁN e colaboradores (2014) demonstraram que o diclofenaco sódico foi responsável por danos no DNA e alterações nos biomarcadores bioquímicos.

\subsubsection{Carta controle}

Nas Figuras 34 e 35, foram apresentados os resultados das cartas controle dos organismos Daphnia similis e Vibrio fischeri, respectivamente. O coeficiente de variação $(\mathrm{CV})$ para o microcrustáceo $D$. similis foi de $6,58 \%$, ao passo que para bactéria bioluminescente $V$. fischeri, o CV encontrado foi de 11,72\%. Portanto foram encontrados valores inferiores a $30 \%$ considerados validos dentre da sensibilidade, demonstrando a aptidão dos organismos para testes.

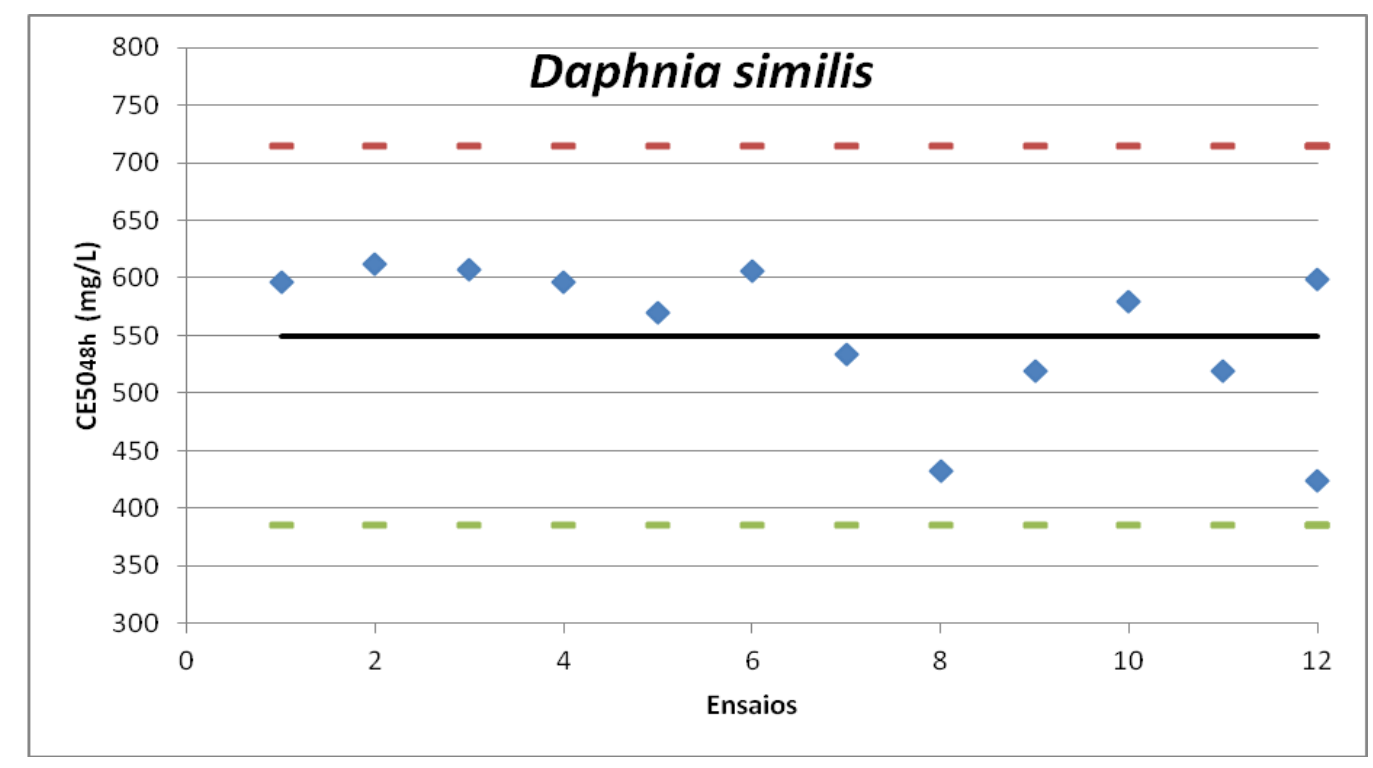

Figura 34 - Carta controle de sensibilidade do organismo $D$. similis em relação ao cloreto de potássio. 


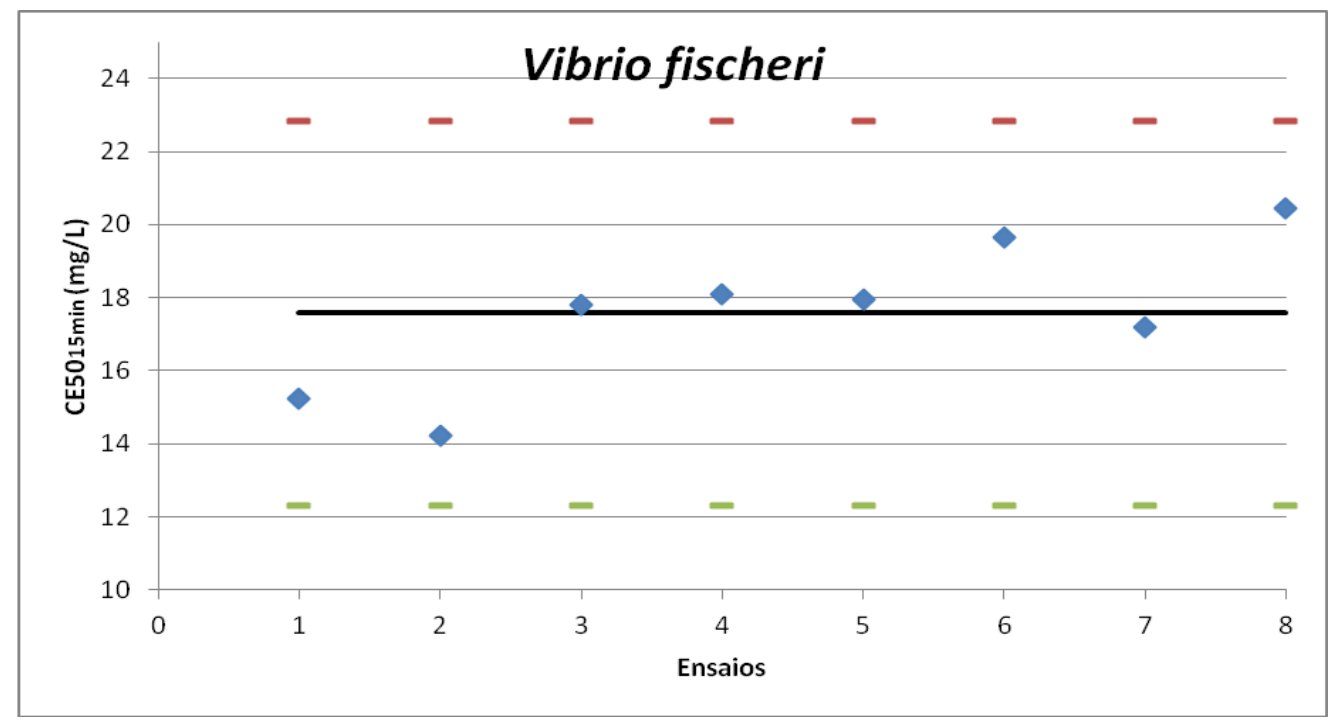

Figura 35 - Carta controle de sensibilidade da bactéria $V$. fischeri em relação ao fenol.

\subsubsection{Parâmetros físico-químicos}

A avaliação de parâmetros como pH, oxigênio, condutividade e dureza torna-se importante, visto que estes são os fatores que mais influenciam na toxicidade (ZAGATTO E BERTOLETTI, 2008).

Nas Tabelas 20, 21 e 22, foram apresentados os valores de pH, Oxigênio dissolvidos $\left(\mathrm{mg} \cdot \mathrm{L}^{-1}\right)$ e Condutividade $\left(\mu \mathrm{S} . \mathrm{cm}^{-1}\right)$ dos ensaios realizados para a ambos os organismos nas diferentes doses de radiação para as diferentes misturas (mistura mais concentrada $(A)$ e mistura diluída 1:10 (B)).

Foi observada a diminuição do valor do $\mathrm{pH}$ com o aumento da dose de radiação para ambas as diluições (Figura 36). Este fenômeno pode ser explicado devido à formação de ácidos orgânicos durante a degradação dos orgânicos decorrentes do tratamento com o processo de radiação (DUARTE, 1999). Outros estudos também verificaram a diminuição com este tipo de tecnologia empregada (SILVA, 2014; SANTOS, 2011; ROMANELLI, 2004; BORRELY, 2001). Ademais, é possível observar também que ambas as misturas apresentam valores de $\mathrm{pH}$ próximos para todas as doses aplicadas. 
Tabela 20 - Valores de $\mathrm{pH}$ da mistura de cloridrato de fluoxetina e diclofenaco sódico (misturas concentrada (A) e diluida 1:10 (B)) utilizadas nos ensaios de toxicidade.

\begin{tabular}{|c|c|c|c|}
\hline \multirow[b]{2}{*}{ Doses (kGy) } & \multirow[b]{2}{*}{ Ensaios } & \multicolumn{2}{|c|}{$\mathrm{pH}$} \\
\hline & & $\begin{array}{l}\text { Mistura mais concentrada } \\
\text { (A) }\end{array}$ & Mistura diluída 1:10 (B) \\
\hline \multirow{4}{*}{0} & 1 & 5,90 & 6,75 \\
\hline & 2 & 7,21 & 4,26 \\
\hline & 3 & 7,26 & 6,46 \\
\hline & $X \pm S$ & $6,79 \pm 0,77$ & $5,82 \pm 1,36$ \\
\hline \multirow{4}{*}{2,5} & 1 & 4,57 & 5,90 \\
\hline & 2 & 5,46 & 4,12 \\
\hline & 3 & 4,70 & 4,66 \\
\hline & $X \pm S$ & $4,91 \pm 0,48$ & $4,89 \pm 0,91$ \\
\hline \multirow{4}{*}{5,0} & 1 & 4,12 & 5,35 \\
\hline & 2 & 4,59 & 4,05 \\
\hline & 3 & 4,18 & 4,19 \\
\hline & $X \pm S$ & $4,30 \pm 0,26$ & $4,53 \pm 0,71$ \\
\hline \multirow{4}{*}{7,5} & 1 & 4,06 & 4,90 \\
\hline & 2 & 4,18 & 3,92 \\
\hline & 3 & 4,00 & 4,09 \\
\hline & $X \pm S$ & $4,08 \pm 0,13$ & $4,30 \pm 0,52$ \\
\hline \multirow{4}{*}{10,0} & 1 & 3,84 & 4,69 \\
\hline & 2 & 3,99 & 3,88 \\
\hline & 3 & 3,89 & 4,02 \\
\hline & $X \pm S$ & $3,91 \pm 0,07$ & $4,20 \pm 0,43$ \\
\hline
\end{tabular}

$X \pm S:$ Média com desvio-padrão

Mistura mais concentrada (A): $50 \mathrm{mg} \cdot \mathrm{L}^{-1}$ de DIC e $5 \mathrm{mg} \cdot \mathrm{L}^{-1} \mathrm{FXT}$

Mistura diluída 1:10 (B): 5 mg. $\mathrm{L}^{-1}$ de DIC e $5 \mathrm{mg} \cdot \mathrm{L}^{-1}$ de FXT

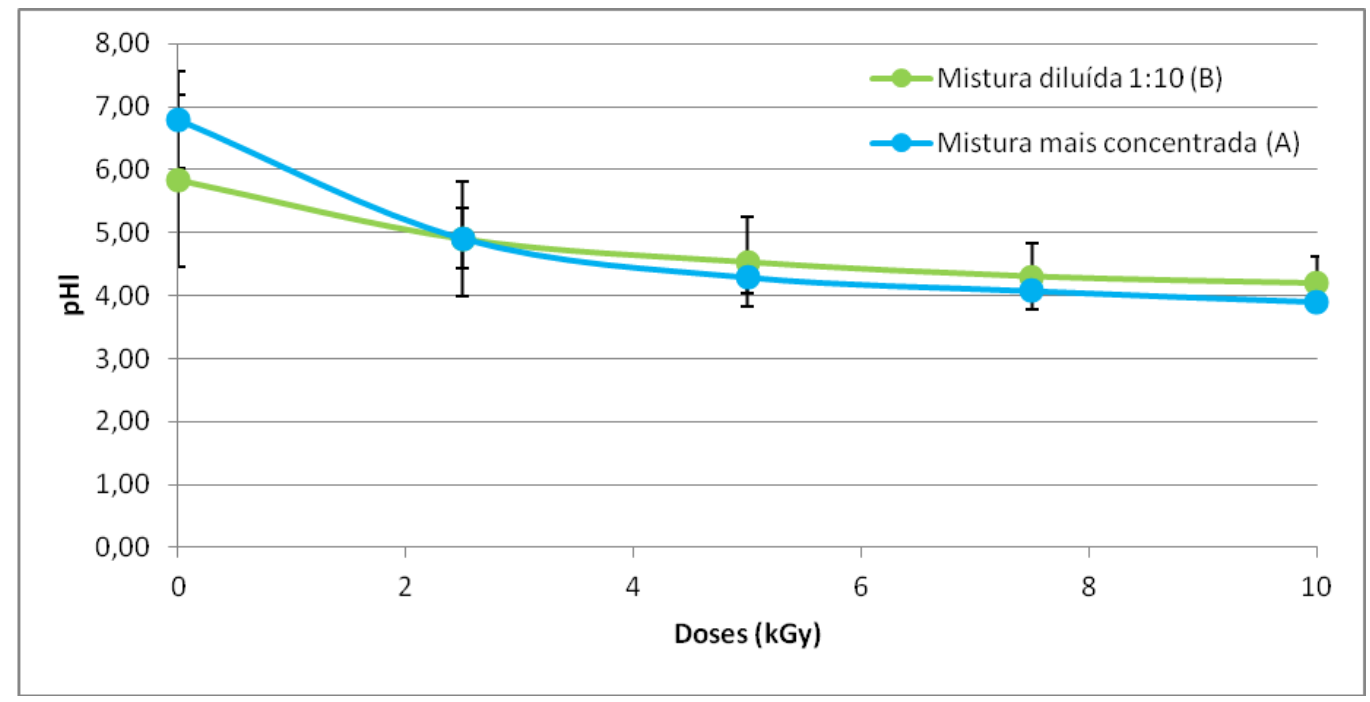

Figura 36 - Média com desvios-padrão dos valores de pH das amostras irradiadas e não irradiadas utilizadas nos ensaios de toxicidade. 
$\mathrm{O} \mathrm{pH}$ é um parâmetro importante para os organismos vivos. Esse parâmetro deve ser considerado em estudos de campo, em saneamento ambiental e monitoramentos visto que apresenta influência em diversos equilíbrios químicos que ocorrem naturalmente ou em processos unitários de tratamento de águas. Desta forma, as restrições de faixas de $\mathrm{pH}$ são estabelecidas para as diversas classes de águas naturais, tanto de acordo com a legislação federal, quanto pela legislação do Estado de São Paulo. Os critérios de proteção à vida aquática fixam o pH entre 6 e 9 (CETESB, 2009).

No presente estudo não foram realizados correções de $\mathrm{pH}$ para as amostras, visando não alterar as condições do meio. Outros estudos realizaram a correção do $\mathrm{pH}$ para valores de acordo com as normas exigidas para avaliar o comportamento da toxicidade. SILVA (2014) alterou os valores de $\mathrm{pH}$ das amostras irradiadas de cloridrato de fluoxetina para 7.3, observando que após a correção do $\mathrm{pH}$, o tratamento demonstrou relações diretamente proporcionais entre as doses de radiação e a eficiência de remoção de toxicidade. No entanto, mesmo com as correções, as eficiências de remoção de toxicidade permaneceram abaixo dos $30 \%$, indicando que a toxicidade também ocorreu pela formação de subprodutos.

Foi observado que valores de oxigênio dissolvido (OD) não sofreram alterações significativas durante as irradiações, variando entre valores de 7,76 a $8,16 \mathrm{mg} \cdot \mathrm{L}^{-1}$ (Tabela 21). 
Tabela 21 - Valores de Oxigênio Dissolvidos da mistura de cloridrato de fluoxetina e diclofenaco sódico utilizados nos ensaios de toxicidade.

\begin{tabular}{|c|c|c|c|}
\hline \multirow[b]{2}{*}{ Doses (kGy) } & \multirow[b]{2}{*}{ Ensaios } & \multicolumn{2}{|c|}{ OD $\left(\mathrm{mg} \cdot \mathrm{L}^{-1}\right)$} \\
\hline & & $\begin{array}{c}\text { Mistura mais } \\
\text { concentrada }(A)\end{array}$ & Mistura diluída 1:10 (B) \\
\hline \multirow{4}{*}{0} & 1 & 8,29 & 8,60 \\
\hline & 2 & 8,25 & 7,31 \\
\hline & 3 & 7,94 & 8,15 \\
\hline & $X \pm S$ & $8,16 \pm 0,19$ & $8,02 \pm 0,65$ \\
\hline \multirow{4}{*}{2,5} & 1 & 8,38 & 7,85 \\
\hline & 2 & 8,00 & 7,35 \\
\hline & 3 & 8,02 & 8,13 \\
\hline & $X \pm S$ & $8,13 \pm 0,21$ & $7,78 \pm 0,40$ \\
\hline \multirow{4}{*}{5,0} & 1 & 8,36 & 7,81 \\
\hline & 2 & 7,85 & 7,27 \\
\hline & 3 & 8,04 & 8,19 \\
\hline & $X \pm S$ & $8,08 \pm 0,26$ & $7,76 \pm 0,46$ \\
\hline \multirow{4}{*}{7,5} & 1 & 8,36 & 7,71 \\
\hline & 2 & 8,01 & 7,31 \\
\hline & 3 & 8,07 & 8,03 \\
\hline & $X \pm S$ & $8,15 \pm 0,04$ & $7,68 \pm 0,36$ \\
\hline \multirow{4}{*}{10,0} & 1 & 8,36 & 7,86 \\
\hline & 2 & 8,01 & 7,27 \\
\hline & 3 & 8,07 & 8,15 \\
\hline & $X \pm S$ & $8,15 \pm 0,04$ & $7,76 \pm 0,45$ \\
\hline
\end{tabular}

$\mathrm{X} \pm \mathrm{S}$ : Média com desvio-padrão

Mistura mais concentrada (A): $50 \mathrm{mg} \cdot \mathrm{L}^{-1}$ de DIC e $5 \mathrm{mg} \cdot \mathrm{L}^{-1} \mathrm{FXT}$

Mistura diluída 1:10 (B): 5 mg. $\mathrm{L}^{-1}$ de DIC e $5 \mathrm{mg} \cdot \mathrm{L}^{-1}$ de FXT

De acordo com as normas exigidas para os cultivo de microrganismos, os valores acima de $5,0 \mathrm{mg} \cdot \mathrm{L}^{-1}$ são adequados para a realização de ensaios ecotoxicólgicos. Além disso, este é um dos parâmetros regulados pela Resolução CONAMA $n^{\circ}$ 357/2005, complementado pelo 430/2011, sendo de extrema importância para regular a biota aquática.

Foi observado um aumento diretamente proporcional conforme o aumento das doses de irradiação ambas as misturas (Figura 37). Este parâmetro está relacionado com a capacidade da água conduzir corrente elétrica. Desta forma, a produção de íons, tais como ácidos orgânicos, favorecem o aumento de condutividade (CETESB, 2009). Outros estudos também verificaram o aumento de condutividade com este tipo de tecnologia empregada (SILVA, 2014; SANTOS, 2011; ROMANELLI, 2004; BORRELY, 2001). 
Tabela 22 - Valores de condutividade da mistura de cloridrato de fluoxetina e diclofenaco sódico utilizados nos ensaios de toxicidade.

\begin{tabular}{|c|c|c|c|}
\hline \multirow[b]{2}{*}{ Doses (kGy) } & \multirow[b]{2}{*}{ Ensaios } & \multicolumn{2}{|c|}{ Condutividade $\left(\mu \mathrm{S} . \mathrm{cm}^{-1}\right)$} \\
\hline & & $\begin{array}{c}\text { Mistura mais } \\
\text { concentrada }(A)\end{array}$ & Mistura diluída 1:10 (B) \\
\hline \multirow{4}{*}{0} & 1 & 80,6 & 71,8 \\
\hline & 2 & 72,7 & 92,5 \\
\hline & 3 & 76,4 & 88,6 \\
\hline & $X \pm S$ & $76,57 \pm 3,95$ & $84,30 \pm 11,00$ \\
\hline \multirow{4}{*}{2,5} & 1 & 100,6 & 77,8 \\
\hline & 2 & 102,6 & 95,5 \\
\hline & 3 & 89,4 & 108,1 \\
\hline & $X \pm S$ & $97,53 \pm 7,11$ & $93,80 \pm 15,22$ \\
\hline \multirow{4}{*}{5,0} & 1 & 118,2 & 99,1 \\
\hline & 2 & 125,9 & 109,7 \\
\hline & 3 & 115,5 & 112,4 \\
\hline & $X \pm S$ & $119,87 \pm 5,40$ & $107,07 \pm 7,03$ \\
\hline \multirow{4}{*}{7,5} & 1 & 131,1 & 104,7 \\
\hline & 2 & 137,7 & 114,4 \\
\hline & 3 & 140 & 104,9 \\
\hline & $X \pm S$ & $136,27 \pm 1,63$ & $108,00 \pm 5,54$ \\
\hline \multirow{4}{*}{10,0} & 1 & 169,5 & 117,6 \\
\hline & 2 & 173,4 & 117,6 \\
\hline & 3 & 154,3 & 117,6 \\
\hline & $X \pm S$ & $165,73 \pm 13,51$ & $115,60 \pm 9,26$ \\
\hline
\end{tabular}

$X \pm S$ : Média com desvio-padrão

Mistura mais concentrada (A): $50 \mathrm{mg} \cdot \mathrm{L}^{-1}$ de DIC e $5 \mathrm{mg} \cdot \mathrm{L}^{-1} \mathrm{FXT}$

Mistura diluída 1:10 (B): 5 mg. $\mathrm{L}^{-1}$ de DIC e $5 \mathrm{mg} \cdot \mathrm{L}^{-1}$ de FXT

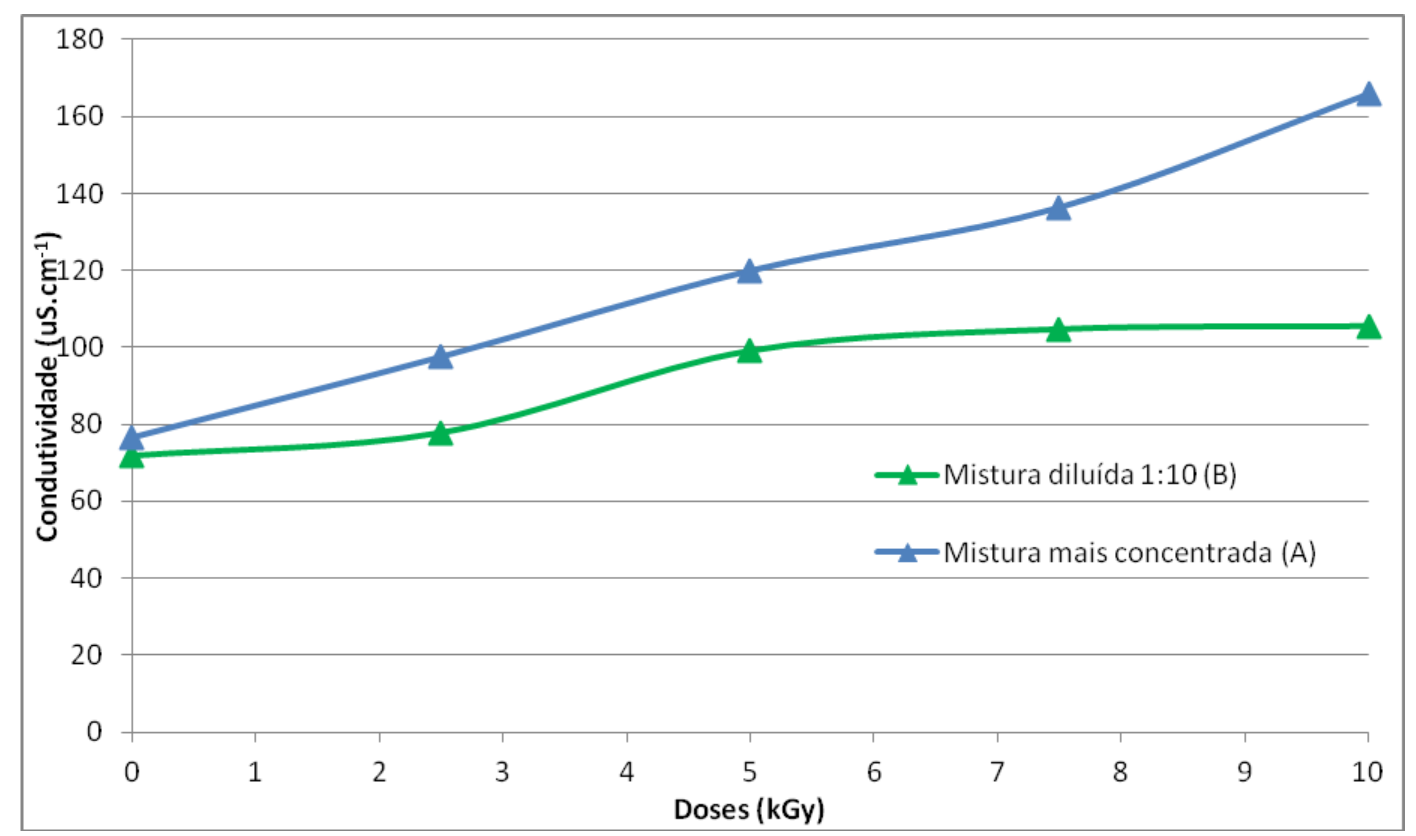

Figura 37 - Médias com desvios-padrão dos valores de condutividade das amostras irradiadas e não irradiadas utilizadas nos ensaios de toxicidade. 


\subsection{Ensaios respitométricos}

Os ensaios de respirometria foram realizados para verificar a biodegradabilidade da mistura de fármacos bruta e irradiadas, uma vez que a oxidação dos compostos tóxicos pode ser insuficiente para aumentar a biocompatibilidade dos compostos intermediários (COELHO et al, 2009).

Os resultados obtidos não indicaram indícios de picos de consumo de oxigênio, ou seja, não houve o consumo dos fármacos como fonte nutricional (Figura 38). Assim é possível observar que a mistura de fármacos (Mistura mais concentrada $(A)$, bem como os produtos formados pela irradiação das amostras na dose de 5.0 kGy não são biodegradáveis. Ademais, é possível observar que não houve um aumento aparente de toxicidade, visto que ao final do experimento foi observado atividade respiratória do lodo. Desta forma, este processo pode ser acoplado a processos biológicos sem interferir no funcionando do sistema operacional.

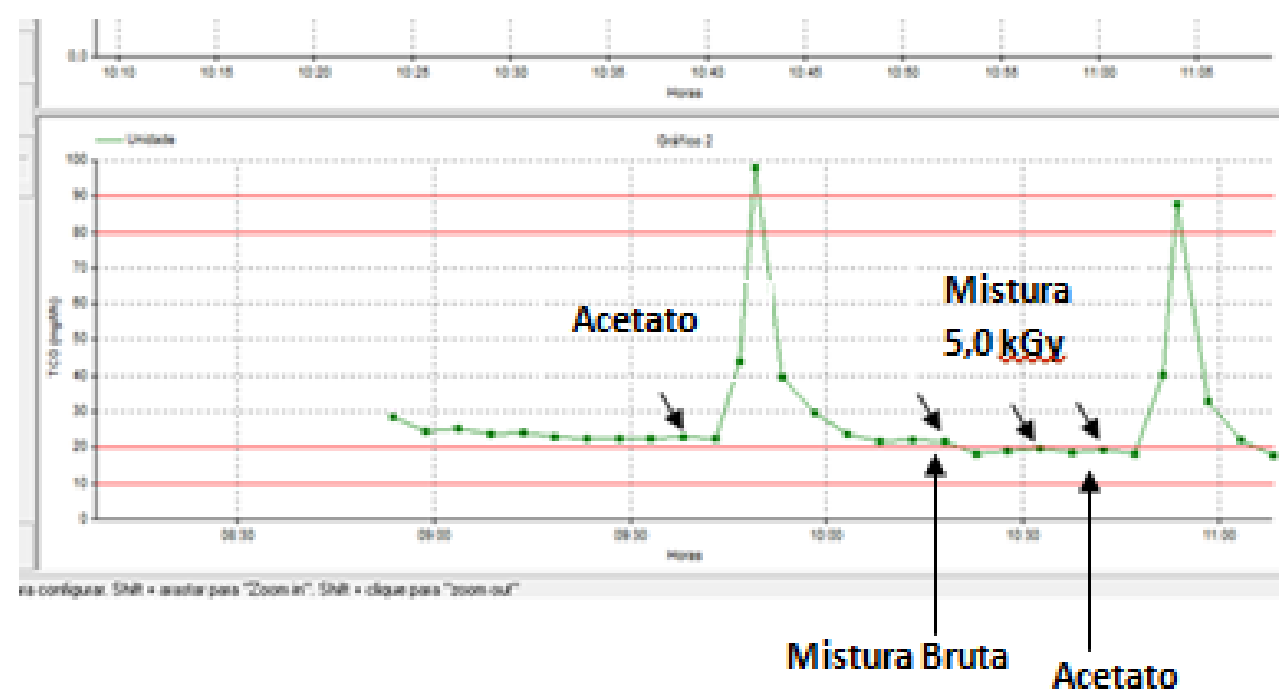

Figura 38 - Respirograma de uma mistura de fármacos (diclofenaco de sódio + cloridrato de fluoxetina) de uma solução bruta e irradiada a 5.0 kGy.

A baixa biodegradabilidade pode estar relacionada com a natureza recalcitrante do substrato à biodegradação. Alguns estudos demonstraram que não houve degradação estatisticamente significativa de fármacos em lodos de 
estações de tratamento de esgoto. REDSHAW e colaboradores (2008) avaliaram a biodegradabilidade da fluoxetina em solos que recebiam lodos de ETE e em culturas líquidas, verificando que não houve degradação significativa do composto. ZWIENER e FRIMMEL observaram que o diclofenaco não apresentou biodegradabilidade nas condições de operações aplicadas de uma estação de tratamento de esgoto piloto, na qual não foi verificada nenhuma degradação de concentrações iniciais de $10 \mu \mathrm{g} \cdot \mathrm{L}^{-1}$ de diclofenaco após 55 horas de tratamento.

Outro fator pode estar relacionado com concentração inicial dos fármacos, ou seja, altas concentrações do substrato podem causar inibição/toxicidade dos microrganismos.

MENDEZ-ARRIAGA e colaboradores (2011) utilizaram-se de ensaios respirométricos para avaliar a biodegradabilidade do cloridrato de fluoxetina submetida a diferentes POAs. Foi observado que a biodegradabilidade dependia da concentração inicial do fármaco, visto que, em solução contendo $0,11 \mathrm{mM}$ de cloridrato de fluoxetina, não foi averiguada biodegradabilidade do composto em um tempo de 5 dias. Entretanto, em uma solução contendo metade da concentração para uma amostra incubada no mesmo período, foi obtido DBO de $90 \mathrm{mg} \cdot \mathrm{L}^{-1}$.

Outro estudo, também observou para o fármaco hidrocloridrato de fluoxetina que a degradação variava dependendo da concentração inicial utilizada (CAMINADA, 2008). Nesse estudo foram observados que mesmo em concentrações de $200 \mu \mathrm{g} \cdot \mathrm{L}^{-1}$, ocorreu redução de $27 \%$ do composto, indicando baixa biodegradabilidade.

Além disso, o consumo de um substrato pode estar relacionado com a adaptação dos microrganismos as condições do meio. Quando as células são expostas a compostos químicos ou tóxicos, estas, mesmo estando em fase exponencial, entram novamente em fase lag (MADIGAN et al, 2004). ROCHA (2010) estudou a biodegradação de diclofenaco sódico utilizando-se do fungo Aspergillus $s p$, e verificou que após o período de adaptação do fungo ao substrato, houve o consumo do fármaco como fonte nutricional, chegando a 
aumentar o consumo máximo de $57 \%$ no quinto dia com Biomassa com esgotamento endógeno (BCE).

\subsection{Análise estatística}

$\mathrm{Na}$ Tabela 23 foram apresentados os valores de $\mathrm{p}$-valor calculados pelo Teste de Turkey. Os valores menores que 0,05 indicam que há variação significativa entre as médias.

Foi observada remoção significativa entre apenas nas doses de 5,0 e 7,5 kGy para a bactéria $V$. fischeri. Desta forma, a dose de 5,0 kGy pode ser considerada como eficiente para a remoção de toxicidade.

Para a $D$. similis, foi obtida remoção significativa de toxicidade das soluções isoladas apenas para o cloridrato de fluoxetina irradiado em $5.0 \mathrm{kGy}$. Para a mistura mais concentrada (A), apenas a dose de 2,5 kGy obteve variação significativa em relação a amostra bruta. Por fim, para a mistura diluída 1:10 (B), a dose de 5.0 kGy resultou em remoção significativa de toxicidade.

Tabela 23 - Dados calculados pelo teste de Turkey para verificar a variação significa entre as médias de CE50.

\begin{tabular}{|c|c|c|c|c|c|}
\hline Organismo & Amostra & Níveis & Estat. F & $\mathrm{P}$ valor & $\begin{array}{c}\text { Variação } \\
\text { significativa }\end{array}$ \\
\hline \multirow{5}{*}{ Vibrio fischeri } & $\begin{array}{l}\text { Diclofenaco } \\
\text { sódico }\end{array}$ & 0-5,0 kGy & 15,665 & 0,017 & Sim \\
\hline & \multirow{4}{*}{$\begin{array}{c}\text { Mistura mais } \\
\text { concentrada } \\
\text { (A) }\end{array}$} & $0-2,5$ kGy & \multirow{4}{*}{9,414} & 0,137 & Não \\
\hline & & 0-5,0 kGy & & 0,04 & Sim \\
\hline & & $0-7,5$ kGy & & 0,02 & Sim \\
\hline & & 0-10,0 kGy & & 0,077 & Não \\
\hline \multirow{5}{*}{$\begin{array}{l}\text { Daphnia } \\
\text { similis }\end{array}$} & $\begin{array}{l}\text { Cloridrato de } \\
\text { Fluoxetina }\end{array}$ & $0-5,0$ kGy & 1,256 & 0,002 & Sim \\
\hline & $\begin{array}{c}\text { Diclofenaco } \\
\text { sódico }\end{array}$ & 0-5,0 kGy & 58,422 & 0,325 & Não \\
\hline & \multirow{2}{*}{$\begin{array}{c}\text { Mistura mais } \\
\text { concentrada } \\
\text { (A) }\end{array}$} & $0-2,5$ kGy & \multirow[b]{2}{*}{7,446} & 0,200 & Sim \\
\hline & & $0-5,0$ kGy & & 0,220 & Não \\
\hline & $\begin{array}{c}\text { Mistura diluída } \\
1: 10(\mathrm{~B})\end{array}$ & 0-5,0 kGy & 68,756 & 0,01 & Sim \\
\hline
\end{tabular}

Mistura mais concentrada (A): $50 \mathrm{mg} \cdot \mathrm{L}^{-1}$ de DIC e $5 \mathrm{mg} \cdot \mathrm{L}^{-1} \mathrm{FXT}$

Mistura diluída 1:10 (B): 5 mg. $\mathrm{L}^{-1}$ de DIC e $5 \mathrm{mg} \cdot \mathrm{L}^{-1}$ de FXT 
Estudos anteriores determinaram doses mais baixas (0,5 a 5,0 kGy) como as mais eficientes para a remoção de toxicidade (MORAIS, 2015; SILVA, 2014; SANTOS, 2011, BORRELY, 2001).

\section{CONCLUSÕES}

$\checkmark$ Foi observada remoção de toxicidade nas amostras irradiadas em todas as doses aplicadas para a bactéria $V$. fischeri, com maior eficiência de 56,8\% de em 7,5 kGy na mistura;

$\checkmark$ Para a $D$. similis, foi observada remoção significativa de toxicidade apenas na dose de 2,5 kGy na mistura mais concentrada $(A)$;

$\checkmark$ Os ensaios respirométricos não demonstraram biodegradabilidade das amostras tratadas e não tratadas. Resultados do Carbono Orgânico Total confirmaram a insignificante mineralização da mistura;

$\checkmark$ A irradiação foi eficiente na degradação do fármaco diclofenaco de sódio (99\%) na mistura com concentrações mais elevadas. O mesmo não ocorrendo para o cloridrato de fluoxetina. Para baixas concentrações de diclofenaco na mistura, houve eficiência na degradação de ambos os fármacos;

$\checkmark$ A presença de diclofenaco na solução pode inibir a degradação do cloridrato de fluoxetina. 


\section{SUGESTÕES PARA TRABAHOS FUTUROS}

$>$ Detecção dos produtos de degradação dos compostos isolados e em mistura;

$>$ Estudar a presença de excipientes e a influência destes compostos na toxicidade e degradação de fármacos;

$>$ Propor trabalhos que enfatizem o descarte racional dos medicamentos, bem como o gerenciamento industrial. 


\section{APÊNDICES}

\section{Apêndice A: Fichas - controle de ensaios de toxicidade aguda com Vibrio fischeri}

Valores de CE50 para os fármacos cloridrato de fluoxetina e diclofenaco sódico

Ensaios de toxicidade aguda com o soluções preparadas a partir do cloridrato de fluoxetina de $10 \mathrm{mg} \cdot \mathrm{L}^{-1}$ (0,0 kGy)

Ensaio 1

\begin{tabular}{|c|c|c|c|c|c|c|c|c|}
\hline \multicolumn{9}{|c|}{ ENSAIOS DE TOXICIDADE AGUDA - Vibrio fischeri-1ำ ensaio } \\
\hline \multicolumn{2}{|c|}{ Data do ensaio: $29 / 04 / 2015$} & \multicolumn{7}{|c|}{ Amostra: Cloridrato de fluoxetina (0,0 kGy) } \\
\hline $\begin{array}{l}\text { Bioluminescência } \\
\text { emitida pela }\end{array}$ & Controle & \multicolumn{4}{|c|}{ Concentração (\%) } & $\mathrm{pH}$ & $\mathrm{OD}$ & $\begin{array}{c}\text { Cond. } \\
\left(\mu \mathrm{S} . \mathrm{cm}^{-1}\right)\end{array}$ \\
\hline & & 5,11 & 10,23 & 20,47 & 40,95 & \multirow{3}{*}{7,75} & \multirow{3}{*}{7,88} & \multirow{4}{*}{18,89} \\
\hline $\mathrm{I}_{0}$ & 93 & 94 & 101 & 95 & 95 & & & \\
\hline$I_{15}$ & 133 & 122 & 118 & 99 & 70 & & & \\
\hline \multicolumn{8}{|c|}{$\mathrm{CE} 0_{15 \min }=46,47(41,17-52,45)$} & \\
\hline
\end{tabular}

Ensaio 2

\begin{tabular}{|c|c|c|c|c|c|c|c|c|}
\hline \multicolumn{9}{|c|}{ ENSAIOS DE TOXICIDADE AGUDA - Vibrio fischeri - $2^{\circ}$ ensaio } \\
\hline \multirow{3}{*}{$\begin{array}{c}\text { Data do ensaio: } 1 \\
\text { Bioluminescência } \\
\text { emitida pela } \\
\text { bactéria }\end{array}$} & \multirow{3}{*}{ Controle } & & & stra: C & idrato $\mathrm{d}$ & fluoxe & $(0,0 \mathrm{kG}$ & \\
\hline & & \multicolumn{4}{|c|}{ Concentração (\%) } & $\mathrm{pH}$ & $\mathrm{OD}^{-1}$ & Cond. \\
\hline & & 5,11 & 10,23 & 20,47 & 40,95 & \multirow{3}{*}{7,92} & \multirow{3}{*}{7,48} & \multirow{3}{*}{21,1} \\
\hline $\mathrm{I}_{0}$ & 83 & 92 & 106 & 94 & 98 & & & \\
\hline $\mathrm{I}_{15}$ & 104 & 111 & 102 & 80 & 65 & & & \\
\hline \multicolumn{9}{|c|}{$\mathrm{CE} 0_{15 \min }=36,87(20,67-65,77)$} \\
\hline
\end{tabular}

Ensaio 3

\begin{tabular}{|c|c|c|c|c|c|c|c|c|}
\hline \multicolumn{9}{|c|}{ ENSAIOS DE TOXICIDADE AGUDA - Vibrio fischeri - $3^{\circ}$ ensaio } \\
\hline \multicolumn{2}{|c|}{ Data do ensaio: $16 / 06 / 2015$} & \multicolumn{7}{|c|}{ Amostra: Cloridrato de fluoxetina (0,0 kGy) } \\
\hline $\begin{array}{l}\text { Bioluminescência } \\
\text { emitida pela }\end{array}$ & Controle & \multicolumn{4}{|c|}{ Concentração (\%) } & $\mathrm{pH}$ & $\mathrm{OD}^{-1}$ & $\begin{array}{l}\text { Cond. } \\
\left.\text { (uS } \mathrm{cm}^{-1}\right)\end{array}$ \\
\hline & & 5,11 & 10,23 & 20,47 & 40,95 & \multirow{3}{*}{8,54} & \multirow{3}{*}{ 7,65 } & \multirow{3}{*}{35,9} \\
\hline $\mathrm{I}_{0}$ & 104 & 98 & 102 & 100 & 93 & & & \\
\hline $\mathrm{I}_{15}$ & 125 & 113 & 101 & 92 & 60 & & & \\
\hline \multicolumn{9}{|c|}{$\mathrm{CE} 0_{15 \min }=44,03(30,46-63,66)$} \\
\hline
\end{tabular}


Ensaio 4

\begin{tabular}{|c|c|c|c|c|c|c|c|c|}
\hline \multicolumn{9}{|c|}{ ENSAIOS DE TOXICIDADE AGUDA - Vibrio fischeri - $4^{\circ}$ ensaio } \\
\hline \multirow{3}{*}{$\begin{array}{c}\text { Data do ensaio: } 1 \\
\text { Bioluminescência } \\
\text { emitida pela } \\
\text { bactéria }\end{array}$} & \multirow{3}{*}{ Controle } & \multicolumn{7}{|c|}{ Amostra: Cloridrato de fluoxetina (0,0 kGy) } \\
\hline & & \multicolumn{4}{|c|}{ Concentração (\%) } & $\mathrm{pH}$ & $\begin{array}{c}\text { OD } \\
\left(m a \cdot L^{-1}\right)\end{array}$ & $\begin{array}{l}\text { Cond. } \\
\left(\mu \mathrm{S} . \mathrm{cm}^{-1}\right)\end{array}$ \\
\hline & & 5,11 & 10,23 & 20,47 & 40,95 & \multirow{3}{*}{8,54} & \multirow{3}{*}{ 7,65 } & \multirow{3}{*}{35,9} \\
\hline $\mathrm{I}_{0}$ & 99 & 94 & 97 & 97 & 72 & & & \\
\hline$I_{15}$ & 99 & 77 & 75 & 65 & 36 & & & \\
\hline
\end{tabular}

Ensaio 5

\begin{tabular}{|c|c|c|c|c|c|c|c|c|}
\hline \multicolumn{9}{|c|}{ ENSAIOS DE TOXICIDADE AGUDA - Vibrio fischeri - $5^{\circ}$ ensaio } \\
\hline \multicolumn{2}{|c|}{ Data do ensaio: 22/10/2015 } & \multicolumn{7}{|c|}{ Amostra: Cloridrato de fluoxetina (0,0 kGy) } \\
\hline \multirow{2}{*}{$\begin{array}{c}\text { Bioluminescência } \\
\text { emitida pela } \\
\text { bacteria }\end{array}$} & \multirow[t]{2}{*}{ Controle } & \multicolumn{4}{|c|}{ Concentração (\%) } & $\mathrm{pH}$ & $\mathrm{OD}^{-1}$ & Cond. \\
\hline & & 5,11 & 10,23 & 20,47 & 40,95 & \multirow{3}{*}{8,54} & \multirow{3}{*}{7,65} & \multirow{3}{*}{35,9} \\
\hline $\mathrm{I}_{0}$ & 87 & 90 & 94 & 93 & 91 & & & \\
\hline$l_{15}$ & 131 & 125 & 121 & 105 & 72 & & & \\
\hline & & CE5 & & $(43$ & 54, & & & \\
\hline
\end{tabular}

\section{Ensaios de toxicidade aguda com o soluções preparadas a partir do diclofenaco} sódico de $100 \mathrm{mg} \cdot \mathrm{L}^{-1}$ (0,0 kGy)

Ensaio 1

\begin{tabular}{|c|c|c|c|c|c|c|c|c|}
\hline \multicolumn{9}{|c|}{ ENSAIOS DE TOXICIDADE AGUDA - Vibrio fischeri-1ํ ensaio } \\
\hline \multicolumn{2}{|c|}{ Data do ensaio: 08/12/2014 } & \multicolumn{7}{|c|}{ Amostra: Diclofenaco sódico (0,0 kGy) } \\
\hline $\begin{array}{l}\text { Bioluminescência } \\
\text { emitida pela }\end{array}$ & Controle & \multicolumn{4}{|c|}{ Concentração (\%) } & $\mathrm{pH}$ & $\frac{\mathrm{OD}}{\left(\mathrm{mg}^{-1} \mathrm{~L}^{-1}\right)}$ & $\begin{array}{l}\text { Cond. } \\
\left(\mu S . \mathrm{cm}^{-1}\right)\end{array}$ \\
\hline & & 2,56 & 5,11 & 10,23 & 20,47 & \multirow{3}{*}{7,95} & \multirow{3}{*}{6,77} & \multirow{3}{*}{64,5} \\
\hline $\mathrm{I}_{0}$ & 85 & 89 & 100 & 91 & 82 & & & \\
\hline $\mathrm{I}_{15}$ & 120 & 87 & 77 & 38 & 2 & & & \\
\hline \multicolumn{9}{|c|}{$\mathrm{CE}{ }_{15 \min }=4,68(1,83-11,97)$} \\
\hline
\end{tabular}

Ensaio 2

\begin{tabular}{|c|c|c|c|c|c|c|c|c|}
\hline \multicolumn{9}{|c|}{ ENSAIOS DE TOXICIDADE AGUDA - Vibrio fischeri - $2^{\circ}$ ensaio } \\
\hline \multicolumn{2}{|c|}{ Data do ensaio: $14 / 04 / 2015$} & \multicolumn{7}{|c|}{ Amostra: Diclofenaco sódico (0,0 kGy) } \\
\hline $\begin{array}{c}\text { Bioluminescência } \\
\text { emitida pela }\end{array}$ & Controle & \multicolumn{4}{|c|}{ Concentração (\%) } & $\mathrm{pH}$ & $\mathrm{OD}^{-1}$ & Cond. \\
\hline & & 2,56 & 5,11 & 10,23 & 20,47 & \multirow{3}{*}{ 7,95 } & \multirow{3}{*}{6,77} & \multirow{3}{*}{64,5} \\
\hline $\mathrm{I}_{0}$ & 92 & 95 & 88 & 85 & 90 & & & \\
\hline$I_{15}$ & 111 & 87 & 63 & 30 & 3 & & & \\
\hline
\end{tabular}


Ensaio 3

\begin{tabular}{|c|c|c|c|c|c|c|c|c|}
\hline \multicolumn{9}{|c|}{ ENSAIOS DE TOXICIDADE AGUDA - Vibrio fischeri $-3^{\circ}$ ensaio } \\
\hline \multirow{3}{*}{$\begin{array}{c}\text { Data do ensaio: } 1 \\
\text { Bioluminescência } \\
\text { emitida pela } \\
\text { bactéria }\end{array}$} & \multirow{3}{*}{ Controle } & & & nostra: & iclofena & sódic & $0,0 \mathrm{kGy})$ & \\
\hline & & \multicolumn{4}{|c|}{ Concentração (\%) } & $\mathrm{pH}$ & $\underset{\left(m g \cdot L^{-1}\right)}{O D}$ & $\begin{array}{l}\text { Cond. } \\
\left(\mu \mathrm{S} . \mathrm{cm}^{-1}\right)\end{array}$ \\
\hline & & 5,11 & 10,23 & 20,47 & 40,95 & \multirow{3}{*}{ 7,95 } & \multirow{3}{*}{6,77} & \multirow{3}{*}{ 64,5 } \\
\hline $\mathrm{I}_{0}$ & 87 & 95 & 88 & 85 & 90 & & & \\
\hline$I_{15}$ & 96 & 64 & 33 & 6 & 1 & & & \\
\hline
\end{tabular}

Ensaio 4

\begin{tabular}{|c|c|c|c|c|c|c|c|c|}
\hline \multicolumn{9}{|c|}{ ENSAIOS DE TOXICIDADE AGUDA - Vibrio fischeri - $4^{\circ}$ ensaio } \\
\hline \multicolumn{2}{|c|}{ Data do ensaio: $23 / 06 / 2015$} & \multicolumn{7}{|c|}{ Amostra: Diclofenaco sódico $(0,0 \mathrm{kGy})$} \\
\hline $\begin{array}{l}\text { Bioluminescência } \\
\text { emitida pela }\end{array}$ & Controle & \multicolumn{4}{|c|}{ Concentração (\%) } & $\mathrm{pH}$ & $\mathrm{OD}^{-1}$ & $\begin{array}{l}\text { Cond. } \\
\left(\mu \mathrm{S} . \mathrm{cm}^{-1}\right)\end{array}$ \\
\hline & & 2,56 & 5,11 & 10,23 & 20,47 & \multirow{3}{*}{ 7,95 } & \multirow{3}{*}{6,77} & \multirow{3}{*}{64,5} \\
\hline $\mathrm{I}_{0}$ & 94 & 99 & 89 & 102 & 90 & & & \\
\hline $\mathrm{I}_{15}$ & 126 & 90 & 64 & 33 & 2 & & & \\
\hline & & $\mathrm{CE}$ & & $(1, \mathrm{~s}$ & $\overline{0,40)}$ & & & \\
\hline
\end{tabular}

Ensaio 5

\begin{tabular}{|c|c|c|c|c|c|c|c|c|}
\hline \multicolumn{9}{|c|}{ ENSAIOS DE TOXICIDADE AGUDA - Vibrio fischeri - $5^{\circ}$ ensaio } \\
\hline \multicolumn{2}{|c|}{ Data do ensaio: 17/08/2015 } & \multicolumn{7}{|c|}{ Amostra: Diclofenaco sódico (0,0 kGy) } \\
\hline $\begin{array}{c}\text { Bioluminescência } \\
\text { emitida pela }\end{array}$ & Controle & \multicolumn{4}{|c|}{ Concentração (\%) } & $\mathrm{pH}$ & $\underset{\left(\mathrm{maL}^{-1}\right)}{\mathrm{OD}}$ & $\begin{array}{l}\text { Cond. } \\
\left(\mathrm{uS} \mathrm{cm}^{-1}\right)\end{array}$ \\
\hline & & 5,11 & 10,23 & 20,47 & 40,95 & \multirow{3}{*}{ 7,95 } & \multirow{3}{*}{6,77} & \multirow{3}{*}{64,5} \\
\hline $\mathrm{I}_{0}$ & 108 & 92 & 44 & 105 & 96 & & & \\
\hline$I_{15}$ & 136 & 47 & 20 & 6 & 1 & & & \\
\hline
\end{tabular}

Ensaios de toxicidade aguda com o soluções preparadas a partir do diclofenaco sódico de $100 \mathrm{mg}^{-\mathrm{L}^{-1}}$ (5,0 kGy)

Ensaio 1

\begin{tabular}{|c|c|c|c|c|c|c|c|c|}
\hline \multicolumn{9}{|c|}{ ENSAIOS DE TOXICIDADE AGUDA - Vibrio fischeri - $1^{\circ}$ ensaio } \\
\hline \multicolumn{2}{|c|}{ Data do ensaio: 14/04/2015 } & \multicolumn{7}{|c|}{ Amostra: Diclofenaco sódico (5,0 kGy) } \\
\hline $\begin{array}{l}\text { Bioluminescência } \\
\text { emitida pela }\end{array}$ & Controle & \multicolumn{4}{|c|}{ Concentração (\%) } & $\mathrm{pH}$ & $\mathrm{OD}_{\left(\mathrm{mg} \mathrm{L}^{-1}\right)}$ & $\begin{array}{l}\text { Cond. } \\
\left(\mathrm{uS} \mathrm{cm}^{-1}\right)\end{array}$ \\
\hline & & 2,56 & 5,11 & 10,23 & 20,47 & \multirow{3}{*}{5,20} & \multirow{3}{*}{ 6,93 } & \multirow{3}{*}{124,3} \\
\hline $\mathrm{I}_{0}$ & 90 & 88 & 80 & 85 & 82 & & & \\
\hline $\mathrm{I}_{15}$ & 109 & 95 & 79 & 62 & 23 & & & \\
\hline \multicolumn{9}{|c|}{$\mathrm{CE} 0_{15 \min }=11,26(7,93-16,00)$} \\
\hline
\end{tabular}


Ensaio 2

\begin{tabular}{|c|c|c|c|c|c|c|c|c|}
\hline \multicolumn{9}{|c|}{ ENSAIOS DE TOXICIDADE AGUDA - Vibrio fischeri $-2^{\circ}$ ensaio } \\
\hline \multicolumn{2}{|c|}{ Data do ensaio: $22 / 10 / 2015$} & \multicolumn{7}{|c|}{ Amostra: Diclofenaco sódico (5,0 kGy) } \\
\hline \multirow{2}{*}{$\begin{array}{c}\text { Bioluminescência } \\
\text { emitida pela } \\
\text { bactéria }\end{array}$} & \multirow[t]{2}{*}{ Controle } & \multicolumn{4}{|c|}{ Concentração (\%) } & $\mathrm{pH}$ & $\frac{O D}{\left(\mathrm{mg}^{-1} \mathrm{~L}^{-1}\right.}$ & $\begin{array}{l}\text { Cond. } \\
\left(\mu \mathrm{S} . \mathrm{cm}^{-1}\right)\end{array}$ \\
\hline & & 2,56 & 5,11 & 10,23 & 20,47 & \multirow{3}{*}{5,20} & \multirow{3}{*}{6,93} & \multirow{3}{*}{124,3} \\
\hline $\mathrm{I}_{0}$ & 86 & 84 & 82 & 81 & 78 & & & \\
\hline$I_{15}$ & 99 & 90 & 81 & 67 & 45 & & & \\
\hline & & CE & & & & & & \\
\hline
\end{tabular}

Ensaio 3

\begin{tabular}{|c|c|c|c|c|c|c|c|c|}
\hline \multicolumn{9}{|c|}{ ENSAIOS DE TOXICIDADE AGUDA - Vibrio fischeri - $3^{\circ}$ ensaio } \\
\hline \multicolumn{2}{|c|}{ Data do ensaio: $22 / 10 / 2015$} & \multicolumn{7}{|c|}{ Amostra: Diclofenaco sódico $(5,0 \mathrm{kGy})$} \\
\hline $\begin{array}{l}\text { Bioluminescência } \\
\text { emitida pela }\end{array}$ & Controle & \multicolumn{4}{|c|}{ Concentração (\%) } & $\mathrm{pH}$ & $\mathrm{OD}^{\left.-\mathrm{mg}^{-1}\right)}$ & $\begin{array}{l}\text { Cond. } \\
\left(\mu \mathrm{S} . \mathrm{cm}^{-1}\right)\end{array}$ \\
\hline & & 2,56 & 5,11 & 10,23 & 20,47 & \multirow{3}{*}{5,20} & \multirow{3}{*}{6,93} & \multirow{3}{*}{124,3} \\
\hline $\mathrm{I}_{0}$ & 86 & 83 & 80 & 82 & 82 & & & \\
\hline $\mathrm{I}_{15}$ & 99 & 90 & 77 & 70 & 45 & & & \\
\hline & & CE5 & - & $(16$ & $-23,8$ & & & \\
\hline
\end{tabular}
(0,0 kGy)

Ensaios de toxicidade aguda com as soluções preparadas a partir da Diluição 1:1

Ensaio 1

\begin{tabular}{|c|c|c|c|c|c|c|c|c|}
\hline \multicolumn{9}{|c|}{ ENSAIOS DE TOXICIDADE AGUDA - Vibrio fischeri - $1^{\circ}$ ensaio } \\
\hline \multicolumn{2}{|c|}{ Data do ensaio: $29 / 04 / 2015$} & \multicolumn{7}{|c|}{ Amostra: Diluição 1:1 (0,0 kGy) } \\
\hline \multirow{2}{*}{$\begin{array}{c}\text { Bioluminescência } \\
\text { emitida pela } \\
\text { bactéria }\end{array}$} & \multirow[t]{2}{*}{ Controle } & \multicolumn{4}{|c|}{ Concentração (\%) } & $\mathrm{pH}$ & $\underset{\left(m g . L^{-1}\right)}{\mathrm{OD}}$ & $\begin{array}{c}\text { Cond. } \\
\left(\mu \mathrm{S}^{-1} \mathrm{~cm}^{-1}\right)\end{array}$ \\
\hline & & 5,11 & 10,23 & 20,47 & 40,95 & \multirow{3}{*}{6,79} & \multirow{3}{*}{8,16} & \multirow{3}{*}{76,57} \\
\hline $\mathrm{I}_{0}$ & 76 & 90 & 89 & 94 & 94 & & & \\
\hline$I_{15}$ & 112 & 101 & 82 & 56 & 20 & & & \\
\hline & & CE5 & $=1$ & $(10$, & $-17,28$ & & & \\
\hline
\end{tabular}

Ensaio 2

\begin{tabular}{|c|c|c|c|c|c|c|c|c|}
\hline \multicolumn{9}{|c|}{ ENSAIOS DE TOXICIDADE AGUDA - Vibrio fischeri - $2^{\circ}$ ensaio } \\
\hline \multicolumn{2}{|c|}{ Data do ensaio: 05/05/2015 } & \multicolumn{7}{|c|}{ Amostra: Diluição 1:1 (0,0 kGy) } \\
\hline $\begin{array}{c}\text { Bioluminescência } \\
\text { emitida pela }\end{array}$ & Controle & \multicolumn{4}{|c|}{ Concentração (\%) } & $\mathrm{pH}$ & $\mathrm{OD}^{-1}$ & $\begin{array}{l}\text { Cond. } \\
\left(u S \mathrm{~cm}^{-1}\right)\end{array}$ \\
\hline & & 5,11 & 10,23 & 20,47 & 40,95 & \multirow{3}{*}{6,79} & \multirow{3}{*}{8,16} & \multirow{3}{*}{76,57} \\
\hline $\mathrm{I}_{0}$ & 105 & 100 & 98 & 95 & 96 & & & \\
\hline $\mathrm{I}_{15}$ & 99 & 80 & 66 & 36 & 9 & & & \\
\hline & & CE5 & $=1$ & $4(10,2$ & $-20,72$ & & & \\
\hline
\end{tabular}


Ensaio 3

\begin{tabular}{|c|c|c|c|c|c|c|c|c|}
\hline \multicolumn{9}{|c|}{ ENSAIOS DE TOXICIDADE AGUDA - Vibrio fischeri - $3^{\circ}$ ensaio } \\
\hline \multicolumn{2}{|c|}{ Data do ensaio: 05/05/2015 } & \multicolumn{7}{|c|}{ Amostra: Diluição 1:1 (0,0 kGy) } \\
\hline \multirow{2}{*}{$\begin{array}{c}\text { Bioluminescência } \\
\text { emitida pela } \\
\text { bactéria }\end{array}$} & \multirow[t]{2}{*}{ Controle } & \multicolumn{4}{|c|}{ Concentração (\%) } & $\mathrm{pH}$ & $\mathrm{OD}^{-1}$ & $\begin{array}{l}\text { Cond. } \\
\left.\text { (uS } \mathrm{cm}^{-1}\right)\end{array}$ \\
\hline & & 5,11 & 10,23 & 20,47 & 40,95 & \multirow{3}{*}{6,79} & \multirow{3}{*}{8,16} & \multirow{3}{*}{76,57} \\
\hline $\mathrm{I}_{0}$ & 105 & 98 & 104 & 99 & 96 & & & \\
\hline$I_{15}$ & 99 & 82 & 69 & 42 & 11 & & & \\
\hline & & $\mathrm{CE}$ & & (12 & & & & \\
\hline
\end{tabular}

\section{Ensaio 4}

\begin{tabular}{|c|c|c|c|c|c|c|c|c|}
\hline \multicolumn{9}{|c|}{ ENSAIOS DE TOXICIDADE AGUDA - Vibrio fischeri - $4^{\circ}$ ensaio } \\
\hline \multicolumn{2}{|c|}{ Data do ensaio: 10/06/2015 } & \multicolumn{7}{|c|}{ Amostra: Diluição 1:1 (0,0 kGy) } \\
\hline $\begin{array}{l}\text { Bioluminescência } \\
\text { emitida pela }\end{array}$ & Controle & \multicolumn{4}{|c|}{ Concentração (\%) } & $\mathrm{pH}$ & OD & Cond. \\
\hline & & 5,11 & 10,23 & 20,47 & 40,95 & \multirow{3}{*}{6,79} & \multirow{3}{*}{8,16} & \multirow{3}{*}{76,57} \\
\hline $\mathrm{I}_{0}$ & 93 & 89 & 94 & 95 & 87 & & & \\
\hline $\mathrm{l}_{15}$ & 111 & 62 & 60 & 43 & 16 & & & \\
\hline & & & $n=$ & (6. & $, 32)$ & & & \\
\hline
\end{tabular}

Ensaio 5

\begin{tabular}{|c|c|c|c|c|c|c|c|c|}
\hline \multicolumn{9}{|c|}{ ENSAIOS DE TOXICIDADE AGUDA - Vibrio fischeri - 5e ensaio } \\
\hline \multicolumn{2}{|c|}{ Data do ensaio: 16/06/2015 } & \multicolumn{7}{|c|}{ Amostra: Diluição 1:1 (0,0 kGy) } \\
\hline $\begin{array}{c}\text { Bioluminescência } \\
\text { emitida pela }\end{array}$ & Controle & \multicolumn{4}{|c|}{ Concentração (\%) } & $\mathrm{pH}$ & $\mathrm{OD}^{-1}$ & $\begin{array}{l}\text { Cond. } \\
\left(u S \mathrm{~cm}^{-1}\right)\end{array}$ \\
\hline & & 5,11 & 10,23 & 20,47 & 40,95 & \multirow{3}{*}{6,79} & \multirow{3}{*}{8,16} & \multirow{3}{*}{76,57} \\
\hline $\mathrm{I}_{0}$ & 106 & 96 & 95 & 95 & 104 & & & \\
\hline$I_{15}$ & 115 & 84 & 82 & 52 & 21 & & & \\
\hline \multicolumn{9}{|c|}{ CE50 $_{15 \mathrm{~min}}: 18,20(10,67-31,06)$} \\
\hline
\end{tabular}

Ensaio 6

\begin{tabular}{|c|c|c|c|c|c|c|c|c|}
\hline \multicolumn{9}{|c|}{ ENSAIOS DE TOXICIDADE AGUDA - Vibrio fischeri - 6 ensaio } \\
\hline \multicolumn{2}{|c|}{ Data do ensaio: $16 / 06 / 2015$} & \multicolumn{7}{|c|}{ Amostra: Diluição 1:1 (0,0 kGy) } \\
\hline $\begin{array}{c}\text { Bioluminescência } \\
\text { emitida pela }\end{array}$ & Controle & \multicolumn{4}{|c|}{ Concentração (\%) } & $\mathrm{pH}$ & $\mathrm{OD}_{\left(m a L^{-1}\right)}$ & $\begin{array}{l}\text { Cond. } \\
\left(u S . m^{-1}\right)\end{array}$ \\
\hline & & 5,11 & 10,23 & 20,47 & 40,95 & \multirow{3}{*}{6,79} & \multirow{3}{*}{8,16} & \multirow{3}{*}{76,57} \\
\hline $\mathrm{I}_{0}$ & 113 & 93 & 95 & 96 & 87 & & & \\
\hline$I_{15}$ & 124 & 83 & 73 & 51 & 19 & & & \\
\hline \multicolumn{9}{|c|}{$\mathrm{CE}_{15 \mathrm{~min}}: 16,94(13,18-21,77)$} \\
\hline
\end{tabular}


Ensaio 7

\begin{tabular}{|c|c|c|c|c|c|c|c|c|}
\hline \multicolumn{9}{|c|}{ ENSAIOS DE TOXICIDADE AGUDA - Vibrio fischeri - $7^{\circ}$ ensaio } \\
\hline \multicolumn{2}{|c|}{ Data do ensaio: $23 / 06 / 2015$} & \multicolumn{7}{|c|}{ Amostra: Diluição 1:1 (0,0 kGy) } \\
\hline \multirow{2}{*}{$\begin{array}{c}\text { Bioluminescência } \\
\text { emitida pela } \\
\text { bactéria }\end{array}$} & \multirow[t]{2}{*}{ Controle } & \multicolumn{4}{|c|}{ Concentração (\%) } & $\mathrm{pH}$ & $\mathrm{OD}^{-1}$ & Cond. \\
\hline & & 5,11 & 10,23 & 20,47 & 40,95 & \multirow{3}{*}{6,79} & \multirow{3}{*}{8,16} & \multirow{3}{*}{76,57} \\
\hline$I_{0}$ & 95 & 108 & 128 & 107 & 66 & & & \\
\hline $\mathrm{I}_{15}$ & 124 & 114 & 108 & 56 & 6 & & & \\
\hline
\end{tabular}

Ensaio 8

\begin{tabular}{|c|c|c|c|c|c|c|c|c|}
\hline \multicolumn{9}{|c|}{ ENSAIOS DE TOXICIDADE AGUDA - Vibrio fischeri $-8^{\circ}$ ensaio } \\
\hline \multicolumn{2}{|c|}{ Data do ensaio: $13 / 08 / 2015$} & \multicolumn{7}{|c|}{ Amostra: Diluição 1:1 (0,0 kGy) } \\
\hline $\begin{array}{l}\text { Bioluminescência } \\
\text { emitida pela }\end{array}$ & Controle & \multicolumn{4}{|c|}{ Concentração (\%) } & $\mathrm{pH}$ & $\mathrm{OD}^{-1}$ & Cond. \\
\hline & & 5,11 & 10,23 & 20,47 & 40,95 & \multirow{3}{*}{ 6,79 } & \multirow{3}{*}{8,16} & \multirow{3}{*}{76,57} \\
\hline $\mathrm{I}_{0}$ & 102 & 97 & 99 & 90 & 97 & & & \\
\hline $\mathrm{I}_{15}$ & 88 & 71 & 63 & 37 & 14 & & & \\
\hline & & $\mathrm{CE}$ & & 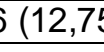 & 88 & & & \\
\hline
\end{tabular}

Ensaio 9

\begin{tabular}{|c|c|c|c|c|c|c|c|c|}
\hline \multicolumn{9}{|c|}{ ENSAIOS DE TOXICIDADE AGUDA - Vibrio fischeri - 9 ensaio } \\
\hline \multicolumn{2}{|c|}{ Data do ensaio: $17 / 08 / 2015$} & \multicolumn{7}{|c|}{ Amostra: Diluição 1:1 (0,0 kGy) } \\
\hline $\begin{array}{c}\text { Bioluminescência } \\
\text { emitida pela }\end{array}$ & Controle & \multicolumn{4}{|c|}{ Concentração (\%) } & $\mathrm{pH}$ & $\frac{\mathrm{OD}}{\left(\mathrm{mg}^{-1} \mathrm{~L}^{-1}\right)}$ & $\begin{array}{l}\text { Cond. } \\
\left(\mathrm{uS} \mathrm{cm}^{-1}\right)\end{array}$ \\
\hline & & 5,11 & 10,23 & 20,47 & 40,95 & \multirow{3}{*}{6,79} & \multirow{3}{*}{8,16} & \multirow{3}{*}{76,57} \\
\hline $\mathrm{I}_{0}$ & 83 & 96 & 105 & 94 & 89 & & & \\
\hline$I_{15}$ & 91 & 77 & 61 & 32 & 4 & & & \\
\hline
\end{tabular}

(2,5 kGy)

Ensaios de toxicidade aguda com as soluções preparadas a partir da Diluição 1:1

Ensaio 1

\begin{tabular}{|c|c|c|c|c|c|c|c|c|}
\hline \multicolumn{9}{|c|}{ ENSAIOS DE TOXICIDADE AGUDA - Vibrio fischeri - $1^{\circ}$ ensaio } \\
\hline \multicolumn{2}{|c|}{ Data do ensaio: $29 / 04 / 2015$} & \multicolumn{7}{|c|}{ Amostra: Diluição 1:1 (2,5 kGy) } \\
\hline \multirow{2}{*}{$\begin{array}{c}\text { Bioluminescência } \\
\text { emitida pela } \\
\text { bactéria }\end{array}$} & \multirow[t]{2}{*}{ Controle } & \multicolumn{4}{|c|}{ Concentração (\%) } & $\mathrm{pH}$ & $\underset{\left(m g . L^{-1}\right)}{O}$ & $\begin{array}{c}\text { Cond. } \\
\left(\mu \mathrm{S} . \mathrm{cm}^{-1}\right)\end{array}$ \\
\hline & & 5,11 & 10,23 & 20,47 & 40,95 & \multirow{3}{*}{4,91} & \multirow{3}{*}{8,13} & \multirow{3}{*}{97,53} \\
\hline $\mathrm{I}_{0}$ & 99 & 94 & 96 & 94 & 93 & & & \\
\hline $\mathrm{I}_{15}$ & 125 & 107 & 100 & 71 & 33 & & & \\
\hline \multicolumn{9}{|c|}{$\mathrm{CE}_{15 \mathrm{~min}}: 24,50(19,21-31,25)$} \\
\hline
\end{tabular}


Ensaio 2

\begin{tabular}{|c|c|c|c|c|c|c|c|c|}
\hline \multicolumn{9}{|c|}{ ENSAIOS DE TOXICIDADE AGUDA - Vibrio fischeri $-2^{\circ}$ ensaio } \\
\hline \multicolumn{2}{|c|}{ Data do ensaio: 05/05/2015 } & \multicolumn{7}{|c|}{ Amostra: Diluição 1:1 (2,5 kGy) } \\
\hline \multirow{2}{*}{$\begin{array}{c}\text { Bioluminescência } \\
\text { emitida pela } \\
\text { bactéria }\end{array}$} & \multirow[t]{2}{*}{ Controle } & \multicolumn{4}{|c|}{ Concentração (\%) } & $\mathrm{pH}$ & $\mathrm{OD}^{-1}$ & Cond. \\
\hline & & 5,11 & 10,23 & 20,47 & 40,95 & \multirow{3}{*}{ 4,91 } & \multirow{3}{*}{8,13} & \multirow{3}{*}{97,53} \\
\hline $\mathrm{I}_{0}$ & 103 & 105 & 100 & 94 & 93 & & & \\
\hline$I_{15}$ & 105 & 99 & 89 & 65 & 27 & & & \\
\hline & & & & 18 & & & & \\
\hline
\end{tabular}

Ensaio 3

\begin{tabular}{|c|c|c|c|c|c|c|c|c|}
\hline \multicolumn{9}{|c|}{ ENSAIOS DE TOXICIDADE AGUDA - Vibrio fischeri - $3^{\circ}$ ensaio } \\
\hline \multicolumn{2}{|c|}{ Data do ensaio: $05 / 05 / 2015$} & \multicolumn{7}{|c|}{ Amostra: Diluição 1:1 (2,5 kGy) } \\
\hline $\begin{array}{l}\text { Bioluminescência } \\
\text { emitida pela }\end{array}$ & Controle & \multicolumn{4}{|c|}{ Concentração (\%) } & $\mathrm{pH}$ & OD & Cond. \\
\hline & & 5,11 & 10,23 & 20,47 & 40,95 & \multirow{3}{*}{4,91} & \multirow{3}{*}{8,13} & \multirow{3}{*}{97,53} \\
\hline $\mathrm{I}_{0}$ & 103 & 95 & 92 & 100 & 98 & & & \\
\hline $\mathrm{l}_{15}$ & 105 & 94 & 84 & 68 & 24 & & & \\
\hline & & CE5 & $=$ & $(21$ & 31. & & & \\
\hline
\end{tabular}

Ensaio 4

\begin{tabular}{|c|c|c|c|c|c|c|c|c|}
\hline \multicolumn{9}{|c|}{ ENSAIOS DE TOXICIDADE AGUDA - Vibrio fischeri - $4^{\circ}$ ensaio } \\
\hline \multicolumn{2}{|c|}{ Data do ensaio: 16/06/2015 } & \multicolumn{7}{|c|}{ Amostra: Diluição 1:1 (2,5 kGy) } \\
\hline $\begin{array}{c}\text { Bioluminescência } \\
\text { emitida pela }\end{array}$ & Controle & \multicolumn{4}{|c|}{ Concentração (\%) } & $\mathrm{pH}$ & $\frac{\mathrm{OD}}{\left(\mathrm{mg}^{-1} \mathrm{~L}^{-1}\right)}$ & $\begin{array}{l}\text { Cond. } \\
\left(\mathrm{uS} \mathrm{cm}^{-1}\right)\end{array}$ \\
\hline & & 5,11 & 10,23 & 20,47 & 40,95 & \multirow{3}{*}{4,91} & \multirow{3}{*}{8,13} & \multirow{3}{*}{97,53} \\
\hline $\mathrm{I}_{0}$ & 96 & 92 & 80 & 84 & 86 & & & \\
\hline$I_{15}$ & 114 & 85 & 74 & 58 & 23 & & & \\
\hline
\end{tabular}

Ensaio 5

\begin{tabular}{|c|c|c|c|c|c|c|c|c|}
\hline \multicolumn{9}{|c|}{ ENSAIOS DE TOXICIDADE AGUDA - Vibrio fischeri - $5^{\circ}$ ensaio } \\
\hline \multirow{3}{*}{$\begin{array}{c}\text { Data do ensalo: } 1 \\
\text { Bioluminescência } \\
\text { emitida pela } \\
\text { bactéria }\end{array}$} & \multirow{3}{*}{ Controle } & \multicolumn{7}{|c|}{ Amostra: Diluição 1:1 (2,5 kGy) } \\
\hline & & \multicolumn{4}{|c|}{ Concentração (\%) } & $\mathrm{pH}$ & $\underset{\left(m g \cdot L^{-1}\right)}{O D}$ & $\begin{array}{l}\text { Cond. } \\
\left(\mu S . \mathrm{cm}^{-1}\right)\end{array}$ \\
\hline & & 5,11 & 10,23 & 20,47 & 40,95 & \multirow{3}{*}{4,91} & \multirow{3}{*}{8,13} & \multirow{3}{*}{97,53} \\
\hline $\mathrm{I}_{0}$ & 113 & 93 & 98 & 94 & 95 & & & \\
\hline$I_{15}$ & 124 & 100 & 90 & 68 & 39 & & & \\
\hline & & CE & 7.6 & $(18$ & $45,18)$ & & & \\
\hline
\end{tabular}


Ensaio 6

\begin{tabular}{|c|c|c|c|c|c|c|c|c|}
\hline \multicolumn{9}{|c|}{ ENSAIOS DE TOXICIDADE AGUDA - Vibrio fischeri - 60 ensaio } \\
\hline \multirow{3}{*}{$\begin{array}{c}\text { Data do ensalo: } 2 \\
\text { Bioluminescência } \\
\text { emitida pela } \\
\text { bactéria }\end{array}$} & \multirow{3}{*}{ Controle } & \multicolumn{7}{|c|}{ Amostra: Diluição 1:1 (2,5 kGy) } \\
\hline & & \multicolumn{4}{|c|}{ Concentração (\%) } & $\mathrm{pH}$ & $\frac{O D}{\left(m g \cdot L^{-1}\right)}$ & $\begin{array}{l}\text { Cond. } \\
\left(\mu \mathrm{S} . \mathrm{cm}^{-1}\right)\end{array}$ \\
\hline & & 5,11 & 10,23 & 20,47 & 40,95 & \multirow{3}{*}{ 4,91 } & \multirow{3}{*}{8,13} & \multirow{3}{*}{97,53} \\
\hline $\mathrm{I}_{0}$ & 95 & 104 & 108 & 101 & 109 & & & \\
\hline $\mathrm{I}_{15}$ & 124 & 124 & 113 & 83 & 33 & & & \\
\hline
\end{tabular}

Ensaio 7

\begin{tabular}{|c|c|c|c|c|c|c|c|c|}
\hline \multicolumn{9}{|c|}{ ENSAIOS DE TOXICIDADE AGUDA - Vibrio fischeri - $7^{\circ}$ ensaio } \\
\hline \multicolumn{2}{|c|}{ Data do ensaio: $13 / 08 / 2015$} & \multicolumn{7}{|c|}{ Amostra: Diluição 1:1 (2,5 kGy) } \\
\hline $\begin{array}{l}\text { Bioluminescência } \\
\text { emitida pela }\end{array}$ & Controle & \multicolumn{4}{|c|}{ Concentração (\%) } & $\mathrm{pH}$ & $\mathrm{OD}$ & $\begin{array}{l}\text { Cond. } \\
\left(\mu \mathrm{S} . \mathrm{cm}^{-1}\right)\end{array}$ \\
\hline & & 5,11 & 10,23 & 20,47 & 40,95 & \multirow{3}{*}{4,91} & \multirow{3}{*}{8,13} & \multirow{3}{*}{97,53} \\
\hline $\mathrm{I}_{0}$ & 102 & 94 & 97 & 96 & 99 & & & \\
\hline $\mathrm{I}_{15}$ & 88 & 75 & 72 & 57 & 28 & & & \\
\hline & & CE5 & ר. & 22, & $39,47)$ & & & \\
\hline
\end{tabular}

Ensaio 8

\begin{tabular}{|c|c|c|c|c|c|c|c|c|}
\hline \multicolumn{9}{|c|}{ ENSAIOS DE TOXICIDADE AGUDA - Vibrio fischeri - $8^{\circ}$ ensaio } \\
\hline \multicolumn{2}{|c|}{ Data do ensaio: $13 / 08 / 2015$} & \multicolumn{7}{|c|}{ Amostra: Diluição 1:1 (2,5 kGy) } \\
\hline $\begin{array}{l}\text { Bioluminescência } \\
\text { emitida pela }\end{array}$ & Controle & \multicolumn{4}{|c|}{ Concentração (\%) } & $\mathrm{pH}$ & $\underset{\left(m g \cdot L^{-1}\right)}{O D}$ & $\begin{array}{l}\text { Cond. } \\
\left(\mu \mathrm{S} . \mathrm{cm}^{-1}\right)\end{array}$ \\
\hline & & 5,11 & 10,23 & 20,47 & 40,95 & \multirow{3}{*}{4,91} & \multirow{3}{*}{8,13} & \multirow{3}{*}{97,53} \\
\hline$I_{0}$ & 103 & 98 & 102 & 89 & 98 & & & \\
\hline$l_{15}$ & 116 & 90 & 81 & 48 & 15 & & & \\
\hline \multicolumn{9}{|c|}{$\mathrm{CE}_{15 \mathrm{~min}}: 15,47(10,23-23,40)$} \\
\hline
\end{tabular}

Ensaio 9

\begin{tabular}{|c|c|c|c|c|c|c|c|c|}
\hline \multicolumn{9}{|c|}{ ENSAIOS DE TOXICIDADE AGUDA - Vibrio fischeri - 9 ensaio } \\
\hline \multicolumn{2}{|c|}{ Data do ensaio: $24 / 08 / 2015$} & \multicolumn{7}{|c|}{ Amostra: Diluição 1:1 (2,5 kGy) } \\
\hline $\begin{array}{l}\text { Bioluminescência } \\
\text { emitida pela }\end{array}$ & Controle & \multicolumn{4}{|c|}{ Concentração (\%) } & $\mathrm{pH}$ & $\mathrm{OD}^{-1}$ & Cond. \\
\hline & & 5,11 & 10,23 & 20,47 & 40,95 & \multirow{3}{*}{4,91} & \multirow{3}{*}{8,13} & \multirow{3}{*}{97,53} \\
\hline $\mathrm{I}_{0}$ & 100 & 97 & 93 & 93 & 94 & & & \\
\hline$I_{15}$ & 141 & 121 & 82 & 20 & & & & \\
\hline \multicolumn{9}{|c|}{ CE50 $15 \min : 18,84(12,03-29,49)$} \\
\hline
\end{tabular}




\section{(5,0 kGy)}

Ensaios de toxicidade aguda com as soluções preparadas a partir da Diluição 1:1

Ensaio 1

\begin{tabular}{|c|c|c|c|c|c|c|c|c|}
\hline \multicolumn{9}{|c|}{ ENSAIOS DE TOXICIDADE AGUDA - Vibrio fischeri - $1^{\circ}$ ensaio } \\
\hline \multicolumn{2}{|c|}{ Data do ensaio: $29 / 04 / 2015$} & \multicolumn{7}{|c|}{ Amostra: Diluição 1:1 (5,0 kGy) } \\
\hline $\begin{array}{l}\text { Bioluminescência } \\
\text { emitida pela }\end{array}$ & Controle & \multicolumn{4}{|c|}{ Concentração (\%) } & $\mathrm{pH}$ & $\mathrm{OD}$ & $\begin{array}{l}\text { Cond. } \\
\left(\mu \mathrm{S} . \mathrm{cm}^{-1}\right)\end{array}$ \\
\hline & & 5,11 & 10,23 & 20,47 & 40,95 & \multirow{3}{*}{4,30} & \multirow{3}{*}{8,08} & \multirow{3}{*}{199,87} \\
\hline $\mathrm{I}_{0}$ & 88 & 95 & 92 & 93 & 97 & & & \\
\hline $\mathrm{I}_{15}$ & 113 & 117 & 109 & 90 & 51 & & & \\
\hline \multicolumn{9}{|c|}{$\mathrm{CE}_{150_{\text {min }}: 36,62(27,14-49,43)}$} \\
\hline
\end{tabular}

Ensaio 2

\begin{tabular}{|c|c|c|c|c|c|c|c|c|}
\hline \multicolumn{9}{|c|}{ ENSAIOS DE TOXICIDADE AGUDA - Vibrio fischeri - $2^{\circ}$ ensaio } \\
\hline \multicolumn{2}{|c|}{ Data do ensaio: 05/05/2015 } & \multicolumn{7}{|c|}{ Amostra: Diluição 1:1 (5,0 kGy) } \\
\hline $\begin{array}{c}\text { Bioluminescência } \\
\text { emitida pela }\end{array}$ & Controle & \multicolumn{4}{|c|}{ Concentração (\%) } & $\mathrm{pH}$ & $\mathrm{OD}_{\left(\mathrm{mg}^{-1}\right)}$ & $\begin{array}{l}\text { Cond. } \\
\left(\mathrm{uS} \mathrm{cm}^{-1}\right)\end{array}$ \\
\hline & & 5,11 & 10,23 & 20,47 & 40,95 & \multirow{3}{*}{4,30} & \multirow{3}{*}{8,08} & \multirow{3}{*}{199,87} \\
\hline $\mathrm{I}_{0}$ & 112 & 108 & 105 & 96 & 95 & & & \\
\hline $\mathrm{I}_{15}$ & 117 & 109 & 98 & 73 & 28 & & & \\
\hline \multicolumn{9}{|c|}{$\mathrm{CE}_{50}{ }_{15 \min }=28,70(21,68-38,00$} \\
\hline
\end{tabular}

Ensaio 3

\begin{tabular}{|c|c|c|c|c|c|c|c|c|}
\hline \multicolumn{9}{|c|}{ ENSAIOS DE TOXICIDADE AGUDA - Vibrio fischeri - $3^{\circ}$ ensaio } \\
\hline \multicolumn{2}{|c|}{ Data do ensaio: 05/05/2015 } & \multicolumn{7}{|c|}{ Amostra: Diluição 1:1 (5,0 kGy) } \\
\hline $\begin{array}{l}\text { Bioluminescência } \\
\text { emitida pela }\end{array}$ & Controle & \multicolumn{4}{|c|}{ Concentração (\%) } & $\mathrm{pH}$ & $\left.\mathrm{OD}_{(\mathrm{mal}}^{-1}\right)$ & $\begin{array}{l}\text { Cond. } \\
\left(u \mathrm{~cm}^{-1}\right)\end{array}$ \\
\hline & & 5,11 & 10,23 & 20,47 & 40,95 & \multirow{3}{*}{4,30} & \multirow{3}{*}{8,08} & \multirow{3}{*}{199,87} \\
\hline $\mathrm{I}_{0}$ & 106 & 106 & 108 & 108 & 88 & & & \\
\hline $\mathrm{I}_{15}$ & 128 & 121 & 107 & 79 & 37 & & & \\
\hline \multicolumn{9}{|c|}{$\mathrm{CE} 0_{15 \min }=27,11(24,49-30,02)$} \\
\hline
\end{tabular}

Ensaio 4

\begin{tabular}{|c|c|c|c|c|c|c|c|c|}
\hline \multicolumn{9}{|c|}{ ENSAIOS DE TOXICIDADE AGUDA - Vibrio fischeri - $4^{\circ}$ ensaio } \\
\hline \multicolumn{2}{|c|}{ Data do ensaio: 10/06/2015 } & \multicolumn{7}{|c|}{ Amostra: Diluição 1:1 (5,0 kGy) } \\
\hline $\begin{array}{l}\text { Bioluminescência } \\
\text { emitida pela }\end{array}$ & Controle & \multicolumn{4}{|c|}{ Concentração (\%) } & $\mathrm{pH}$ & OD & Cond. \\
\hline & & 5,11 & 10,23 & 20,47 & 40,95 & \multirow{3}{*}{4,30} & \multirow{3}{*}{8,08} & \multirow{3}{*}{199,87} \\
\hline $\mathrm{I}_{0}$ & 93 & 90 & 78 & 98 & 98 & & & \\
\hline $\mathrm{I}_{15}$ & 110 & 65 & 70 & 61 & 32 & & & \\
\hline & & $\overline{\mathrm{CE}}$ & & 19 & 36 & & & \\
\hline
\end{tabular}


Ensaio 5

\begin{tabular}{|c|c|c|c|c|c|c|c|c|}
\hline \multicolumn{9}{|c|}{ ENSAIOS DE TOXICIDADE AGUDA - Vibrio fischeri - 50 ensaio } \\
\hline \multirow{3}{*}{$\begin{array}{c}\text { Data do ensaio: } 1 \\
\text { Bioluminescência } \\
\text { emitida pela } \\
\text { bactéria }\end{array}$} & \multirow{3}{*}{ Controle } & \multicolumn{7}{|c|}{ Amostra: Diluição 1:1 (5,0 kGy) } \\
\hline & & \multicolumn{4}{|c|}{ Concentração (\%) } & $\mathrm{pH}$ & $\underset{\left(m g \cdot L^{-1}\right)}{O D}$ & $\begin{array}{l}\text { Cond. } \\
\left(\mu \mathrm{S} . \mathrm{cm}^{-1}\right)\end{array}$ \\
\hline & & 5,11 & 10,23 & 20,47 & 40,95 & \multirow{3}{*}{4,30} & \multirow{3}{*}{8,08} & \multirow{3}{*}{199,87} \\
\hline $\mathrm{I}_{0}$ & 113 & 96 & 97 & 86 & 92 & & & \\
\hline$I_{15}$ & 124 & 102 & 95 & 75 & 44 & & & \\
\hline \multicolumn{9}{|c|}{ CE50 $_{15 \min }: 38,67(30,02-49,04)$} \\
\hline
\end{tabular}

\section{Ensaio 6}

\begin{tabular}{|c|c|c|c|c|c|c|c|c|}
\hline \multicolumn{9}{|c|}{ ENSAIOS DE TOXICIDADE AGUDA - Vibrio fischeri - 6 ensaio } \\
\hline \multicolumn{2}{|c|}{ Data do ensaio: 16/06/2015 } & \multicolumn{7}{|c|}{ Amostra: Diluição 1:1 (5,0 kGy) } \\
\hline $\begin{array}{l}\text { Bioluminescência } \\
\text { emitida pela }\end{array}$ & Controle & \multicolumn{4}{|c|}{ Concentração (\%) } & $\mathrm{pH}$ & OD & $\begin{array}{l}\text { Cond. } \\
\left(u \mathrm{~cm}^{-1}\right)\end{array}$ \\
\hline & & 5,11 & 10,23 & 20,47 & 40,95 & \multirow{3}{*}{4,30} & \multirow{3}{*}{8,08} & \multirow{3}{*}{199,87} \\
\hline $\mathrm{I}_{0}$ & 98 & 95 & 81 & 94 & 91 & & & \\
\hline$l_{15}$ & 124 & 108 & 90 & 89 & 41 & & & \\
\hline \multicolumn{9}{|c|}{ :34,77 $(20,61-58,64)$} \\
\hline
\end{tabular}

Ensaio 7

\begin{tabular}{|c|c|c|c|c|c|c|c|c|}
\hline \multicolumn{9}{|c|}{ ENSAIOS DE TOXICIDADE AGUDA - Vibrio fischeri - $7^{\circ}$ ensaio } \\
\hline \multicolumn{2}{|c|}{ Data do ensaio: $23 / 06 / 2015$} & \multicolumn{7}{|c|}{ Amostra: Diluição 1:1 (5,0 kGy) } \\
\hline $\begin{array}{l}\text { Bioluminescência } \\
\text { emitida pela }\end{array}$ & Controle & \multicolumn{4}{|c|}{ Concentração (\%) } & $\mathrm{pH}$ & $\begin{array}{c}\mathrm{OD} \\
\left(\mathrm{mg}^{-1} \mathrm{~L}^{-1}\right)\end{array}$ & $\begin{array}{l}\text { Cond. } \\
\left(\mu S . \mathrm{cm}^{-1}\right)\end{array}$ \\
\hline & & 5,11 & 10,23 & 20,47 & 40,95 & \multirow{3}{*}{4,30} & \multirow{3}{*}{8,08} & \multirow{3}{*}{199,87} \\
\hline$I_{0}$ & 95 & 109 & 95 & 112 & 100 & & & \\
\hline$l_{15}$ & 124 & 134 & 118 & 107 & 42 & & & \\
\hline \multicolumn{9}{|c|}{$\mathrm{CE}{ }_{15 \mathrm{~min}}: 33,22(15,15-72,84)$} \\
\hline
\end{tabular}

Ensaio 8

\begin{tabular}{|c|c|c|c|c|c|c|c|c|}
\hline \multicolumn{9}{|c|}{ ENSAIOS DE TOXICIDADE AGUDA - Vibrio fischeri $-8^{\circ}$ ensaio } \\
\hline \multicolumn{2}{|c|}{ Data do ensaio: $17 / 08 / 2015$} & \multicolumn{7}{|c|}{ Amostra: Diluição 1:1 (5,0 kGy) } \\
\hline $\begin{array}{l}\text { Bioluminescência } \\
\text { emitida pela }\end{array}$ & Controle & \multicolumn{4}{|c|}{ Concentração (\%) } & $\mathrm{pH}$ & $\mathrm{OD}^{-1}$ & Cond. \\
\hline & & 5,11 & 10,23 & 20,47 & 40,95 & \multirow{3}{*}{4,30} & \multirow{3}{*}{8,08} & \multirow{3}{*}{199,87} \\
\hline $\mathrm{I}_{0}$ & 100 & 94 & 80 & 96 & 98 & & & \\
\hline $\mathrm{I}_{15}$ & 115 & 106 & 91 & 79 & 29 & & & \\
\hline \multicolumn{9}{|c|}{$\mathrm{CE} 0_{15 \min }: 31,45(8,65-114,25)$} \\
\hline
\end{tabular}


Ensaio 9

\begin{tabular}{|c|c|c|c|c|c|c|c|c|}
\hline \multicolumn{9}{|c|}{ ENSAIOS DE TOXICIDADE AGUDA - Vibrio fischeri - $9^{\circ}$ ensaio } \\
\hline \multicolumn{2}{|c|}{ Data do ensaio: $24 / 08 / 2015$} & \multicolumn{7}{|c|}{ Amostra: Diluição 1:1 (5,0 kGy) } \\
\hline \multirow{2}{*}{$\begin{array}{c}\text { Bioluminescência } \\
\text { emitida pela } \\
\text { bactéria }\end{array}$} & \multirow[t]{2}{*}{ Controle } & \multicolumn{4}{|c|}{ Concentração (\%) } & $\mathrm{pH}$ & $\mathrm{OD}^{-1}$ & $\begin{array}{l}\text { Cond. } \\
\left.\text { (uS } \mathrm{cm}^{-1}\right)\end{array}$ \\
\hline & & 5,11 & 10,23 & 20,47 & 40,95 & \multirow{3}{*}{4,30} & \multirow{3}{*}{8,08} & \multirow{3}{*}{199,87} \\
\hline $\mathrm{I}_{0}$ & 100 & 96 & 96 & 100 & 98 & & & \\
\hline$I_{15}$ & 160 & 149 & 145 & 117 & 45 & & & \\
\hline & & CE5 & & & & & & \\
\hline
\end{tabular}
(7,5 kGy)

Ensaios de toxicidade aguda com as soluções preparadas a partir da Diluição 1:1

\section{Ensaio 1}

\begin{tabular}{|c|c|c|c|c|c|c|c|c|}
\hline \multicolumn{9}{|c|}{ ENSAIOS DE TOXICIDADE AGUDA - Vibrio fischeri - $1^{\circ}$ ensaio } \\
\hline \multirow{3}{*}{$\begin{array}{c}\text { Data do ensaio: } \\
\text { Bioluminescência } \\
\text { emitida pela } \\
\text { bactéria }\end{array}$} & \multirow{3}{*}{ Controle } & \multicolumn{7}{|c|}{ Amostra: Diluição 1:1 (7,5 kGy) } \\
\hline & & \multicolumn{4}{|c|}{ Concentração (\%) } & $\mathrm{pH}$ & $\frac{\mathrm{OD}}{\left(m \mathrm{~m} \cdot \mathrm{L}^{-1}\right)}$ & $\begin{array}{l}\text { Cond. } \\
\left(\mu \mathrm{uS} . \mathrm{cm}^{-1}\right)\end{array}$ \\
\hline & & 5,11 & 10,23 & 20,47 & 40,95 & \multirow{3}{*}{4,08} & \multirow{3}{*}{8,15} & \multirow{3}{*}{136,27} \\
\hline $\mathrm{I}_{0}$ & 100 & 95 & 97 & 88 & 78 & & & \\
\hline $\mathrm{I}_{15}$ & 128 & 117 & 112 & 86 & 34 & & & \\
\hline & & UL & & 130 & 44,5 & & & \\
\hline
\end{tabular}

Ensaio 2

\begin{tabular}{|c|c|c|c|c|c|c|c|c|}
\hline \multicolumn{9}{|c|}{ ENSAIOS DE TOXICIDADE AGUDA - Vibrio fischeri - $2^{\circ}$ ensaio } \\
\hline \multirow{3}{*}{$\begin{array}{c}\text { Bata do ensalo: } \\
\text { emitida pela } \\
\text { bactéria }\end{array}$} & $5 / 2015$ & \multicolumn{7}{|c|}{ Amostra: Diluição 1:1 (7,5 kGy) } \\
\hline & \multirow[t]{2}{*}{ Controle } & \multicolumn{4}{|c|}{ Concentração (\%) } & $\mathrm{pH}$ & $\mathrm{OD}$ & Cond. \\
\hline & & 5,11 & 10,23 & 20,47 & 40,95 & \multirow{3}{*}{4,08} & \multirow{3}{*}{8,15} & \multirow{3}{*}{136,27} \\
\hline $\mathrm{I}_{0}$ & 101 & 101 & 98 & 95 & 101 & & & \\
\hline $\mathrm{I}_{15}$ & 124 & 120 & 110 & 83 & 47 & & & \\
\hline \multicolumn{9}{|c|}{$\mathrm{CE} 0_{15 \min }=32,68(28,11-38,00)$} \\
\hline
\end{tabular}

Ensaio 3

\begin{tabular}{|c|c|c|c|c|c|c|c|c|}
\hline \multicolumn{9}{|c|}{ ENSAIOS DE TOXICIDADE AGUDA - Vibrio fischeri $-3^{\circ}$ ensaio } \\
\hline \multirow{3}{*}{$\begin{array}{c}\text { Bioluminescência } \\
\text { emitida pela } \\
\text { bactéria }\end{array}$} & \multirow{3}{*}{ Controle } & \multicolumn{7}{|c|}{ Amostra: Diluição 1:1 (7,5 kGy) } \\
\hline & & \multicolumn{4}{|c|}{ Concentração (\%) } & $\mathrm{pH}$ & $\frac{\mathrm{OD}}{\left(\mathrm{mg}^{-1} \mathrm{~L}^{-1}\right)}$ & $\begin{array}{l}\text { Cond. } \\
\left(\mu S . \mathrm{cm}^{-1}\right)\end{array}$ \\
\hline & & 5,11 & 10,23 & 20,47 & 40,95 & \multirow{3}{*}{4,08} & \multirow{3}{*}{8,15} & \multirow{3}{*}{136,27} \\
\hline $\mathrm{I}_{0}$ & 98 & 98 & 101 & 97 & 89 & & & \\
\hline $\mathrm{I}_{15}$ & 122 & 114 & 100 & 78 & 38 & & & \\
\hline & & CES & $1=2$ & $5(23$, & $-32,49)$ & & & \\
\hline
\end{tabular}


Ensaio 4

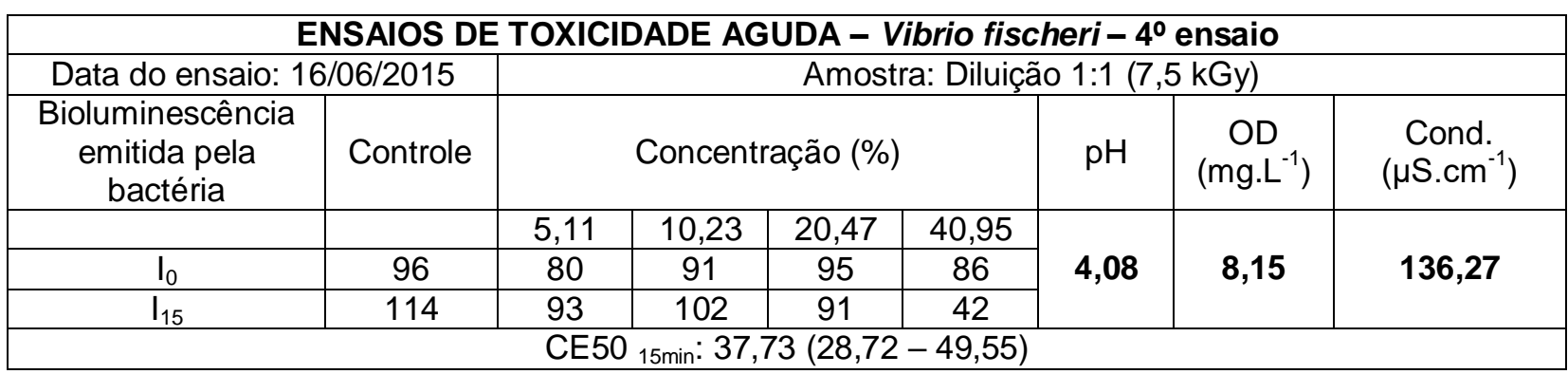

Ensaio 5

\begin{tabular}{|c|c|c|c|c|c|c|c|c|}
\hline \multicolumn{9}{|c|}{ ENSAIOS DE TOXICIDADE AGUDA - Vibrio fischeri - $5^{\circ}$ ensaio } \\
\hline \multicolumn{2}{|c|}{ Data do ensaio: $16 / 06 / 2015$} & \multicolumn{7}{|c|}{ Amostra: Diluição 1:1 (7,5 kGy) } \\
\hline \multirow{2}{*}{$\begin{array}{c}\text { Bioluminescência } \\
\text { emitida pela } \\
\text { bactéria }\end{array}$} & \multirow[t]{2}{*}{ Controle } & \multicolumn{4}{|c|}{ Concentração (\%) } & $\mathrm{pH}$ & $\mathrm{OD}_{\left(\mathrm{mg}^{-1}\right)}$ & $\begin{array}{l}\text { Cond. } \\
\left(\mu \mathrm{S} . \mathrm{cm}^{-1}\right)\end{array}$ \\
\hline & & 5,11 & 10,23 & 20,47 & 40,95 & \multirow{3}{*}{4,08} & \multirow{3}{*}{8,15} & \multirow{3}{*}{136,27} \\
\hline $\mathrm{I}_{0}$ & 106 & 92 & 98 & 102 & 96 & & & \\
\hline $\mathrm{I}_{15}$ & 115 & 99 & 104 & 96 & 53 & & & \\
\hline & & $\mathrm{CE}$ & :4 & $(31$, & $62,43)$ & & & \\
\hline
\end{tabular}

Ensaio 6

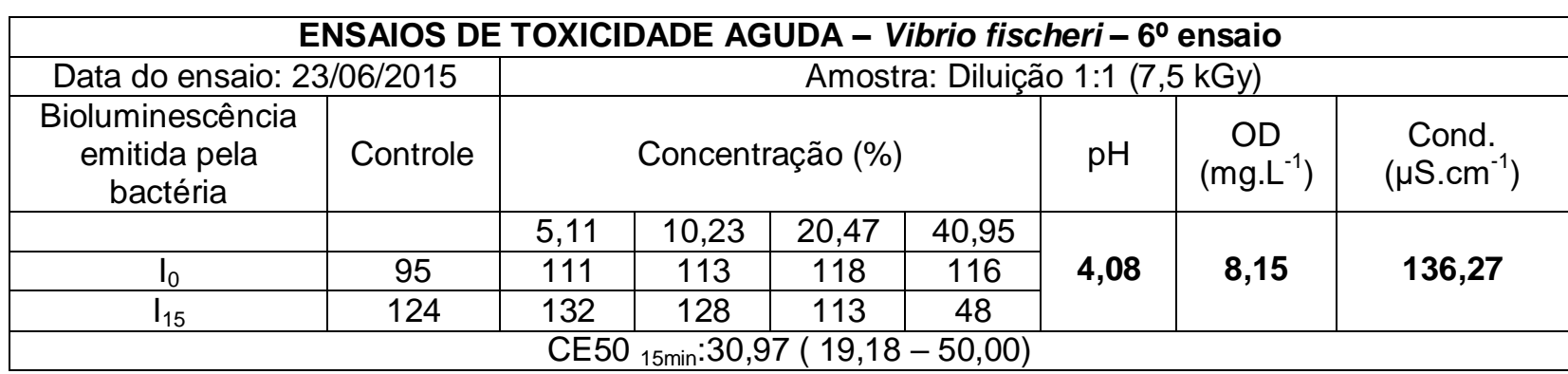

Ensaio 7

\begin{tabular}{|c|c|c|c|c|c|c|c|c|}
\hline \multicolumn{9}{|c|}{ ENSAIOS DE TOXICIDADE AGUDA - Vibrio fischeri - $7^{\circ}$ ensaio } \\
\hline \multirow{3}{*}{$\begin{array}{c}\text { Data do ensalo: } 1 \\
\text { Bioluminescência } \\
\text { emitida pela } \\
\text { bactéria }\end{array}$} & 88/2015 & & & Amos & : Diluiç & 1:1(7 & kGy) & \\
\hline & \multirow[t]{2}{*}{ Controle } & \multicolumn{4}{|c|}{ Concentração (\%) } & $\mathrm{pH}$ & $\frac{\mathrm{OD}}{\left(m \mathrm{LL}^{-1}\right)}$ & $\begin{array}{l}\text { Cond. } \\
\left.\text { (uS . } \mathrm{cm}^{-1}\right)\end{array}$ \\
\hline & & 5,11 & 10,23 & 20,47 & 40,95 & \multirow{3}{*}{4,08} & \multirow{3}{*}{8,15} & \multirow{3}{*}{136,27} \\
\hline $\mathrm{I}_{0}$ & 99 & 91 & 93 & 86 & 94 & & & \\
\hline $\mathrm{I}_{15}$ & 99 & 79 & 81 & 63 & 37 & & & \\
\hline & & CE & 0. & 22 & $64,01)$ & & & \\
\hline
\end{tabular}

Ensaio 8

\begin{tabular}{|c|c|c|c|c|c|c|c|c|}
\hline \multicolumn{9}{|c|}{ ENSAIOS DE TOXICIDADE AGUDA - Vibrio fischeri - $8^{\circ}$ ensaio } \\
\hline \multicolumn{2}{|c|}{ Data do ensaio: $17 / 08 / 2015$} & \multicolumn{7}{|c|}{ Amostra: Diluição 1:1 (7,5 kGy) } \\
\hline $\begin{array}{l}\text { Bioluminescência } \\
\text { emitida pela }\end{array}$ & Controle & \multicolumn{4}{|c|}{ Concentração (\%) } & $\mathrm{pH}$ & $\frac{O D}{\left(m a \cdot L^{-1}\right)}$ & $\begin{array}{l}\text { Cond. } \\
\left(\mu S \mathrm{~cm}^{-1}\right)\end{array}$ \\
\hline & & 5,11 & 10,23 & 20,47 & 40,95 & \multirow{3}{*}{4,08} & \multirow{3}{*}{8,15} & \multirow{3}{*}{136,27} \\
\hline $\mathrm{I}_{0}$ & 100 & 86 & 93 & 100 & 101 & & & \\
\hline $\mathrm{I}_{15}$ & 115 & 97 & 99 & 79 & 26 & & & \\
\hline \multicolumn{9}{|c|}{$\mathrm{CE}_{150_{\mathrm{min}}: 26,43(21,22-32,91)}$} \\
\hline
\end{tabular}


Ensaio 9

\begin{tabular}{|c|c|c|c|c|c|c|c|c|}
\hline \multicolumn{9}{|c|}{ ENSAIOS DE TOXICIDADE AGUDA - Vibrio fischeri - $9^{\circ}$ ensaio } \\
\hline \multicolumn{2}{|c|}{ Data do ensaio: $24 / 08 / 2015$} & \multicolumn{7}{|c|}{ Amostra: Diluição 1:1 (7,5 kGy) } \\
\hline \multirow{2}{*}{$\begin{array}{c}\text { Bioluminescência } \\
\text { emitida pela } \\
\text { bactéria }\end{array}$} & \multirow[t]{2}{*}{ Controle } & \multicolumn{4}{|c|}{ Concentração (\%) } & $\mathrm{pH}$ & $\mathrm{OD}^{-1}$ & $\begin{array}{l}\text { Cond. } \\
\left.\text { (uS } \mathrm{cm}^{-1}\right)\end{array}$ \\
\hline & & 5,11 & 10,23 & 20,47 & 40,95 & \multirow{3}{*}{4,08} & \multirow{3}{*}{8,15} & \multirow{3}{*}{136,27} \\
\hline $\mathrm{I}_{0}$ & 100 & 106 & 99 & 99 & 102 & & & \\
\hline$I_{15}$ & 160 & 164 & 151 & 114 & 23 & & & \\
\hline & & & & & & & & \\
\hline
\end{tabular}
(10,0 kGy)

Ensaios de toxicidade aguda com as soluções preparadas a partir da Diluição 1:1

Ensaio 1

\begin{tabular}{|c|c|c|c|c|c|c|c|c|}
\hline \multicolumn{9}{|c|}{ ENSAIOS DE TOXICIDADE AGUDA - Vibrio fischeri - $1^{\circ}$ ensaio } \\
\hline \multicolumn{2}{|c|}{ Data do ensaio: $05 / 05 / 2015$} & \multicolumn{7}{|c|}{ Amostra: Diluição 1:1 (10,0 kGy) } \\
\hline $\begin{array}{l}\text { Bioluminescência } \\
\text { emitida pela }\end{array}$ & Controle & \multicolumn{4}{|c|}{ Concentração (\%) } & $\mathrm{pH}$ & $\mathrm{OD}^{-1}$ & $\begin{array}{l}\text { Cond. } \\
\left(u \mathrm{~cm}^{-1}\right)\end{array}$ \\
\hline & & 5,11 & 10,23 & 20,47 & 40,95 & \multirow{3}{*}{3,91} & \multirow{3}{*}{8,15} & \multirow{3}{*}{165,73} \\
\hline $\mathrm{I}_{0}$ & 94 & 91 & 92 & 88 & 101 & & & \\
\hline $\mathrm{I}_{15}$ & 117 & 108 & 99 & 81 & 29 & & & \\
\hline \multicolumn{9}{|c|}{$\mathrm{CE} 0_{15 \min }=26,53(16,48-42,71)$} \\
\hline
\end{tabular}

Ensaio 2

\begin{tabular}{|c|c|c|c|c|c|c|c|c|}
\hline \multicolumn{9}{|c|}{ ENSAIOS DE TOXICIDADE AGUDA - Vibrio fischeri - $2^{\circ}$ ensaio } \\
\hline \multicolumn{2}{|c|}{ Data do ensaio: 05/05/2015 } & \multicolumn{7}{|c|}{ Amostra: Diluição 1:1 (10,0 kGy) } \\
\hline $\begin{array}{l}\text { Bioluminescência } \\
\text { emitida pela }\end{array}$ & Controle & \multicolumn{4}{|c|}{ Concentração (\%) } & $\mathrm{pH}$ & $\frac{\mathrm{OD}}{\left(\mathrm{mg} \cdot \mathrm{L}^{-1}\right)}$ & $\begin{array}{c}\text { Cond. } \\
\left(\mu \mathrm{S}^{-\mathrm{cm}^{-1}}\right)\end{array}$ \\
\hline & & 5,11 & 10,23 & 20,47 & 40,95 & \multirow{3}{*}{3,91} & \multirow{3}{*}{8,15} & \multirow{3}{*}{165,73} \\
\hline $\mathrm{I}_{0}$ & 94 & 96 & 85 & 93 & 95 & & & \\
\hline $\mathrm{I}_{15}$ & 117 & 113 & 98 & 78 & 36 & & & \\
\hline \multicolumn{9}{|c|}{ CE50 $_{15 \min }=29,53(17,67-49,33)$} \\
\hline
\end{tabular}

Ensaio 3

\begin{tabular}{|c|c|c|c|c|c|c|c|c|}
\hline \multicolumn{9}{|c|}{ ENSAIOS DE TOXICIDADE AGUDA - Vibrio fischeri - $3^{\circ}$ ensaio } \\
\hline \multicolumn{2}{|c|}{ Data do ensaio: $16 / 06 / 2015$} & \multicolumn{7}{|c|}{ Amostra: Diluição 1:1 (10,0 kGy) } \\
\hline $\begin{array}{l}\text { Bioluminescência } \\
\text { emitida pela }\end{array}$ & Controle & \multicolumn{4}{|c|}{ Concentração (\%) } & $\mathrm{pH}$ & $\underset{\left(m a \cdot L^{-1}\right)}{O D}$ & $\begin{array}{l}\text { Cond. } \\
\left(\mu \mathrm{S} \mathrm{cm}^{-1}\right)\end{array}$ \\
\hline & & 5,11 & 10,23 & 20,47 & 40,95 & \multirow{3}{*}{3,91} & \multirow{3}{*}{8,15} & \multirow{4}{*}{165,73} \\
\hline $\mathrm{I}_{0}$ & 83 & 98 & 92 & 108 & 91 & & & \\
\hline$l_{15}$ & 104 & 109 & 102 & 99 & 16 & & & \\
\hline \multicolumn{8}{|c|}{ CE50 ${ }_{15 \min }: 22,71(8,41-61,33)$} & \\
\hline
\end{tabular}


Ensaio 4

\begin{tabular}{|c|c|c|c|c|c|c|c|c|}
\hline \multicolumn{9}{|c|}{ ENSAIOS DE TOXICIDADE AGUDA - Vibrio fischeri - $4^{\circ}$ ensaio } \\
\hline \multicolumn{2}{|c|}{ Data do ensaio: $23 / 06 / 2015$} & \multicolumn{7}{|c|}{ Amostra: Diluição 1:1 (10,0 kGy) } \\
\hline \multirow{2}{*}{$\begin{array}{c}\text { Bioluminescência } \\
\text { emitida pela } \\
\text { bactéria }\end{array}$} & \multirow[t]{2}{*}{ Controle } & \multicolumn{4}{|c|}{ Concentração (\%) } & $\mathrm{pH}$ & $\underset{\left(m g \cdot L^{-1}\right)}{O D}$ & $\begin{array}{l}\text { Cond. } \\
\left(\mu \mathrm{S} . \mathrm{cm}^{-1}\right)\end{array}$ \\
\hline & & 5,11 & 10,23 & 20,47 & 40,95 & \multirow{3}{*}{3,91} & \multirow{3}{*}{8,15} & \multirow{3}{*}{165,73} \\
\hline $\mathrm{I}_{0}$ & 95 & 92 & 84 & 110 & 108 & & & \\
\hline$I_{15}$ & 124 & 113 & 105 & 96 & 40 & & & \\
\hline & & & & 2 & & & & \\
\hline
\end{tabular}

Ensaio 5

\begin{tabular}{|c|c|c|c|c|c|c|c|c|}
\hline \multicolumn{9}{|c|}{ ENSAIOS DE TOXICIDADE AGUDA - Vibrio fischeri - $5^{\circ}$ ensaio } \\
\hline \multicolumn{2}{|c|}{ Data do ensaio: $23 / 06 / 2015$} & \multicolumn{7}{|c|}{ Amostra: Diluição 1:1 (10,0 kGy) } \\
\hline $\begin{array}{l}\text { Bioluminescência } \\
\text { emitida pela }\end{array}$ & Controle & \multicolumn{4}{|c|}{ Concentração (\%) } & $\mathrm{pH}$ & $\mathrm{OD}_{\left(\mathrm{mq} \cdot \mathrm{L}^{-1}\right)}$ & $\begin{array}{l}\text { Cond. } \\
\left(\mu \mathrm{S} . \mathrm{cm}^{-1}\right)\end{array}$ \\
\hline & & 5,11 & 10,23 & 20,47 & 40,95 & \multirow{3}{*}{3,91} & \multirow{3}{*}{8,15} & \multirow{3}{*}{165,73} \\
\hline $\mathrm{I}_{0}$ & 98 & 94 & 96 & 85 & 80 & & & \\
\hline $\mathrm{I}_{15}$ & 116 & 104 & 97 & 68 & 12 & & & \\
\hline & & $\mathrm{CE}$ & 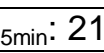 & $(10$, & 41,2 & & & \\
\hline
\end{tabular}

Ensaio 6

\begin{tabular}{|c|c|c|c|c|c|c|c|c|}
\hline \multicolumn{9}{|c|}{ ENSAIOS DE TOXICIDADE AGUDA - Vibrio fischeri - $6^{\circ}$ ensaio } \\
\hline \multicolumn{2}{|c|}{ Data do ensaio: $13 / 08 / 2015$} & \multicolumn{7}{|c|}{ Amostra: Diluição 1:1 (10,0 kGy) } \\
\hline \multirow{2}{*}{$\begin{array}{c}\text { Bioluminescência } \\
\text { emitida pela } \\
\text { bactéria }\end{array}$} & \multirow[t]{2}{*}{ Controle } & \multicolumn{4}{|c|}{ Concentração (\%) } & $\mathrm{pH}$ & $\underset{\left(m g \cdot L^{-1}\right)}{O D}$ & $\begin{array}{l}\text { Cond. } \\
\left(\mu \mathrm{S} . \mathrm{cm}^{-1}\right)\end{array}$ \\
\hline & & 5,11 & 10,23 & 20,47 & 40,95 & \multirow{3}{*}{3,91} & \multirow{3}{*}{8,15} & \multirow{3}{*}{165,73} \\
\hline$I_{0}$ & 99 & 89 & 92 & 92 & 91 & & & \\
\hline$l_{15}$ & 99 & 80 & 80 & 71 & 30 & & & \\
\hline & & $\mathrm{CE}$ & $: 3$ & (18, & 1,4 & & & \\
\hline
\end{tabular}

Ensaio 7

\begin{tabular}{|c|c|c|c|c|c|c|c|c|}
\hline \multicolumn{9}{|c|}{ ENSAIOS DE TOXICIDADE AGUDA - Vibrio fischeri - $7^{\circ}$ ensaio } \\
\hline \multicolumn{2}{|c|}{ Data do ensaio: $17 / 08 / 2015$} & \multicolumn{7}{|c|}{ Amostra: Diluição 1:1 (10,0 kGy) } \\
\hline $\begin{array}{c}\text { Bioluminescência } \\
\text { emitida pela }\end{array}$ & Controle & \multicolumn{4}{|c|}{ Concentração (\%) } & $\mathrm{pH}$ & $\mathrm{OD}^{-1}$ & Cond. \\
\hline & & 5,11 & 10,23 & 20,47 & 40,95 & \multirow{3}{*}{3,91} & \multirow{3}{*}{8,15} & \multirow{3}{*}{165,73} \\
\hline $\mathrm{I}_{0}$ & 100 & 111 & 100 & 85 & 99 & & & \\
\hline $\mathrm{I}_{15}$ & 115 & 117 & 105 & 65 & 12 & & & \\
\hline & & CES & $\min : 2$ & $(7,8$ & $6,37)$ & & & \\
\hline
\end{tabular}

Ensaio 8

ENSAIOS DE TOXICIDADE AGUDA - Vibrio fischeri - 8 ensaio

\begin{tabular}{|c|c|c|c|c|c|c|c|c|}
\hline \multicolumn{9}{|c|}{ ENSAIOS DE TOXICIDADE AGUDA - Vibrio fischeri - $8^{\circ}$ ensaio } \\
\hline \multicolumn{2}{|c|}{ Data do ensaio: $24 / 08 / 2015$} & \multicolumn{7}{|c|}{ Amostra: Diluição 1:1 (10,0 kGy) } \\
\hline $\begin{array}{l}\text { Bioluminescência } \\
\text { emitida pela }\end{array}$ & Controle & \multicolumn{4}{|c|}{ Concentração (\%) } & $\mathrm{pH}$ & $\mathrm{OD}^{-1}$ & Cond. \\
\hline & & 5,11 & 10,23 & 20,47 & 40,95 & \multirow{3}{*}{3,91} & \multirow{3}{*}{8,15} & \multirow{3}{*}{165,73} \\
\hline $\mathrm{I}_{0}$ & 108 & 111 & 111 & 114 & 108 & & & \\
\hline$l_{15}$ & 136 & 130 & 130 & 89 & 17 & & & \\
\hline \multicolumn{9}{|c|}{ CE50 $_{15 \min }: 21,82(8,82-53,96)$} \\
\hline
\end{tabular}


Ensaio 9

\begin{tabular}{|c|c|c|c|c|c|c|c|c|}
\hline \multicolumn{9}{|c|}{ ENSAIOS DE TOXICIDADE AGUDA - Vibrio fischeri - 9 ensaio } \\
\hline \multicolumn{2}{|c|}{ Data do ensaio: $24 / 08 / 2015$} & \multicolumn{7}{|c|}{ Amostra: Diluição 1:1 (10,0 kGy) } \\
\hline \multirow{2}{*}{$\begin{array}{c}\text { Bioluminescência } \\
\text { emitida pela } \\
\text { bactéria }\end{array}$} & \multirow[t]{2}{*}{ Controle } & \multicolumn{4}{|c|}{ Concentração (\%) } & $\mathrm{pH}$ & $\underset{\left(m g \cdot L^{-1}\right)}{O D}$ & $\begin{array}{l}\text { Cond. } \\
\left(\mu S . \mathrm{cm}^{-1}\right)\end{array}$ \\
\hline & & 5,11 & 10,23 & 20,47 & 40,95 & \multirow{3}{*}{3,91} & \multirow{3}{*}{8,15} & \multirow{3}{*}{165,73} \\
\hline $\mathrm{I}_{0}$ & 103 & 90 & 101 & 99 & 83 & & & \\
\hline $\mathrm{I}_{15}$ & 116 & 101 & 101 & 68 & 4 & & & \\
\hline
\end{tabular}

Apêndice B: Fichas - controle de ensaios de toxicidade aguda com Daphnia similis

Ensaios de toxicidade aguda com o soluções preparadas a partir do cloridrato de fluoxetina de $10 \mathrm{mg} \cdot \mathrm{L}^{-1}(0,0 \mathrm{kGy})$

Ensaio 1

\begin{tabular}{|c|c|c|c|c|c|c|c|c|c|c|c|}
\hline \multicolumn{8}{|c|}{ ENSAIO DE TOXICIDADE AGUDA - Daphnia similis } & \multirow{2}{*}{\multicolumn{4}{|c|}{$\begin{array}{c}\text { Dose de radiação: 0,0 kGy } \\
\text { Água de diluição }\end{array}$}} \\
\hline \multicolumn{5}{|c|}{ Início } & \multicolumn{3}{|c|}{ Término } & & & & \\
\hline $\begin{array}{c}\text { Data: } \\
\text { 17/03/2015 }\end{array}$ & \multicolumn{4}{|c|}{$\begin{array}{l}\text { Hora: } \\
14: 20\end{array}$} & $\begin{array}{c}\text { Data: } \\
\text { 19/03/2015 }\end{array}$ & \multicolumn{2}{|c|}{$\begin{array}{l}\text { Hora: } \\
14: 20\end{array}$} & $\begin{array}{r}\text { Dureza } \\
45,0 \mathrm{mg} \\
\end{array}$ & $\begin{array}{l}\text { la água: } \\
\mathrm{CaCO}_{3} \cdot \mathrm{L}^{-1}\end{array}$ & \multicolumn{2}{|c|}{$\begin{array}{l}\text { Manancial: } \\
\text { Salto - SP }\end{array}$} \\
\hline \multicolumn{5}{|c|}{$\begin{array}{c}\text { Organismo-teste: } \\
\text { Daphnia similis }\end{array}$} & \multicolumn{3}{|c|}{$\begin{array}{c}\text { Amostra: } \\
\text { Cloridrato de fluoxetina } \\
(0,0 \mathrm{kGy})\end{array}$} & \multicolumn{4}{|c|}{ Operador: Flávio } \\
\hline & 1 & 2 & 3 & 4 & $\begin{array}{c}\% \text { de } \\
\text { imóveis }\end{array}$ & $\mathrm{pH}_{\mathrm{i}}$ & $\mathrm{pH}_{\mathrm{f}}$ & $\begin{array}{c}O^{O D_{i}} \\
\left(m g \cdot L^{-1}\right)\end{array}$ & $\begin{array}{c}O_{\mathrm{f}} \\
\left(\mathrm{mg} \cdot \mathrm{L}^{-1}\right)\end{array}$ & $\begin{array}{c}\text { Cond }_{\mathrm{i}} \\
\left(\mu \mathrm{S} . \mathrm{cm}^{-1}\right)\end{array}$ & $\begin{array}{c}\text { Cond }_{f} \\
\left(\mu S . \mathrm{cm}^{-1}\right)\end{array}$ \\
\hline Controle & 0 & 0 & 0 & 0 & 0 & 7,00 & 6,84 & 7,51 & 7,52 & 244 & 267 \\
\hline 3,125 & $\mathbf{0}$ & 0 & $\mathbf{0}$ & 0 & 0 & 7,12 & 7,12 & $\mathbf{7 , 4 7}$ & 7,69 & 228 & 228 \\
\hline 6,25 & 0 & 0 & 0 & 0 & 0 & 7,13 & 7,18 & 7,48 & 7,75 & 232 & 233 \\
\hline 12,5 & 5 & 5 & 5 & 4 & 19 & 7,19 & 7,25 & 7,51 & 7,71 & 209,1 & 210,7 \\
\hline 25,0 & 4 & 5 & 5 & 5 & 19 & 7,29 & 7,31 & 7,57 & 7,82 & 181,4 & 183,1 \\
\hline 50,0 & 5 & 5 & 5 & 5 & 20 & 7,38 & 7,45 & 7,69 & 7,93 & 135,0 & 137,9 \\
\hline 75 & 5 & 5 & 5 & 5 & 20 & 7,50 & 7,47 & 7,84 & 7,96 & 76,3 & 78,9 \\
\hline 100 & 5 & 5 & 5 & 5 & 20 & 7,75 & 7,55 & 7,88 & 7,95 & 18,89 & 21,61 \\
\hline
\end{tabular}


Ensaio 2

\begin{tabular}{|c|c|c|c|c|c|c|c|c|c|c|c|}
\hline \multicolumn{8}{|c|}{ ENSAIO DE TOXICIDADE AGUDA - Daphnia similis } & \multirow{2}{*}{\multicolumn{4}{|c|}{$\begin{array}{c}\text { Dose de radiação: } 0,0 \text { kGy } \\
\text { Áqua de diluição }\end{array}$}} \\
\hline \multicolumn{5}{|c|}{ Início } & \multicolumn{3}{|c|}{ Término } & & & & \\
\hline $\begin{array}{c}\text { Data: } \\
07 / 04 / 2015\end{array}$ & & & & & $\begin{array}{c}\text { Data: } \\
09 / 04 / 2015\end{array}$ & & & \multicolumn{2}{|c|}{ Agua } & \multicolumn{2}{|c|}{$\begin{array}{r}\text { Manancial: } \\
\text { Salto - SP }\end{array}$} \\
\hline \multicolumn{5}{|c|}{$\begin{array}{l}\text { Organismo-teste: } \\
\text { Daphnia similis }\end{array}$} & \multicolumn{3}{|c|}{$\begin{array}{c}\text { Amostra: } \\
\text { Cloridrato de fluoxetina } \\
(0,0 \mathrm{kGy})\end{array}$} & \multicolumn{4}{|c|}{ Operador: Flávio } \\
\hline & 1 & 2 & 3 & 4 & $\begin{array}{c}\% \text { de } \\
\text { imóveis }\end{array}$ & $\mathrm{pH}_{\mathrm{i}}$ & $\mathrm{pH}_{\mathrm{f}}$ & $\begin{array}{c}\mathrm{OD}_{\mathrm{i}} \\
\left(\mathrm{mg} \cdot \mathrm{L}^{-1}\right)\end{array}$ & $\begin{array}{c}\mathrm{OD}_{\mathrm{f}} \\
\left(\mathrm{mg} \cdot \mathrm{L}^{-1}\right)\end{array}$ & $\underset{\left(\mu S . \mathrm{cm}^{-1}\right)}{\text { Cond }_{\mathrm{i}}}$ & $\begin{array}{c}\text { Cond }_{f} \\
\left(\mu \text { S.cm }^{-1}\right)\end{array}$ \\
\hline Controle & 0 & 0 & 0 & 0 & 0 & 8,10 & 7,20 & 7,60 & $\mathbf{7 , 7 1}$ & 263 & 285 \\
\hline 3,125 & $\mathbf{0}$ & 0 & 1 & $\mathbf{0}$ & 1 & 7,76 & 7,19 & 7,47 & 7,83 & 227 & 231 \\
\hline 6,25 & 1 & 2 & 1 & 0 & 4 & $\mathbf{7 , 7 8}$ & 7,19 & 7,45 & 7,87 & 231 & 232 \\
\hline 12,5 & 3 & 5 & 4 & 5 & 17 & 7,85 & 7,22 & 7,44 & 7,84 & 230 & 234 \\
\hline 25,0 & 5 & 4 & 5 & 5 & 19 & 7,88 & 7,29 & 7,46 & 7,80 & 228 & 231 \\
\hline 50,0 & 5 & 4 & 4 & 4 & 17 & 7,90 & 7,32 & 7,47 & 7,76 & 221 & 225 \\
\hline 100 & 5 & 5 & 5 & 4 & 19 & 7,92 & 7,35 & 7,48 & 7,75 & 211,2 & 218,7 \\
\hline
\end{tabular}

Ensaio 3

\begin{tabular}{|c|c|c|c|c|c|c|c|c|c|c|c|}
\hline \multicolumn{8}{|c|}{ ENSAIO DE TOXICIDADE AGUDA - Daphnia similis } & \multirow{2}{*}{\multicolumn{4}{|c|}{$\begin{array}{c}\text { Dose de radiação: 0,0 kGy } \\
\text { Água de diluição }\end{array}$}} \\
\hline \multicolumn{5}{|c|}{ Início } & \multicolumn{3}{|c|}{ Término } & & & & \\
\hline $\begin{array}{c}\text { Data: } \\
\text { 28/04/2015 }\end{array}$ & \multicolumn{4}{|c|}{$\begin{array}{l}\text { Hora: } \\
\text { 14:00 }\end{array}$} & $\begin{array}{c}\text { Data: } \\
30 / 04 / 2015\end{array}$ & \multicolumn{2}{|c|}{$\begin{array}{l}\text { Hora: } \\
\text { 14:00 }\end{array}$} & $\begin{array}{r}\text { Dureza } \\
45,0 \mathrm{mg}\end{array}$ & $\begin{array}{l}\text { la água: } \\
\mathrm{ACO}_{3} \cdot \mathrm{L}^{-1}\end{array}$ & \multicolumn{2}{|c|}{$\begin{array}{l}\text { Manancial: } \\
\text { Salto - SP }\end{array}$} \\
\hline \multicolumn{5}{|c|}{$\begin{array}{l}\text { Organismo-teste: } \\
\text { Daphnia similis }\end{array}$} & \multicolumn{3}{|c|}{$\begin{array}{c}\text { Amostra: } \\
\text { Cloridrato de fluoxetina } \\
(0,0 \mathrm{kGy})\end{array}$} & \multicolumn{4}{|c|}{ Operador: Flávio } \\
\hline & 1 & 2 & 3 & 4 & $\begin{array}{c}\% \text { de } \\
\text { imóveis }\end{array}$ & $\mathrm{pH}_{\mathrm{i}}$ & $\mathrm{pH}_{\mathrm{f}}$ & $\begin{array}{c}\mathrm{OD}_{\mathrm{i}} \\
\left(\mathrm{mg} \cdot \mathrm{L}^{-1}\right)\end{array}$ & $\begin{array}{c}O D_{f} \\
\left(m g \cdot L^{-1}\right)\end{array}$ & $\begin{array}{c}\text { Cond }_{\mathrm{i}} \\
\left(\mu \mathrm{S} . \mathrm{cm}^{-1}\right)\end{array}$ & $\begin{array}{c}\text { Cond }_{f} \\
\left(\mu S . \mathrm{cm}^{-1}\right)\end{array}$ \\
\hline Controle & $\mathbf{0}$ & 0 & $\mathbf{0}$ & 0 & $\mathbf{0}$ & 6,67 & 7,94 & 7,85 & 8,16 & 233 & 263 \\
\hline 3,125 & 2 & 0 & 0 & 0 & 2 & 7,60 & 8,14 & 7,38 & 7,81 & 221 & 230 \\
\hline 6,25 & 1 & 2 & 2 & 0 & 5 & $\mathbf{7 , 7 4}$ & 8,17 & 7,38 & 7,80 & 222 & 231 \\
\hline 12,5 & 4 & 4 & 5 & 5 & 18 & 7,81 & 8,17 & 7,40 & 7,73 & 208,5 & 209,8 \\
\hline 25,0 & 5 & 5 & 5 & 5 & 20 & 7,85 & 8,10 & 7,43 & 7,61 & 184,5 & 186,3 \\
\hline 50,0 & 5 & 5 & 5 & 5 & 20 & 8,40 & 8,18 & 7,55 & 7,66 & 137,2 & 138,8 \\
\hline 100 & 5 & 5 & 5 & 5 & 20 & 8,54 & 8,19 & 7,65 & 7,80 & 35,9 & 38,3 \\
\hline
\end{tabular}

Ensaio 4

\begin{tabular}{|c|c|c|c|c|c|c|c|c|c|c|c|}
\hline \multicolumn{8}{|c|}{ ENSAIO DE TOXICIDADE AGUDA - Daphnia similis } & \multirow{2}{*}{\multicolumn{4}{|c|}{$\begin{array}{c}\text { Dose de radiação: 0,0 kGy } \\
\text { Água de diluição }\end{array}$}} \\
\hline \multicolumn{5}{|c|}{ Início } & \multicolumn{3}{|c|}{ Término } & & & & \\
\hline $\begin{array}{c}\text { Data: } \\
\text { 16/06/2015 }\end{array}$ & \multicolumn{4}{|c|}{$\begin{array}{l}\text { Hora: } \\
14: 00\end{array}$} & $\begin{array}{c}\text { Data: } \\
\text { 18/06/2015 }\end{array}$ & \multicolumn{2}{|c|}{$\begin{array}{l}\text { Hora: } \\
\text { 14:00 }\end{array}$} & $\begin{array}{r}\text { Dureza } \\
45,0 \mathrm{mg}\end{array}$ & $\begin{array}{l}\text { la água: } \\
\mathrm{AaCO}_{3} \cdot \mathrm{L}^{-1}\end{array}$ & \multicolumn{2}{|c|}{$\begin{array}{l}\text { Manancial: } \\
\text { Salto - SP }\end{array}$} \\
\hline \multicolumn{5}{|c|}{$\begin{array}{l}\text { Organismo-teste: } \\
\text { Daphnia similis }\end{array}$} & \multicolumn{3}{|c|}{$\begin{array}{c}\text { Amostra: } \\
\text { Cloridrato de fluoxetina } \\
(0,0 \mathrm{kGy})\end{array}$} & \multicolumn{4}{|c|}{ Operador: Flávio } \\
\hline & 1 & 2 & 3 & 4 & $\begin{array}{c}\% \text { de } \\
\text { imóveis }\end{array}$ & $\mathrm{pH}_{\mathrm{i}}$ & $\mathrm{pH}_{\mathrm{f}}$ & $\begin{array}{c}\mathrm{OD}_{\mathrm{i}} \\
\left(\mathrm{mg} \cdot \mathrm{L}^{-1}\right)\end{array}$ & $\begin{array}{c}\mathrm{OD}_{\mathrm{f}} \\
\left(\mathrm{mg} \cdot \mathrm{L}^{-1}\right)\end{array}$ & $\begin{array}{c}\text { Cond }_{\mathrm{i}} \\
\left(\mu \mathrm{S} . \mathrm{cm}^{-1}\right)\end{array}$ & $\begin{array}{c}\text { Cond }_{f} \\
\left(\mu S . \mathrm{cm}^{-1}\right)\end{array}$ \\
\hline Controle & 0 & 0 & 0 & 0 & 0 & 7,65 & 6,50 & 8,07 & 7,72 & 201,2 & 223 \\
\hline 2,5 & 0 & 0 & 0 & 1 & 1 & 6,22 & 6,32 & 7,99 & 7,77 & 179,7 & 178,5 \\
\hline 7,5 & 3 & 3 & 2 & $\mathbf{0}$ & 8 & 6,51 & 6,54 & 8,04 & 7,77 & 175,6 & 178,1 \\
\hline 10 & 5 & 5 & 4 & 4 & 18 & 6,64 & 6,71 & 8,04 & 7,78 & 172,5 & 173,9 \\
\hline 12,5 & 2 & 2 & 3 & 5 & 12 & 6,78 & 6,88 & 8,08 & 7,82 & 168,9 & 170,4 \\
\hline 25 & 5 & 3 & 4 & 5 & 17 & 6,93 & 7,00 & 8,10 & 7,71 & 152,2 & 154,2 \\
\hline
\end{tabular}


Ensaio 5

\begin{tabular}{|c|c|c|c|c|c|c|c|c|c|c|c|}
\hline \multicolumn{8}{|c|}{ ENSAIO DE TOXICIDADE AGUDA - Daphnia similis } & \multirow{2}{*}{\multicolumn{4}{|c|}{$\begin{array}{c}\text { Dose de radiação: 0,0 kGy } \\
\text { Água de diluição }\end{array}$}} \\
\hline & Início & & & & \multicolumn{3}{|c|}{ Término } & & & & \\
\hline $\begin{array}{c}\text { Data: } \\
\text { 17/06/2015 }\end{array}$ & \multicolumn{4}{|c|}{$\begin{array}{l}\text { Hora: } \\
12: 31\end{array}$} & $\begin{array}{c}\text { Data: } \\
\text { 19/06/2015 }\end{array}$ & \multicolumn{2}{|c|}{$\begin{array}{l}\text { Hora: } \\
12: 31\end{array}$} & $\begin{array}{r}\text { Dureza } \\
45,0 \mathrm{mg}\end{array}$ & $\begin{array}{l}\text { la água: } \\
\text { jaCO } \\
\mathrm{L}^{-1}\end{array}$ & \multicolumn{2}{|c|}{$\begin{array}{l}\text { Manancial: } \\
\text { Salto - SP }\end{array}$} \\
\hline \multicolumn{5}{|c|}{$\begin{array}{l}\text { Organismo-teste: } \\
\text { Daphnia similis }\end{array}$} & \multicolumn{3}{|c|}{$\begin{array}{c}\text { Amostra: } \\
\text { Cloridrato de fluoxetina } \\
(0,0 \text { kGy })\end{array}$} & \multicolumn{4}{|c|}{ Operador: Flávio } \\
\hline & 1 & 2 & 3 & 4 & $\begin{array}{c}\% \text { de } \\
\text { imóveis }\end{array}$ & $\mathrm{pH}_{\mathrm{i}}$ & $\mathrm{pH}_{\mathrm{f}}$ & $\begin{array}{c}\mathrm{OD}_{\mathrm{i}} \\
\left(\mathrm{mg} \cdot \mathrm{L}^{-1}\right)\end{array}$ & $\begin{array}{c}\mathrm{OD}_{\mathrm{f}} \\
\left(\mathrm{mg} \cdot \mathrm{L}^{-1}\right)\end{array}$ & $\underset{\left(\mu S . \mathrm{cm}^{-1}\right)}{\text { Cond }_{i}}$ & $\begin{array}{c}\text { Cond }_{\mathrm{f}} \\
\left(\mu \mathrm{SS}^{-1} \mathrm{~cm}^{-1}\right)\end{array}$ \\
\hline Controle & 0 & 0 & $\mathbf{0}$ & 0 & 0 & 7,65 & 6,50 & 8,07 & 7,72 & 201,2 & 223 \\
\hline 2,5 & 0 & $\mathbf{0}$ & $\mathbf{0}$ & $\mathbf{0}$ & $\mathbf{0}$ & 6,22 & 6,32 & 7,99 & 7,77 & 179,7 & 178,5 \\
\hline 7,5 & 3 & 2 & 2 & 3 & 10 & 6,51 & 6,54 & 8,04 & 7,77 & 175,6 & 178,1 \\
\hline 10 & 5 & 2 & 4 & 2 & 13 & 6,64 & 6,71 & 8,04 & 7,78 & 172,5 & 173,9 \\
\hline 12,5 & 5 & 5 & 5 & 5 & 20 & 6,78 & 6,88 & 8,08 & 7,82 & 168,9 & 170,4 \\
\hline 25 & 5 & 5 & 5 & 4 & 19 & 6,93 & 7,00 & 8,10 & 7,71 & 152,2 & 154,2 \\
\hline
\end{tabular}

Ensaio 6

\begin{tabular}{|c|c|c|c|c|c|c|c|c|c|c|c|}
\hline \multicolumn{8}{|c|}{ ENSAIO DE TOXICIDADE AGUDA - Daphnia similis } & \multirow{2}{*}{\multicolumn{4}{|c|}{$\frac{\text { Dose de radiação: } 0,0 \text { kGy }}{\text { Agua de diluição }}$}} \\
\hline \multicolumn{5}{|c|}{ Início } & \multicolumn{3}{|c|}{ Término } & & & & \\
\hline $\begin{array}{c}\text { Data: } \\
17 / 06 / 2015\end{array}$ & \multicolumn{4}{|c|}{$\begin{array}{l}\text { Hora: } \\
12: 43\end{array}$} & $\begin{array}{c}\text { Data: } \\
19 / 06 / 2015\end{array}$ & \multicolumn{2}{|c|}{$\begin{array}{l}\text { Hora: } \\
12: 43\end{array}$} & $\begin{array}{r}\text { Dureza } \\
45,0 \mathrm{mg}\end{array}$ & $\begin{array}{l}\text { la água: } \\
\mathrm{aCO}_{3 \cdot L^{-1}}\end{array}$ & \multicolumn{2}{|c|}{$\begin{array}{l}\text { Manancial: } \\
\text { Salto-SP }\end{array}$} \\
\hline \multicolumn{5}{|c|}{$\begin{array}{l}\text { Organismo-teste: } \\
\text { Daphnia similis }\end{array}$} & \multicolumn{3}{|c|}{$\begin{array}{c}\text { Amostra: } \\
\text { Cloridrato de fluoxetina } \\
(0,0 \mathrm{kGy})\end{array}$} & \multicolumn{4}{|c|}{ Operador: Flávio } \\
\hline & 1 & 2 & 3 & 4 & $\begin{array}{c}\% \text { de } \\
\text { imóveis }\end{array}$ & $\mathrm{pH}_{\mathrm{i}}$ & $\mathrm{pH}_{\mathrm{f}}$ & $\begin{array}{c}\mathrm{OD}_{\mathrm{i}} \\
\left(\mathrm{mg} \cdot \mathrm{L}^{-1}\right)\end{array}$ & $\begin{array}{c}\mathrm{OD}_{\mathrm{f}} \\
\left(\mathrm{mg} \cdot \mathrm{L}^{-1}\right)\end{array}$ & $\underset{\left(\mu S . \mathrm{cm}^{-1}\right)}{\text { Cond }_{\mathrm{i}}}$ & $\begin{array}{c}\text { Cond }_{f} \\
\left(\mu S_{.} \mathrm{cm}^{-1}\right)\end{array}$ \\
\hline Controle & 0 & 0 & 0 & 0 & 0 & 7,65 & 6,50 & 8,07 & 7,72 & 201,2 & 223 \\
\hline 2,5 & 0 & 0 & 0 & 0 & 0 & 6,22 & 6,32 & 7,99 & 7,77 & 179,7 & 178,5 \\
\hline 7,5 & 4 & 0 & 2 & 1 & 7 & 6,51 & 6,54 & 8,04 & 7,77 & 175,6 & 178,1 \\
\hline 10 & 4 & 5 & 4 & 5 & 18 & 6,64 & 6,71 & 8,04 & 7,78 & 172,5 & 173,9 \\
\hline 12,5 & 5 & 4 & 5 & 4 & 18 & 6,78 & 6,88 & 8,08 & 7,82 & 168,9 & 170,4 \\
\hline 25 & 5 & 5 & 5 & 5 & 20 & 6.93 & 7.00 & 8.10 & 7.71 & 152.2 & 154.2 \\
\hline
\end{tabular}

Ensaio 7

\begin{tabular}{|c|c|c|c|c|c|c|c|c|c|c|c|}
\hline \multicolumn{8}{|c|}{ ENSAIO DE TOXICIDADE AGUDA - Daphnia similis } & \multirow{2}{*}{\multicolumn{4}{|c|}{$\begin{array}{c}\text { Dose de radiação: } \mathbf{0 , 0} \text { kGy } \\
\text { Água de diluição }\end{array}$}} \\
\hline \multicolumn{5}{|c|}{ Início } & \multicolumn{3}{|c|}{ Término } & & & & \\
\hline $\begin{array}{l}\text { Data: } \\
11 / 08 / 2015\end{array}$ & & & & & $\begin{array}{c}\text { Data: } \\
\text { 13/082015 }\end{array}$ & & & \multicolumn{2}{|c|}{ Dureza da água: } & \multicolumn{2}{|c|}{$\begin{array}{l}\text { Manancial: } \\
\text { Salto - SP }\end{array}$} \\
\hline \multicolumn{5}{|c|}{$\begin{array}{l}\text { Organismo-teste: } \\
\text { Daphnia similis }\end{array}$} & \multicolumn{3}{|c|}{$\begin{array}{c}\text { Amostra: } \\
\text { Cloridrato de fluoxetina } \\
(0,0 \mathrm{kGy})\end{array}$} & \multicolumn{4}{|c|}{ Operador: Flávio } \\
\hline & 1 & 2 & 3 & 4 & $\begin{array}{c}\% \text { de } \\
\text { imóveis }\end{array}$ & $\mathrm{pH}_{\mathrm{i}}$ & $\mathrm{pH}_{\mathrm{f}}$ & $\begin{array}{c}\mathrm{OD}_{\mathrm{i}} \\
\left(\mathrm{mg} \cdot \mathrm{L}^{-1}\right)\end{array}$ & $\begin{array}{c}\mathrm{OD}_{\mathrm{f}} \\
\left(\mathrm{mg} \cdot \mathrm{L}^{-1}\right)\end{array}$ & $\underset{\left(\mu S \cdot \mathrm{cm}^{-1}\right)}{\text { Cond }_{\mathrm{i}}}$ & $\begin{array}{c}\text { Cond }_{f} \\
\left(\mu S . \mathrm{cm}^{-1}\right)\end{array}$ \\
\hline Controle & 0 & 0 & 0 & 0 & 0 & 7,24 & 6,99 & 7,80 & 7,87 & 208,7 & 231 \\
\hline 3,125 & 0 & 0 & $\mathbf{0}$ & $\mathbf{0}$ & $\mathbf{0}$ & 7,22 & 7 & 7,81 & 7,81 & 9,4 & 207,6 \\
\hline 6,25 & 0 & 0 & 0 & 0 & 0 & 7,23 & 7,25 & 7,81 & 7,77 & 195,4 & 199,6 \\
\hline 9,375 & 0 & 0 & 0 & 0 & $\mathbf{0}$ & 6,21 & 7,33 & 7,81 & $\mathbf{7 , 7 1}$ & 189,5 & 193,9 \\
\hline 12,5 & 3 & 0 & 0 & 5 & 8 & 7,35 & 7,34 & 7,78 & 7,66 & 185,0 & 187,8 \\
\hline 25,0 & 2 & 5 & 5 & 4 & 16 & 7,40 & 7,37 & 7,77 & 7,58 & 167,7 & 170,5 \\
\hline
\end{tabular}


Ensaio 8

\begin{tabular}{|c|c|c|c|c|c|c|c|c|c|c|c|}
\hline \multicolumn{8}{|c|}{ ENSAIO DE TOXICIDADE AGUDA - Daphnia similis } & \multirow{2}{*}{\multicolumn{4}{|c|}{$\begin{array}{c}\text { Dose de radiação: 0,0 kGy } \\
\text { Água de diluição }\end{array}$}} \\
\hline \multicolumn{5}{|c|}{ Início } & \multicolumn{3}{|c|}{ Término } & & & & \\
\hline $\begin{array}{c}\text { Data: } \\
\text { 19/08/2015 }\end{array}$ & & & & & $\begin{array}{c}\text { Data: } \\
\text { 21/08/2015 }\end{array}$ & & & \multicolumn{2}{|c|}{$\begin{array}{l}\text { Agua c } \\
\text { da água: } \\
\mathrm{CaCO}_{3} \cdot \mathrm{L}^{-1}\end{array}$} & \multicolumn{2}{|c|}{$\begin{array}{c}\text { Manancial: } \\
\text { Salto - SP }\end{array}$} \\
\hline \multicolumn{5}{|c|}{$\begin{array}{c}\text { Organismo-teste: } \\
\text { Daphnia similis }\end{array}$} & \multicolumn{3}{|c|}{$\begin{array}{c}\text { Amostra: } \\
\text { Cloridrato de fluoxetina } \\
(0,0 \mathrm{kGy})\end{array}$} & \multicolumn{4}{|c|}{ Operador: Flávio } \\
\hline & 1 & 2 & 3 & 4 & $\begin{array}{c}\text { \% de } \\
\text { imóveis }\end{array}$ & $\mathrm{pH}_{\mathrm{i}}$ & $\mathrm{pH}_{\mathrm{f}}$ & $\begin{array}{c}\mathrm{OD}_{\mathrm{i}} \\
\left(\mathrm{mg} \cdot \mathrm{L}^{-1}\right)\end{array}$ & $\begin{array}{c}O_{\mathrm{OD}} \\
\left(\mathrm{mg} \cdot \mathrm{L}^{-1}\right)\end{array}$ & $\begin{array}{c}\text { Cond }_{\mathrm{i}} \\
\left(\mu \mathrm{S} . \mathrm{cm}^{-1}\right)\end{array}$ & $\begin{array}{c}\text { Cond }_{f} \\
\left(\mu S . \mathrm{cm}^{-1}\right)\end{array}$ \\
\hline Controle & 0 & 0 & 0 & 0 & 0 & 7,04 & 6,53 & 7,48 & 7,82 & 232 & 240 \\
\hline 3,125 & 1 & $\mathbf{0}$ & $\mathbf{0}$ & $\mathbf{0}$ & 1 & 7,31 & 7,09 & 7,42 & 7,71 & 197 & 195,7 \\
\hline 6,25 & 0 & $\mathbf{0}$ & $\mathbf{0}$ & 0 & $\mathbf{0}$ & 7,39 & 7,18 & 7,43 & 7,70 & 194,3 & 195,2 \\
\hline 9,375 & 3 & 0 & 2 & 3 & 8 & $\mathbf{7 , 4 7}$ & 7,22 & 7,46 & 7,67 & 189,3 & 190,6 \\
\hline 12,5 & 5 & 5 & 4 & 4 & 18 & 7,51 & 7,26 & 7,48 & 7,57 & 186,1 & 188,5 \\
\hline 25,0 & 5 & 4 & 5 & 5 & 19 & 7,55 & 7,24 & 7,55 & 7,19 & 169,6 & 173,3 \\
\hline
\end{tabular}

Ensaio 9

\begin{tabular}{|c|c|c|c|c|c|c|c|c|c|c|c|}
\hline \multicolumn{8}{|c|}{ ENSAIO DE TOXICIDADE AGUDA - Daphnia similis } & \multirow{2}{*}{\multicolumn{4}{|c|}{$\begin{array}{c}\text { Dose de radiação: } 0,0 \text { kGy } \\
\text { Agua de diluição }\end{array}$}} \\
\hline \multicolumn{5}{|c|}{ Início } & \multicolumn{3}{|c|}{ Término } & & & & \\
\hline $\begin{array}{c}\text { Data: } \\
25 / 08 / 2015\end{array}$ & \multicolumn{4}{|c|}{$\begin{array}{l}\text { Hora: } \\
15: 12\end{array}$} & $\begin{array}{c}\text { Data: } \\
\text { 27/08/2015 }\end{array}$ & \multicolumn{2}{|c|}{$\begin{array}{l}\text { Hora: } \\
15: 12\end{array}$} & $\begin{array}{r}\text { Dureza } \\
45,0 \mathrm{mg}\end{array}$ & $\begin{array}{l}\text { la água: } \\
\mathrm{aCO}_{3} \cdot \mathrm{L}^{-1}\end{array}$ & \multicolumn{2}{|c|}{$\begin{array}{l}\text { Manancial: } \\
\text { Salto - SP }\end{array}$} \\
\hline \multicolumn{5}{|c|}{$\begin{array}{l}\text { Organismo-teste: } \\
\text { Daphnia similis }\end{array}$} & \multicolumn{3}{|c|}{$\begin{array}{c}\text { Amostra: } \\
\text { Cloridrato de fluoxetina } \\
(0,0 \mathrm{kGy})\end{array}$} & \multicolumn{4}{|c|}{ Operador: Flávio } \\
\hline & 1 & 2 & 3 & 4 & $\begin{array}{c}\text { \% de } \\
\text { imóveis }\end{array}$ & $\mathrm{pH}_{\mathrm{i}}$ & $\mathrm{pH}_{\mathrm{f}}$ & $\begin{array}{c}\mathrm{OD}_{\mathrm{i}} \\
\left(\mathrm{mg} \cdot \mathrm{L}^{-1}\right)\end{array}$ & $\begin{array}{c}\mathrm{OD}_{\mathrm{f}} \\
\left(\mathrm{mg} \cdot \mathrm{L}^{-1}\right)\end{array}$ & $\underset{\left(\mu S . \mathrm{cm}^{-1}\right)}{\text { Cond }_{\mathrm{i}}}$ & $\begin{array}{c}\text { Cond }_{f} \\
\left(\mu S . \mathrm{cm}^{-1}\right)\end{array}$ \\
\hline Controle & 0 & 0 & 0 & 0 & $\mathbf{0}$ & 7,96 & $\mathbf{7 , 7 3}$ & 7,96 & 7,80 & 230 & 245 \\
\hline 3,125 & 0 & 0 & 0 & 0 & $\mathbf{0}$ & 7,36 & 7,70 & 7,90 & 7,72 & 194,3 & 209,7 \\
\hline 6,25 & 5 & 0 & 1 & 1 & 7 & 7,42 & 7,78 & 7,90 & 7,73 & 192,8 & 195,7 \\
\hline 9,375 & 4 & 4 & 2 & 5 & 15 & 7,48 & 7,81 & 7,91 & 7,73 & 188,8 & 190,0 \\
\hline 12,5 & 4 & 4 & 2 & 5 & 15 & 7,53 & 7,80 & 7,91 & 7,53 & 185,5 & 187,5 \\
\hline 25,0 & 5 & 5 & 5 & 3 & 18 & 7,53 & 7,73 & 7,88 & 7,22 & 168,9 & 171,3 \\
\hline
\end{tabular}

Ensaio 10

\begin{tabular}{|c|c|c|c|c|c|c|c|c|c|c|c|}
\hline \multicolumn{8}{|c|}{ ENSAIO DE TOXICIDADE AGUDA - Daphnia similis } & \multirow{2}{*}{\multicolumn{4}{|c|}{$\frac{\text { Dose de radiação: } 0,0 \text { kGy }}{\text { Água de diluição }}$}} \\
\hline \multicolumn{5}{|c|}{ Início } & \multicolumn{3}{|c|}{ Término } & & & & \\
\hline $\begin{array}{c}\text { Data: } \\
01 / 09 / 2015\end{array}$ & \multicolumn{4}{|c|}{$\begin{array}{l}\text { Hora: } \\
\text { 15:32 }\end{array}$} & $\begin{array}{c}\text { Data: } \\
\text { 03/09/2015 }\end{array}$ & \multicolumn{2}{|c|}{$\begin{array}{l}\text { Hora: } \\
15: 32\end{array}$} & $\begin{array}{r}\text { Dureza } \\
45,0 \mathrm{mg}\end{array}$ & la água: & \multicolumn{2}{|c|}{$\begin{array}{l}\text { Manancial: } \\
\text { Salto - SP }\end{array}$} \\
\hline \multicolumn{5}{|c|}{$\begin{array}{l}\text { Organismo-teste: } \\
\text { Daphnia similis }\end{array}$} & \multicolumn{3}{|c|}{$\begin{array}{c}\text { Amostra: } \\
\text { Cloridrato de fluoxetina } \\
(0,0 \mathrm{kGy})\end{array}$} & \multicolumn{4}{|c|}{ Operador: Flávio } \\
\hline & 1 & 2 & 3 & 4 & $\begin{array}{c}\text { \% de } \\
\text { imóveis }\end{array}$ & $\mathrm{pH}_{\mathrm{i}}$ & $\mathrm{pH}_{\mathrm{f}}$ & $\begin{array}{c}\mathrm{OD}_{\mathrm{i}} \\
\left(\mathrm{mg} \cdot \mathrm{L}^{-1}\right)\end{array}$ & $\begin{array}{c}\mathrm{OD}_{\mathrm{f}} \\
\left(\mathrm{mg} \cdot \mathrm{L}^{-1}\right)\end{array}$ & $\begin{array}{c}\text { Cond }_{\mathrm{i}} \\
\left(\mu \mathrm{S} . \mathrm{cm}^{-1}\right)\end{array}$ & $\begin{array}{c}\text { Cond }_{f} \\
\left(\mu S . \mathrm{cm}^{-1}\right)\end{array}$ \\
\hline Controle & 0 & 0 & 0 & 0 & 0 & 7,07 & 7,20 & 7,85 & 7,54 & 211,8 & 291 \\
\hline 3,125 & 0 & $\mathbf{0}$ & 0 & $\mathbf{0}$ & $\mathbf{0}$ & 7,12 & 7,47 & 8,18 & 7,76 & 204,3 & 219 \\
\hline 6,25 & 2 & 0 & 0 & 0 & 2 & 7,30 & 7,68 & 8,13 & 7,77 & 200,0 & 203,4 \\
\hline 9,375 & 3 & 4 & 3 & 4 & 14 & 7,45 & 7,72 & 8,14 & 7,69 & 195,1 & 198,1 \\
\hline 12,5 & 4 & 3 & 2 & 1 & 10 & 7,48 & 7,74 & 8,15 & 7,56 & 191,8 & 194,4 \\
\hline 25,0 & 4 & 5 & 5 & 4 & 18 & 7,53 & 7,69 & 8,17 & 7,47 & 173,9 & 177,1 \\
\hline
\end{tabular}


Ensaios de toxicidade aguda com o soluções preparadas a partir do cloridrato de fluoxetina de $10 \mathrm{mg} \cdot \mathrm{L}^{-1}$ (5,0 kGy)

Ensaio 1

\begin{tabular}{|c|c|c|c|c|c|c|c|c|c|c|c|}
\hline \multicolumn{8}{|c|}{ ENSAIO DE TOXICIDADE AGUDA - Daphnia similis } & \multirow{2}{*}{\multicolumn{4}{|c|}{$\begin{array}{c}\text { Dose de radiação: 5,0 kGy } \\
\text { Água de diluição }\end{array}$}} \\
\hline \multicolumn{5}{|c|}{ Início } & \multicolumn{3}{|c|}{ Término } & & & & \\
\hline $\begin{array}{l}\text { Data: } \\
\text { 20/10/2015 }\end{array}$ & & & & & $\begin{array}{c}\text { Data: } \\
\text { 22/10/2015 }\end{array}$ & & & \multicolumn{2}{|c|}{$\begin{array}{l}\text { da água: } \\
\mathrm{CaCO}_{3} \cdot \mathrm{L}^{-1}\end{array}$} & \multicolumn{2}{|c|}{$\begin{array}{l}\text { Manancial: } \\
\text { Salto - SP }\end{array}$} \\
\hline \multicolumn{5}{|c|}{$\begin{array}{l}\text { Organismo-teste: } \\
\text { Daphnia similis }\end{array}$} & \multicolumn{3}{|c|}{$\begin{array}{c}\text { Amostra: } \\
\text { Cloridrato de fluoxetina } \\
(5,0 \mathrm{kGy})\end{array}$} & \multicolumn{4}{|c|}{ Operador: Flávio } \\
\hline & 1 & 2 & 3 & 4 & $\begin{array}{l}\text { \% de } \\
\text { imóveis }\end{array}$ & $\mathrm{pH}_{\mathrm{i}}$ & $\mathrm{pH}_{\mathrm{f}}$ & $\begin{array}{c}\mathrm{OD}_{\mathrm{i}} \\
\left(\mathrm{mg} \cdot \mathrm{L}^{-1}\right)\end{array}$ & $\begin{array}{c}\mathrm{OD}_{\mathrm{f}} \\
\left(\mathrm{mg} \cdot \mathrm{L}^{-1}\right)\end{array}$ & $\underset{\left(\mu S . \mathrm{cm}^{-1}\right)}{\text { Cond }_{\mathrm{i}}}$ & $\begin{array}{c}\text { Cond }_{f} \\
\left(\mu S . \mathrm{cm}^{-1}\right)\end{array}$ \\
\hline Controle & 0 & 0 & 0 & 0 & $\mathbf{0}$ & 7,61 & 6,99 & 7,24 & 7,36 & 221 & 224 \\
\hline 6,25 & 0 & 0 & 1 & 0 & 1 & 6,73 & 6,67 & 7,39 & 7,40 & 163,5 & 174,3 \\
\hline 12,5 & 0 & 0 & 1 & 1 & 2 & 6,77 & 6,79 & 7,39 & 7,36 & 159,9 & 162,3 \\
\hline 25,0 & 0 & 0 & 1 & 1 & 2 & 6,87 & 6,86 & 7,39 & 7,31 & 144,6 & 145,5 \\
\hline 50,0 & 3 & 4 & 5 & 4 & 16 & 6,94 & 6,92 & 7,27 & 7,36 & 116,5 & 119,7 \\
\hline 100 & 5 & 5 & 5 & 5 & 20 & 5.70 & 5,60 & 6.76 & 7,52 & 86.4 & 88.3 \\
\hline
\end{tabular}

Ensaio 2

\begin{tabular}{|c|c|c|c|c|c|c|c|c|c|c|c|}
\hline \multicolumn{8}{|c|}{ ENSAIO DE TOXICIDADE AGUDA - Daphnia similis } & \multirow{2}{*}{\multicolumn{4}{|c|}{$\begin{array}{c}\text { Dose de radiação: 5,0 kGy } \\
\text { Água de diluição }\end{array}$}} \\
\hline \multicolumn{5}{|c|}{ Início } & \multicolumn{3}{|c|}{ Término } & & & & \\
\hline $\begin{array}{l}\text { Data: } \\
\text { 20/10/2015 }\end{array}$ & \multicolumn{4}{|c|}{$\begin{array}{l}\text { Hora: } \\
12: 42\end{array}$} & $\begin{array}{c}\text { Data: } \\
22 / 10 / 2015\end{array}$ & \multicolumn{2}{|c|}{$\begin{array}{l}\text { Hora: } \\
12: 42\end{array}$} & $\begin{array}{l}\text { Dureza } \\
45,0 \mathrm{mg}\end{array}$ & $\begin{array}{l}\text { la água: } \\
\text { aCO } \\
3 \cdot L^{-1}\end{array}$ & \multicolumn{2}{|c|}{$\begin{array}{l}\text { Manancial: } \\
\text { Salto - SP }\end{array}$} \\
\hline \multicolumn{5}{|c|}{$\begin{array}{l}\text { Organismo-teste: } \\
\text { Daphnia similis }\end{array}$} & \multicolumn{3}{|c|}{$\begin{array}{c}\text { Amostra: } \\
\text { Cloridrato de fluoxetina } \\
(5,0 \text { kGy })\end{array}$} & \multicolumn{4}{|c|}{ Operador: Flávio } \\
\hline & 1 & 2 & 3 & 4 & $\begin{array}{c}\% \text { de } \\
\text { imóveis }\end{array}$ & $\mathrm{pH}_{\mathrm{i}}$ & $\mathrm{pH}_{\mathrm{f}}$ & $\begin{array}{c}\mathrm{OD}_{\mathrm{i}} \\
\left(\mathrm{mg} \cdot \mathrm{L}^{-1}\right)\end{array}$ & $\begin{array}{c}\mathrm{OD}_{\mathrm{f}} \\
\left(\mathrm{mg} \cdot \mathrm{L}^{-1}\right)\end{array}$ & $\underset{\left(\mu S . \mathrm{cm}^{-1}\right)}{\text { Cond }_{\mathrm{i}}}$ & $\begin{array}{c}\text { Cond }_{f} \\
\left(\mu S . \mathrm{cm}^{-1}\right)\end{array}$ \\
\hline Controle & 0 & 0 & 0 & 0 & 0 & 7,61 & 6,99 & 7,24 & 7,36 & 221 & 224 \\
\hline 6,25 & 0 & 0 & 0 & 0 & 0 & 6,73 & 6,67 & 7,39 & 7,40 & 163,5 & 174,3 \\
\hline 12,5 & 0 & 0 & 0 & 0 & 0 & 6,77 & 6,79 & 7,39 & 7,36 & 159,9 & 162,3 \\
\hline 25,0 & 2 & 3 & 2 & 1 & 8 & 6,87 & 6,86 & 7,39 & 7,31 & 144,6 & 145,5 \\
\hline 50,0 & 5 & 4 & 4 & 3 & 16 & 6,94 & 6,92 & 7,27 & 7,36 & 116,5 & 119,7 \\
\hline 100 & 5 & 5 & 5 & 5 & 20 & 5,70 & 5,60 & 6,76 & 7,52 & 86,4 & 88,3 \\
\hline
\end{tabular}

Ensaio 3

\begin{tabular}{|c|c|c|c|c|c|c|c|c|c|c|c|}
\hline \multicolumn{8}{|c|}{ ENSAIO DE TOXICIDADE AGUDA - Daphnia similis } & \multirow{2}{*}{\multicolumn{4}{|c|}{$\begin{array}{c}\text { Dose de radiação: 5,0 kGy } \\
\text { Água de diluição }\end{array}$}} \\
\hline \multicolumn{5}{|c|}{ Início } & \multicolumn{3}{|c|}{ Término } & & & & \\
\hline $\begin{array}{l}\text { Data: } \\
\text { 20/10/2015 }\end{array}$ & \multicolumn{4}{|c|}{$\begin{array}{l}\text { Hora: } \\
12: 50\end{array}$} & $\begin{array}{l}\text { Data: } \\
\text { 22/10/2015 }\end{array}$ & \multicolumn{2}{|c|}{$\begin{array}{l}\text { Hora: } \\
\text { 12:50 }\end{array}$} & $\begin{array}{r}\text { Dureza } \\
45,0 \mathrm{mg}\end{array}$ & $\begin{array}{l}\text { la água: } \\
\mathrm{CaCO}_{3} \cdot \mathrm{L}^{-1}\end{array}$ & \multicolumn{2}{|c|}{$\begin{array}{l}\text { Manalancial: } \\
\text { Salto - SP }\end{array}$} \\
\hline \multicolumn{5}{|c|}{$\begin{array}{l}\text { Organismo-teste: } \\
\text { Daphnia similis }\end{array}$} & \multicolumn{3}{|c|}{$\begin{array}{c}\text { Amostra: } \\
\text { Cloridrato de fluoxetina } \\
(5,0 \mathrm{kGy})\end{array}$} & \multicolumn{4}{|c|}{ Operador: Flávio } \\
\hline & 1 & 2 & 3 & 4 & $\begin{array}{c}\% \text { de } \\
\text { imóveis }\end{array}$ & $\mathrm{pH}_{\mathrm{i}}$ & $\mathrm{pH}_{\mathrm{f}}$ & $\begin{array}{c}\mathrm{OD}_{\mathrm{i}} \\
\left(\mathrm{mg} \cdot \mathrm{L}^{-1}\right)\end{array}$ & $\begin{array}{c}\mathrm{OD}_{\mathrm{f}} \\
\left(\mathrm{mg} \cdot \mathrm{L}^{-1}\right)\end{array}$ & $\begin{array}{c}\text { Cond }_{\mathrm{i}} \\
\left(\mu \mathrm{S} . \mathrm{cm}^{-1}\right)\end{array}$ & $\begin{array}{c}\text { Cond }_{\mathrm{f}} \\
\left(\mu \mathrm{S} \cdot \mathrm{cm}^{-1}\right)\end{array}$ \\
\hline Controle & 0 & 0 & 0 & 0 & 0 & 7,61 & 6,99 & 7,24 & 7,36 & 221 & 224 \\
\hline 6,25 & 0 & 0 & 0 & 0 & 0 & 6,73 & 6,67 & 7,39 & 7,40 & 163,5 & 174,3 \\
\hline 12,5 & 0 & 1 & 0 & 0 & 1 & 6,77 & 6,79 & 7,39 & 7,36 & 159,9 & 162,3 \\
\hline 25,0 & 0 & 0 & 2 & 0 & 2 & 6,87 & 6,86 & 7,39 & 7,31 & 144,6 & 145,5 \\
\hline 50,0 & 3 & 3 & 4 & 5 & 15 & 6,94 & 6,92 & 7,27 & 7,36 & 116,5 & 119,7 \\
\hline 100 & 5 & 5 & 5 & 5 & 20 & 5,70 & 5,60 & 6,76 & 7,52 & 86,4 & 88,3 \\
\hline
\end{tabular}


Ensaios de toxicidade aguda com as soluções preparadas a partir do diclofenaco sódico de $100 \mathrm{mg} \cdot \mathrm{L}^{-1}$ (0,0 kGy)

Ensaio 1

\begin{tabular}{|c|c|c|c|c|c|c|c|c|c|c|c|}
\hline \multicolumn{8}{|c|}{ ENSAIO DE TOXICIDADE AGUDA - Daphnia similis } & \multirow{2}{*}{\multicolumn{4}{|c|}{$\begin{array}{c}\text { Dose de radiação: 0,0 kGy } \\
\text { Água de diluição }\end{array}$}} \\
\hline \multicolumn{5}{|c|}{ Início } & \multicolumn{3}{|c|}{ Término } & & & & \\
\hline $\begin{array}{l}\text { Data: } \\
09 / 12 / 2014\end{array}$ & \multicolumn{4}{|c|}{$\begin{array}{l}\text { Hora: } \\
14: 30\end{array}$} & $\begin{array}{c}\text { Data: } \\
11 / 12 / 2014\end{array}$ & \multicolumn{2}{|c|}{$\begin{array}{l}\text { Hora: } \\
\text { 14:30 }\end{array}$} & $\begin{array}{r}\text { Dureza } \\
45,0 \mathrm{mg}\end{array}$ & $\begin{array}{l}\text { la água: } \\
\mathrm{aCO}_{3 \cdot L^{-1}}\end{array}$ & \multicolumn{2}{|c|}{$\begin{array}{l}\text { Manancial: } \\
\text { Salto-SP }\end{array}$} \\
\hline \multicolumn{5}{|c|}{$\begin{array}{l}\text { Organismo-teste: } \\
\text { Daphnia similis }\end{array}$} & \multicolumn{3}{|c|}{$\begin{array}{c}\text { Amostra: } \\
\text { Diclofenaco sódico } \\
(0,0 \text { kGy) }\end{array}$} & \multicolumn{4}{|c|}{ Operador: Flávio } \\
\hline & 1 & 2 & 3 & 4 & $\begin{array}{l}\text { \% de } \\
\text { imóveis }\end{array}$ & $\mathrm{pH}_{\mathrm{i}}$ & $\mathrm{pH}_{\mathrm{f}}$ & $\underset{\left(m g \cdot L^{-1}\right)}{O D_{i}}$ & $\begin{array}{c}\mathrm{OD}_{\mathrm{f}} \\
\left(\mathrm{mg} \cdot \mathrm{L}^{-1}\right)\end{array}$ & $\underset{\left(\mu S . \mathrm{cm}^{-1}\right)}{\text { Cond }_{\mathrm{i}}}$ & $\begin{array}{c}\text { Cond }_{f} \\
\left(\mu \text { S.cm }^{-1}\right)\end{array}$ \\
\hline Controle & 0 & 0 & 0 & 0 & 0 & 7,12 & 6,85 & 7,07 & 7,65 & 226 & 226 \\
\hline 6,25 & 0 & 0 & 0 & 0 & 0 & 7,58 & 7,06 & 7,09 & 7,76 & 209,6 & 211,7 \\
\hline 12,5 & 0 & 0 & 0 & 0 & 0 & 7,67 & 7,18 & 7,06 & 7,75 & 201,9 & 203,1 \\
\hline 25,0 & 1 & 0 & 0 & 1 & 2 & 7,71 & 7,32 & 7,03 & 7,69 & 182,0 & 183,0 \\
\hline 50,0 & 5 & 5 & 5 & 5 & 20 & 7,86 & 7,39 & 6,96 & 7,42 & 140,7 & 142,3 \\
\hline 75 & 5 & 5 & 5 & 5 & 20 & 7,90 & 7,34 & 6,81 & 6,90 & 103,5 & 104,3 \\
\hline 100 & 5 & 5 & 5 & 5 & 20 & 7,95 & 7,42 & 6,77 & 7,08 & 64,5 & 65,3 \\
\hline
\end{tabular}

Ensaio 2

\begin{tabular}{|c|c|c|c|c|c|c|c|c|c|c|c|}
\hline \multicolumn{8}{|c|}{ ENSAIO DE TOXICIDADE AGUDA - Daphnia similis } & \multirow{2}{*}{\multicolumn{4}{|c|}{$\begin{array}{c}\text { Dose de radiação: 0,0 kGy } \\
\text { Aggua de diluição }\end{array}$}} \\
\hline \multicolumn{5}{|c|}{ Início } & \multicolumn{3}{|c|}{ Término } & & & & \\
\hline $\begin{array}{l}\text { Data: } \\
\text { 10/03/2015 }\end{array}$ & \multicolumn{4}{|c|}{$\begin{array}{l}\text { Hora: } \\
14: 22\end{array}$} & $\begin{array}{c}\text { Data: } \\
\text { 12/03/2015 }\end{array}$ & \multicolumn{2}{|c|}{$\begin{array}{l}\text { Hora: } \\
14: 22\end{array}$} & $\begin{array}{r}\text { Dureza } \\
45,0 \mathrm{mg}\end{array}$ & $\begin{array}{l}\text { la água: } \\
\mathrm{aCO}_{3 \cdot} \mathrm{L}^{-1}\end{array}$ & \multicolumn{2}{|c|}{$\begin{array}{l}\text { Manancial: } \\
\text { Salto-SP }\end{array}$} \\
\hline \multicolumn{5}{|c|}{$\begin{array}{l}\text { Organismo-teste: } \\
\text { Daphnia similis }\end{array}$} & \multicolumn{3}{|c|}{$\begin{array}{c}\text { Amostra: } \\
\text { Diclofenaco sódico } \\
\text { (0,0 kGy) }\end{array}$} & \multicolumn{4}{|c|}{ Operador: Flávio } \\
\hline & 1 & 2 & 3 & 4 & $\begin{array}{l}\% \text { de } \\
\text { imóveis }\end{array}$ & $\mathrm{pH}_{\mathrm{i}}$ & $\mathrm{pH}_{\mathrm{f}}$ & $\begin{array}{c}\mathrm{OD}_{\mathrm{i}} \\
\left(\mathrm{mg} \cdot \mathrm{L}^{-1}\right)\end{array}$ & $\begin{array}{c}\mathrm{OD}_{\mathrm{f}} \\
\left(\mathrm{mg} \cdot \mathrm{L}^{-1}\right)\end{array}$ & $\underset{\left(\mu S . \mathrm{cm}^{-1}\right)}{\text { Cond }_{\mathrm{i}}}$ & $\begin{array}{c}\text { Cond }_{f} \\
\left(\mu S . \mathrm{cm}^{-1}\right)\end{array}$ \\
\hline Controle & 0 & 0 & 0 & 0 & 0 & 7,12 & 6,85 & 7,07 & 7,65 & 226 & 226 \\
\hline 12,5 & 0 & 0 & 0 & 0 & 0 & 7,67 & 7,18 & 7,06 & 7,75 & 201,9 & 203,1 \\
\hline 25,0 & 0 & 2 & 0 & 0 & 2 & 7,71 & 7,32 & 7,03 & 7,69 & 182,0 & 183,0 \\
\hline 50,0 & 5 & 5 & 5 & 5 & 20 & 7,86 & 7,39 & 6,96 & 7,42 & 140,7 & 142,3 \\
\hline 75 & 5 & 5 & 5 & 5 & 20 & 7,90 & 7,34 & 6,81 & 6,90 & 103,5 & 104,3 \\
\hline 100 & 5 & 5 & 5 & 5 & 20 & 7,95 & 7,42 & 6,77 & 7,08 & 64,5 & 65,3 \\
\hline
\end{tabular}


Ensaio 3

\begin{tabular}{|c|c|c|c|c|c|c|c|c|c|c|c|}
\hline \multicolumn{8}{|c|}{ ENSAIO DE TOXICIDADE AGUDA - Daphnia similis } & \multirow{2}{*}{\multicolumn{4}{|c|}{$\begin{array}{c}\text { Dose de radiação: 0,0 kGy } \\
\text { Água de diluição }\end{array}$}} \\
\hline \multicolumn{5}{|c|}{ Início } & \multicolumn{3}{|c|}{ Término } & & & & \\
\hline $\begin{array}{c}\text { Data: } \\
16 / 06 / 2015\end{array}$ & & & & & $\begin{array}{c}\text { Data: } \\
\text { 18/06/2015 }\end{array}$ & & & \multicolumn{2}{|c|}{$\begin{array}{r}\text { Água c } \\
\text { Dureza da água: }\end{array}$} & \multicolumn{2}{|c|}{$\begin{array}{l}\text { Manancial: } \\
\text { Salto - SP }\end{array}$} \\
\hline \multicolumn{5}{|c|}{$\begin{array}{l}\text { Organismo-teste: } \\
\text { Daphnia similis }\end{array}$} & \multicolumn{3}{|c|}{$\begin{array}{c}\text { Amostra: } \\
\text { Diclofenaco sódico } \\
(0,0 \mathrm{kGy})\end{array}$} & \multicolumn{4}{|c|}{ Operador: Flávio } \\
\hline & 1 & 2 & 3 & 4 & $\begin{array}{c}\% \text { de } \\
\text { imóveis }\end{array}$ & $\mathrm{pH}_{\mathrm{i}}$ & $\mathrm{pH}_{\mathrm{f}}$ & $\begin{array}{c}\mathrm{OD}_{\mathrm{i}} \\
\left(\mathrm{mg} \cdot \mathrm{L}^{-1}\right)\end{array}$ & $\begin{array}{c}\mathrm{OD}_{\mathrm{f}} \\
\left(\mathrm{mg} \cdot \mathrm{L}^{-1}\right)\end{array}$ & $\underset{\left(\mu S . \mathrm{cm}^{-1}\right)}{\text { Cond }_{i}}$ & $\begin{array}{c}\text { Cond }_{\mathrm{f}} \\
\left(\mu \mathrm{SS}^{-1} \mathrm{~cm}^{-1}\right)\end{array}$ \\
\hline Controle & 0 & 0 & 0 & 0 & 0 & 7,65 & 6,50 & 8,07 & 7,72 & 201,2 & 223 \\
\hline 25 & 2 & 1 & 3 & 2 & 8 & 7,86 & 6,69 & 8,10 & 7,90 & 154,8 & 165,3 \\
\hline 30 & 5 & 3 & 2 & 5 & 15 & 7,87 & 6,80 & 8,10 & 7,90 & 147,2 & 153,5 \\
\hline 35 & 3 & 5 & 5 & 5 & 18 & 7,63 & 6,82 & 8,10 & 7,94 & 145,0 & 149,4 \\
\hline 40 & 5 & 5 & 5 & 4 & 19 & 7,77 & 6,93 & 8,04 & 7,94 & 134,4 & 140,9 \\
\hline 50 & 5 & 5 & 5 & 5 & 20 & 7,76 & 6,99 & 8,10 & 7,94 & 121,9 & 132,1 \\
\hline
\end{tabular}

Ensaio 4

\begin{tabular}{|c|c|c|c|c|c|c|c|c|c|c|c|}
\hline \multicolumn{8}{|c|}{ ENSAIO DE TOXICIDADE AGUDA - Daphnia similis } & \multirow{2}{*}{\multicolumn{4}{|c|}{$\begin{array}{c}\text { Dose de radiação: } 0,0 \text { kGy } \\
\text { Agua de diluição }\end{array}$}} \\
\hline \multicolumn{5}{|c|}{ Início } & \multicolumn{3}{|c|}{ Término } & & & & \\
\hline $\begin{array}{c}\text { Data: } \\
\text { 23/06/2015 }\end{array}$ & \multicolumn{4}{|c|}{$\begin{array}{l}\text { Hora: } \\
8: 45\end{array}$} & $\begin{array}{c}\text { Data: } \\
25 / 06 / 2015\end{array}$ & \multicolumn{2}{|c|}{$\begin{array}{l}\text { Hora: } \\
8: 55\end{array}$} & $\begin{array}{r}\text { Dureza } \\
45,0 \mathrm{mg}\end{array}$ & $\begin{array}{l}\text { la água: } \\
\mathrm{aCO}_{3} \cdot \mathrm{L}^{-1}\end{array}$ & \multicolumn{2}{|c|}{$\begin{array}{l}\text { Manancial: } \\
\text { Salto - SP }\end{array}$} \\
\hline \multicolumn{5}{|c|}{$\begin{array}{l}\text { Organismo-teste: } \\
\text { Daphnia similis }\end{array}$} & \multicolumn{3}{|c|}{$\begin{array}{c}\text { Amostra: } \\
\text { Diclofenaco sódico } \\
(0,0 \mathrm{kGy})\end{array}$} & \multicolumn{4}{|c|}{ Operador: Flávio } \\
\hline & 1 & 2 & 3 & 4 & $\begin{array}{l}\% \text { de } \\
\text { imóveis }\end{array}$ & $\mathrm{pH}_{\mathrm{i}}$ & $\mathrm{pH}_{\mathrm{f}}$ & $\begin{array}{c}\mathrm{OD}_{\mathrm{i}} \\
\left(\mathrm{mg} \cdot \mathrm{L}^{-1}\right)\end{array}$ & $\begin{array}{c}\mathrm{OD}_{\mathrm{f}} \\
\left(\mathrm{mg} \cdot \mathrm{L}^{-1}\right)\end{array}$ & $\underset{\left(\mu S . \mathrm{cm}^{-1}\right)}{\text { Cond }_{\mathrm{i}}}$ & $\begin{array}{c}\text { Cond }_{f} \\
\left(\mu S . \mathrm{cm}^{-1}\right)\end{array}$ \\
\hline Controle & 0 & 0 & 0 & 0 & $\mathbf{0}$ & 7,96 & 6,58 & 7,86 & 8,46 & 177,6 & 196,9 \\
\hline 12,5 & 0 & 0 & 0 & 0 & $\mathbf{0}$ & 7,17 & 6,15 & 8,06 & 8,55 & 163 & 215,2 \\
\hline 25,0 & 1 & 0 & 1 & 1 & 3 & 6,62 & 6,40 & 8,04 & 8,47 & 147,9 & 215,2 \\
\hline 30,0 & 3 & 0 & 3 & 1 & 7 & 6,95 & 6,58 & 8,07 & 8,47 & 141,9 & 150,6 \\
\hline 35,0 & 4 & 5 & 4 & 3 & 16 & 7,03 & 6,68 & 8,05 & 8,42 & 135,5 & 141,8 \\
\hline 50,0 & 5 & 5 & 5 & 5 & 20 & 7,08 & 6,76 & 8,10 & 8,42 & 116,8 & 123,3 \\
\hline
\end{tabular}

Ensaio 5

\begin{tabular}{|c|c|c|c|c|c|c|c|c|c|c|c|}
\hline \multicolumn{8}{|c|}{ ENSAIO DE TOXICIDADE AGUDA - Daphnia similis } & \multirow{2}{*}{\multicolumn{4}{|c|}{$\frac{\text { Dose de radiação: } 0,0 \text { kGy }}{\text { Água de diluição }}$}} \\
\hline \multicolumn{5}{|c|}{ Início } & \multicolumn{3}{|c|}{ Término } & & & & \\
\hline $\begin{array}{c}\text { Data: } \\
\text { 23/06/2015 }\end{array}$ & & & & & $\begin{array}{c}\text { Data: } \\
\text { 25/06/2015 }\end{array}$ & & & \multicolumn{2}{|c|}{ da água: } & \multicolumn{2}{|c|}{$\begin{array}{l}\text { Manancial: } \\
\text { Salto - SP }\end{array}$} \\
\hline \multicolumn{5}{|c|}{$\begin{array}{l}\text { Organismo-teste: } \\
\text { Daphnia similis }\end{array}$} & \multicolumn{3}{|c|}{$\begin{array}{c}\text { Amostra: } \\
\text { Diclofenaco sódico } \\
\text { (0,0 kGy) }\end{array}$} & \multicolumn{4}{|c|}{ Operador: Flávio } \\
\hline & 1 & 2 & 3 & 4 & $\begin{array}{c}\text { \% de } \\
\text { imóveis }\end{array}$ & $\mathrm{pH}_{\mathrm{i}}$ & $\mathrm{pH}_{\mathrm{f}}$ & $\begin{array}{c}\mathrm{OD}_{\mathrm{i}} \\
\left(\mathrm{mg} \cdot \mathrm{L}^{-1}\right)\end{array}$ & $\begin{array}{c}\mathrm{OD}_{\mathrm{f}} \\
\left(\mathrm{mg} \cdot \mathrm{L}^{-1}\right)\end{array}$ & $\begin{array}{c}\text { Cond }_{\mathrm{i}} \\
\left(\mu \mathrm{S} . \mathrm{cm}^{-1}\right)\end{array}$ & $\begin{array}{c}\text { Cond }_{f} \\
\left(\mu S . \mathrm{cm}^{-1}\right)\end{array}$ \\
\hline Controle & 0 & 0 & 0 & 0 & 0 & 7,96 & 6,58 & 7,86 & 8,46 & 177,6 & 196,9 \\
\hline 12,5 & 0 & $\mathbf{0}$ & $\mathbf{0}$ & 0 & $\mathbf{0}$ & 7,17 & 6,15 & 8,06 & 8,55 & 163 & 215,2 \\
\hline 25,0 & 0 & 0 & 1 & 1 & 2 & 6,62 & 6,40 & 8,04 & 8,47 & 147,9 & 215,2 \\
\hline 30,0 & 1 & 3 & 2 & 1 & 7 & 6,95 & 6,58 & 8,07 & 8,47 & 141,9 & 150,6 \\
\hline 35,0 & 3 & 4 & 3 & 5 & 15 & 7,03 & 6,68 & 8,05 & 8,42 & 135,5 & 141,8 \\
\hline 50,0 & 5 & 5 & 5 & 5 & 20 & 7,08 & 6,76 & 8,10 & 8,42 & 116,8 & 123,3 \\
\hline
\end{tabular}


Ensaio 6

\begin{tabular}{|c|c|c|c|c|c|c|c|c|c|c|c|}
\hline \multicolumn{8}{|c|}{ ENSAIO DE TOXICIDADE AGUDA - Daphnia similis } & \multirow{2}{*}{\multicolumn{4}{|c|}{$\frac{\text { Dose de radiação: } \mathbf{0 , 0} \text { kGy }}{\text { Água de diluição }}$}} \\
\hline \multicolumn{5}{|c|}{ Início } & \multicolumn{3}{|c|}{ Término } & & & & \\
\hline $\begin{array}{c}\text { Data: } \\
11 / 08 / 2015\end{array}$ & & \multicolumn{3}{|c|}{$\begin{array}{l}\text { Hora: } \\
14: 00\end{array}$} & $\begin{array}{c}\text { Data: } \\
13 / 08 / 2015\end{array}$ & \multicolumn{2}{|c|}{$\begin{array}{l}\text { Hora: } \\
14: 00\end{array}$} & $\begin{array}{r}\text { Dureza } \\
45,0 \mathrm{mg}\end{array}$ & $\begin{array}{l}\text { la água: } \\
\mathrm{aCO}_{3} \cdot \mathrm{L}^{-1}\end{array}$ & \multicolumn{2}{|c|}{$\begin{array}{l}\text { Manancial: } \\
\text { Salto - SP }\end{array}$} \\
\hline \multicolumn{5}{|c|}{$\begin{array}{l}\text { Organismo-teste: } \\
\text { Daphnia similis }\end{array}$} & \multicolumn{3}{|c|}{$\begin{array}{c}\text { Amostra: } \\
\text { Diclofenaco sódico } \\
\text { (0,0 kGy) }\end{array}$} & \multicolumn{4}{|c|}{ Operador: Flávio } \\
\hline & 1 & 2 & 3 & 4 & $\begin{array}{l}\text { \% de } \\
\text { imóveis }\end{array}$ & $\mathrm{pH}_{\mathrm{i}}$ & $\mathrm{pH}_{\mathrm{f}}$ & $\begin{array}{c}\mathrm{OD}_{\mathrm{i}} \\
\left(\mathrm{mg} \cdot \mathrm{L}^{-1}\right)\end{array}$ & $\begin{array}{c}\mathrm{OD}_{\mathrm{f}} \\
\left(\mathrm{mg} \cdot \mathrm{L}^{-1}\right)\end{array}$ & $\begin{array}{c}\text { Cond }_{\mathrm{i}} \\
\left(\mu \mathrm{S} . \mathrm{cm}^{-1}\right)\end{array}$ & $\begin{array}{c}\text { Cond }_{\mathrm{f}} \\
\left(\mu \mathrm{S}_{\mathrm{c}} \mathrm{cm}^{-1}\right)\end{array}$ \\
\hline Controle & 0 & 0 & 0 & 0 & 0 & 7,24 & 6,99 & 7,80 & 7,87 & 208,7 & 231 \\
\hline 6,25 & 0 & 0 & 0 & 1 & 1 & 7,77 & 7,36 & 7,82 & 7,54 & 193,9 & 196,0 \\
\hline 12,5 & 0 & 5 & 4 & 5 & 14 & 7,61 & 7,38 & 7,82 & 7,51 & 191,0 & 194,7 \\
\hline 25 & 0 & 2 & 2 & 5 & 9 & 7,65 & 7,38 & 7,77 & 7,42 & 174,3 & 178,5 \\
\hline 37,5 & 4 & 5 & 5 & 5 & 19 & 7,68 & 7,38 & 7,75 & 7,37 & 159,6 & 165,9 \\
\hline 50 & 5 & 5 & 5 & 5 & 20 & 7,68 & 7,40 & 7,80 & 7,44 & 145,7 & 156,3 \\
\hline
\end{tabular}

Ensaio 7

\begin{tabular}{|c|c|c|c|c|c|c|c|c|c|c|c|}
\hline \multicolumn{8}{|c|}{ ENSAIO DE TOXICIDADE AGUDA - Daphnia similis } & \multirow{2}{*}{\multicolumn{4}{|c|}{$\frac{\text { Dose de radiação: } 0,0 \text { kGy }}{\text { Água de diluição }}$}} \\
\hline \multicolumn{5}{|c|}{ Início } & \multicolumn{3}{|c|}{ Término } & & & & \\
\hline $\begin{array}{c}\text { Data: } \\
\text { 19/08/2015 }\end{array}$ & & & & & $\begin{array}{c}\text { Data: } \\
\text { 21/08/2015 }\end{array}$ & & & $\begin{array}{r}\text { Dureza } \\
45,0 \mathrm{mg}\end{array}$ & $\begin{array}{l}\text { la água: } \\
\text { :aCO} \\
\mathrm{L}_{3} \mathrm{~L}^{-1}\end{array}$ & \multicolumn{2}{|c|}{$\begin{array}{l}\text { Manancial: } \\
\text { Salto-SP }\end{array}$} \\
\hline \multicolumn{5}{|c|}{$\begin{array}{l}\text { Organismo-teste: } \\
\text { Daphnia similis }\end{array}$} & \multicolumn{3}{|c|}{$\begin{array}{c}\text { Amostra: } \\
\text { Diclofenaco sódico } \\
\text { (0,0 kGy) }\end{array}$} & \multicolumn{4}{|c|}{ Operador: Flávio } \\
\hline & 1 & 2 & 3 & 4 & $\begin{array}{l}\text { \% de } \\
\text { imóveis }\end{array}$ & $\mathrm{pH}_{\mathrm{i}}$ & $\mathrm{pH}_{\mathrm{f}}$ & $\begin{array}{c}\mathrm{OD}_{\mathrm{i}} \\
\left(\mathrm{mg} \cdot \mathrm{L}^{-1}\right)\end{array}$ & $\begin{array}{c}\mathrm{OD}_{\mathrm{f}} \\
\left(\mathrm{mg} \cdot \mathrm{L}^{-1}\right)\end{array}$ & $\begin{array}{c}\text { Cond }_{\mathrm{i}} \\
\left(\mu \mathrm{S} \cdot \mathrm{cm}^{-1}\right)\end{array}$ & $\underset{\left(\mu S . \mathrm{cm}^{-1}\right)}{\text { Cond }_{f}}$ \\
\hline Controle & $\mathbf{0}$ & $\mathbf{0}$ & $\mathbf{0}$ & $\mathbf{0}$ & $\mathbf{0}$ & 7,04 & 6,53 & 7,48 & 7,82 & 232 & 240 \\
\hline 6,25 & $\mathbf{0}$ & 0 & $\mathbf{0}$ & $\mathbf{0}$ & $\mathbf{0}$ & 7,23 & 6,68 & 7,43 & 7,71 & 196,1 & 199,2 \\
\hline 12,5 & 0 & 0 & $\mathbf{0}$ & $\mathbf{0}$ & $\mathbf{0}$ & 7,30 & 6,78 & 7,45 & 7,61 & 186,9 & 188,9 \\
\hline 25 & $\mathbf{0}$ & 2 & 1 & $\mathbf{0}$ & 3 & 7,29 & 6,92 & 7,45 & 7,30 & 172,0 & 176,5 \\
\hline 37,5 & 5 & 5 & 5 & 5 & 20 & 7,23 & 7,00 & 7,51 & 7,51 & 156,9 & 160,9 \\
\hline 50 & 5 & 5 & 5 & 5 & 20 & 7,20 & 7,05 & 7,57 & 7,53 & 142,3 & 146,8 \\
\hline
\end{tabular}

Ensaio 8

\begin{tabular}{|c|c|c|c|c|c|c|c|c|c|c|c|}
\hline \multicolumn{8}{|c|}{ ENSAIO DE TOXICIDADE AGUDA - Daphnia similis } & \multirow{2}{*}{\multicolumn{4}{|c|}{$\frac{\text { Dose de radiação: } 0,0 \text { kGy }}{\text { Água de diluição }}$}} \\
\hline \multicolumn{5}{|c|}{ Início } & \multicolumn{3}{|c|}{ Término } & & & & \\
\hline $\begin{array}{c}\text { Data: } \\
\text { 25/08/2015 }\end{array}$ & & & & & $\begin{array}{c}\text { Data: } \\
\text { 27/08/2015 }\end{array}$ & & & \multicolumn{2}{|c|}{ da água: } & \multicolumn{2}{|c|}{$\begin{array}{l}\text { Manancial: } \\
\text { Salto - SP }\end{array}$} \\
\hline \multicolumn{5}{|c|}{$\begin{array}{l}\text { Organismo-teste: } \\
\text { Daphnia similis }\end{array}$} & \multicolumn{3}{|c|}{$\begin{array}{c}\text { Amostra: } \\
\text { Diclofenaco sódico } \\
\text { (0,0 kGy) }\end{array}$} & \multicolumn{4}{|c|}{ Operador: Flávio } \\
\hline & 1 & 2 & 3 & 4 & $\begin{array}{c}\text { \% de } \\
\text { imóveis }\end{array}$ & $\mathrm{pH}_{\mathrm{i}}$ & $\mathrm{pH}_{\mathrm{f}}$ & $\begin{array}{c}\mathrm{OD}_{\mathrm{i}} \\
\left(\mathrm{mg} \cdot \mathrm{L}^{-1}\right)\end{array}$ & $\begin{array}{c}\mathrm{OD}_{\mathrm{f}} \\
\left(\mathrm{mg} \cdot \mathrm{L}^{-1}\right)\end{array}$ & $\begin{array}{c}\text { Cond }_{\mathrm{i}} \\
\left(\mu \mathrm{S} . \mathrm{cm}^{-1}\right)\end{array}$ & $\begin{array}{c}\text { Cond }_{f} \\
\left(\mu S . \mathrm{cm}^{-1}\right)\end{array}$ \\
\hline Controle & 0 & 0 & 0 & 0 & 0 & 7,96 & 7,73 & 7,96 & 7,80 & 230 & 245 \\
\hline 6,25 & 0 & $\mathbf{0}$ & 0 & 1 & 1 & 6,83 & 7,80 & 7,89 & 7,69 & 197,2 & 202,1 \\
\hline 12,5 & 0 & 0 & 0 & 0 & $\mathbf{0}$ & 7,10 & 7,80 & 7,93 & 7,48 & 187,3 & 190,3 \\
\hline 25 & 3 & 3 & 4 & 5 & 15 & 7,18 & $\mathbf{7 , 7 9}$ & 7,93 & 7,53 & 175,8 & 178,3 \\
\hline 37,5 & 5 & 5 & 5 & 5 & 20 & 7,21 & 7,80 & 7,94 & 7,48 & 157,1 & 159,8 \\
\hline 50 & 5 & 5 & 5 & 5 & 20 & 7,22 & 7,78 & 7,94 & 7,46 & 142,3 & 146,2 \\
\hline
\end{tabular}


Ensaio 9

\begin{tabular}{|c|c|c|c|c|c|c|c|c|c|c|c|}
\hline \multicolumn{8}{|c|}{ ENSAIO DE TOXICIDADE AGUDA - Daphnia similis } & \multirow{2}{*}{\multicolumn{4}{|c|}{$\begin{array}{c}\text { Dose de radiação: 0,0 kGy } \\
\text { Água de diluição }\end{array}$}} \\
\hline \multicolumn{5}{|c|}{ Início } & \multicolumn{3}{|c|}{ Término } & & & & \\
\hline $\begin{array}{c}\text { Data: } \\
01 / 09 / 2015\end{array}$ & & & & & $\begin{array}{c}\text { Data: } \\
\text { 03/09/2015 }\end{array}$ & & & \multicolumn{2}{|c|}{$\begin{array}{l}\text { Água } 0 \\
\text { da água: }\end{array}$} & \multicolumn{2}{|c|}{$\begin{array}{l}\text { Manancial: } \\
\text { Salto - SP }\end{array}$} \\
\hline \multicolumn{5}{|c|}{$\begin{array}{l}\text { Organismo-teste: } \\
\text { Daphnia similis }\end{array}$} & \multicolumn{3}{|c|}{$\begin{array}{c}\text { Amostra: } \\
\text { Diclofenaco sódico } \\
(0,0 \text { kGy })\end{array}$} & \multicolumn{4}{|c|}{ Operador: Flávio } \\
\hline & 1 & 2 & 3 & 4 & $\begin{array}{c}\% \text { de } \\
\text { imóveis }\end{array}$ & $\mathrm{pH}_{\mathrm{i}}$ & $\mathrm{pH}_{\mathrm{f}}$ & $\begin{array}{c}\mathrm{OD}_{\mathrm{i}} \\
\left(\mathrm{mg} \cdot \mathrm{L}^{-1}\right)\end{array}$ & $\begin{array}{c}\mathrm{OD}_{\mathrm{f}} \\
\left(\mathrm{mg} \cdot \mathrm{L}^{-1}\right)\end{array}$ & $\underset{\left(\mu S . \mathrm{cm}^{-1}\right)}{\text { Cond }_{i}}$ & $\begin{array}{c}\text { Cond }_{\mathrm{f}} \\
\left(\mu \mathrm{SS}^{-1} \mathrm{~cm}^{-1}\right)\end{array}$ \\
\hline Controle & 0 & 0 & $\mathbf{0}$ & 0 & 0 & 7,07 & 7,20 & 7,85 & 7,54 & 211,8 & 291 \\
\hline 6,25 & 0 & $\mathbf{0}$ & $\mathbf{0}$ & $\mathbf{0}$ & $\mathbf{0}$ & 7,35 & 7,54 & 8,20 & 7,46 & 198,7 & 208,5 \\
\hline 12,5 & 0 & $\mathbf{0}$ & $\mathbf{0}$ & 0 & $\mathbf{0}$ & 7,42 & 7,63 & 8,22 & 7,43 & 191,7 & 194,9 \\
\hline 25 & 2 & 5 & 5 & 3 & 15 & 7,43 & 7,62 & 8,26 & 7,21 & 175,9 & 178,5 \\
\hline 37,5 & 4 & 4 & 5 & 4 & 17 & 7,39 & 7,61 & 8,29 & 7,18 & 160,1 & 165,0 \\
\hline 50 & 5 & 5 & 5 & 5 & 20 & 7,36 & 7,55 & 8,30 & 7,24 & 146,4 & 153,1 \\
\hline
\end{tabular}

Ensaio 10

\begin{tabular}{|c|c|c|c|c|c|c|c|c|c|c|c|}
\hline \multicolumn{8}{|c|}{ ENSAIO DE TOXICIDADE AGUDA - Daphnia similis } & \multirow{2}{*}{\multicolumn{4}{|c|}{$\begin{array}{c}\text { Dose de radiação: } 0,0 \text { kGy } \\
\text { Aggua de diluição }\end{array}$}} \\
\hline \multicolumn{5}{|c|}{ Início } & \multicolumn{3}{|c|}{ Término } & & & & \\
\hline $\begin{array}{c}\text { Data: } \\
01 / 09 / 2015\end{array}$ & \multicolumn{4}{|c|}{$\begin{array}{l}\text { Hora: } \\
16: 11\end{array}$} & $\begin{array}{l}\text { Data: } \\
\text { 03/09/2015 }\end{array}$ & \multicolumn{2}{|c|}{$\begin{array}{l}\text { Hora: } \\
16: 11\end{array}$} & $\begin{array}{r}\text { Dureza } \\
45,0 \mathrm{mg}\end{array}$ & $\begin{array}{l}\text { a água: } \\
\mathrm{aCO}_{3} \cdot \mathrm{L}^{-1}\end{array}$ & \multicolumn{2}{|c|}{$\begin{array}{l}\text { Manancial: } \\
\text { Salto - SP }\end{array}$} \\
\hline \multicolumn{5}{|c|}{$\begin{array}{l}\text { Organismo-teste: } \\
\text { Daphnia similis }\end{array}$} & \multicolumn{3}{|c|}{$\begin{array}{c}\text { Amostra: } \\
\text { Diclofenaco sódico } \\
(0,0 \text { kGy) }\end{array}$} & \multicolumn{4}{|c|}{ Operador: Flávio } \\
\hline & 1 & 2 & 3 & 4 & $\begin{array}{c}\% \text { de } \\
\text { imóveis }\end{array}$ & $\mathrm{pH}_{\mathrm{i}}$ & $\mathrm{pH}_{\mathrm{f}}$ & $\begin{array}{c}\mathrm{OD}_{\mathrm{i}} \\
\left(\mathrm{mg} \cdot \mathrm{L}^{-1}\right)\end{array}$ & $\begin{array}{c}\mathrm{OD}_{\mathrm{f}} \\
\left(\mathrm{mg} \cdot \mathrm{L}^{-1}\right)\end{array}$ & $\underset{\left(\mu \mathrm{S} . \mathrm{cm}^{-1}\right)}{\text { Cond }_{\mathrm{i}}}$ & $\begin{array}{c}\text { Cond }_{f} \\
\left(\mu S \cdot \mathrm{cm}^{-1}\right)\end{array}$ \\
\hline Controle & $\mathbf{0}$ & 0 & $\mathbf{0}$ & $\mathbf{0}$ & 0 & 7,07 & 7,20 & 7,85 & 7,54 & 211,8 & 291 \\
\hline 6,25 & 0 & 0 & $\mathbf{0}$ & 0 & 0 & 7,35 & 7,54 & 8,20 & 7,46 & 198,7 & 208,5 \\
\hline 12,5 & 0 & 0 & 0 & 1 & 1 & 7,42 & 7,63 & 8,22 & 7,43 & 191,7 & 194,9 \\
\hline 25 & 1 & 3 & 3 & 1 & 8 & 7,43 & 7,62 & 8,26 & 7,21 & 175,9 & 178,5 \\
\hline 37,5 & 5 & 4 & 3 & 4 & 12 & 7,39 & 7,61 & 8,29 & 7,18 & 160,1 & 165,0 \\
\hline 50 & 5 & 5 & 5 & 5 & 20 & 7,36 & 7,55 & 8,30 & 7,24 & 146,4 & 153,1 \\
\hline
\end{tabular}

Observações: CE50 $48 \mathrm{~h}: 27,27(23,30-31,92)$

Ensaios de toxicidade aguda com as soluções preparadas a partir do diclofenaco sódico de $100 \mathrm{mg} \cdot \mathrm{L}^{-1}$ (5,0 kGy)

Ensaio 1

\begin{tabular}{|c|c|c|c|c|c|c|c|c|c|c|c|}
\hline \multicolumn{8}{|c|}{ ENSAIO DE TOXICIDADE AGUDA - Daphnia similis } & \multirow{2}{*}{\multicolumn{4}{|c|}{$\begin{array}{c}\text { Dose de radiação: 5,0 kGy } \\
\text { Água de diluição }\end{array}$}} \\
\hline \multicolumn{5}{|c|}{ Início } & \multicolumn{3}{|c|}{ Término } & & & & \\
\hline $\begin{array}{l}\text { Data: } \\
\text { 20/12/2014 }\end{array}$ & \multicolumn{4}{|c|}{$\begin{array}{l}\text { Hora: } \\
12: 11\end{array}$} & $\begin{array}{c}\text { Data: } \\
\text { 22/12/2014 }\end{array}$ & \multicolumn{2}{|c|}{$\begin{array}{l}\text { Hora: } \\
12: 11\end{array}$} & $\begin{array}{r}\text { Dureza } \\
45,0 \mathrm{mg}\end{array}$ & $\begin{array}{l}\text { a água: } \\
\mathrm{aCO}_{3} \cdot \mathrm{L}^{-1}\end{array}$ & \multicolumn{2}{|c|}{$\begin{array}{l}\text { Manancial: } \\
\text { Salto - SP }\end{array}$} \\
\hline \multicolumn{5}{|c|}{$\begin{array}{l}\text { Organismo-teste: } \\
\text { Daphnia similis }\end{array}$} & \multicolumn{3}{|c|}{$\begin{array}{c}\text { Amostra: } \\
\text { Diclofenaco sódico } \\
(0,0 \text { kGy) }\end{array}$} & \multicolumn{4}{|c|}{ Operador: Flávio } \\
\hline & 1 & 2 & 3 & 4 & $\begin{array}{l}\text { \% de } \\
\text { imóveis }\end{array}$ & $\mathrm{pH}_{\mathrm{i}}$ & $\mathrm{pH}_{\mathrm{f}}$ & $\begin{array}{c}\mathrm{OD}_{\mathrm{i}} \\
\left(\mathrm{mg} \cdot \mathrm{L}^{-1}\right)\end{array}$ & $\begin{array}{c}\mathrm{OD}_{\mathrm{f}} \\
\left(\mathrm{mg} \cdot \mathrm{L}^{-1}\right)\end{array}$ & $\begin{array}{l}\text { Cond }_{\mathrm{i}} \\
\left(\mu \mathrm{S} \cdot \mathrm{cm}^{-1}\right)\end{array}$ & $\begin{array}{c}\text { Cond }_{f} \\
\left(\mu \mathrm{S}_{\mathrm{f}} \mathrm{cm}^{-1}\right)\end{array}$ \\
\hline Controle & 0 & 0 & 0 & 0 & 0 & 7,84 & 6,6 & 7,51 & 7,37 & 183,8 & 195,5 \\
\hline 6,25 & 0 & 0 & 0 & 0 & 0 & 7,83 & 6,67 & 7,46 & 7,42 & 169,4 & 174,2 \\
\hline 12,5 & 0 & 0 & 0 & 0 & 0 & 7,79 & 6,78 & 7,42 & 7,38 & 162,7 & 164,6 \\
\hline 25,0 & 0 & 1 & 1 & 1 & 3 & 7,72 & 6,83 & 7,39 & 7,34 & 153,7 & 154,4 \\
\hline 37,5 & 5 & 5 & 5 & 5 & 20 & 7,63 & 6,88 & 7,27 & 7,31 & 143,8 & 144,1 \\
\hline 50 & 5 & 5 & 5 & 5 & 20 & 7,52 & 6,96 & 7,20 & 7,34 & 134,7 & 134,5 \\
\hline
\end{tabular}


Ensaio 2

\begin{tabular}{|c|c|c|c|c|c|c|c|c|c|c|c|}
\hline \multicolumn{8}{|c|}{ ENSAIO DE TOXICIDADE AGUDA - Daphnia similis } & \multirow{2}{*}{\multicolumn{4}{|c|}{$\begin{array}{c}\text { Dose de radiação: } 5,0 \text { kGy } \\
\text { Água de diluição }\end{array}$}} \\
\hline \multicolumn{5}{|c|}{ Início } & \multicolumn{3}{|c|}{ Término } & & & & \\
\hline $\begin{array}{c}\text { Data: } \\
\text { 20/12/2014 }\end{array}$ & & & & & $\begin{array}{c}\text { Data: } \\
\text { 22/12/2014 }\end{array}$ & & & \multicolumn{2}{|c|}{$\begin{array}{l}\text { Água c } \\
\text { a da água: } \\
\mathrm{CaCO}_{3} \mathrm{~L}^{-1}\end{array}$} & \multicolumn{2}{|c|}{$\begin{array}{l}\text { Manancial: } \\
\text { Salto - SP }\end{array}$} \\
\hline \multicolumn{5}{|c|}{$\begin{array}{l}\text { Organismo-teste: } \\
\text { Daphnia similis }\end{array}$} & \multicolumn{3}{|c|}{$\begin{array}{c}\text { Amostra: } \\
\text { Diclofenaco sódico } \\
(0,0 \mathrm{kGy})\end{array}$} & \multicolumn{4}{|c|}{ Operador: Flávio } \\
\hline & 1 & 2 & 3 & 4 & $\begin{array}{c}\text { \% de } \\
\text { imóveis }\end{array}$ & $\mathrm{pH}_{\mathrm{i}}$ & $\mathrm{pH}_{\mathrm{f}}$ & $\begin{array}{c}\mathrm{OD}_{\mathrm{i}} \\
\left(\mathrm{mg} \cdot \mathrm{L}^{-1}\right)\end{array}$ & $\begin{array}{c}O_{\mathrm{OD}} \\
\left(\mathrm{mg} \cdot \mathrm{L}^{-1}\right)\end{array}$ & $\begin{array}{c}\text { Cond }_{\mathrm{i}} \\
\left(\mu \mathrm{S} . \mathrm{cm}^{-1}\right)\end{array}$ & $\begin{array}{c}\text { Cond }_{f} \\
\left(\mu S . \mathrm{cm}^{-1}\right)\end{array}$ \\
\hline Controle & 0 & 0 & 0 & 0 & 0 & 7,84 & 6,61 & 7,51 & 7,37 & 183,8 & 195,5 \\
\hline 6,25 & 0 & 0 & $\mathbf{0}$ & $\mathbf{0}$ & $\mathbf{0}$ & 7,83 & 6,67 & 7,46 & 7,42 & 169,4 & 174,2 \\
\hline 12,5 & 0 & 0 & $\mathbf{0}$ & 0 & $\mathbf{0}$ & 7,79 & 6,78 & 7,42 & 7,38 & 162,7 & 164,6 \\
\hline 25,0 & 0 & 0 & 1 & 0 & 1 & 7,72 & 6,83 & 7,39 & 7,34 & 153,7 & 154,4 \\
\hline 37,5 & 5 & 5 & 4 & 5 & 19 & 7,63 & 6,88 & 7,27 & 7,31 & 143,8 & 144,1 \\
\hline 50 & 5 & 5 & 5 & 5 & 20 & 7,52 & 6,96 & 7,20 & 7,34 & 134,7 & 134,5 \\
\hline
\end{tabular}

Ensaios de toxicidade aguda com as soluções preparadas a partir da Diluição 1:1

(0,0 kGy)

Ensaio 1

\begin{tabular}{|c|c|c|c|c|c|c|c|c|c|c|c|}
\hline \multicolumn{8}{|c|}{ ENSAIO DE TOXICIDADE AGUDA - Daphnia similis } & \multirow{2}{*}{\multicolumn{4}{|c|}{$\begin{array}{c}\text { Dose de radiação: 0,0 kGy } \\
\text { Aqua de diluicão }\end{array}$}} \\
\hline \multicolumn{5}{|c|}{ Início } & \multicolumn{3}{|c|}{ Término } & & & & \\
\hline $\begin{array}{c}\text { Data: } \\
\text { 17/03/2015 }\end{array}$ & & & & & $\begin{array}{c}\text { Data: } \\
\text { 19/03/2015 }\end{array}$ & & & \multicolumn{2}{|c|}{$\begin{array}{l}\text { Agua } \\
\text { da água: }\end{array}$} & \multicolumn{2}{|c|}{$\begin{array}{l}\text { Manancial: } \\
\text { Salto-SP }\end{array}$} \\
\hline \multicolumn{5}{|c|}{$\begin{array}{c}\text { Organismo-teste: } \\
\text { Daphnia similis }\end{array}$} & \multicolumn{3}{|c|}{$\begin{array}{c}\text { Amostra: } \\
\text { Diluição 1:1 (0,0 kGy) }\end{array}$} & \multicolumn{4}{|c|}{ Operador: Flávio } \\
\hline & 1 & 2 & 3 & 4 & $\begin{array}{l}\text { \% de } \\
\text { imóveis }\end{array}$ & $\mathrm{pH}_{\mathrm{i}}$ & $\mathrm{pH}_{\mathrm{f}}$ & $\underset{\left(m g \cdot L^{-1}\right)}{O D_{i}}$ & $\underset{\left(m g \cdot L^{-1}\right)}{O D_{f}}$ & $\begin{array}{l}\text { Cond }_{i} \\
\left(\mu \mathrm{S} . \mathrm{cm}^{-1}\right)\end{array}$ & $\begin{array}{l}\text { Cond }_{f} \\
\left(\mu S . \mathrm{cm}^{-1}\right)\end{array}$ \\
\hline Controle & 0 & $\mathbf{0}$ & $\mathbf{0}$ & $\mathbf{0}$ & $\mathbf{0}$ & 7,00 & 6,84 & 7,51 & 7,52 & 244 & 267 \\
\hline 6,25 & $\mathbf{0}$ & $\mathbf{0}$ & $\mathbf{0}$ & $\mathbf{0}$ & 0 & 7,40 & 7,36 & 7,39 & 7,76 & 221 & 223 \\
\hline 12,5 & $\mathbf{0}$ & $\mathbf{0}$ & $\mathbf{0}$ & 1 & 1 & 7,43 & 7,40 & 7,42 & 7,75 & 231208,2 & 208,9 \\
\hline 25 & 3 & 5 & 3 & 5 & 18 & 7,47 & 7,46 & 7,46 & 7,79 & 227182,3 & 184,5 \\
\hline 50 & 5 & 5 & 5 & 5 & 20 & 7,56 & 7,54 & 7,62 & 7,78 & 131,3 & 133,1 \\
\hline 100 & 5 & 5 & 5 & 5 & 20 & 7,86 & 7,74 & 7,96 & 7,89 & 32,3 & 36,8 \\
\hline
\end{tabular}

Ensaio 2

\begin{tabular}{|c|c|c|c|c|c|c|c|c|c|c|c|}
\hline \multicolumn{8}{|c|}{ ENSAIO DE TOXICIDADE AGUDA - Daphnia similis } & \multirow{2}{*}{\multicolumn{4}{|c|}{$\begin{array}{c}\text { Dose de radiação: } 0,0 \text { kGy } \\
\text { Água de diluição }\end{array}$}} \\
\hline \multicolumn{5}{|c|}{ Início } & \multicolumn{3}{|c|}{ Término } & & & & \\
\hline $\begin{array}{l}\text { Data: } \\
\text { 24/03/2015 }\end{array}$ & \multicolumn{4}{|c|}{$\begin{array}{l}\text { Hora: } \\
15: 15\end{array}$} & $\begin{array}{c}\text { Data: } \\
26 / 03 / 2015\end{array}$ & \multicolumn{2}{|c|}{$\begin{array}{l}\text { Hora: } \\
15: 15\end{array}$} & $\begin{array}{r}\text { Dureza } \\
45,0 \mathrm{mg} \\
\end{array}$ & $\begin{array}{l}\text { la água: } \\
\text { jaCO } \\
\mathrm{L}^{-1}\end{array}$ & \multicolumn{2}{|c|}{$\begin{array}{l}\text { Manancial: } \\
\text { Salto - SP }\end{array}$} \\
\hline \multicolumn{5}{|c|}{$\begin{array}{l}\text { Organismo-teste: } \\
\text { Daphnia similis }\end{array}$} & \multicolumn{3}{|c|}{$\begin{array}{c}\text { Amostra: } \\
\text { Diluição 1:1 (0,0 kGy) }\end{array}$} & \multicolumn{4}{|c|}{ Operador: Flávio } \\
\hline & 1 & 2 & 3 & 4 & $\begin{array}{l}\% \text { de } \\
\text { imóveis }\end{array}$ & $\mathrm{pH}_{\mathrm{i}}$ & $\mathrm{pH}_{\mathrm{f}}$ & $\begin{array}{c}\mathrm{OD}_{\mathrm{i}} \\
\left(\mathrm{mg} \cdot \mathrm{L}^{-1}\right)\end{array}$ & $\begin{array}{c}\mathrm{OD}_{\mathrm{f}} \\
\left(\mathrm{mg} \cdot \mathrm{L}^{-1}\right)\end{array}$ & $\begin{array}{c}\text { Cond }_{\mathrm{i}} \\
\left(\mu \mathrm{S} . \mathrm{cm}^{-1}\right)\end{array}$ & $\begin{array}{c}\text { Cond }_{\mathrm{f}} \\
\left(\mu \mathrm{S} . \mathrm{cm}^{-1}\right)\end{array}$ \\
\hline Controle & 0 & $\mathbf{0}$ & $\mathbf{0}$ & $\mathbf{0}$ & $\mathbf{0}$ & $\mathbf{7 , 7 8}$ & 7,11 & 7,67 & 7,63 & 254 & 263 \\
\hline 6,25 & 0 & 0 & 0 & $\mathbf{0}$ & $\mathbf{0}$ & 8,07 & 7, & 7,63 & 7, & 214,9 & 216,9 \\
\hline 12,5 & 0 & 0 & $\mathbf{0}$ & $\mathbf{0}$ & 0 & 8,07 & 7,44 & 7,63 & 7,7 & 206,5 & 208,4 \\
\hline 25 & 4 & 3 & 3 & 3 & 13 & 8,09 & 7 , & 7,65 & 7, & 179,2 & 182,1 \\
\hline 50 & 5 & 5 & 5 & 5 & 20 & 8,14 & 7,58 & 7,76 & 7,6 & 130,7 & 133,2 \\
\hline 100 & 5 & 5 & 5 & 5 & 20 & 8,37 & 7,85 & 8,09 & 7,82 & 35,8 & 39,2 \\
\hline
\end{tabular}


Ensaio 3

\begin{tabular}{|c|c|c|c|c|c|c|c|c|c|c|c|}
\hline \multicolumn{8}{|c|}{ ENSAIO DE TOXICIDADE AGUDA - Daphnia similis } & \multirow{2}{*}{\multicolumn{4}{|c|}{$\begin{array}{c}\text { Dose de radiação: 0,0 kGy } \\
\text { Água de diluição }\end{array}$}} \\
\hline \multicolumn{5}{|c|}{ Início } & \multicolumn{3}{|c|}{ Término } & & & & \\
\hline $\begin{array}{c}\text { Data: } \\
24 / 03 / 2015\end{array}$ & & & & & $\begin{array}{c}\text { Data: } \\
\text { 26/03/2015 }\end{array}$ & & & \multicolumn{2}{|c|}{$\begin{array}{l}\text { Água o } \\
\text { da água: } \\
\mathrm{CaCO}_{3} \cdot \mathrm{L}^{-1}\end{array}$} & \multicolumn{2}{|c|}{$\begin{array}{l}\text { Manancial: } \\
\text { Salto - SP }\end{array}$} \\
\hline \multicolumn{5}{|c|}{$\begin{array}{l}\text { Organismo-teste: } \\
\text { Daphnia similis }\end{array}$} & \multicolumn{3}{|c|}{$\begin{array}{c}\text { Amostra: } \\
\text { Diluição 1:1 (0,0 kGy) }\end{array}$} & \multicolumn{4}{|c|}{ Operador: Flávio } \\
\hline & 1 & 2 & 3 & 4 & $\begin{array}{l}\% \text { de } \\
\text { imóveis }\end{array}$ & $\mathrm{pH}_{\mathrm{i}}$ & $\mathrm{pH}_{\mathrm{f}}$ & $\begin{array}{c}\mathrm{OD}_{\mathrm{i}} \\
\left(\mathrm{mg} \cdot \mathrm{L}^{-1}\right)\end{array}$ & $\begin{array}{c}\mathrm{OD}_{\mathrm{f}} \\
\left(\mathrm{mg} \cdot \mathrm{L}^{-1}\right)\end{array}$ & $\begin{array}{c}\text { Cond }_{\mathrm{i}} \\
\left(\mu{\left.\mathrm{S} . \mathrm{cm}^{-1}\right)}^{-1}\right.\end{array}$ & $\begin{array}{c}\text { Cond }_{f} \\
\left(\mu \text { S.cm }^{-1}\right)\end{array}$ \\
\hline Controle & 0 & 0 & 0 & 0 & 0 & $\mathbf{7 , 7 8}$ & 7,11 & 7,67 & 7,63 & 254 & 263 \\
\hline 6,25 & $\mathbf{0}$ & $\mathbf{0}$ & 0 & $\mathbf{0}$ & 0 & 8,07 & 7,4 & 7 & 7,7 & 214,9 & 216,9 \\
\hline 12,5 & 0 & 0 & 0 & 0 & 0 & 8,07 & 7, & 7,63 & 7,72 & 206,5 & 208,4 \\
\hline 25 & 0 & 0 & 0 & 0 & 1 & 8,09 & 7,48 & 7,65 & 7,61 & 179,2 & 182,1 \\
\hline 50 & 4 & 0 & 5 & 2 & 11 & 8,14 & 7,58 & 7,76 & 7,63 & 130,7 & 133,2 \\
\hline 100 & 5 & 5 & 5 & 5 & 20 & 8,37 & 7,85 & 8,09 & 7,82 & 35,8 & 39,2 \\
\hline
\end{tabular}

Ensaio 4

\begin{tabular}{|c|c|c|c|c|c|c|c|c|c|c|c|}
\hline \multicolumn{8}{|c|}{ ENSAIO DE TOXICIDADE AGUDA - Daphnia similis } & \multirow{2}{*}{\multicolumn{4}{|c|}{$\begin{array}{c}\text { Dose de radiação: 0,0 kGy } \\
\text { Agua de diluição }\end{array}$}} \\
\hline \multicolumn{5}{|c|}{ Início } & \multicolumn{3}{|c|}{ Término } & & & & \\
\hline $\begin{array}{l}\text { Data: } \\
06 / 05 / 2015\end{array}$ & \multicolumn{4}{|c|}{$\begin{array}{l}\text { Hora: } \\
14: 25\end{array}$} & $\begin{array}{c}\text { Data: } \\
08 / 05 / 2015\end{array}$ & \multicolumn{2}{|c|}{$\begin{array}{l}\text { Hora: } \\
14: 25\end{array}$} & $\begin{array}{l}\text { Dureza } \\
45,0 \mathrm{mg}\end{array}$ & $\begin{array}{l}\text { la água: } \\
\mathrm{aCO}_{3 \cdot \mathrm{L}^{-1}}\end{array}$ & \multicolumn{2}{|c|}{$\begin{array}{l}\text { Manancial: } \\
\text { Salto - SP }\end{array}$} \\
\hline \multicolumn{5}{|c|}{$\begin{array}{l}\text { Organismo-teste: } \\
\text { Daphnia similis }\end{array}$} & \multicolumn{3}{|c|}{$\begin{array}{c}\text { Amostra: } \\
\text { Diluição 1:1 (0,0 kGy) }\end{array}$} & \multicolumn{4}{|c|}{ Operador: Flávio } \\
\hline & 1 & 2 & 3 & 4 & $\begin{array}{l}\text { \% de } \\
\text { imóveis }\end{array}$ & $\mathrm{pH}_{\mathrm{i}}$ & $\mathrm{pH}_{\mathrm{f}}$ & $\begin{array}{c}\mathrm{OD}_{\mathrm{i}} \\
\left(\mathrm{mg} \cdot \mathrm{L}^{-1}\right)\end{array}$ & $\begin{array}{c}\mathrm{OD}_{\mathrm{f}} \\
\left(\mathrm{mg} \cdot \mathrm{L}^{-1}\right)\end{array}$ & $\underset{\left(\mu S . \mathrm{cm}^{-1}\right)}{\text { Cond }_{\mathrm{i}}}$ & $\begin{array}{c}\text { Cond }_{f} \\
\left(\mu S \cdot \mathrm{cm}^{-1}\right)\end{array}$ \\
\hline Controle & 0 & 0 & 0 & 0 & 0 & 6,67 & 7,94 & 7,85 & 8,16 & 233 & 263 \\
\hline 15 & 3 & 0 & 0 & 0 & 3 & 7,55 & 7,93 & $7,8^{1}$ & 8,2 & 206,8 & 222 \\
\hline 20 & 0 & 4 & 5 & 0 & 9 & 7,42 & 7,90 & 7,86 & 8,23 & 194,2 & 202,5 \\
\hline 25 & 0 & 5 & 4 & 4 & 13 & 7,42 & 7,91 & 7,86 & 8,21 & 185,6 & 191,6 \\
\hline 30 & 4 & 1 & 4 & 3 & 12 & 7,46 & 7,89 & 7,9 & 8,2 & 178,3 & 181,8 \\
\hline 40 & 5 & 5 & 5 & 5 & 20 & 7,51 & 7,90 & 7,90 & 8,16 & 160,9 & 165,6 \\
\hline
\end{tabular}

Ensaio 5

\begin{tabular}{|c|c|c|c|c|c|c|c|c|c|c|c|}
\hline \multicolumn{8}{|c|}{ ENSAIO DE TOXICIDADE AGUDA - Daphnia similis } & \multirow{2}{*}{\multicolumn{4}{|c|}{$\frac{\text { Dose de radiação: 0,0 kGy }}{\text { Água de diluição }}$}} \\
\hline \multicolumn{5}{|c|}{ Início } & \multicolumn{3}{|c|}{ Término } & & & & \\
\hline $\begin{array}{c}\text { Data: } \\
\text { 09/06/2015 }\end{array}$ & \multicolumn{4}{|c|}{$\begin{array}{l}\text { Hora: } \\
\text { 14:30 }\end{array}$} & $\begin{array}{c}\text { Data: } \\
11 / 06 / 2015\end{array}$ & \multicolumn{2}{|c|}{$\begin{array}{l}\text { Hora: } \\
14: 30\end{array}$} & $\begin{array}{r}\text { Dureza } \\
45,0 \mathrm{mg}\end{array}$ & la água: & \multicolumn{2}{|c|}{$\begin{array}{l}\text { Manancial: } \\
\text { Salto - SP }\end{array}$} \\
\hline \multicolumn{5}{|c|}{$\begin{array}{l}\text { Organismo-teste: } \\
\text { Daphnia similis }\end{array}$} & \multicolumn{3}{|c|}{$\begin{array}{c}\text { Amostra: } \\
\text { Diluição 1:1 (0,0 kGy) }\end{array}$} & \multicolumn{4}{|c|}{ Operador: Flávio } \\
\hline & 1 & 2 & 3 & 4 & $\begin{array}{c}\text { \% de } \\
\text { imóveis }\end{array}$ & $\mathrm{pH}_{\mathrm{i}}$ & $\mathrm{pH}_{\mathrm{f}}$ & $\begin{array}{c}\mathrm{OD}_{\mathrm{i}} \\
\left(\mathrm{mg} \cdot \mathrm{L}^{-1}\right)\end{array}$ & $\begin{array}{c}\mathrm{OD}_{\mathrm{f}} \\
\left(\mathrm{mg} \cdot \mathrm{L}^{-1}\right)\end{array}$ & $\begin{array}{c}\text { Cond }_{\mathrm{i}} \\
\left(\mu \mathrm{S} . \mathrm{cm}^{-1}\right)\end{array}$ & $\begin{array}{l}\text { Cond }_{f} \\
\left(\mu S . \mathrm{cm}^{-1}\right)\end{array}$ \\
\hline Controle & 0 & 0 & $\mathbf{0}$ & $\mathbf{0}$ & 0 & 7,21 & 7,68 & $\mathbf{7 , 7 4}$ & 7,81 & 185,8 & 223 \\
\hline 7,5 & 0 & 0 & $\mathbf{0}$ & $\mathbf{0}$ & 0 & 7,36 & 7,88 & 7,65 & 7, &, 5 & 196,5 \\
\hline 15 & 2 & 1 & 1 & $\mathbf{0}$ & 4 & 7,32 & 7,82 & 7, & 7, &, 3 & 170,2 \\
\hline 20 & 2 & 2 & 3 & 4 & 11 & 7,41 & 7,79 & 7,77 & 7 ; & 153,4 & 159,9 \\
\hline 25 & 4 & 4 & 3 & 5 & 16 & 7,45 & 7,78 & 7,79 & 7,65 & 146,5 & 152,4 \\
\hline 50 & 5 & 5 & 5 & 5 & 20 & 7,47 & 7,79 & 7,80 & 7,66 & 114,3 & 121,1 \\
\hline
\end{tabular}


Ensaio 6

\begin{tabular}{|c|c|c|c|c|c|c|c|c|c|c|c|}
\hline \multicolumn{8}{|c|}{ ENSAIO DE TOXICIDADE AGUDA - Daphnia similis } & \multirow{2}{*}{\multicolumn{4}{|c|}{$\begin{array}{c}\text { Dose de radiação: } 0,0 \text { kGy } \\
\text { Água de diluição }\end{array}$}} \\
\hline \multicolumn{5}{|c|}{ Início } & \multicolumn{3}{|c|}{ Término } & & & & \\
\hline $\begin{array}{c}\text { Data: } \\
01 / 08 / 2015\end{array}$ & & & & & $\begin{array}{c}\text { Data: } \\
03 / 08 / 2015\end{array}$ & & & \multicolumn{2}{|c|}{$\begin{array}{c}\text { Água o } \\
\text { a da água: } \\
\mathrm{CaCO}_{3} \mathrm{~L}^{-1}\end{array}$} & \multicolumn{2}{|c|}{$\begin{array}{l}\text { Manancial: } \\
\text { Salto - SP }\end{array}$} \\
\hline \multicolumn{5}{|c|}{$\begin{array}{l}\text { Organismo-teste: } \\
\text { Daphnia similis }\end{array}$} & \multicolumn{3}{|c|}{$\begin{array}{c}\text { Amostra: } \\
\text { Diluição 1:1 (0,0 kGy) }\end{array}$} & \multicolumn{4}{|c|}{ Operador: Flávio } \\
\hline & 1 & 2 & 3 & 4 & $\begin{array}{c}\text { \% de } \\
\text { imóveis }\end{array}$ & $\mathrm{pH}_{\mathrm{i}}$ & $\mathrm{pH}_{\mathrm{f}}$ & $\begin{array}{c}\mathrm{OD}_{\mathrm{i}} \\
\left(\mathrm{mg} \cdot \mathrm{L}^{-1}\right)\end{array}$ & $\begin{array}{c}\mathrm{OD}_{\mathrm{f}} \\
\left(\mathrm{mg} \cdot \mathrm{L}^{-1}\right)\end{array}$ & $\begin{array}{c}\text { Cond }_{i} \\
\left(\mu \text { S.cm }^{-1}\right)\end{array}$ & $\begin{array}{l}\text { Cond }_{f} \\
\left(\mu S \cdot \mathrm{cm}^{-1}\right)\end{array}$ \\
\hline Controle & 0 & 0 & 0 & 0 & 0 & 6,22 & 6,48 & 7,22 & 7,41 & 192,2 & 202,6 \\
\hline 12,5 & 0 & 0 & 0 & 0 & 0 & 7,22 & 7,28 & 8,26 & 7,74 & 0,9 & 208,0 \\
\hline 18,75 & 2 & 0 & 0 & 1 & 3 & 7,31 & 7,40 & 8,23 & 7,74 & 187,2 & 198,0 \\
\hline 25 & 2 & 2 & 4 & 1 & 9 & 7,34 & 7,46 & 8,24 & 7,64 & 175,7 & 188,3 \\
\hline 37,5 & 3 & 4 & 5 & 1 & 13 & 7,37 & 7,50 & 8,28 & 7,65 & 158,0 & 175,8 \\
\hline 50 & 4 & 5 & 5 & 5 & 19 & 7,36 & 7,52 & 8,34 & 7,79 & 140,0 & 164,4 \\
\hline
\end{tabular}

Ensaio 7

\begin{tabular}{|c|c|c|c|c|c|c|c|c|c|c|c|}
\hline \multicolumn{8}{|c|}{ ENSAIO DE TOXICIDADE AGUDA - Daphnia similis } & \multirow{2}{*}{\multicolumn{4}{|c|}{$\begin{array}{c}\text { Dose de radiação: } 0,0 \text { kGy } \\
\text { Aggua de diluição }\end{array}$}} \\
\hline \multicolumn{5}{|c|}{ Início } & \multicolumn{3}{|c|}{ Término } & & & & \\
\hline $\begin{array}{l}\text { Data: } \\
01 / 08 / 2015\end{array}$ & & & & & $\begin{array}{c}\text { Data: } \\
03 / 08 / 2015\end{array}$ & & & \multicolumn{2}{|r|}{$\begin{array}{l}\text { la água: } \\
\mathrm{aCO}_{3} \mathrm{~L}^{-1}\end{array}$} & \multicolumn{2}{|c|}{$\begin{array}{l}\text { Manancial: } \\
\text { Salto - SP }\end{array}$} \\
\hline \multicolumn{5}{|c|}{$\begin{array}{l}\text { Organismo-teste: } \\
\text { Daphnia similis }\end{array}$} & \multicolumn{3}{|c|}{$\begin{array}{c}\text { Amostra: } \\
\text { Diluição 1:1 (0,0 kGy) }\end{array}$} & \multicolumn{4}{|c|}{ Operador: Flávio } \\
\hline & 1 & 2 & 3 & 4 & $\begin{array}{l}\text { \% de } \\
\text { imóveis }\end{array}$ & $\mathrm{pH}_{\mathrm{i}}$ & $\mathrm{pH}_{\mathrm{f}}$ & $\begin{array}{c}\mathrm{OD}_{\mathrm{i}} \\
\left(\mathrm{mg} \cdot \mathrm{L}^{-1}\right)\end{array}$ & $\begin{array}{c}\mathrm{OD}_{\mathrm{f}} \\
\left(\mathrm{mg} \cdot \mathrm{L}^{-1}\right)\end{array}$ & $\underset{\left(\mu S . \mathrm{cm}^{-1}\right)}{\text { Cond }_{\mathrm{i}}}$ & $\begin{array}{l}\text { Cond }_{f} \\
\left(\mu S . \mathrm{cm}^{-1}\right)\end{array}$ \\
\hline Controle & 0 & 0 & 0 & 0 & 0 & 6,22 & 6,48 & 7,22 & 7,41 & 192,2 & 202,6 \\
\hline 12,5 & 1 & 2 & 0 & 0 & 3 & 7,22 & 7,28 & 8,26 & 7,7 & 200,9 & 208,0 \\
\hline 18,75 & 1 & 1 & 1 & 1 & 4 & 7,31 & 7,40 & 8,23 & 7,74 & 187,2 & 198,0 \\
\hline 25 & 4 & 4 & 1 & 2 & 11 & 7,34 & 7,46 & 8,24 & 7,64 & 175,7 & 188,3 \\
\hline 37,5 & 5 & 5 & 3 & 4 & 18 & 7,37 & 7,50 & 8,28 & 7,6 & 158,0 & 175,8 \\
\hline 50 & 4 & 5 & 5 & 5 & 19 & 7,36 & 7,52 & 8,34 & 7,79 & 140,0 & 164,4 \\
\hline
\end{tabular}

Ensaio 8

\begin{tabular}{|c|c|c|c|c|c|c|c|c|c|c|c|}
\hline \multicolumn{8}{|c|}{ ENSAIO DE TOXICIDADE AGUDA - Daphnia similis } & \multirow{2}{*}{\multicolumn{4}{|c|}{$\begin{array}{c}\text { Dose de radiação: 0,0 kGy } \\
\text { Água de diluição }\end{array}$}} \\
\hline \multicolumn{5}{|c|}{ Início } & \multicolumn{3}{|c|}{ Término } & & & & \\
\hline $\begin{array}{l}\text { Data: } \\
\text { 10/08/2015 }\end{array}$ & \multicolumn{4}{|c|}{$\begin{array}{l}\text { Hora: } \\
\text { 11:00 }\end{array}$} & $\begin{array}{c}\text { Data: } \\
\text { 12/08/2015 }\end{array}$ & \multicolumn{2}{|c|}{$\begin{array}{l}\text { Hora: } \\
11: 00\end{array}$} & $\begin{array}{l}\text { Dureza } \\
45,0 \mathrm{mg}\end{array}$ & $\begin{array}{l}\text { la água: } \\
\mathrm{aCO}_{3} \cdot \mathrm{L}^{-1}\end{array}$ & $\begin{array}{l}\text { Mane } \\
\text { Saltc }\end{array}$ & $\begin{array}{l}\text { ncial: } \\
\text {-SP }\end{array}$ \\
\hline \multicolumn{5}{|c|}{$\begin{array}{l}\text { Organismo-teste: } \\
\text { Daphnia similis }\end{array}$} & \multicolumn{3}{|c|}{$\begin{array}{c}\text { Amostra: } \\
\text { Diluição 1:1 (0,0 kGy) }\end{array}$} & \multicolumn{4}{|c|}{ Operador: Flávio } \\
\hline & 1 & 2 & 3 & 4 & $\begin{array}{c}\text { \% de } \\
\text { imóveis }\end{array}$ & $\mathrm{pH}_{\mathrm{i}}$ & $\mathrm{pH}_{\mathrm{f}}$ & $\begin{array}{c}\mathrm{OD}_{\mathrm{i}} \\
\left(\mathrm{mg} \cdot \mathrm{L}^{-1}\right)\end{array}$ & $\begin{array}{c}\mathrm{OD}_{\mathrm{f}} \\
\left(\mathrm{mg} \cdot \mathrm{L}^{-1}\right)\end{array}$ & $\underset{\left(\mu \text { S.cm }^{-1}\right)}{\text { Cond }_{i}}$ & $\begin{array}{l}\text { Cond }_{f} \\
\left(\mu S . \mathrm{cm}^{-1}\right)\end{array}$ \\
\hline Controle & 0 & 0 & 0 & 0 & 0 & 7,26 & 7,46 & 764 & 7,76 & 210,7 & 238 \\
\hline 12,5 & 1 & 2 & 2 & 0 & 5 & 7,34 & 7,60 & 7,6 & 7,7 & 186,3 & 195,8 \\
\hline 18,75 & 0 & 1 & 4 & 0 & 5 & 7,37 & 7,62 & 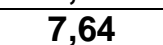 & 7, & 7,2 & 183,3 \\
\hline 25 & 2 & 3 & 5 & 5 & 15 & 7,39 & 7,60 & 7,66 & 7,62 & 169,0 & 174,1 \\
\hline 37,5 & 2 & 3 & 3 & 2 & 12 & 7,42 & 7,60 & 7,66 & 7,53 & 152,2 & 157,2 \\
\hline 50 & 5 & 5 & 5 & 5 & 20 & 7,43 & 7,58 & 7,68 & 7,53 & 134,2 & 142,8 \\
\hline
\end{tabular}


Ensaio 9

\begin{tabular}{|c|c|c|c|c|c|c|c|c|c|c|c|}
\hline \multicolumn{8}{|c|}{ ENSAIO DE TOXICIDADE AGUDA - Daphnia similis } & \multirow{2}{*}{\multicolumn{4}{|c|}{$\begin{array}{c}\text { Dose de radiação: } 0,0 \text { kGy } \\
\text { Áqua de diluicão }\end{array}$}} \\
\hline \multicolumn{5}{|c|}{ Início } & \multicolumn{3}{|c|}{ Término } & & & & \\
\hline $\begin{array}{l}\text { Data: } \\
\text { 19/08/2015 }\end{array}$ & & & & & $\begin{array}{c}\text { Data: } \\
21 / 08 / 2015\end{array}$ & & & \multicolumn{2}{|c|}{$\begin{array}{c}\text { Água c c } \\
\text { a da água: } \\
\mathrm{CaCO}_{3} \mathrm{~L}^{-1}\end{array}$} & \multicolumn{2}{|c|}{$\begin{array}{l}\text { Manancial: } \\
\text { Salto - SP }\end{array}$} \\
\hline \multicolumn{5}{|c|}{$\begin{array}{l}\text { Organismo-teste: } \\
\text { Daphnia similis }\end{array}$} & \multicolumn{3}{|c|}{$\begin{array}{c}\text { Amostra: } \\
\text { Diluição 1:1 (0,0 kGy) }\end{array}$} & \multicolumn{4}{|c|}{ Operador: Flávio } \\
\hline & 1 & 2 & 3 & 4 & $\begin{array}{c}\text { \% de } \\
\text { imóveis }\end{array}$ & $\mathrm{pH}_{\mathrm{i}}$ & $\mathrm{pH}_{\mathrm{f}}$ & $\begin{array}{c}\mathrm{OD}_{\mathrm{i}} \\
\left(\mathrm{mg} \cdot \mathrm{L}^{-1}\right)\end{array}$ & $\begin{array}{c}\mathrm{OD}_{\mathrm{f}} \\
\left(\mathrm{mg} \cdot \mathrm{L}^{-1}\right)\end{array}$ & $\begin{array}{c}\text { Cond }_{\mathrm{i}} \\
\left(\mu{\left.\mathrm{S} . \mathrm{cm}^{-1}\right)}\right.\end{array}$ & $\begin{array}{l}\text { Cond }_{f} \\
\left(\mu S . \mathrm{cm}^{-1}\right)\end{array}$ \\
\hline Controle & 0 & 0 & 0 & 0 & 0 & 7,04 & 6,53 & 7,48 & 7,82 & 232 & 240 \\
\hline 12,5 & $\mathbf{0}$ & $\mathbf{0}$ & $\mathbf{0}$ & $\mathbf{0}$ & $\mathbf{0}$ & 7,45 & 7,28 & 7,42 & 7,6 & 185,1 & 184,6 \\
\hline 18,75 & 0 & 0 & 0 & 0 & 0 & 7,46 & 7 , & 7,42 & 7 &, 3 & 191,2 \\
\hline 25 & 3 & 4 & 2 & 4 & 13 & 7,49 & 7,36 & 7,48 & 7,56 & 171,1 & 172,7 \\
\hline 37,5 & 5 & 5 & 5 & 5 & 20 & 7,50 & 7,38 & 7,52 & 7,51 & 155,4 & 157,5 \\
\hline 50 & 5 & 5 & 5 & 5 & 20 & 7,49 & 7,39 & 7,57 & 7,59 & 140,5 & 144,2 \\
\hline
\end{tabular}

Ensaio 10

\begin{tabular}{|c|c|c|c|c|c|c|c|c|c|c|c|}
\hline \multicolumn{8}{|c|}{ ENSAIO DE TOXICIDADE AGUDA - Daphnia similis } & \multirow{2}{*}{\multicolumn{4}{|c|}{$\begin{array}{c}\text { Dose de radiação: 0,0 kGy } \\
\text { Agua de diluição }\end{array}$}} \\
\hline \multicolumn{5}{|c|}{ Início } & \multicolumn{3}{|c|}{ Término } & & & & \\
\hline $\begin{array}{c}\text { Data: } \\
\text { 25/08/2015 }\end{array}$ & & & & & $\begin{array}{c}\text { Data: } \\
27 / 08 / 2015\end{array}$ & & & \multicolumn{2}{|c|}{$\begin{array}{l}\text { Agua o } \\
\text { a da água: } \\
\mathrm{CaCO}_{3} \mathrm{~L}^{-1}\end{array}$} & \multicolumn{2}{|c|}{$\begin{array}{l}\text { Manancial: } \\
\text { Salto - SP }\end{array}$} \\
\hline \multicolumn{5}{|c|}{$\begin{array}{l}\text { Organismo-teste: } \\
\text { Daphnia similis }\end{array}$} & \multicolumn{3}{|c|}{$\begin{array}{c}\text { Amostra: } \\
\text { Diluição 1:1 (0,0 kGy) }\end{array}$} & \multicolumn{4}{|c|}{ Operador: Flávio } \\
\hline & 1 & 2 & 3 & 4 & $\begin{array}{l}\text { \% de } \\
\text { imóveis }\end{array}$ & $\mathrm{pH}_{\mathrm{i}}$ & $\mathrm{pH}_{\mathrm{f}}$ & $\begin{array}{c}\mathrm{OD}_{\mathrm{i}} \\
\left(\mathrm{mg} \cdot \mathrm{L}^{-1}\right)\end{array}$ & $\begin{array}{c}\mathrm{OD}_{\mathrm{f}} \\
\left(\mathrm{mg} \cdot \mathrm{L}^{-1}\right)\end{array}$ & $\underset{\left(\mu S . \mathrm{cm}^{-1}\right)}{\text { Cond }_{\mathrm{i}}}$ & $\begin{array}{l}\text { Cond }_{f} \\
\left(\mu S . \mathrm{cm}^{-1}\right)\end{array}$ \\
\hline Controle & 0 & 0 & 0 & 0 & 0 & 7,96 & 7,73 & 7,96 & 7,80 & 230 & 245 \\
\hline 12,5 & 1 & 0 & 0 & 0 & 1 & 7,57 & 7,76 & 7, & 7, & 181,4 & 179,8 \\
\hline 18,75 & 1 & 1 & 2 & 1 & 5 & 7,60 & 7,78 & 7,94 & 7,72 & 177,4 & 184,3 \\
\hline 25 & 4 & 1 & 3 & 3 & 11 & 7,57 & 7,77 & 7,92 & 7,61 & 169,9 & 178 \\
\hline 37,5 & 4 & 3 & 4 & 5 & 16 & 7,57 & 7,77 & 7,95 & 7,61 & 154,2 & 156,2 \\
\hline 50 & 5 & 5 & 5 & 5 & 20 & 7,56 & 7,77 & 7,97 & 7,59 & 139,0 & 140,7 \\
\hline
\end{tabular}

Ensaios de toxicidade aguda com as soluções preparadas a partir da Diluição 1:1

(2,5 kGy)

Ensaio 1

\begin{tabular}{|c|c|c|c|c|c|c|c|c|c|c|c|}
\hline \multicolumn{8}{|c|}{ ENSAIO DE TOXICIDADE AGUDA - Daphnia similis } & \multirow{2}{*}{\multicolumn{4}{|c|}{$\begin{array}{c}\text { Dose de radiação: } 2,5 \text { kGy } \\
\text { Água de diluicão }\end{array}$}} \\
\hline \multicolumn{5}{|c|}{ Início } & \multicolumn{3}{|c|}{ Término } & & & & \\
\hline $\begin{array}{l}\text { Data: } \\
\text { 09/06/2015 }\end{array}$ & & & & & $\begin{array}{c}\text { Data: } \\
11 / 06 / 2015\end{array}$ & & & \multicolumn{2}{|c|}{$\begin{array}{l}\text { Água o o } \\
\text { da água: } \\
\mathrm{CaCO}_{3} \cdot \mathrm{L}^{-1}\end{array}$} & \multicolumn{2}{|c|}{$\begin{array}{l}\text { Manancial: } \\
\text { Salto - SP }\end{array}$} \\
\hline \multicolumn{5}{|c|}{$\begin{array}{l}\text { Organismo-teste: } \\
\text { Daphnia similis }\end{array}$} & \multicolumn{3}{|c|}{$\begin{array}{c}\text { Amostra: } \\
\text { Diluição 1:1 (2,5 kGy) }\end{array}$} & \multicolumn{4}{|c|}{ Operador: Flávio } \\
\hline & 1 & 2 & 3 & 4 & $\begin{array}{l}\% \text { de } \\
\text { imóveis }\end{array}$ & $\mathrm{pH}_{\mathrm{i}}$ & $\mathrm{pH}_{\mathrm{f}}$ & $\begin{array}{c}\mathrm{OD}_{\mathrm{i}} \\
\left(\mathrm{mg} \cdot \mathrm{L}^{-1}\right)\end{array}$ & $\begin{array}{c}\mathrm{OD}_{\mathrm{f}} \\
\left(\mathrm{mg} \cdot \mathrm{L}^{-1}\right)\end{array}$ & $\underset{\left(\mu S . \mathrm{cm}^{-1}\right)}{\text { Cond }_{i}}$ & $\begin{array}{c}\text { Cond }_{\mathrm{f}} \\
\left(\mu{\left.\mathrm{S} . \mathrm{cm}^{-1}\right)}\right)\end{array}$ \\
\hline Controle & 0 & 0 & 0 & 0 & 0 & 7,21 & 7,68 & 7,74 & 7,81 & 185,8 & 223 \\
\hline 12,5 & 1 & 0 & 0 & 0 & 1 & 7,28 & 7,76 & 7,68 & 7, & 162,9 & 171,8 \\
\hline 20 & 0 & 0 & 0 & 0 & 0 & 7,36 & 7,76 & 7,55 & 7, & 153,4 & 153,1 \\
\hline 25 & 0 & 0 & 0 & 0 & 0 & 7,35 & 7,78 & 7,50 & 7,90 & 146,5 & 153,0 \\
\hline 50 & 3 & 1 & 3 & 5 & 12 & 7,30 & 7,80 & 7,45 & 7,86 & 114,4 & 119,4 \\
\hline 100 & 5 & 5 & 5 & 5 & 20 & 5,52 & 6,05 & 7,47 & 8,01 & 74,9 & 83,4 \\
\hline
\end{tabular}


Ensaio 2

\begin{tabular}{|c|c|c|c|c|c|c|c|c|c|c|c|}
\hline \multicolumn{8}{|c|}{ ENSAIO DE TOXICIDADE AGUDA - Daphnia similis } & \multirow{2}{*}{\multicolumn{4}{|c|}{$\begin{array}{c}\text { Dose de radiação: } 2,5 \mathrm{kGy} \\
\text { Água de diluição }\end{array}$}} \\
\hline \multicolumn{5}{|c|}{ Início } & \multicolumn{3}{|c|}{ Término } & & & & \\
\hline $\begin{array}{c}\text { Data: } \\
16 / 06 / 2015\end{array}$ & & & & & $\begin{array}{c}\text { Data: } \\
18 / 06 / 2015\end{array}$ & & & \multicolumn{2}{|c|}{$\begin{array}{l}\text { Água o } \\
\text { da água: } \\
\mathrm{CaCO}_{3} \cdot \mathrm{L}^{-1}\end{array}$} & \multicolumn{2}{|c|}{$\begin{array}{l}\text { Manancial: } \\
\text { Salto - SP }\end{array}$} \\
\hline \multicolumn{5}{|c|}{$\begin{array}{l}\text { Organismo-teste: } \\
\text { Daphnia similis }\end{array}$} & \multicolumn{3}{|c|}{$\begin{array}{c}\text { Amostra: } \\
\text { Diluição 1:1 (2,5 kGy) }\end{array}$} & \multicolumn{4}{|c|}{ Operador: Flávio } \\
\hline & 1 & 2 & 3 & 4 & $\begin{array}{c}\% \text { de } \\
\text { imóveis }\end{array}$ & $\mathrm{pH}_{\mathrm{i}}$ & $\mathrm{pH}_{\mathrm{f}}$ & $\begin{array}{c}\mathrm{OD}_{\mathrm{i}} \\
\left(\mathrm{mg} \cdot \mathrm{L}^{-1}\right)\end{array}$ & $\begin{array}{c}\mathrm{OD}_{\mathrm{f}} \\
\left(\mathrm{mg} \cdot \mathrm{L}^{-1}\right)\end{array}$ & $\begin{array}{c}\text { Cond }_{\mathrm{i}} \\
\left(\mu{\left.\mathrm{S} . \mathrm{cm}^{-1}\right)}^{-1}\right.\end{array}$ & $\begin{array}{c}\text { Cond }_{f} \\
\left(\mu \text { S.cm }^{-1}\right)\end{array}$ \\
\hline Controle & 0 & 0 & 0 & 0 & 0 & 7,65 & 6,50 & 807 & 7,72 & 201,2 & 223 \\
\hline 12,5 & $\mathbf{0}$ & $\mathbf{0}$ & $\mathbf{0}$ & $\mathbf{0}$ & 0 & 7,64 & 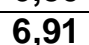 & 5 & 7,92 & 165,9 & 170,9 \\
\hline 20 & 0 & 0 & 0 & 0 & $\mathbf{0}$ & 7,61 & 7 & 8,03 & 7,97 & 106,7 & 164,5 \\
\hline 30 & 0 & 5 & 0 & 5 & 10 & 7,61 & 7,02 & 8,01 & 7,99 & 149,8 & 152,8 \\
\hline 40 & 5 & 0 & 5 & 5 & 13 & 7,62 & 7,06 & 8,03 & 7,98 & 136,7 & 139,2 \\
\hline 50 & 5 & 5 & 5 & 5 & 20 & 7,58 & 7,09 & 8,02 & 7,98 & 125,3 & 128,8 \\
\hline
\end{tabular}

Ensaio 3

\begin{tabular}{|c|c|c|c|c|c|c|c|c|c|c|c|}
\hline \multicolumn{8}{|c|}{ ENSAIO DE TOXICIDADE AGUDA - Daphnia similis } & \multirow{2}{*}{\multicolumn{4}{|c|}{$\begin{array}{c}\text { Dose de radiação: 2,5 kGy } \\
\text { Agua de diluição }\end{array}$}} \\
\hline \multicolumn{5}{|c|}{ Início } & \multicolumn{3}{|c|}{ Término } & & & & \\
\hline $\begin{array}{c}\text { Data: } \\
\text { 16/06/2015 }\end{array}$ & & $\begin{array}{l}\mathrm{Ho} \\
8:\end{array}$ & & & $\begin{array}{c}\text { Data: } \\
18 / 06 / 2015\end{array}$ & & & \multicolumn{2}{|c|}{$\begin{array}{l}\text { Água o } \\
\text { da água: } \\
\mathrm{CaCO}_{3} \mathrm{~L}^{-1}\end{array}$} & \multicolumn{2}{|c|}{$\begin{array}{r}\text { Manancial: } \\
\text { Salto - SP }\end{array}$} \\
\hline \multicolumn{5}{|c|}{$\begin{array}{l}\text { Organismo-teste: } \\
\text { Daphnia similis }\end{array}$} & \multicolumn{3}{|c|}{$\begin{array}{c}\text { Amostra: } \\
\text { Diluição 1:1 (2,5 kGy) }\end{array}$} & \multicolumn{4}{|c|}{ Operador: Flávio } \\
\hline & 1 & 2 & 3 & 4 & $\begin{array}{l}\text { \% de } \\
\text { imóveis }\end{array}$ & $\mathrm{pH}_{\mathrm{i}}$ & $\mathrm{pH}_{\mathrm{f}}$ & $\begin{array}{c}\mathrm{OD}_{\mathrm{i}} \\
\left(\mathrm{mg} \cdot \mathrm{L}^{-1}\right)\end{array}$ & $\begin{array}{c}\mathrm{OD}_{\mathrm{f}} \\
\left(\mathrm{mg} \cdot \mathrm{L}^{-1}\right)\end{array}$ & $\begin{array}{c}\text { Cond }_{\mathrm{i}} \\
\left(\mu \mathrm{S} . \mathrm{cm}^{-1}\right)\end{array}$ & $\begin{array}{c}\text { Cond }_{f} \\
(\mu \text { S.cm }\end{array}$ \\
\hline Controle & 0 & 0 & 0 & 0 & 0 & 7,65 & 6,50 & 8,07 & 7,72 & 201,2 & 223 \\
\hline 20 & 0 & 0 & 0 & 0 & 0 & 7,61 & 77 & 8 , & 7,97 & 8,7 & 164,5 \\
\hline 30 & 1 & 0 & 5 & 3 & 9 & 7,61 & 7,02 & 8,01 & 7,99 & 149,8 & 152,8 \\
\hline 40 & 5 & 4 & 0 & 5 & 14 & 7,62 & 7,06 & 8,03 & 7,98 & 136,7 & 139,2 \\
\hline 50 & 5 & 4 & 5 & 1 & 15 & 7,58 & 7,09 & 8,02 & 7,98 & 125,3 & 128,8 \\
\hline 100 & 5 & 5 & 5 & 5 & 20 & 5,16 & 5,68 & 8,07 & 8,08 & 84,5 & 91,2 \\
\hline
\end{tabular}

Ensaio 4

\begin{tabular}{|c|c|c|c|c|c|c|c|c|c|c|c|}
\hline \multicolumn{8}{|c|}{ ENSAIO DE TOXICIDADE AGUDA - Daphnia similis } & \multirow{2}{*}{\multicolumn{4}{|c|}{$\frac{\text { Dose de radiação: 2,5 kGy }}{\text { Água de diluição }}$}} \\
\hline \multicolumn{5}{|c|}{ Início } & \multicolumn{3}{|c|}{ Término } & & & & \\
\hline $\begin{array}{c}\text { Data: } \\
\text { 23/06/2015 }\end{array}$ & \multicolumn{4}{|c|}{$\begin{array}{l}\text { Hora: } \\
\text { 15:00 }\end{array}$} & $\begin{array}{c}\text { Data: } \\
\text { 25/06/2015 }\end{array}$ & \multicolumn{2}{|c|}{$\begin{array}{l}\text { Hora: } \\
15: 00\end{array}$} & $\begin{array}{r}\text { Dureza } \\
45,0 \mathrm{mg}\end{array}$ & la água: & \multicolumn{2}{|c|}{$\begin{array}{l}\text { Manancial: } \\
\text { Salto - SP }\end{array}$} \\
\hline \multicolumn{5}{|c|}{$\begin{array}{l}\text { Organismo-teste: } \\
\text { Daphnia similis }\end{array}$} & \multicolumn{3}{|c|}{$\begin{array}{c}\text { Amostra: } \\
\text { Diluição 1:1 }(2,5 \mathrm{kGy})\end{array}$} & \multicolumn{4}{|c|}{ Operador: Flávio } \\
\hline & 1 & 2 & 3 & 4 & $\begin{array}{l}\text { \% de } \\
\text { imóveis }\end{array}$ & $\mathrm{pH}_{\mathrm{i}}$ & $\mathrm{pH}_{\mathrm{f}}$ & $\begin{array}{c}\mathrm{OD}_{\mathrm{i}} \\
\left(\mathrm{mg} \cdot \mathrm{L}^{-1}\right)\end{array}$ & $\begin{array}{c}\mathrm{OD}_{\mathrm{f}} \\
\left(\mathrm{mg} \cdot \mathrm{L}^{-1}\right)\end{array}$ & $\begin{array}{c}\text { Cond }_{\mathrm{i}} \\
\left(\mu \mathrm{S} . \mathrm{cm}^{-1}\right)\end{array}$ & $\begin{array}{c}\text { Cond }_{f} \\
\left(\mu \text { S.cm }^{-1}\right)\end{array}$ \\
\hline Controle & 0 & 0 & $\mathbf{0}$ & 0 & 0 & 7,96 & 6,58 & 7,86 & 8,46 & 177,6 & 196,9 \\
\hline 12,5 & 0 & 0 & $\mathbf{0}$ & $\mathbf{0}$ & 0 & 7,82 & 6,82 & 7, & 8, & 170,9 & 107,3 \\
\hline 2 & 0 & 0 & 4 & $\mathbf{0}$ & 4 & 7,58 & 6,87 & $7, \varepsilon$ & 8,22 & 1,6 & 155,3 \\
\hline 37,5 & 1 & 1 & $\mathbf{5}$ & $\mathbf{0}$ & 7 & 7,47 & 6,99 & 7,86 & 8,1 & 134,9 & 137,0 \\
\hline 50 & 1 & 2 & 2 & 1 & 6 & 7,35 & 7,03 & 7,86 & 8,3 & 120,1 & 122,1 \\
\hline 100 & 5 & 5 & 5 & 5 & 20 & 5,75 & 5,90 & 7,76 & 8,35 & 80,8 & 86,4 \\
\hline
\end{tabular}


Ensaio 5

\begin{tabular}{|c|c|c|c|c|c|c|c|c|c|c|c|}
\hline \multicolumn{8}{|c|}{ ENSAIO DE TOXICIDADE AGUDA - Daphnia similis } & \multirow{2}{*}{\multicolumn{4}{|c|}{$\begin{array}{c}\text { Dose de radiação: 2,5 kGy } \\
\text { Água de diluição }\end{array}$}} \\
\hline \multicolumn{5}{|c|}{ Início } & \multicolumn{3}{|c|}{ Término } & & & & \\
\hline $\begin{array}{l}\text { Data: } \\
\text { 23/06/2015 }\end{array}$ & & & & & $\begin{array}{c}\text { Data: } \\
25 / 06 / 2015\end{array}$ & & & \multicolumn{2}{|c|}{$\begin{array}{l}\text { Água o } \\
\text { da água: } \\
\mathrm{CaCO}_{3} \mathrm{~L}^{-1}\end{array}$} & \multicolumn{2}{|c|}{$\begin{array}{l}\text { Manancial: } \\
\text { Salto - SP }\end{array}$} \\
\hline \multicolumn{5}{|c|}{$\begin{array}{l}\text { Organismo-teste: } \\
\text { Daphnia similis }\end{array}$} & \multicolumn{3}{|c|}{$\begin{array}{c}\text { Amostra: } \\
\text { Diluição 1:1 (2,5 kGy) }\end{array}$} & \multicolumn{4}{|c|}{ Operador: Flávio } \\
\hline & 1 & 2 & 3 & 4 & $\begin{array}{c}\% \text { de } \\
\text { imóveis }\end{array}$ & $\mathrm{pH}_{\mathrm{i}}$ & $\mathrm{pH}_{\mathrm{f}}$ & $\begin{array}{c}\mathrm{OD}_{\mathrm{i}} \\
\left(\mathrm{mg} \cdot \mathrm{L}^{-1}\right)\end{array}$ & $\begin{array}{c}\mathrm{OD}_{\mathrm{f}} \\
\left(\mathrm{mg} \cdot \mathrm{L}^{-1}\right)\end{array}$ & $\underset{\left(\mu S . \mathrm{cm}^{-1}\right)}{\text { Cond }_{\mathrm{i}}}$ & $\begin{array}{c}\text { Cond }_{f} \\
\left(\mu S^{-1} \mathrm{~cm}^{-1}\right)\end{array}$ \\
\hline Controle & 0 & 0 & 0 & 0 & 0 & 7,96 & 6,58 & 7,86 & 8,46 & 177,6 & 196,9 \\
\hline 12,5 & 0 & 0 & 0 & 0 & 0 & 7,82 & 6,82 & 7,93 & 8,24 & 170,9 & 107,3 \\
\hline 25 & 1 & 1 & 0 & 0 & 2 & 7,58 & 6,87 & 7,86 & 8,22 & 151,6 & 155,3 \\
\hline 37,5 & 1 & 2 & 0 & 1 & 4 & 7,47 & 6,99 & 7,86 & 8,18 & 134,9 & 137,0 \\
\hline 50 & 5 & 3 & 4 & 4 & 16 & 7,35 & 7,03 & 7,86 & 8,30 & 120,1 & 122,1 \\
\hline 100 & 5 & 5 & 5 & 5 & 20 & 5,75 & 5,90 & 7,76 & 8,35 & 80,8 & 86,4 \\
\hline
\end{tabular}

Ensaio 6

\begin{tabular}{|c|c|c|c|c|c|c|c|c|c|c|c|}
\hline \multicolumn{8}{|c|}{ ENSAIO DE TOXICIDADE AGUDA - Daphnia similis } & \multirow{2}{*}{\multicolumn{4}{|c|}{$\frac{\text { Dose de radiação: 2,5 kGy }}{\text { Agua de diluição }}$}} \\
\hline \multicolumn{5}{|c|}{ Iń́cio } & \multicolumn{3}{|c|}{ Término } & & & & \\
\hline $\begin{array}{c}\text { Data: } \\
01 / 07 / 2015\end{array}$ & \multicolumn{4}{|c|}{$\begin{array}{l}\text { Hora: } \\
14: 30\end{array}$} & $\begin{array}{c}\text { Data: } \\
03 / 07 / 2015\end{array}$ & \multicolumn{2}{|c|}{$\begin{array}{l}\text { Hora: } \\
14: 30\end{array}$} & $\begin{array}{r}\text { Dureza } \\
45,0 \mathrm{mg}\end{array}$ & $\begin{array}{l}\text { la água: } \\
\mathrm{aCO}_{3} \cdot \mathrm{L}^{-1}\end{array}$ & $\begin{array}{l}\text { Mane } \\
\text { Saltc }\end{array}$ & $\begin{array}{l}\text { ncial: } \\
\text { - SP }\end{array}$ \\
\hline \multicolumn{5}{|c|}{$\begin{array}{l}\text { Organismo-teste: } \\
\text { Daphnia similis }\end{array}$} & \multicolumn{3}{|c|}{$\begin{array}{c}\text { Amostra: } \\
\text { Diluição 1:1 (2,5 kGy) }\end{array}$} & \multicolumn{4}{|c|}{ Operador: Flávio } \\
\hline & 1 & 2 & 3 & 4 & $\begin{array}{l}\text { \% de } \\
\text { imóveis }\end{array}$ & $\mathrm{pH}_{\mathrm{i}}$ & $\mathrm{pH}_{\mathrm{f}}$ & $\begin{array}{c}\mathrm{OD}_{\mathrm{i}} \\
\left(\mathrm{mg} \cdot \mathrm{L}^{-1}\right)\end{array}$ & $\underset{\left(m g \cdot L^{-1}\right)}{O^{\prime}}$ & $\begin{array}{c}\text { Cond }_{\mathrm{i}} \\
\left(\mu \mathrm{S} . \mathrm{cm}^{-1}\right)\end{array}$ & $\begin{array}{l}\text { Cond }_{f} \\
\left(\mu S . \mathrm{cm}^{-1}\right)\end{array}$ \\
\hline Controle & 0 & 0 & 0 & 0 & 0 & 7,80 & 7,60 & 7,89 & 7,51 & 198,2 & 195,7 \\
\hline 12,5 & 0 & 0 & 0 & 0 & 0 & 7,62 & 7,84 & 8,05 & 7 & 188 & 201,6 \\
\hline 25 & 0 & 0 & 0 & 0 & 0 & 7,65 & 7,76 & 7,91 & 7,47 & 174,2 & 117,6 \\
\hline 45 & 0 & 0 & 0 & 0 & 0 & 7,63 & 7,74 & 7,84 & 7,47 & 141,3 & 144,1 \\
\hline 55 & 3 & 5 & 5 & 5 & 18 & 7,53 & 7,72 & 7,79 & 7,45 & 130,4 & 1333,6 \\
\hline 100 & 5 & 5 & 5 & 5 & 20 & 6,61 & 6,14 & 7,70 & 7,54 & 93,0 & 100,4 \\
\hline
\end{tabular}

Ensaio 7

\begin{tabular}{|c|c|c|c|c|c|c|c|c|c|c|c|}
\hline \multicolumn{8}{|c|}{ ENSAIO DE TOXICIDADE AGUDA - Daphnia similis } & \multirow{2}{*}{\multicolumn{4}{|c|}{$\begin{array}{c}\text { Dose de radiação: 2,5 kGy } \\
\text { Água de diluição }\end{array}$}} \\
\hline \multicolumn{5}{|c|}{ Início } & \multicolumn{3}{|c|}{ Término } & & & & \\
\hline $\begin{array}{l}\text { Data: } \\
07 / 07 / 2015\end{array}$ & \multicolumn{4}{|c|}{$\begin{array}{l}\text { Hora: } \\
14: 25\end{array}$} & \begin{tabular}{|l} 
Data: \\
09/07/2015
\end{tabular} & \multicolumn{2}{|c|}{$\begin{array}{l}\text { Hora: } \\
14: 25\end{array}$} & $\begin{array}{l}\text { Dureza } \\
45,0 \mathrm{mg}\end{array}$ & $\begin{array}{l}\text { la água: } \\
\mathrm{aCO}_{3} \cdot \mathrm{L}^{-1}\end{array}$ & $\begin{array}{l}\text { Mane } \\
\text { Saltc }\end{array}$ & $\begin{array}{l}\text { ncial: } \\
\text { - SP }\end{array}$ \\
\hline \multicolumn{5}{|c|}{$\begin{array}{l}\text { Organismo-teste: } \\
\text { Daphnia similis }\end{array}$} & \multicolumn{3}{|c|}{$\begin{array}{c}\text { Amostra: } \\
\text { Diluição 1:1 (2,5 kGy) }\end{array}$} & \multicolumn{4}{|c|}{ Operador: Flávio } \\
\hline & 1 & 2 & 3 & 4 & $\begin{array}{c}\text { \% de } \\
\text { imóveis }\end{array}$ & $\mathrm{pH}_{\mathrm{i}}$ & $\mathrm{pH}_{\mathrm{f}}$ & $\begin{array}{c}\mathrm{OD}_{\mathrm{i}} \\
\left(\mathrm{mg} \cdot \mathrm{L}^{-1}\right)\end{array}$ & $\begin{array}{c}\mathrm{OD}_{\mathrm{f}} \\
\left(\mathrm{mg} \cdot \mathrm{L}^{-1}\right)\end{array}$ & $\underset{\left(\mu S^{\prime} \cdot \mathrm{cm}^{-1}\right)}{\text { Cond }_{i}}$ & $\begin{array}{c}\text { Cond }_{f} \\
\left(\mu S \cdot \mathrm{cm}^{-1}\right)\end{array}$ \\
\hline Controle & 0 & 0 & 0 & 0 & 0 & 7,42 & 6,62 & 8.24 & 8,11 & 231 & 295 \\
\hline 12,5 & 0 & 0 & 0 & 0 & 0 & 6,46 & 7,10 & 8,25 & 8 & 187,7 & 210,1 \\
\hline 25 & 0 & 0 & 3 & 2 & 5 & 6,61 & 7,24 & 8, & 8 , & 170,7 & 179,7 \\
\hline 37,5 & 4 & 5 & 4 & 5 & 18 & 6,65 & 7,27 & 8,26 & 7,96 & 154,2 & 159,2 \\
\hline 50 & 5 & 5 & 5 & 5 & 20 & 6,66 & 7,26 & 8,36 & 7,93 & 135,1 & 139,4 \\
\hline 100 & 5 & 5 & 5 & 5 & 20 & 5,02 & 5,68 & 8,86 & 7,98 & 89,3 & 97,4 \\
\hline
\end{tabular}


Ensaio 8

\begin{tabular}{|c|c|c|c|c|c|c|c|c|c|c|c|}
\hline \multicolumn{8}{|c|}{ ENSAIO DE TOXICIDADE AGUDA - Daphnia similis } & \multirow{2}{*}{\multicolumn{4}{|c|}{$\begin{array}{c}\text { Dose de radiação: } 2,5 \text { kGy } \\
\text { Água de diluição }\end{array}$}} \\
\hline \multicolumn{5}{|c|}{ Início } & \multicolumn{3}{|c|}{ Término } & & & & \\
\hline $\begin{array}{l}\text { Data: } \\
11 / 08 / 2015\end{array}$ & & $\begin{array}{l}\mathrm{Ho} \\
14 \\
\end{array}$ & ra: & & $\begin{array}{c}\text { Data: } \\
\text { 13/08/2015 }\end{array}$ & & & \multicolumn{2}{|c|}{$\begin{array}{c}\text { Água c c } \\
\text { da água: }\end{array}$} & \multicolumn{2}{|c|}{$\begin{array}{l}\text { Manancial: } \\
\text { Salto - SP }\end{array}$} \\
\hline \multicolumn{5}{|c|}{$\begin{array}{l}\text { Organismo-teste: } \\
\text { Daphnia similis }\end{array}$} & \multicolumn{3}{|c|}{$\begin{array}{c}\text { Amostra: } \\
\text { Diluição 1:1 (2,5 kGy) }\end{array}$} & \multicolumn{4}{|c|}{ Operador: Flávio } \\
\hline & 1 & 2 & 3 & 4 & $\begin{array}{c}\% \text { de } \\
\text { imóveis }\end{array}$ & $\mathrm{pH}_{\mathrm{i}}$ & $\mathrm{pH}_{\mathrm{f}}$ & $\begin{array}{c}\mathrm{OD}_{\mathrm{i}} \\
\left(\mathrm{mg} \cdot \mathrm{L}^{-1}\right)\end{array}$ & $\begin{array}{c}\mathrm{OD}_{\mathrm{f}} \\
\left(\mathrm{mg} \cdot \mathrm{L}^{-1}\right)\end{array}$ & $\underset{\left(\mu S . \mathrm{cm}^{-1}\right)}{\text { Cond }_{\mathrm{i}}}$ & $\begin{array}{c}\text { Cond }_{f} \\
\left(\mu S \cdot \mathrm{cm}^{-1}\right)\end{array}$ \\
\hline Controle & 0 & 0 & 0 & 0 & 0 & 7,24 & 6,99 & 7,80 & 7,87 & 208,7 & 231 \\
\hline 25 & 0 & $\mathbf{0}$ & 1 & $\mathbf{0}$ & 1 & 7,20 & 7,52 & 7,51 & 7,7 & 169,3 & 182,9 \\
\hline 37,5 & 5 & 5 & 3 & 3 & 16 & 7,22 & 7,51 & 7,49 & 7,82 & 153,3 & 159,9 \\
\hline 50 & 5 & 5 & 5 & 5 & 20 & 7,06 & 7,47 & 7,48 & 7,61 & 137,7 & 143,3 \\
\hline 75 & 5 & 5 & 5 & 5 & 20 & 6,68 & 7,34 & 7,49 & 7,52 & 107,5 & 113,3 \\
\hline 100 & 5 & 5 & 5 & 5 & 20 & 5,16 & 5,61 & 7,57 & 7,79 & 96,4 & 106,9 \\
\hline
\end{tabular}

Ensaio 9

\begin{tabular}{|c|c|c|c|c|c|c|c|c|c|c|c|}
\hline \multicolumn{8}{|c|}{ ENSAIO DE TOXICIDADE AGUDA - Daphnia similis } & \multirow{2}{*}{\multicolumn{4}{|c|}{$\frac{\text { Dose de radiação: } 2,5 \text { kGy }}{\text { Agua de diluição }}$}} \\
\hline \multicolumn{5}{|c|}{ Início } & \multicolumn{3}{|c|}{ Término } & & & & \\
\hline $\begin{array}{c}\text { Data: } \\
01 / 09 / 2015\end{array}$ & & & & & $\begin{array}{c}\text { Data: } \\
03 / 09 / 2015\end{array}$ & & & \multicolumn{2}{|c|}{$\begin{array}{r}\text { Agua c } \\
\text { Dureza da água: }\end{array}$} & \multicolumn{2}{|c|}{$\begin{array}{l}\text { Manancial: } \\
\text { Salto - SP }\end{array}$} \\
\hline \multicolumn{5}{|c|}{$\begin{array}{l}\text { Organismo-teste: } \\
\text { Daphnia similis }\end{array}$} & \multicolumn{3}{|c|}{$\begin{array}{c}\text { Amostra: } \\
\text { Diluição 1:1 (2,5 kGy) }\end{array}$} & \multicolumn{4}{|c|}{ Operador: Flávio } \\
\hline & 1 & 2 & 3 & 4 & $\begin{array}{l}\text { \% de } \\
\text { imóveis }\end{array}$ & $\mathrm{pH}_{\mathrm{i}}$ & $\mathrm{pH}_{\mathrm{f}}$ & $\begin{array}{c}\mathrm{OD}_{\mathrm{i}} \\
\left(\mathrm{mg} \cdot \mathrm{L}^{-1}\right)\end{array}$ & $\begin{array}{c}\mathrm{OD}_{\mathrm{f}} \\
\left(\mathrm{mg} \cdot \mathrm{L}^{-1}\right)\end{array}$ & $\underset{\left(\mu S . \mathrm{cm}^{-1}\right)}{\text { Cond }_{\mathrm{i}}}$ & $\begin{array}{c}\text { Cond }_{f} \\
\left(\mu S . \mathrm{cm}^{-1}\right)\end{array}$ \\
\hline Controle & 0 & 0 & 0 & 0 & 0 & 7,07 & 7,20 & 7,85 & 7,54 & 211,8 & 291 \\
\hline 6.25 & 0 & 0 & 0 & 0 & 0 & 7,12 & 7.34 & 8.17 & 7,71 & 200,7 & 227 \\
\hline 12,5 & 0 & 3 & 1 & 0 & 4 & 7,29 & 7,58 & 8,23 & 7,73 & 193,8 & 207,6 \\
\hline 25 & 2 & 1 & 0 & 0 & 3 & 7,32 & 7,60 & 8,29 & 7,74 & 178,4 & 185,8 \\
\hline 37,5 & 2 & 5 & 4 & 3 & 14 & 7,30 & 7,59 & 8,34 & 7,60 & 163,3 & 169,7 \\
\hline 50 & 3 & 5 & 5 & 4 & 17 & 7,25 & 7,53 & 8,39 & 7,60 & 148,9 & 152,8 \\
\hline
\end{tabular}

Ensaios de toxicidade aguda com as soluções preparadas a partir da Diluição 1:1

(5,0 kGy)

Ensaio 1

\begin{tabular}{|c|c|c|c|c|c|c|c|c|c|c|c|}
\hline \multicolumn{8}{|c|}{ ENSAIO DE TOXICIDADE AGUDA - Daphnia similis } & \multirow{2}{*}{\multicolumn{4}{|c|}{$\begin{array}{c}\text { Dose de radiação: 5,0 kGy } \\
\text { Água de diluição }\end{array}$}} \\
\hline \multicolumn{5}{|c|}{ Início } & \multicolumn{3}{|c|}{ Término } & & & & \\
\hline $\begin{array}{c}\text { Data: } \\
\text { 24/05/2015 }\end{array}$ & & & & & $\begin{array}{c}\text { Data: } \\
26 / 05 / 2015 \\
\end{array}$ & & Pra: & \multicolumn{2}{|c|}{$\begin{array}{c}\text { Água c c } \\
\text { a da água: } \\
\mathrm{CaCO}_{3} \mathrm{~L}^{-1}\end{array}$} & \multicolumn{2}{|c|}{$\begin{array}{l}\text { Manancial: } \\
\text { Salto - SP }\end{array}$} \\
\hline \multicolumn{5}{|c|}{$\begin{array}{l}\text { Organismo-teste: } \\
\text { Daphnia similis }\end{array}$} & \multicolumn{3}{|c|}{$\begin{array}{c}\text { Amostra: } \\
\text { Diluição 1:1 (5,0 kGy) }\end{array}$} & \multicolumn{4}{|c|}{ Operador: Flávio } \\
\hline & 1 & 2 & 3 & 4 & $\begin{array}{c}\text { \% de } \\
\text { imóveis }\end{array}$ & $\mathrm{pH}_{\mathrm{i}}$ & $\mathrm{pH}_{\mathrm{f}}$ & $\begin{array}{c}\mathrm{OD}_{\mathrm{i}} \\
\left(\mathrm{mg} \cdot \mathrm{L}^{-1}\right)\end{array}$ & $\begin{array}{c}\mathrm{OD}_{\mathrm{f}} \\
\left(\mathrm{mg} \cdot \mathrm{L}^{-1}\right)\end{array}$ & $\begin{array}{c}\text { Cond }_{\mathrm{i}} \\
\left(\mu \mathrm{S} . \mathrm{cm}^{-1}\right)\end{array}$ & $\begin{array}{c}\text { Cond }_{f} \\
\left(\mu S . \mathrm{cm}^{-1}\right)\end{array}$ \\
\hline Controle & 0 & 0 & 0 & 0 & 0 & 7,94 & 7,10 & 8,16 & 8,47 & 224 & 237 \\
\hline 20 & 0 & 0 & 0 & $\mathbf{0}$ & 0 & 8,03 & 7,05 & 8,19 & 8,46 & 154,4 & 166,3 \\
\hline 30 & $\mathbf{0}$ & 5 & 3 & 5 & 13 & 7,93 & 7,15 & 8,21 & 8,43 & 145,7 & 148,7 \\
\hline 40 & 5 & 5 & 2 & 4 & 16 & 7,84 & 7,19 & 8,24 & 8,36 & 133,4 & 135,8 \\
\hline 50 & 3 & 5 & 5 & $\mathbf{5}$ & 18 & 7,73 & 7,21 & 8,29 & 8,35 & 121,5 & 123,8 \\
\hline 60 & 5 & 5 & 5 & 5 & 20 & 7,62 & 7,10 & 8,32 & 8,36 & 111,1 & 114,5 \\
\hline
\end{tabular}


Ensaio 2

\begin{tabular}{|c|c|c|c|c|c|c|c|c|c|c|c|}
\hline \multicolumn{8}{|c|}{ ENSAIO DE TOXICIDADE AGUDA - Daphnia similis } & \multirow{2}{*}{\multicolumn{4}{|c|}{$\begin{array}{c}\text { Dose de radiação: } 5,0 \text { kGy } \\
\text { Água de diluição }\end{array}$}} \\
\hline \multicolumn{5}{|c|}{ Início } & \multicolumn{3}{|c|}{ Término } & & & & \\
\hline $\begin{array}{l}\text { Data: } \\
\text { 24/05/2015 }\end{array}$ & & & & & $\begin{array}{c}\text { Data: } \\
\text { 26/05/2015 }\end{array}$ & & & \multicolumn{2}{|c|}{ Água o } & \multicolumn{2}{|c|}{$\begin{array}{l}\text { Manancial: } \\
\text { Salto - SP }\end{array}$} \\
\hline \multicolumn{5}{|c|}{$\begin{array}{l}\text { Organismo-teste: } \\
\text { Daphnia similis }\end{array}$} & \multicolumn{3}{|c|}{$\begin{array}{c}\text { Amostra: } \\
\text { Diluição 1:1 (5,0 kGy) }\end{array}$} & \multicolumn{4}{|c|}{ Operador: Flávio } \\
\hline & 1 & 2 & 3 & 4 & $\begin{array}{c}\% \text { de } \\
\text { imóveis }\end{array}$ & $\mathrm{pH}_{\mathrm{i}}$ & $\mathrm{pH}_{\mathrm{f}}$ & $\begin{array}{c}\mathrm{OD}_{\mathrm{i}} \\
\left(\mathrm{mg} \cdot \mathrm{L}^{-1}\right)\end{array}$ & $\begin{array}{c}\mathrm{OD}_{\mathrm{f}} \\
\left(\mathrm{mg} \cdot \mathrm{L}^{-1}\right)\end{array}$ & $\underset{\left(\mu S . \mathrm{cm}^{-1}\right)}{\text { Cond }_{\mathrm{i}}}$ & $\begin{array}{c}\text { Cond }_{f} \\
\left(\mu S \cdot \mathrm{cm}^{-1}\right)\end{array}$ \\
\hline Controle & 0 & 0 & 0 & 0 & 0 & 7,94 & 7,10 & 8,16 & 8,47 & 224 & 237 \\
\hline 20 & $\mathbf{0}$ & 1 & $\mathbf{0}$ & $\mathbf{0}$ & 1 & 8,03 & 7,05 & 8,19 & 8, & 154,4 & 166,3 \\
\hline 30 & 0 & 1 & 4 & 4 & 9 & 7,93 & 7, & 8 & 8,43 & 145,7 & 148,7 \\
\hline 40 & 2 & 5 & 4 & 5 & 16 & 7,84 & 7,19 & 8,24 & 8,36 & 133,4 & 135,8 \\
\hline 50 & 5 & 2 & 5 & 5 & 17 & 7,73 & 7,21 & 8,29 & 8,35 & 121,5 & 123,8 \\
\hline 60 & 1 & 5 & 5 & 5 & 16 & 7,62 & 7,10 & 8,32 & 8,36 & 111,1 & 114,5 \\
\hline
\end{tabular}

Ensaio 3

\begin{tabular}{|c|c|c|c|c|c|c|c|c|c|c|c|}
\hline \multicolumn{8}{|c|}{ ENSAIO DE TOXICIDADE AGUDA - Daphnia similis } & \multirow{2}{*}{\multicolumn{4}{|c|}{$\begin{array}{c}\text { Dose de radiação: 5,0 kGy } \\
\text { Agua de diluição }\end{array}$}} \\
\hline \multicolumn{5}{|c|}{ Início } & \multicolumn{3}{|c|}{ Término } & & & & \\
\hline $\begin{array}{l}\text { Data: } \\
\text { 10/06/2015 }\end{array}$ & \multicolumn{4}{|c|}{$\begin{array}{l}\text { Hora: } \\
13: 30\end{array}$} & $\begin{array}{c}\text { Data: } \\
\text { 12/06/2015 }\end{array}$ & \multicolumn{2}{|c|}{$\begin{array}{l}\text { Hora: } \\
13: 30\end{array}$} & $\begin{array}{l}\text { Dureza } \\
45,0 \mathrm{mg}\end{array}$ & $\begin{array}{l}\text { la água: } \\
\mathrm{aCO}_{3 \cdot \mathrm{L}^{-1}}\end{array}$ & $\begin{array}{l}\text { Mane } \\
\text { Saltc }\end{array}$ & $\begin{array}{l}\text { ncial: } \\
\text { - SP }\end{array}$ \\
\hline \multicolumn{5}{|c|}{$\begin{array}{c}\text { Organismo-teste: } \\
\text { Daphnia similis }\end{array}$} & \multicolumn{3}{|c|}{$\begin{array}{c}\text { Amostra: } \\
\text { Diluição 1:1 (5,0 kGy) }\end{array}$} & \multicolumn{4}{|c|}{ Operador: Flávio } \\
\hline & 1 & 2 & 3 & 4 & $\begin{array}{l}\% \text { de } \\
\text { imóveis }\end{array}$ & $\mathrm{pH}_{\mathrm{i}}$ & $\mathrm{pH}_{\mathrm{f}}$ & $\begin{array}{c}\mathrm{OD}_{\mathrm{i}} \\
\left(\mathrm{mg} \cdot \mathrm{L}^{-1}\right)\end{array}$ & $\begin{array}{c}\mathrm{OD}_{\mathrm{f}} \\
\left(\mathrm{mg} \cdot \mathrm{L}^{-1}\right)\end{array}$ & $\underset{\left(\mu S . \mathrm{cm}^{-1}\right)}{\text { Cond }_{\mathrm{i}}}$ & $\underset{\left(\mu S \cdot \mathrm{cm}^{-1}\right)}{\text { Cond }_{f}}$ \\
\hline Controle & 0 & 0 & 0 & 0 & 0 & 7,21 & 7,68 & $\mathbf{7 , 7 4}$ & 7,81 & 185,8 & 223 \\
\hline 7,5 & 0 & 0 & $\mathbf{0}$ & $\mathbf{0}$ & $\mathbf{0}$ & 7,14 & 6,88 & 7,56 & - & 169,2 & - \\
\hline 15 & 0 & $\mathbf{0}$ & $\mathbf{0}$ & $\mathbf{0}$ & $\mathbf{0}$ & 7,06 & 7,01 & 7,62 & - & 160,8 & - \\
\hline 20 & 0 & 0 & 0 & 0 & 0 & 7,12 & 7,12 & 7,51 & - & 153,5 & - \\
\hline 25 & 0 & 0 & 0 & 4 & 4 & 7,22 & 7,25 & 7,50 & - & 141,7 & - \\
\hline 50 & 5 & 5 & 5 & 5 & 20 & 6,86 & 7,25 & 7,53 & - & 115,9 & - \\
\hline
\end{tabular}

Ensaio 4

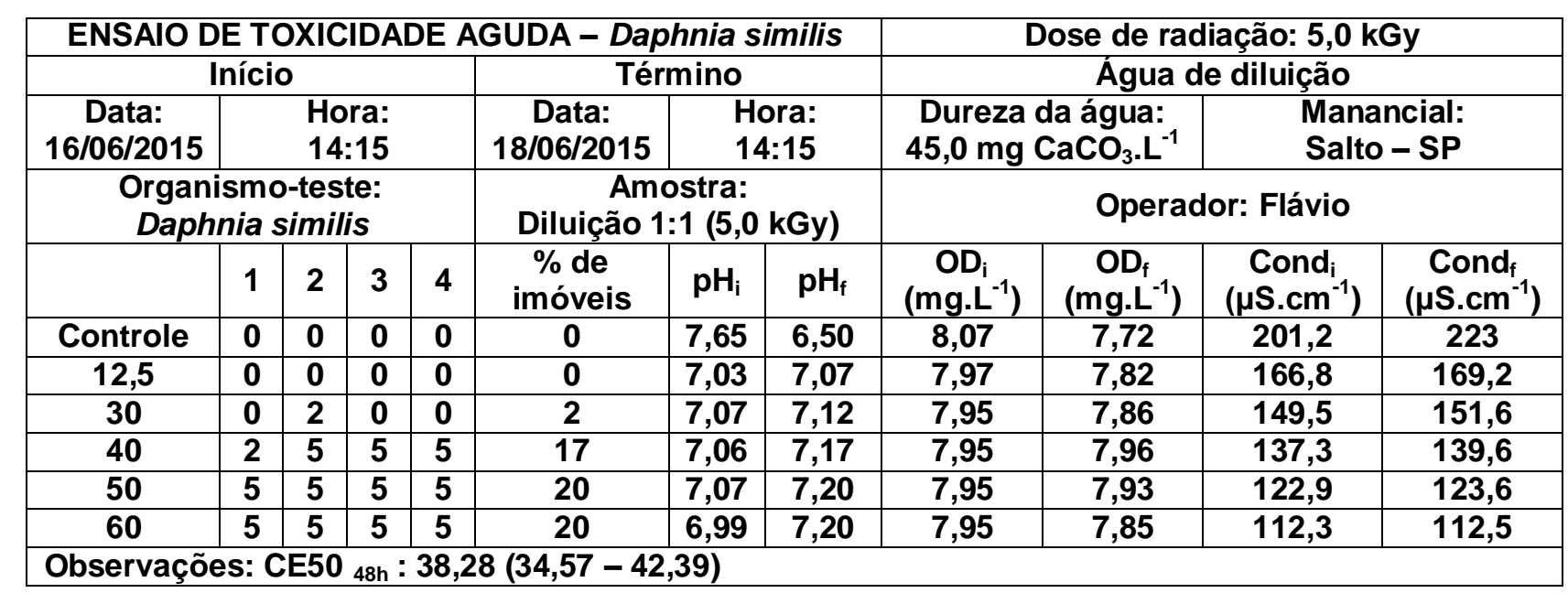


Ensaio 5

\begin{tabular}{|c|c|c|c|c|c|c|c|c|c|c|c|}
\hline \multicolumn{8}{|c|}{ ENSAIO DE TOXICIDADE AGUDA - Daphnia similis } & \multirow{2}{*}{\multicolumn{4}{|c|}{$\begin{array}{c}\text { Dose de radiação: } 5,0 \mathrm{kGy} \\
\text { Água de diluição }\end{array}$}} \\
\hline \multicolumn{5}{|c|}{ Início } & \multicolumn{3}{|c|}{ Término } & & & & \\
\hline $\begin{array}{c}\text { Data: } \\
09 / 06 / 2015\end{array}$ & & & & & $\begin{array}{c}\text { Data: } \\
11 / 06 / 2015\end{array}$ & & & \multicolumn{2}{|c|}{$\begin{array}{l}\text { Água o } \\
\text { da água: } \\
\mathrm{CaCO}_{3} \cdot \mathrm{L}^{-1}\end{array}$} & \multicolumn{2}{|c|}{$\begin{array}{l}\text { Manancial: } \\
\text { Salto - SP }\end{array}$} \\
\hline \multicolumn{5}{|c|}{$\begin{array}{l}\text { Organismo-teste: } \\
\text { Daphnia similis }\end{array}$} & \multicolumn{3}{|c|}{$\begin{array}{c}\text { Amostra: } \\
\text { Diluição 1:1 (5,0 kGy) }\end{array}$} & \multicolumn{4}{|c|}{ Operador: Flávio } \\
\hline & 1 & 2 & 3 & 4 & $\begin{array}{c}\% \text { de } \\
\text { imóveis }\end{array}$ & $\mathrm{pH}_{\mathrm{i}}$ & $\mathrm{pH}_{\mathrm{f}}$ & $\begin{array}{c}\mathrm{OD}_{\mathrm{i}} \\
\left(\mathrm{mg} \cdot \mathrm{L}^{-1}\right)\end{array}$ & $\begin{array}{c}\mathrm{OD}_{\mathrm{f}} \\
\left(\mathrm{mg} \cdot \mathrm{L}^{-1}\right)\end{array}$ & $\begin{array}{c}\text { Cond }_{\mathrm{i}} \\
\left(\mu{\left.\mathrm{S} . \mathrm{cm}^{-1}\right)}^{-1}\right.\end{array}$ & $\begin{array}{c}\text { Cond }_{f} \\
\left(\mu \text { S.cm }^{-1}\right)\end{array}$ \\
\hline Controle & 0 & 0 & 0 & $\mathbf{0}$ & 0 & 7,21 & 7,68 & $\mathbf{7 , 7 4}$ & 7,81 & 185,8 & 223 \\
\hline 15 & 0 & $\mathbf{0}$ & 1 & $\mathbf{0}$ & 1 & 7,06 & 6,88 & 7,62 & - & 160,8 & - \\
\hline 20 & 0 & 0 & 0 & $\mathbf{0}$ & $\mathbf{0}$ & 7,12 & 7,01 & 7,51 & - & 153,5 & - \\
\hline 25 & 1 & 0 & 0 & 0 & 0 & 7,22 & 7,12 & 7,50 & - & 141,7 & - \\
\hline 50 & 4 & 4 & 0 & 5 & 13 & 6,86 & 7,25 & 7,53 & - & 115,9 & - \\
\hline 100 & 5 & 5 & 5 & 5 & 20 & 5,39 & 5,19 & 7,53 & - & 109,6 & - \\
\hline
\end{tabular}

Ensaio 6

\begin{tabular}{|c|c|c|c|c|c|c|c|c|c|c|c|}
\hline \multicolumn{8}{|c|}{ ENSAIO DE TOXICIDADE AGUDA - Daphnia similis } & \multirow{2}{*}{\multicolumn{4}{|c|}{$\begin{array}{c}\text { Dose de radiação: 5,0 kGy } \\
\text { Agua de diluição }\end{array}$}} \\
\hline \multicolumn{5}{|c|}{ Início } & \multicolumn{3}{|c|}{ Término } & & & & \\
\hline $\begin{array}{c}\text { Data: } \\
01 / 07 / 2015\end{array}$ & & $\begin{array}{l}\mathrm{Ho} \\
14 \\
\end{array}$ & & & $\begin{array}{c}\text { Data: } \\
\text { 03/07/2015 }\end{array}$ & & & \multicolumn{2}{|c|}{$\begin{array}{l}\text { Água o } \\
\text { da água: } \\
\mathrm{CaCO}_{3} \mathrm{~L}^{-1}\end{array}$} & \multicolumn{2}{|c|}{$\begin{array}{r}\text { Manancial: } \\
\text { Salto - SP }\end{array}$} \\
\hline \multicolumn{5}{|c|}{$\begin{array}{l}\text { Organismo-teste: } \\
\text { Daphnia similis }\end{array}$} & \multicolumn{3}{|c|}{$\begin{array}{c}\text { Amostra: } \\
\text { Diluição 1:1 (5,0 kGy) }\end{array}$} & \multicolumn{4}{|c|}{ Operador: Flávio } \\
\hline & 1 & 2 & 3 & 4 & $\begin{array}{l}\text { \% de } \\
\text { imóveis }\end{array}$ & $\mathrm{pH}_{\mathrm{i}}$ & $\mathrm{pH}_{\mathrm{f}}$ & $\begin{array}{c}\mathrm{OD}_{\mathrm{i}} \\
\left(\mathrm{mg} \cdot \mathrm{L}^{-1}\right)\end{array}$ & $\underset{\left(m g \cdot L^{-1}\right)}{O^{\prime}}$ & $\begin{array}{c}\text { Cond }_{\mathrm{i}} \\
\left(\mu \mathrm{S} . \mathrm{cm}^{-1}\right)\end{array}$ & $\begin{array}{l}\text { Cond }_{f} \\
\left(\mu S . \mathrm{cm}^{-1}\right)\end{array}$ \\
\hline Controle & 0 & 0 & 0 & 0 & 0 & 7,80 & 7,60 & 7,89 & 7,51 & 198,2 & 195,7 \\
\hline 25 & 0 & 0 & 1 & 0 & 1 & 7,24 & 6 & $7, \varepsilon$ & 7 & 3,6 & 182,8 \\
\hline 35 & 1 & 0 & 3 & 0 & 4 & 7,14 & 6,92 & 7,85 & 7,5 & 156,5 & 157,3 \\
\hline 45 & 1 & 3 & 5 & 0 & 9 & 7,09 & 7,18 & 7,83 & 7,50 & 140,5 & 145,1 \\
\hline 55 & 5 & 5 & 5 & 5 & 20 & 6,97 & 7,21 & 7,78 & 7,57 & 128,8 & 128,3 \\
\hline 100 & 5 & 5 & 5 & 5 & 20 & 5,39 & 5,19 & 7,53 & 7,62 & 109,6 & 114,1 \\
\hline
\end{tabular}

Ensaio 7

\begin{tabular}{|c|c|c|c|c|c|c|c|c|c|c|c|}
\hline \multicolumn{8}{|c|}{ ENSAIO DE TOXICIDADE AGUDA - Daphnia similis } & \multirow{2}{*}{\multicolumn{4}{|c|}{$\begin{array}{c}\text { Dose de radiação: 5,0 kGy } \\
\text { Água de diluição }\end{array}$}} \\
\hline \multicolumn{5}{|c|}{ Início } & \multicolumn{3}{|c|}{ Término } & & & & \\
\hline $\begin{array}{l}\text { Data: } \\
07 / 07 / 2015\end{array}$ & \multicolumn{4}{|c|}{$\begin{array}{l}\text { Hora: } \\
10: 30\end{array}$} & \begin{tabular}{|l} 
Data: \\
09/07/2015
\end{tabular} & \multicolumn{2}{|c|}{$\begin{array}{l}\text { Hora: } \\
10: 30\end{array}$} & $\begin{array}{l}\text { Dureza } \\
45,0 \mathrm{mg}\end{array}$ & $\begin{array}{l}\text { la água: } \\
\mathrm{aCO}_{3} \cdot \mathrm{L}^{-1}\end{array}$ & $\begin{array}{l}\text { Mane } \\
\text { Saltc }\end{array}$ & $\begin{array}{l}\text { ncial: } \\
\text { - SP }\end{array}$ \\
\hline \multicolumn{5}{|c|}{$\begin{array}{l}\text { Organismo-teste: } \\
\text { Daphnia similis }\end{array}$} & \multicolumn{3}{|c|}{$\begin{array}{c}\text { Amostra: } \\
\text { Diluição 1:1 (5,0 kGy) }\end{array}$} & \multicolumn{4}{|c|}{ Operador: Flávio } \\
\hline & 1 & 2 & 3 & 4 & $\begin{array}{c}\text { \% de } \\
\text { imóveis }\end{array}$ & $\mathrm{pH}_{\mathrm{i}}$ & $\mathrm{pH}_{\mathrm{f}}$ & $\begin{array}{c}\mathrm{OD}_{\mathrm{i}} \\
\left(\mathrm{mg} \cdot \mathrm{L}^{-1}\right)\end{array}$ & $\begin{array}{c}\mathrm{OD}_{\mathrm{f}} \\
\left(\mathrm{mg} \cdot \mathrm{L}^{-1}\right)\end{array}$ & $\underset{\left(\mu S^{\prime} \cdot \mathrm{cm}^{-1}\right)}{\text { Cond }_{i}}$ & $\begin{array}{c}\text { Cond }_{f} \\
\left(\mu S \cdot \mathrm{cm}^{-1}\right)\end{array}$ \\
\hline Controle & 0 & 0 & 0 & 0 & 0 & 7,42 & 6,62 & 8.24 & 8,11 & 231 & 295 \\
\hline 20 & 0 & 3 & 0 & 0 & 3 & 8,38 & 7,85 & 3 & 7,9 & 179,5 & 180 \\
\hline 40 & 5 & 5 & 2 & 5 & 17 & 7,67 & 7,78 & 8,36 & 7, & 151,9 & 162 \\
\hline 50 & 5 & 5 & 5 & 5 & 20 & 7,46 & 7,62 & 8,38 & 7,89 & 137,8 & 144 \\
\hline 60 & 5 & 5 & 5 & 5 & 20 & 7,20 & 7,58 & 8,39 & 7,91 & 125,4 & 130,2 \\
\hline 100 & 5 & 5 & 5 & 5 & 20 & 4,86 & 4,34 & 8,65 & 7,95 & 100 & 101,5 \\
\hline
\end{tabular}


Ensaio 8

\begin{tabular}{|c|c|c|c|c|c|c|c|c|c|c|c|}
\hline \multicolumn{8}{|c|}{ ENSAIO DE TOXICIDADE AGUDA - Daphnia similis } & \multirow{2}{*}{\multicolumn{4}{|c|}{$\begin{array}{c}\text { Dose de radiação: } 5,0 \mathrm{kGy} \\
\text { Água de diluição }\end{array}$}} \\
\hline \multicolumn{5}{|c|}{ Início } & \multicolumn{3}{|c|}{ Término } & & & & \\
\hline $\begin{array}{l}\text { Data: } \\
\text { 18/08/2015 }\end{array}$ & & & & & $\begin{array}{l}\text { Data: } \\
\text { 20/08/2015 }\end{array}$ & & & \multicolumn{2}{|c|}{$\begin{array}{l}\text { Água o } \\
\text { da água: } \\
\mathrm{CaCO}_{3} \cdot \mathrm{L}^{-1}\end{array}$} & \multicolumn{2}{|c|}{$\begin{array}{l}\text { Manancial: } \\
\text { Salto - SP }\end{array}$} \\
\hline \multicolumn{5}{|c|}{$\begin{array}{l}\text { Organismo-teste: } \\
\text { Daphnia similis }\end{array}$} & \multicolumn{3}{|c|}{$\begin{array}{c}\text { Amostra: } \\
\text { Diluição 1:1 (5,0 kGy) }\end{array}$} & \multicolumn{4}{|c|}{ Operador: Flávio } \\
\hline & 1 & 2 & 3 & 4 & $\begin{array}{c}\% \text { de } \\
\text { imóveis }\end{array}$ & $\mathrm{pH}_{\mathrm{i}}$ & $\mathrm{pH}_{\mathrm{f}}$ & $\begin{array}{c}\mathrm{OD}_{\mathrm{i}} \\
\left(\mathrm{mg} \cdot \mathrm{L}^{-1}\right)\end{array}$ & $\begin{array}{c}\mathrm{OD}_{\mathrm{f}} \\
\left(\mathrm{mg} \cdot \mathrm{L}^{-1}\right)\end{array}$ & $\begin{array}{c}\text { Cond }_{\mathrm{i}} \\
\left(\mu{\left.\mathrm{S} . \mathrm{cm}^{-1}\right)}^{-1}\right.\end{array}$ & $\begin{array}{c}\text { Cond }_{f} \\
\left(\mu \text { S.cm }^{-1}\right)\end{array}$ \\
\hline Controle & 0 & 0 & 0 & 0 & 0 & 7,64 & 7,78 & 7,53 & 7,77 & 208,0 & 309 \\
\hline 12,5 & $\mathbf{0}$ & $\mathbf{0}$ & 0 & $\mathbf{0}$ & 0 & 7,64 & 7,82 & 7,48 & 7,7 & 186,6 & 256 \\
\hline 25 & 3 & 4 & 1 & 5 & 13 & 7,52 & 7,82 & 7,54 & $7,($ & 171,0 & 207,8 \\
\hline 37,5 & 5 & 5 & 5 & 5 & 20 & 7,32 & 7,75 & 7,59 & 7,57 & 155,2 & 181,4 \\
\hline 50 & 5 & 5 & 5 & 5 & 20 & 7,20 & 7,71 & 7,67 & 7,53 & 139,7 & 160,6 \\
\hline 100 & 5 & 5 & 5 & 5 & 20 & 6,05 & 5,77 & 7,92 & 7,72 & 113,7 & 143,5 \\
\hline
\end{tabular}

Ensaio 9

\begin{tabular}{|c|c|c|c|c|c|c|c|c|c|c|c|}
\hline \multicolumn{8}{|c|}{ ENSAIO DE TOXICIDADE AGUDA - Daphnia similis } & \multirow{2}{*}{\multicolumn{4}{|c|}{$\begin{array}{c}\text { Dose de radiação: 5,0 kGy } \\
\text { Aqua de diluição }\end{array}$}} \\
\hline \multicolumn{5}{|c|}{ Início } & \multicolumn{3}{|c|}{ Término } & & & & \\
\hline $\begin{array}{l}\text { Data: } \\
01 / 09 / 2015\end{array}$ & & & & & $\begin{array}{c}\text { Data: } \\
03 / 09 / 2015\end{array}$ & & & \multicolumn{2}{|r|}{ da água: } & \multicolumn{2}{|c|}{$\begin{array}{l}\text { Manancial: } \\
\text { Salto - SP }\end{array}$} \\
\hline \multicolumn{5}{|c|}{$\begin{array}{l}\text { Organismo-teste: } \\
\text { Daphnia similis }\end{array}$} & \multicolumn{3}{|c|}{$\begin{array}{c}\text { Amostra: } \\
\text { Diluição 1:1 (5,0 kGy) }\end{array}$} & \multicolumn{4}{|c|}{ Operador: Flávio } \\
\hline & 1 & 2 & 3 & 4 & $\begin{array}{l}\% \text { de } \\
\text { imóveis }\end{array}$ & $\mathrm{pH}_{\mathrm{i}}$ & $\mathrm{pH}_{\mathrm{f}}$ & $\begin{array}{c}\mathrm{OD}_{\mathrm{i}} \\
\left(\mathrm{mg} \cdot \mathrm{L}^{-1}\right)\end{array}$ & $\begin{array}{c}\mathrm{OD}_{\mathrm{f}} \\
\left(\mathrm{mg} \cdot \mathrm{L}^{-1}\right)\end{array}$ & $\underset{\left(\mu S . \mathrm{cm}^{-1}\right)}{\text { Cond }_{\mathrm{i}}}$ & $\begin{array}{c}\text { Cond }_{f} \\
\left(\mu S \cdot \mathrm{cm}^{-1}\right)\end{array}$ \\
\hline Controle & 0 & 0 & 0 & 0 & 0 & 7,07 & 7,20 & 7,85 & 7,54 & 211,8 & 291 \\
\hline 6,25 & 0 & 0 & 0 & 1 & 1 & 7,11 & 7,45 & 8,27 & 7, & 199,3 & 196,6 \\
\hline 12,5 & 0 & 0 & 1 & 0 & 1 & 7,26 & 7,57 & 8,27 & 7,72 & 193,6 & 198,0 \\
\hline 25 & 4 & 3 & 1 & 3 & 11 & 7,28 & 7,59 & 8,32 & 7,68 & 178,4 & 184,1 \\
\hline 37,5 & 4 & 4 & 2 & 4 & 14 & 7,24 & 7,50 & 8,4 & 7,57 & 163,7 & 170,2 \\
\hline 50 & 5 & 5 & 5 & 5 & 20 & 7,18 & 7,51 & 8,49 & 7,51 & 149,3 & 156,2 \\
\hline
\end{tabular}

Ensaio 10

\begin{tabular}{|c|c|c|c|c|c|c|c|c|c|c|c|}
\hline \multicolumn{8}{|c|}{ ENSAIO DE TOXICIDADE AGUDA - Daphnia similis } & \multirow{2}{*}{\multicolumn{4}{|c|}{$\begin{array}{c}\text { Dose de radiação: 5,0 kGy } \\
\text { Áqua de diluicão }\end{array}$}} \\
\hline \multicolumn{5}{|c|}{ Início } & \multicolumn{3}{|c|}{ Término } & & & & \\
\hline $\begin{array}{c}\text { Data: } \\
01 / 09 / 2015\end{array}$ & \multicolumn{4}{|c|}{$\begin{array}{l}\text { Hora: } \\
15: 20\end{array}$} & $\begin{array}{c}\text { Data: } \\
\text { 03/09/2015 }\end{array}$ & \multicolumn{2}{|c|}{$\begin{array}{l}\text { Hora: } \\
15: 20\end{array}$} & $\begin{array}{l}\text { Dureza } \\
45,0 \mathrm{mg}\end{array}$ & $\begin{array}{l}\text { la água: } \\
\mathrm{aCO}_{3} \cdot \mathrm{L}^{-1}\end{array}$ & $\begin{array}{l}\text { Mane } \\
\text { Saltc }\end{array}$ & $\begin{array}{l}\text { ncial: } \\
\text { - SP }\end{array}$ \\
\hline \multicolumn{5}{|c|}{$\begin{array}{l}\text { Organismo-teste: } \\
\text { Daphnia similis }\end{array}$} & \multicolumn{3}{|c|}{$\begin{array}{c}\text { Amostra: } \\
\text { Diluição 1:1 (5,0 kGy) }\end{array}$} & \multicolumn{4}{|c|}{ Operador: Flávio } \\
\hline & 1 & 2 & 3 & 4 & $\begin{array}{c}\text { \% de } \\
\text { imóveis }\end{array}$ & $\mathrm{pH}_{\mathrm{i}}$ & $\mathrm{pH}_{\mathrm{f}}$ & $\begin{array}{c}\mathrm{OD}_{\mathrm{i}} \\
\left(\mathrm{mg} \cdot \mathrm{L}^{-1}\right)\end{array}$ & $\begin{array}{c}\mathrm{OD}_{\mathrm{f}} \\
\left(\mathrm{mg} \cdot \mathrm{L}^{-1}\right)\end{array}$ & $\underset{\left(\mu S^{\prime} \cdot \mathrm{cm}^{-1}\right)}{\text { Cond }_{i}}$ & $\begin{array}{c}\text { Cond }_{f} \\
\left(\mu S \cdot \mathrm{cm}^{-1}\right)\end{array}$ \\
\hline Controle & 0 & 0 & 0 & 0 & 0 & 7,07 & 7,20 & 785 & 7,54 & 211,8 & 291 \\
\hline 6,25 & 0 & 0 & 0 & 0 & 0 & 7,11 & 7,45 & 8,27 & 7,7 & 199,3 & 196,6 \\
\hline 12,5 & 0 & 2 & 0 & 0 & 2 & 7,26 & 57 & 8 & 7 & 93,6 & 198,0 \\
\hline 25 & 4 & 0 & 0 & 2 & 6 & 7,28 & 7,59 & 8,32 & 7,68 & 178,4 & 184,1 \\
\hline 37,5 & 3 & 5 & 5 & 5 & 18 & 7,24 & 7,50 & 8,40 & 7,57 & 163,7 & 170,2 \\
\hline 50 & 5 & 5 & 5 & 5 & 20 & 7,18 & 7,51 & 8,49 & 7,51 & 149,3 & 156,2 \\
\hline
\end{tabular}


Ensaios de toxicidade aguda com as soluções preparadas a partir da Diluição 1:10 (0,0 kGy)

Ensaio 1

\begin{tabular}{|c|c|c|c|c|c|c|c|c|c|c|c|}
\hline \multicolumn{8}{|c|}{ ENSAIO DE TOXICIDADE AGUDA - Daphnia similis } & \multirow{2}{*}{\multicolumn{4}{|c|}{$\begin{array}{c}\text { Dose de radiação: 0,0 kGy } \\
\text { Água de diluiçãa }\end{array}$}} \\
\hline \multicolumn{5}{|c|}{ Início } & \multicolumn{3}{|c|}{ Término } & & & & \\
\hline $\begin{array}{l}\text { Data: } \\
\text { 27/10/2015 }\end{array}$ & & & ra: & & $\begin{array}{c}\text { Data: } \\
\text { 29/10/2015 }\end{array}$ & & & \multicolumn{2}{|c|}{$\begin{array}{l}\text { Água } \\
\text { da água: } \\
\mathrm{CaCO}_{3} \mathrm{~L}^{-1}\end{array}$} & \multicolumn{2}{|c|}{$\begin{array}{l}\text { Manancial: } \\
\text { Salto - SP }\end{array}$} \\
\hline \multicolumn{5}{|c|}{$\begin{array}{l}\text { Organismo-teste: } \\
\text { Daphnia similis }\end{array}$} & \multicolumn{3}{|c|}{$\begin{array}{c}\text { Amostra: } \\
\text { Diluição 1:10 (0,0 kGy) }\end{array}$} & \multicolumn{4}{|c|}{ Operador: Flávio } \\
\hline & 1 & 2 & 3 & 4 & $\begin{array}{l}\text { \% de } \\
\text { imóveis }\end{array}$ & $\mathrm{pH}_{\mathrm{i}}$ & $\mathrm{pH}_{\mathrm{f}}$ & $\begin{array}{c}\mathrm{OD}_{\mathrm{i}} \\
\left(\mathrm{mg} \cdot \mathrm{L}^{-1}\right)\end{array}$ & $\begin{array}{c}\mathrm{OD}_{\mathrm{f}} \\
\left(\mathrm{mg} \cdot \mathrm{L}^{-1}\right)\end{array}$ & $\underset{\left(\mu S . \mathrm{cm}^{-1}\right)}{\text { Cond }_{\mathrm{i}}}$ & $\begin{array}{c}\text { Cond }_{f} \\
\left(\mu \text { S.cm }^{-1}\right)\end{array}$ \\
\hline Controle & 0 & 0 & 0 & 1 & 1 & 7,55 & 6,27 & 7,40 & 7,93 & 173,2 & 189,0 \\
\hline 12,5 & 1 & 0 & 0 & 0 & 1 & 7,52 & 6,63 & 7,3 & 7,8 & 1618 & 168,4 \\
\hline 25 & 3 & 3 & 2 & 0 & 8 & 7,54 & 6,80 & 7,38 & 7,87 & 149,0 & 157,2 \\
\hline 50 & 5 & 5 & 4 & 5 & 19 & 7,57 & 6,88 & 7,36 & 7,87 & 126,6 & 123,2 \\
\hline 75 & 5 & 5 & 5 & 5 & 20 & 7,60 & 6,95 & 7,47 & 7,82 & 87,5 & 91,0 \\
\hline 100 & 5 & 5 & 5 & 3 & 18 & 7,41 & 6,95 & 7,02 & 7,80 & 56,3 & 59,7 \\
\hline
\end{tabular}

Ensaio 2

\begin{tabular}{|c|c|c|c|c|c|c|c|c|c|c|c|}
\hline \multicolumn{8}{|c|}{ ENSAIO DE TOXICIDADE AGUDA - Daphnia similis } & \multirow{2}{*}{\multicolumn{4}{|c|}{$\begin{array}{c}\text { Dose de radiação: } 0,0 \text { kGy } \\
\text { Água de diluicão }\end{array}$}} \\
\hline \multicolumn{5}{|c|}{ Início } & \multicolumn{3}{|c|}{ Término } & & & & \\
\hline $\begin{array}{l}\text { Data: } \\
\text { 27/10/2015 }\end{array}$ & & & & & $\begin{array}{c}\text { Data: } \\
\text { 29/10/2015 }\end{array}$ & & & \multicolumn{2}{|c|}{ da água: } & \multicolumn{2}{|c|}{$\begin{array}{l}\text { Manancial: } \\
\text { Salto - SP }\end{array}$} \\
\hline \multicolumn{5}{|c|}{$\begin{array}{l}\text { Organismo-teste: } \\
\text { Daphnia similis }\end{array}$} & \multicolumn{3}{|c|}{$\begin{array}{c}\text { Amostra: } \\
\text { Diluição 1:10 (0,0 kGy) }\end{array}$} & \multicolumn{4}{|c|}{ Operador: Flávio } \\
\hline & 1 & 2 & 3 & 4 & $\begin{array}{l}\text { \% de } \\
\text { imóveis }\end{array}$ & $\mathrm{pH}_{\mathrm{i}}$ & $\mathrm{pH}_{\mathrm{f}}$ & $\begin{array}{c}\mathrm{OD}_{\mathrm{i}} \\
\left(\mathrm{mg} \cdot \mathrm{L}^{-1}\right)\end{array}$ & $\begin{array}{c}\mathrm{OD}_{\mathrm{f}} \\
\left(\mathrm{mg} \cdot \mathrm{L}^{-1}\right)\end{array}$ & $\underset{\left(\mu S . \mathrm{cm}^{-1}\right)}{\text { Cond }_{\mathrm{i}}}$ & $\begin{array}{c}\text { Cond }_{f} \\
\left(\mu S^{-1} \mathrm{~cm}^{-1}\right)\end{array}$ \\
\hline Controle & 0 & 0 & $\mathbf{0}$ & 1 & 1 & 7,55 & 6,27 & 7,40 & 7,93 & 173,2 & 189,0 \\
\hline 12,5 & 0 & 0 & 0 & 0 & 0 & 7,52 & 6,63 & 7,38 & 7, & 1618 & 168,4 \\
\hline 25 & 0 & 3 & 4 & 1 & 8 & 7,54 & 6,80 & 7,38 & 7,87 & 149,0 & 157,2 \\
\hline 50 & 5 & 4 & 5 & 5 & 19 & 7,57 & 6,88 & 7,36 & 7,87 & 126,6 & 123,2 \\
\hline 75 & 5 & 4 & 5 & 3 & 17 & 7,60 & 6,95 & 7,47 & 7,82 & 87,5 & 91,0 \\
\hline 100 & 5 & 5 & 5 & 5 & 20 & 7,41 & 6,95 & 7,02 & 7,80 & 56,3 & 59,7 \\
\hline
\end{tabular}

Ensaio 3

\begin{tabular}{|c|c|c|c|c|c|c|c|c|c|c|c|}
\hline \multicolumn{8}{|c|}{ ENSAIO DE TOXICIDADE AGUDA - Daphnia similis } & \multirow{2}{*}{\multicolumn{4}{|c|}{$\begin{array}{c}\text { Dose de radiação: 0,0 kGy } \\
\text { Água de diluição }\end{array}$}} \\
\hline \multicolumn{5}{|c|}{ Início } & \multicolumn{3}{|c|}{ Término } & & & & \\
\hline $\begin{array}{l}\text { Data: } \\
\text { 16/12/2015 }\end{array}$ & & $\begin{array}{l}\text { Ho } \\
14:\end{array}$ & & & $\begin{array}{c}\text { Data: } \\
18 / 12 / 2015\end{array}$ & & & \multicolumn{2}{|c|}{$\begin{array}{l}\text { Água c } \\
\text { a da água: } \\
\mathrm{CaCO}_{3} \mathrm{~L}^{-1}\end{array}$} & \multicolumn{2}{|c|}{$\begin{array}{l}\text { Manancial: } \\
\text { Salto - SP }\end{array}$} \\
\hline \multicolumn{5}{|c|}{$\begin{array}{l}\text { Organismo-teste: } \\
\text { Daphnia similis }\end{array}$} & \multicolumn{3}{|c|}{$\begin{array}{c}\text { Amostra: } \\
\text { Diluição 1:10 (0,0 kGy) }\end{array}$} & \multicolumn{4}{|c|}{ Operador: Flávio } \\
\hline & 1 & 2 & 3 & 4 & $\begin{array}{l}\% \text { de } \\
\text { imóveis }\end{array}$ & $\mathrm{pH}_{\mathrm{i}}$ & $\mathrm{pH}_{\mathrm{f}}$ & $\begin{array}{c}\mathrm{OD}_{\mathrm{i}} \\
\left(\mathrm{mg} \cdot \mathrm{L}^{-1}\right)\end{array}$ & $\begin{array}{c}\mathrm{OD}_{\mathrm{f}} \\
\left(\mathrm{mg} \cdot \mathrm{L}^{-1}\right)\end{array}$ & $\begin{array}{c}\text { Cond }_{\mathrm{i}} \\
\left(\mu \mathrm{S} \cdot \mathrm{cm}^{-1}\right)\end{array}$ & $\begin{array}{c}\text { Cond }_{\mathrm{f}} \\
\left(\mu \mathrm{S} . \mathrm{cm}^{-1}\right)\end{array}$ \\
\hline Controle & 0 & 0 & 0 & 0 & 0 & 7,20 & 7,15 & 7,12 & 7,58 & 180,5 & 202 \\
\hline 3,125 & 0 & 0 & 0 & 0 & 0 & 7,71 & 6,67 & 7,20 & 7, & 5,7 & 202,2 \\
\hline 6,25 & 0 & 0 & 0 & 0 & 0 & 7,74 & 6,82 & 7,1 & 7,6 & 173,7 & 193,8 \\
\hline 12,5 & 1 & 0 & 0 & 1 & 2 & 7,76 & 6,92 & 7,20 & 7,68 & 165,3 & 171,8 \\
\hline 25 & 4 & 2 & 4 & 2 & 12 & 7,77 & 7,00 & 7,25 & 7,60 & 152,1 & 157,7 \\
\hline 50 & 5 & 5 & 5 & 5 & 20 & 7,78 & 7,03 & 7,37 & 7,63 & 128,3 & 134,7 \\
\hline
\end{tabular}


Ensaio 4

\begin{tabular}{|c|c|c|c|c|c|c|c|c|c|c|c|}
\hline \multicolumn{8}{|c|}{ ENSAIO DE TOXICIDADE AGUDA - Daphnia similis } & \multirow{2}{*}{\multicolumn{4}{|c|}{$\begin{array}{c}\text { Dose de radiação: 0,0 kGy } \\
\text { Água de diluição }\end{array}$}} \\
\hline \multicolumn{5}{|c|}{ Início } & \multicolumn{3}{|c|}{ Término } & & & & \\
\hline $\begin{array}{l}\text { Data: } \\
\text { 19/01/2016 }\end{array}$ & & & $\begin{array}{ll}\text { ra: } \\
17\end{array}$ & & $\begin{array}{c}\text { Data: } \\
21 / 01 / 2016\end{array}$ & & & \multicolumn{2}{|c|}{$\begin{array}{c}\text { Água c c } \\
\text { da água: }\end{array}$} & \multicolumn{2}{|c|}{$\begin{array}{l}\text { Manancial: } \\
\text { Salto - SP }\end{array}$} \\
\hline \multicolumn{5}{|c|}{$\begin{array}{l}\text { Organismo-teste: } \\
\text { Daphnia similis }\end{array}$} & \multicolumn{3}{|c|}{$\begin{array}{c}\text { Amostra: } \\
\text { Diluição 1:10 (0,0 kGy) }\end{array}$} & \multicolumn{4}{|c|}{ Operador: Flávio } \\
\hline & 1 & 2 & 3 & 4 & $\begin{array}{c}\% \text { de } \\
\text { imóveis }\end{array}$ & $\mathrm{pH}_{\mathrm{i}}$ & $\mathrm{pH}_{\mathrm{f}}$ & $\begin{array}{c}\mathrm{OD}_{\mathrm{i}} \\
\left(\mathrm{mg} \cdot \mathrm{L}^{-1}\right)\end{array}$ & $\begin{array}{c}\mathrm{OD}_{\mathrm{f}} \\
\left(\mathrm{mg} \cdot \mathrm{L}^{-1}\right)\end{array}$ & $\underset{\left(\mu S . \mathrm{cm}^{-1}\right)}{\text { Cond }_{\mathrm{i}}}$ & $\begin{array}{c}\text { Cond }_{f} \\
\left(\mu S \cdot \mathrm{cm}^{-1}\right)\end{array}$ \\
\hline Controle & 0 & 0 & 0 & 1 & 1 & 7,21 & 7,53 & 7,59 & 7,68 & & 204,6 \\
\hline 12,5 & 1 & 1 & 1 & 1 & 4 & 7,56 & 6,98 & 7,70 & 7,7 & 1,5 & $\mathbf{1 7 4 , 9}$ \\
\hline 25 & 3 & 2 & 2 & 5 & 12 & 7,63 & 7,02 & 7,79 & 7,7 & 141,3 & 148,9 \\
\hline 37,5 & 5 & 5 & 4 & 5 & 19 & 7,66 & 7,50 & 7,67 & 7,73 & 153,9 & 160,6 \\
\hline 50 & 5 & 5 & 5 & 5 & 20 & 7,65 & 7,15 & 7,73 & 7,76 & 129,0 & 136,8 \\
\hline 100 & 5 & 5 & 5 & 5 & 20 & 7,72 & 7,08 & 8,22 & 7,75 & 73,3 & 85,0 \\
\hline
\end{tabular}

Ensaio 5

\begin{tabular}{|c|c|c|c|c|c|c|c|c|c|c|c|}
\hline \multicolumn{8}{|c|}{ ENSAIO DE TOXICIDADE AGUDA - Daphnia similis } & \multirow{2}{*}{\multicolumn{4}{|c|}{$\begin{array}{c}\text { Dose de radiação: 0,0 kGy } \\
\text { Agua de diluição }\end{array}$}} \\
\hline \multicolumn{5}{|c|}{ Início } & \multicolumn{3}{|c|}{ Término } & & & & \\
\hline $\begin{array}{c}\text { Data: } \\
\text { 20/01/2016 }\end{array}$ & \multicolumn{4}{|c|}{$\begin{array}{l}\text { Hora: } \\
8: 20\end{array}$} & $\begin{array}{c}\text { Data: } \\
\text { 22/01/2016 }\end{array}$ & \multicolumn{2}{|c|}{$\begin{array}{l}\text { Hora: } \\
8: 20\end{array}$} & $\begin{array}{r}\text { Dureza } \\
45,0 \mathrm{mg}\end{array}$ & $\begin{array}{l}\text { la água: } \\
\mathrm{CaCO}_{3} \cdot \mathrm{L}^{-1}\end{array}$ & $\begin{array}{l}\text { Mane } \\
\text { Saltc }\end{array}$ & $\begin{array}{l}\text { ncial: } \\
\text { - SP }\end{array}$ \\
\hline \multicolumn{5}{|c|}{$\begin{array}{l}\text { Organismo-teste: } \\
\text { Daphnia similis }\end{array}$} & \multicolumn{3}{|c|}{$\begin{array}{c}\text { Amostra: } \\
\text { Diluição 1:10 (0,0 kGy) }\end{array}$} & \multicolumn{4}{|c|}{ Operador: Flávio } \\
\hline & 1 & 2 & 3 & 4 & $\begin{array}{l}\% \text { de } \\
\text { imóveis }\end{array}$ & $\mathrm{pH}_{\mathrm{i}}$ & $\mathrm{pH}_{\mathrm{f}}$ & $\begin{array}{c}\mathrm{OD}_{\mathrm{i}} \\
\left(\mathrm{mg} \cdot \mathrm{L}^{-1}\right)\end{array}$ & $\begin{array}{c}\mathrm{OD}_{\mathrm{f}} \\
\left(\mathrm{mg} \cdot \mathrm{L}^{-1}\right)\end{array}$ & $\begin{array}{c}\text { Cond }_{\mathrm{i}} \\
\left(\mu \mathrm{S} . \mathrm{cm}^{-1}\right)\end{array}$ & $\begin{array}{c}\text { Cond }_{f} \\
(\mu \text { S.cm }\end{array}$ \\
\hline Controle & 0 & 0 & 0 & 1 & 1 & 7,21 & 7,53 & 7,59 & 7,68 & 185,5 & 204,6 \\
\hline 12,5 & 1 & 1 & 2 & 0 & 4 & 7,56 & 6,98 & 7,70 & $\mathbf{7 , 7 0}$ & 164,5 & 174,9 \\
\hline 25 & 4 & 4 & 2 & 1 & 11 & 7,63 & 7,02 & 7,79 & $\mathbf{7 , 7 1}$ & 141,3 & 148,9 \\
\hline 37,5 & 5 & 5 & 5 & 5 & 20 & 7,66 & 7,50 & 7,67 & 7,73 & 153,9 & 160,6 \\
\hline 50 & 5 & 5 & 5 & 5 & 20 & 7,65 & 7,15 & 7,73 & 7,76 & 129,0 & 136,8 \\
\hline 100 & 5 & 5 & 5 & 5 & 20 & 7,72 & 7,08 & 8,22 & 7,75 & 73,3 & 85,0 \\
\hline
\end{tabular}

Ensaios de toxicidade aguda com as soluções preparadas a partir da Diluição 1:10

(5,0 kGy)

Ensaio 1

\begin{tabular}{|c|c|c|c|c|c|c|c|c|c|c|c|}
\hline \multicolumn{8}{|c|}{ ENSAIO DE TOXICIDADE AGUDA - Daphnia similis } & \multirow{2}{*}{\multicolumn{4}{|c|}{$\begin{array}{c}\text { Dose de radiação: 5,0 kGy } \\
\text { Água de diluição }\end{array}$}} \\
\hline \multicolumn{5}{|c|}{ Início } & \multicolumn{3}{|c|}{ Término } & & & & \\
\hline $\begin{array}{c}\text { Data: } \\
17 / 11 / 2015\end{array}$ & \multicolumn{4}{|c|}{$\begin{array}{l}\text { Hora: } \\
14: 15\end{array}$} & $\begin{array}{c}\text { Data: } \\
\text { 19/11/2015 }\end{array}$ & \multicolumn{2}{|c|}{$\begin{array}{l}\text { Hora: } \\
14: 15\end{array}$} & $\begin{array}{r}\text { Dureza } \\
45,0 \mathrm{mg} \\
\end{array}$ & $\begin{array}{l}\text { Ja água: } \\
\mathrm{CaCO}_{3} \cdot \mathrm{L}^{-1}\end{array}$ & \multicolumn{2}{|c|}{$\begin{array}{l}\text { Manancial: } \\
\text { Salto - SP }\end{array}$} \\
\hline \multicolumn{5}{|c|}{$\begin{array}{l}\text { Organismo-teste: } \\
\text { Daphnia similis }\end{array}$} & \multicolumn{3}{|c|}{$\begin{array}{c}\text { Amostra: } \\
\text { Diluição 1:10 (5,0 kGy) }\end{array}$} & \multicolumn{4}{|c|}{ Operador: Flávio } \\
\hline & 1 & 2 & 3 & 4 & $\begin{array}{c}\% \text { de } \\
\text { imóveis }\end{array}$ & $\mathrm{pH}_{\mathrm{i}}$ & $\mathrm{pH}_{\mathrm{f}}$ & $\begin{array}{c}\mathrm{OD}_{\mathrm{i}} \\
\left(\mathrm{mg} \cdot \mathrm{L}^{-1}\right)\end{array}$ & $\begin{array}{c}\mathrm{OD}_{\mathrm{f}} \\
\left(\mathrm{mg} \cdot \mathrm{L}^{-1}\right)\end{array}$ & $\begin{array}{c}\text { Cond }_{\mathrm{i}} \\
\left(\mu \mathrm{S} . \mathrm{cm}^{-1}\right)\end{array}$ & $\begin{array}{l}\text { Cond }_{f} \\
\left(\mu \text { S.cm }^{-1}\right)\end{array}$ \\
\hline Controle & 0 & 0 & 0 & 0 & 0 & 6,44 & 7,97 & 7,33 & 7,38 & 187,6 & 195,8 \\
\hline 12,5 & 0 & 0 & 0 & 0 & 0 & 8,10 & 8,04 & 7,11 & 8 & 172,4 & 193,0 \\
\hline 25 & 0 & 0 & 0 & 0 & 0 & 7,96 & 8,02 & 7,1 & 8 & 3,1 & 163,6 \\
\hline 50 & 2 & 0 & 0 & 2 & 4 & 7,95 & 8,05 & 7,13 & 8 , & 126,2 & 132,3 \\
\hline 75 & 0 & 3 & 0 & 4 & 7 & 8,14 & 8,07 & 7,03 & 8,07 & 101,0 & 106,2 \\
\hline 100 & 5 & 5 & 5 & 5 & 20 & 6,69 & 6,27 & 6,91 & 6,27 & 105,2 & 106,8 \\
\hline
\end{tabular}


Ensaio 2

\begin{tabular}{|c|c|c|c|c|c|c|c|c|c|c|c|}
\hline \multicolumn{8}{|c|}{ ENSAIO DE TOXICIDADE AGUDA - Daphnia similis } & \multirow{2}{*}{\multicolumn{4}{|c|}{$\frac{\text { Dose de radiação: 5,0 kGy }}{\text { Água de diluição }}$}} \\
\hline \multicolumn{5}{|c|}{ Início } & \multicolumn{3}{|c|}{ Término } & & & & \\
\hline $\begin{array}{l}\text { Data: } \\
16 / 12 / 2015\end{array}$ & & & & & $\begin{array}{c}\text { Data: } \\
18 / 12 / 2015\end{array}$ & & & \multicolumn{2}{|c|}{$\begin{array}{l}\text { Agua c } \\
\text { da água: }\end{array}$} & \multicolumn{2}{|c|}{$\begin{array}{l}\text { Manancial: } \\
\text { Salto - SP }\end{array}$} \\
\hline \multicolumn{5}{|c|}{$\begin{array}{l}\text { Organismo-teste: } \\
\text { Daphnia similis }\end{array}$} & \multicolumn{3}{|c|}{$\begin{array}{c}\text { Amostra: } \\
\text { Diluição 1:10 (5,0 kGy) }\end{array}$} & \multicolumn{4}{|c|}{ Operador: Flávio } \\
\hline & 1 & 2 & 3 & 4 & $\begin{array}{c}\text { \% de } \\
\text { imóveis }\end{array}$ & $\mathrm{pH}_{\mathrm{i}}$ & $\mathrm{pH}_{\mathrm{f}}$ & $\begin{array}{c}\mathrm{OD}_{\mathrm{i}} \\
\left(\mathrm{mg} \cdot \mathrm{L}^{-1}\right)\end{array}$ & $\begin{array}{c}\mathrm{OD}_{\mathrm{f}} \\
\left(\mathrm{mg} \cdot \mathrm{L}^{-1}\right)\end{array}$ & $\begin{array}{c}\text { Cond }_{\mathrm{i}} \\
\left(\mu \mathrm{S} . \mathrm{cm}^{-1}\right)\end{array}$ & $\begin{array}{c}\text { Cond }_{f} \\
\left(\mu \text { S.cm }^{-1}\right)\end{array}$ \\
\hline Controle & 0 & 0 & 0 & 0 & 0 & 7,20 & 7,15 & 7,12 & 7,58 & 180,5 & 202 \\
\hline 25 & 0 & $\mathbf{0}$ & $\mathbf{0}$ & $\mathbf{0}$ & $\mathbf{0}$ & 7,75 & 7,03 & 7,29 & & 149,4 & 159,3 \\
\hline 50 & 0 & 0 & $\mathbf{0}$ & $\mathbf{0}$ & 0 & 7,51 & 7,15 & 7,5 & & 127,7 & 173,6 \\
\hline 7 & 0 & 1 & 1 & 0 & 2 & 7,26 & 6,97 & 7,6 & & 100,2 & 107,5 \\
\hline 87,5 & 5 & 5 & 4 & 2 & 16 & 6,29 & 5,71 & 7,82 & 7, & 99 & 106,8 \\
\hline 100 & 5 & 5 & 5 & 5 & 20 & 4,40 & 4,56 & 8,09 & 7,75 & 107,9 & 117,5 \\
\hline
\end{tabular}

Ensaio 3

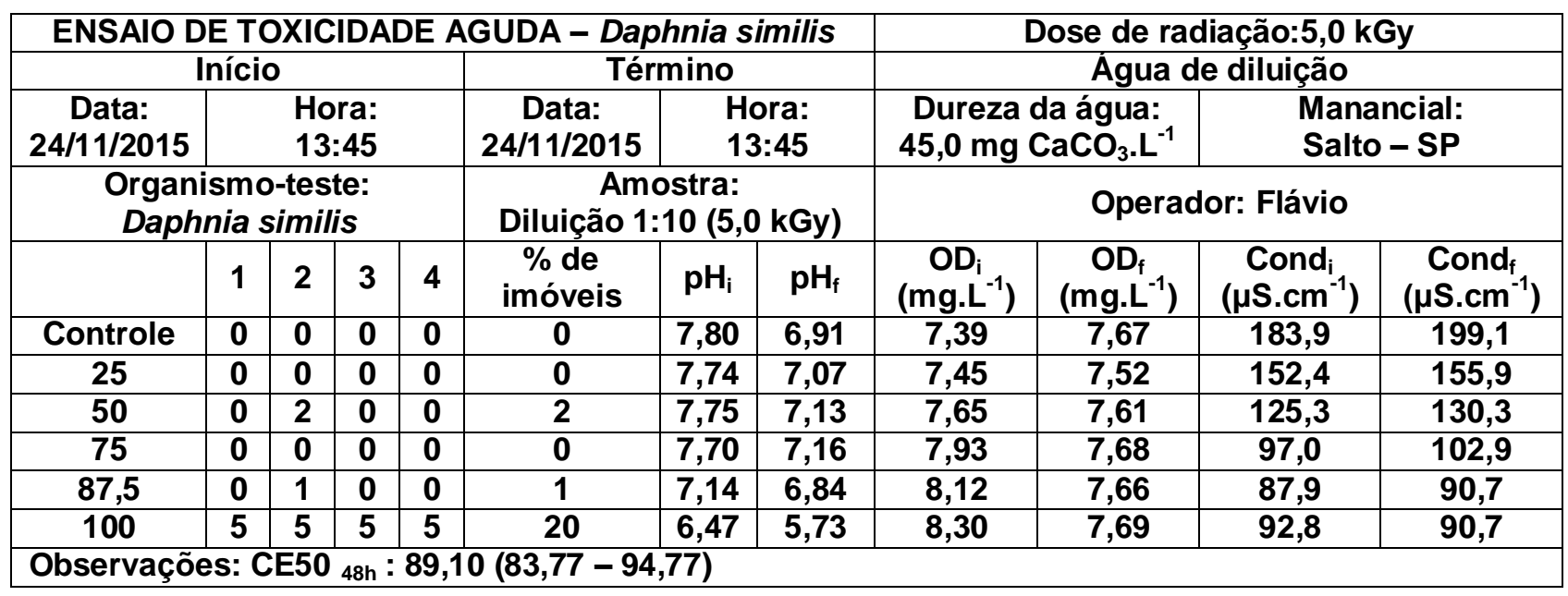

Ensaio 4

\begin{tabular}{|c|c|c|c|c|c|c|c|c|c|c|c|}
\hline \multicolumn{8}{|c|}{ ENSAIO DE TOXICIDADE AGUDA - Daphnia similis } & \multirow{2}{*}{\multicolumn{4}{|c|}{$\begin{array}{c}\text { Dose de radiação: } 5,0 \text { kGy } \\
\text { Água de diluicãa }\end{array}$}} \\
\hline \multicolumn{5}{|c|}{ Início } & \multicolumn{3}{|c|}{ Término } & & & & \\
\hline $\begin{array}{c}\text { Data: } \\
19 / 01 / 2015\end{array}$ & \multicolumn{4}{|c|}{$\begin{array}{l}\text { Hora: } \\
8: 50\end{array}$} & $\begin{array}{c}\text { Data: } \\
21 / 01 / 2015\end{array}$ & \multicolumn{2}{|c|}{$\begin{array}{l}\text { Hora: } \\
8: 50\end{array}$} & $\begin{array}{r}\text { Dureza } \\
45,0 \mathrm{mg}\end{array}$ & $\begin{array}{l}\text { la água: } \\
\mathrm{aCO}_{3} \cdot \mathrm{L}^{-1}\end{array}$ & \multicolumn{2}{|c|}{$\begin{array}{l}\text { Manancial: } \\
\text { Salto-SP }\end{array}$} \\
\hline \multicolumn{5}{|c|}{$\begin{array}{l}\text { Organismo-teste: } \\
\text { Daphnia similis }\end{array}$} & \multicolumn{3}{|c|}{$\begin{array}{c}\text { Amostra: } \\
\text { Diluição 1:10 (5,0 kGy) }\end{array}$} & \multicolumn{4}{|c|}{ Operador: Flávio } \\
\hline & 1 & 2 & 3 & 4 & $\begin{array}{c}\text { \% de } \\
\text { imóveis }\end{array}$ & $\mathrm{pH}_{\mathrm{i}}$ & $\mathrm{pH}_{\mathrm{f}}$ & $\begin{array}{c}\mathrm{OD}_{\mathrm{i}} \\
\left(\mathrm{mg} \cdot \mathrm{L}^{-1}\right)\end{array}$ & $\begin{array}{c}\mathrm{OD}_{\mathrm{f}} \\
\left(\mathrm{mg} \cdot \mathrm{L}^{-1}\right)\end{array}$ & $\underset{\left(\mu S^{\prime} \cdot \mathrm{cm}^{-1}\right)}{\text { Cond }_{i}}$ & $\begin{array}{c}\text { Cond }_{f} \\
\left(\mu S^{-1} \text { cm }^{-1}\right)\end{array}$ \\
\hline Controle & 0 & 1 & 0 & 1 & 2 & 7,21 & 7,53 & 7,59 & 7,68 & 185,5 & 204,6 \\
\hline 25 & 0 & 0 & 0 & 0 & 0 & 7,24 & 7,63 & 7, & 7, & 5,5 & 162,7 \\
\hline 50 & 1 & 1 & 2 & 1 & 5 & 7,10 & 7 & 7 & 7, & ,9 & 155,4 \\
\hline 75 & 5 & 3 & 5 & 4 & 17 & 6,84 & 7,31 & 7,94 & 7,8 & 104,3 & 109,6 \\
\hline 87,5 & 5 & 5 & 5 & 5 & 20 & 6,35 & 6,05 & 8,04 & 7,80 & 97,0 & 101,9 \\
\hline 100 & 5 & 5 & 5 & 5 & 20 & 5,08 & 4,67 & 8,20 & 7,82 & 103,9 & 110,3 \\
\hline
\end{tabular}


Ensaio 5

\begin{tabular}{|c|c|c|c|c|c|c|c|c|c|c|c|}
\hline \multicolumn{8}{|c|}{ ENSAIO DE TOXICIDADE AGUDA - Daphnia similis } & \multirow{2}{*}{\multicolumn{4}{|c|}{$\begin{array}{c}\text { Dose de radiação: } 5,0 \mathrm{kGy} \\
\text { Água de diluição }\end{array}$}} \\
\hline \multicolumn{5}{|c|}{ Início } & \multicolumn{3}{|c|}{ Término } & & & & \\
\hline $\begin{array}{c}\text { Data: } \\
20 / 01 / 2015\end{array}$ & & & & & $\begin{array}{c}\text { Data: } \\
\text { 22/01/2015 }\end{array}$ & & & \multicolumn{2}{|c|}{$\begin{array}{l}\text { Água o } \\
\text { da água: } \\
\mathrm{CaCO}_{3} \cdot \mathrm{L}^{-1}\end{array}$} & \multicolumn{2}{|c|}{$\begin{array}{l}\text { Manancial: } \\
\text { Salto - SP }\end{array}$} \\
\hline \multicolumn{5}{|c|}{$\begin{array}{l}\text { Organismo-teste: } \\
\text { Daphnia similis }\end{array}$} & \multicolumn{3}{|c|}{$\begin{array}{c}\text { Amostra: } \\
\text { Diluição 1:10 (5,0 kGy) }\end{array}$} & \multicolumn{4}{|c|}{ Operador: Flávio } \\
\hline & 1 & 2 & 3 & 4 & $\begin{array}{c}\% \text { de } \\
\text { imóveis }\end{array}$ & $\mathrm{pH}_{\mathrm{i}}$ & $\mathrm{pH}_{\mathrm{f}}$ & $\begin{array}{c}\mathrm{OD}_{\mathrm{i}} \\
\left(\mathrm{mg} \cdot \mathrm{L}^{-1}\right)\end{array}$ & $\begin{array}{c}\mathrm{OD}_{\mathrm{f}} \\
\left(\mathrm{mg} \cdot \mathrm{L}^{-1}\right)\end{array}$ & $\begin{array}{c}\text { Cond }_{\mathrm{i}} \\
\left(\mu{\left.\mathrm{S} . \mathrm{cm}^{-1}\right)}^{-1}\right.\end{array}$ & $\begin{array}{c}\text { Cond }_{f} \\
\left(\mu \text { S.cm }^{-1}\right)\end{array}$ \\
\hline Controle & 0 & 1 & 0 & 1 & 2 & 7,21 & 7,53 & 7,59 & 7,68 & 185,5 & 204,6 \\
\hline 25 & 0 & 0 & $\mathbf{0}$ & $\mathbf{0}$ & $\mathbf{0}$ & 7,24 & 7,63 & 7,7 & 7, & 156,5 & 162,7 \\
\hline 5 & 1 & 4 & 4 & 1 & 10 & 7,10 & 7,65 & 7,83 & 7,7 & 9 & 155,4 \\
\hline 75 & 5 & 5 & 5 & 5 & 20 & 6,84 & 7,31 & 7,94 & 7,80 & 104,3 & 109,6 \\
\hline 87,5 & 5 & 3 & 5 & 5 & 17 & 6,35 & 6,05 & 8,04 & 7,80 & 97,0 & 101,9 \\
\hline 100 & 5 & 5 & 5 & 5 & 20 & 5,08 & 4,67 & 8,20 & 7,82 & 103,9 & 110,3 \\
\hline
\end{tabular}




\section{REFERÊNCIAS BIBLIOGRÁFICAS}

ACUÑA, V.; GINEBREDA, A.; MOR, J. R.; PETROVIC, M.; SABATER, S.; SUMPTER, J.; BARCELÓ, D. Balancing the health benefits and environmental risks of pharmaceuticals: Diclofenac as an example. Environment International n. 85, p. 327-333, 2015.

AGUIAR, F. A. Caracterização das propriedades do estado sólido do diclofenaco de sódio e avaliação destas propriedades no perfil in vitro de dissolução e no efeito farmacológico. 2009. Dissertação (Mestrado) Faculdade de Ciências Farmacêuticas de Ribeirão Preto, Universidade de São Paulo, Ribeirão Preto. Disponível em: < http://www.teses.usp.br/teses/disponiveis/60/60137/tde-13052009-133219/ptbr.php > Acesso em: 18 de março de 2016.

ALMEIDA, E. C. Análise ecotoxicológica da fração inorgânica do efluente da deslignificação do línter na produção de nitrocelulose. 2013. Trabalho de conclusão de curso - Escola de Engenheria de Lorena - Universidade de São Paulo, Lorena. Disponível em: < http://sistemas.eel.usp.br/bibliotecas/monografias/2013/MBl13006.pdf $>$. Acesso em: 18 de março de 2016.

ALMEIDA, G. A.; WEBER, R. R. Fármacos na Represa Billings. Revista Saúde e Meio Ambiente, v. 6, p. 7-13, 2005.

ALMEIDA, L; M; Crustacea. In: RIBEIRO-COSTA, C. S.; ROCHA, R. M. (Coord.). Invertebrados: manual de aulas práticas. Ribeirão Preto: Holos. p. 148 - 151, 2002 (Serie Manuais Práticos em Biologia, 3).

ANDRADE, R. V.; SILVA, A. F.; MOREIRA, F. N; SANTOS, H. P. S.; DANTAS, H. F.; ALMEIDA I. F.; LOBO, L. P. B.; NASCIMENTO, M. A.. Atuação dos Neurotransmissores na Depressão. Revista das ciências farmacêuticas, v.1, n.1, 2003.

ANDREU, V.; GIMENO-GARCÍA, E.; PASCUAL, J. A.; VAZQUEZ-ROIG, P.; PICÓ, Y. Presence of pharmaceuticals and heavy metals in the waters of a Mediterranean coastal wetland: Potential interactions and the influence of the environment. Science of the Total Environment n. 540, p. 278-286, 2016.

AGENCIA NACIONAL DE VIGILÂNCIA SANITÁRIA (ANVISA). Portaria no. 344 de 12 de maio de 1998. Aprova o Regulamento Técnico sobre substancias e medicamentos sujeitos a controle especial. Disponível em: < http://www.anvisa.gov.br/hotsite/talidomida/legis/Portaria 344 98.pdf > Acesso em: 18 de março de 2016.

AGENCIA NACIONAL DE VIGILÂNCIA SANITÁRIA (ANVISA). Resultados 2009, SNGPC. 2009. 
AGÊNCIA SENADO. Aumenta em 161\% o consumo de medicamentos controlados no país. AGÊNCIA SENADO, 20 de maio de 2015. Disponível em: < http://www12.senado.leg.br/noticias/materias/2015/05/20/aumenta-em-161-o-

consumo-de-medicamentos-controlados-no-pais/table $t>$ Acesso em: 18 de março de 2016.

AMÉRICO, J. H. P.; ISIQUE, W. D.; MINILLO, A.; CARVALHO, S. L.: TORRES, N. $\mathrm{H}$. Fármacos em uma estação de tratamento de esgoto na região Centro-oeste do Brasil e os riscos aos recursos hídricos. Revista Brasileira de Recursos Hídricos, Porto Alegre, v.17, n.3, p. 61-67, 2012.

ANDREOTTOLA, G.; OLIVEIRA, E . L.; FOLADORI, P.; DALLAGO, L.; PETERLINI, R.; CADONNA, M. Método respirométrico para o monitoramento de processos biológicos. Engenharia Sanitária e Ambiental, v. 10, n. 1, p. 14-23, 2005.

ARAUJO, K.; NEVES, M.; SÁ, M.; SILVA, L.; BRITO, N. Fármacos residuais: um problema de caráter ambiental. In: CONGRESSO DE PESQUISA E INOVAÇÃO DA REDE NORTE NORDESTE DE EDUCAÇÃO TECNOLÓGICA. Nov, 17-19, Maceió, $\quad \mathrm{AL}, \quad 2010 . \quad$ Disponível em: < http://connepi.ifal.edu.br/ocs/index.php/connepi/CONNEPI2010/paper/viewFile/14 $\underline{18 / 467}$ >. Acesso em: 18 de março de 2016.

ASSOCIAÇÃO BRASILEIRA DE NORMAS TÉCNICAS. Ecotoxicologia aquática - determinação do efeito inibitório de amostras de água sobre a emissão de luz de Vibrio fischeri (Ensaio de bactéria luminescente). Rio de Janeiro: ABNT, 2012. (NBR-15411)

ASSOCIAÇÃO BRASILEIRA DE NORMAS TÉCNICAS. Ecotoxicologia Aquática - Toxicidade aguda - Método de ensaio com Dapnhia spp (Crustacea, Cladocera). Rio de Janeiro: ABNT, 2004. (NBR 12713).

ASSOCIAÇÃO BRASILEIRA DE NORMAS TÉCNICAS. Ecotoxicologia Aquática - Toxicidade aguda - Método de ensaio com Dapnhia spp (Crustacea, Cladocera). Rio de Janeiro: ABNT, 2009. (NBR 12713).

ASSOCIAÇÃO BRASILEIRA DE NORMAS TÉCNICAS. Ecotoxicologia Aquática - Toxicidade crônica - Método de ensaio com alga (Chlorophyceae). Rio de Janeiro: ABNT, 2011. (NBR) 12648.

BARCELÓ, D. Pharmaceutical-residue analysis. Trends in Analytical Chemistry, v. 26 , n. 6 , p. 454-455, 2007.

BARNES, R. D; RUPPERT, E. E. Zoologia dos invertebrados. 6. Ed. Rio de Janeiro: Roca, 1996.

BARROS, F. G. N.; AMIN, M. M. Água: um bem econômico de valor para o Brasil e o mundo. Revista Brasileira de Gestão e Desenvolvimento Regional. v. 4, n. 1, p. 75-108, 2008.

BILA, D. M.; DEZOTTI, M. Fármacos no meio ambiente. Quimica. Nova, v. 26, n. 4, p. 523-530, 2003. 
BORRELY, S.I. Redução da toxicidade aguda de efluentes industriais e domésticos tratados por irradiação com feixes de elétrons, avaliada com as espécies Vibrio fischeri, Daphnia similis e Poecilia reticulata. 2001. Tese (Doutorado) - Instituto de Pesquisas Energéticas e Nucleares - Universidade de São Paulo, São Paulo. Disponível em: < http://pelicano.ipen.br/PosG30/TextoCompleto/Sueli\%20lvone\%20Borrely D.pdf >. Acesso em: 18 de março de 2016.

BORRELY, S. I.; CAMINADA, S. M. L.; PONEZI, A. N.; SANTOS, D. R.; SILVA, V. H. O. Contaminação das águas por resíduos de medicamentos: ênfase ao cloridrato de fluoxetina. O Mundo da Saúde, São Paulo, v. 4, n. 36, p. 556-563, 2012.

BORRELY, S. I.; CRUZ, A. C.; Del MASTRO, N. L. SAMPA, M. H. O. SOMESSARI, E. S. Radiation Processing of Sewege and Sludge. A Review. Progress in Nuclear Energy, v. 33, n.3 1/2, p. 3-21, 1998.

BRASIL. Ministério do Meio Ambiente. CONAMA. Resolução n 357, de 17 de Março de 2005. Dispõem sobre a classificação dos corpos de água e diretrizes ambientais para seu enquadramento, bem como estabelece as condições e padrões de lançamento de efluentes, e dá outras providências.

BRASIL. Ministério do Meio Ambiente. CONAMA. Resolução № 430, de 13 de Maio de 2011. Dispõem sobre as condições e padrões de lançamento de efluentes, complementa e altera a resolução no357, de 17 de março de 2005, do Conselho Nacional do Meio Ambiente - CONAMA. Brasília.

BROOKS, B., FORAN, C., RICHARDS, S., WESTON, J., TURNER, P., STANLEY, J. Aquatic ecotoxicity of Fluoxetine. Toxicology Letter, n. 142, p 169-183, 2003.

BUSER, H. R.; POIGER, T.; MÜLLER, M. D. Occurrence and Fate of the Pharmaceutical Drug Diclofenac in Surface Waters: Rapid Photodegradation in a Lake Environmental Science Technology, n. 32, p. 3449, 1998.

BUSS, D. F.; OLIVEIRA, R. B.; BAPTISTA, D. F. Monitoramento biólogico de ecossistemas aquáticos continentais. Oecologia Australis. v. 12, n. 3, p. 339345, 2008.

CALZA, P.; SAKKAS, V. A.; MEDANA, C.; BAIOCCHI, C.; DIMOU, A.; PELIZZETTI, E.; ALBANIS, T. Photocatalytic degradation study of diclofenac over aqueous TiO2 suspensions. Applied Catalysis n. 67, p. 197-205, 2006.

CAMBRICOLI, F.; DIOGÉNESE, J. Uso de medicamento cresce 52\% em 4 anos na rede municipal de São Paulo. Estadão, São Paulo, 12 out de 2015. Estadão Sáude. Disponível em: < http://saude.estadao.com.br/noticias/geral,uso-deremedios-tarja-preta-cresce-52-em-4-anos-na-rede-municipal-de-sp,1778070 $>$. Acesso em: 18 de março de 2016.

CAMINADA, S. M. L. Estudo da biodegradação do Hidrocloridrato de Fluoxetina, empregando ensaios de respirometria e toxicidade. 2008. Dissertação (Mestrado) - Universidade estadual de campinas faculdade de engenharia civil, arquitetura e urbanismo, UNICAMP, Campinas. Disponível em: < 
http://www.bibliotecadigital.unicamp.br/document/?code $=000445077>$ Acesso em: 18 de março de 2016.

CANADIAN NUCLEAR SAFETY COMMISSION (CNSC). Introduction to Radiation. 2012.

CARLSSON, C.; JOHANSSON A.; ALVAN, G.; BERGMAN, K.; KUHLER, T. Are pharmaceuticals potent environmental pollutants? Part I: Environmental risk assessments of selected active pharmaceutical ingredientes. Science of the Total Environment, v. 364, p. 67-87, 2006.

CASTRO, F. J.; SANTOS, D. R. A.; BUONGERMINO, C. R. P.; CORTEZ, F. S.; PEREIRA, C. D. S.; CHOERI, R. B.; CESAR, A. Ecotoxicological assessment of four pharmaceuticals compounds through acute toxicity tests. $O$ Mundo da Saúde, São Paulo, v. 1, n. 38, p. 51-55, 2014.

COELHO, A. D. Degradação dos antiinflamatórios diclofenaco, ibuprofeno e naproxeno por ozonização. 2008. Tese (doutorado) - Universidade Federal do Rio de Janeiro, Rio de Janeiro. Disponível em: < http://portal.peq.coppe.ufrj.br/index.php/producao-academica/teses-dedoutorado/2008/206-degradacao-dos-antinflamatorios-diclofenaco-ibuprofeno-enaproxeno-por-ozonizacao/file >. Acesso em: 18 de março de 2016.

COELHO, A. D.; SANS, C.; AGÜERA, A.; GÓMEZ, M. J.; ESPLUGAS, S.; DEZOTTI, M. Effects of ozone pre-treatment on diclofenac: Intermediates, biodegradability and toxicity assessment. Science of the Total Environment, n. 407, p. 3572-3578, 2009.

COMISSION OF THE EUROPEAN COMMUNITIES (CEC). Technical Guidance Document in Support of Commission Directive 93/67/EEC on Risk Assement for New Notified Substances and Commision Regulation (EC) no 1488/94 on Risk Assement for Existing Substances. Part II: Environmental Risk Assessment. Office for Official Publications of the European Communities, Luxembourg, 1996.

COMPANHIA CATARINENSE DE ÁGUAS E SANEAMENTO - CASAN. Sistema de Tratamento de Esgoto Insular de Florianópolis. RELATÓRIO DE AUDITORIA OPERACIONAL. 2004.

COMPANHIA DE TECNOLOGIA DE SANEAMENTO AMBIENTAL (CETESB). Carbono Orgânico Dissolvido (COD) e Carbono Orgânico Total (COT). 2014.

COMPANHIA DE TECNOLOGIA DE SANEAMENTO AMBIENTAL (CETESB). Norma Técnica: Determinação da durera toral em águas - método titulométrico do EDTA: método de ensaio, maio 1992. CETESB, São Paulo. 1992.

COMPANHIA DE TECNOLOGIA E SANEAMENTO AMBIENTAL (CETESB). Significado ambiental e sanitário das variáveis de qualidade das águas e dos sedimentos e metodologias analíticas e de amostragem. Série de relatórios: Qualidade das águas interiores no estado de São Paulo. CETESB, São Paulo. 2009. 
COSTA, C. R.; OLIVI, P. A toxicidade em ambientes aquáticos: discussão e métodos de avaliação. Química Nova, v. 31, n. 7, p. 1820-1830, 2008.

COSTA JUNIOR, I. L.; PLETSCH, AL. L.; TORRES, Y. R. Ocorrência de Fármacos Antidepressivos no Meio Ambiente - Revisão. Revista Virtual de Química. v. 6, n. 5, p. 1408-1431, 2014

DASTIDAR, S. G.; GANGULY. K.; CHAUDHURI, K.; CHAKRABARTY, A.N. The anti-bacterial action of diclofenac shown by inhibition of DNA synthesis. International Journal of Antimicrobial Agents, n. 14, p. 249-251, 2000.

DÍAZ-CRUZ, M. S.; LOPEZ DE ALDA, M. J.; BARCELÒ, D. Environmental behavior and analysis of veterinary and human drugs in soils, sediments and sludge. Trends in Analytical Chemistry, v. 22, n. 6, p. 340-351, 2003.

DUARTE, C.L. Aplicação do Processo Avançado de Oxidação por feixe de elétrons na degradação de compostos orgânicos presentes em efluentes industriais. 1999. Tese (doutorado) - Instituto de Pesquisas Energéticas e Nucleares - Universidade de São Paulo, São Paulo. Disponível em: < http://pelicano.ipen.br/PosG30/TextoCompleto/Celina\%20Lopes\%20Duarte D.pdf >. Acesso em: 18 de março de 2016.

ELI LILLY \& COMPANY, Prozac. Disponível em: < https://www.lilly.com.br/Inserts/Patients/Bula Prozac Pac CDS22NOV10 v5.0 1 5JUN11.pdf > Acesso em: 18 de março de 2016.

EMEA. Work Programme for the European Agency for Evaluation of Medicinal Products. (EMEA/MB/58/03). 2004.

FARRÉ, M.; PÉREZ, S.; KANTIANI, L.; BARCELÓ, D. Fate and toxicity of emerging pollutants, their metabolites and transformation products in the aquatic environment. Trends in Analytical Chemistry, v. 27, n. 11, p. 991-1007, 2008.

FAVARIN, F. H. P. Cromatografia líquida bidimensional aplicada a senosídeos e na determinação simultânea de Diclofenaco sódico, paracetamol e cafeína. 2012. Dissertação (Mestrado) - UNIVERSIDADE FEDERAL DE SÃO CARLOS, São Carlos. Disponível em: < https://repositorio.ufscar.br/handle/ufscar/6642 >. Acesso em: 18 de março de 2016.

FENT, K., WESTON, A.A., CAMINADA, D., 2006. Ecotoxicology of human pharmaceuticals. Aquatic Toxicology. n. 76, p 122-159.

FERNICOLA, N. A. G. G.; BOHRER-MOREL, M. B. C.; BAINY, A. C. D. Ecotoxicologia. Bases toxicológicas da ecotoxicologia. Rima Editora, São Carlos. 2004.

FLAHERTY, C. M.; DODSON, S. I. Effects of pharmaceuticals on Daphnia survival, growth, and reproduction. Chemosphere n. 61, p. 200-207, 2005.

FRIAS, M. C. Laboratórios farmacêuticos têm alta de $11,4 \%$ no faturamento em 2014. Folha de São Paulo, São Paulo, 26 de janeiro de 2015. Mercado aberto. 
Disponível em: < http://www1.folha.uol.com.br/fsp/mercado/205542-laboratoriosfarmaceuticos-tem-alta-de-114-no-faturamento-em-2014.shtml > Acesso em: 18 de março de 2016.

FONG, P. P.; MOLNAR, N. Norfluoxetine induces spawning and parturition in estuarine and freshwater bivalves. Bulletin Environmental Contamination and Toxicology, n. 81, p. 535-538, 2008.

GAFFNEY, V. J.; CARDOSO, V. V.; RODRIGUES, A.; FERREIRA, E.; BENOLIEL, M. J.; ALMEIDA, C. M. M. Análise de fármacos em águas por spe-uplc-esi-ms $/ \mathrm{ms}$. Quimica Nova, v. 37, n. 1, p. 138-149, 2014.

GOGATE, P. R.; PANDIT, A. B. A review of imperative technologies for wastewater treatment I: oxidation technologies at ambient conditions. Advances in Environmental Research. n. 8, p. 501-551, 2004.

GÓMEZ-OLIVÁN, L. M.; GALAR-MARTÍNEZ, M.; GARCÍA-MEDINA, S.; VALDÉSALANÍS, A.; ISLAS-FLORES, H.; NERI-CRUZ, N. Genotoxic response and oxidative stress induced by diclofenac, ibuprofen and naproxen in Daphnia magna. Drug and Chemical Toxicology. 2014.

GONZALEZ-REY, M. BEBIANNO, M. J.; Does selective serotonina reuptake inhibitor (SSRI) fluoxetine affects mussel Mytilus galloprovincialis? Environmental Pollution, v. 173, p 200-2009, 2013.4

GOZMEN, B.; KAYAN, B.; GIZIR, A. M.; HESENOV, A. Oxidative degradations of reactive blue 4 dye by diferente advanced oxidation methods. Jounal of Hazardous Material, v. 168, p. 129-136, 2009.

GRINEVICIUS, V. M. A. S. Avaliação da remediação de efluentes de uma indústria têxtil utilizando biodincadores e biomarcadores. 2006. Dissertação (Mestrado) - Universidade Federal de Santa Catarina. Florianopolis, Santa Catarina. Disponível em: < https://repositorio.ufsc.br/xmlui/bitstream/handle/123456789/89140/227245.pdf?se quence $=1$ \&isAllowed $=y$ > $>$. Acesso em: 18 de março de 2016 .

GROS, M.; PETROVIC, M.; BARCELÓ, D. Tracing Pharmaceutical Residues of Different Therapeutic Classes in Environmental Waters by Using Liquid Chromatography/Quadrupole-Linear Ion Trap Mass Spectrometry and Automated Library Searching. Analytical Chemistry, v. 81, p. 989-912, 2009.

GUIEYSSE B., NORVILL Z.N. Sequential chemical-biological processes for the treatment of industrial wastewaters: Review of recent progresses and critical assessment. Journal of Hazardous Materials. v. 267 p. 142-152, 2014.

GURKE, R.; Rößler, M.; MARX, C.; DIAMOND, S.; SCHUBERT, S.; OERTEL, R.; FAULER, J. Occurrence and removal of frequently prescribed pharmaceuticals and corresponding metabolites in wastewater of a sewage treatment plant. Science of the Total Environment n. 532, p. 762-770, 2015. 
HAMILTON, M. A.; RUSSO, R.C.; THURSTON, R. V. Trimmed Spearman-Karber method for estimatinf median lethal concentrations in toxicity bioassays. Enviromental Science \& Technology, v. 11, n. 7, p. 714-719, 1977.

HAN, B.; KIM, J. K.; KIM, Y.; CHOI, J. S.; JEONG, K. Y. Operation of industrialscale electron beam wastewater treatment plant. Radiation Physics and Chemistry, n. 81, p. 1475-1478, 2012.

HAN, B. KIM, S. M.; SALIMOV, R. A.; KUKSANOV, N. K.; High Power accelerator for environmental application. In INTERNATIONAL TOPICAL MEETING IN NICLEAR APPLICATIONS AND UTILIZATION OF ACCELERATORS (ACCAPP07). 8., 2007, Pocatello, Idaho, Jul. 29 - Aug. 2. Anais ..LaGrange Park, Illionois. American Nuclear Society, 2007. P. 2038 - 1041.

HARVEY, B. G. Introduction to Nuclear Physics and Chemistry. Englewwod Cliffs, N. J.: Prentice-Hall, 1969.

HIGA, M. C. Aplicação de ensaios de toxicidade na avaliação da eficiência da radiação ionizante e da adsorção em zeólitas para o tratamento de efluentes coloridos. 2008. Dissertação (Mestrado) - Instituto de Pesquisas Energéticas e Nucleares - Universidade de São Paulo, São Paulo. Disponível em: < http://www.teses.usp.br/teses/disponiveis/85/85131/tde-15092009-173013/ptbr.php $>$. Acesso em: 18 de março de 2016.

HOMLOK, R.; TAKÁCS, E.; WOJNÁROVITS, L. Elimination of diclofenac from water using irradiation technology.Chemosphere, n. 85, p. 603-608, 2011.

HOMLOK, R.; TAKÁCS, E. WOJNÁROVITS, L. Degradation of organic molecules in advanced oxidation processes: Relation between chemical structure and degradability. Chemosphere, n 91, p. 383-389, 2013.

HONG, H.N., KIM, H.N., PARK, K.S., LEE, S.K.; GU, M.B. Analysis of the effects diclofenac has on Japonese medaka (Oryzias latipes) using real-time PCR. Chemosphere, v. 67, n. 11, p. 2115-2121, 2007.

HORA, A. S.; COSTA, I. G. F.; GOMES, S. C.; FERREIRA, S. V.; LIMA JR., E. H.. MEDICAMENTO E LUCRO: até que ponto essa associação pode ser saudável? Revista presença. v. 1, n. 1, 2015.

INMETRO, 2007. Instituto Nacional de Metrologia, Normalização e Qualidade Industrial. Sistema Internacional de Unidades, Tradução da 7. Ed do original francês "Le Système International d' Unités", elaborado pelo Bureau International dês Poids ET Mesures - BIPM. 8. Ed. (revisada). Rio de Janeiro: INMETRO, 2007.

INTERNATIONAL ATOMIC ENERGY AGENCY (IAEA). Emerging applications of radiation processing Vienna, 2004. Disponível em: < pub.iaea.org/books/IAEABooks/6926/Emerging-Applications-of-Radiation-

Processing >. Acesso em: 18 de março de 2016.

INTERNATIONAL ATOMIC ENERGY AGENCY (IAEA). Radiaton Processing: Environmental Applications. Vienna, 2007. Disponível em: < http://www- 
pub.iaea.org/books/IAEABooks/7631/Radiation-Processing-EnvironmentalApplications >. Acesso em: 18 de março de 2016.

INSTITUTO DE PESQUISAS ENERGÉTICAS E NUCLEARES, IPEN. Workshop promove interação entre pesquisadores do IPEN e do Senai-SP. 2015. Disponível em:

https://www.ipen.br/portal_por/portal/interna.php?secao id=38\&campo=5123 >. Acesso em: 18 de março de 2016.

IUPAC. Nomenclature for chromatography. Pure \& Applied Chemistry, v. 64, n. 4, p. 819-872, 1993.

KLAVARIOTI, M., MANTZAVINOS, D., KASSINOS, D. Removal of residual pharmaceuticals from aqueous systems by advanced oxidation processes. Environmental International. v. 35, n.2, p 402-417, 2009.

KNIE, J. L. W.; LOPES, E. W. B. Testes Ecotoxicológicos: métodos, técnicas e aplicações. Florianópolis: FATMA / GTZ, 2004. P. 289, 2004.

KUMAR, K. A.; MOHAN, S. V.; SARMA, P. N. Sorptive removal of endocrinedisruptive compound (estriol, E3) from aqueous phase by batch and column studies: Kinetic and mechanistic evaluation. Journal of Hazardous Materials, v. 164, p. 820-828, 2009.

KWON, J. W.; ARMBRUST, K .L. Laboratory persistence and fate of fluoxetine in aquatic environments. Environmental Toxicology Chemistry .n. 25, p.25612568, 2006.

LI, W.C. Occurrence, sources, and fate of pharmaceuticals in aquatic environment and soil. Environmental Pollution, n. 187, p. 193-201, 2014.

LESTER, Y.; MAMANE, H.; ZUCKER. I.; Avisar, D. Treating wastewater from a pharmaceutical formulation facility by biological process and ozone. Water research, v. 47, p. 4349-4356, 2013.

LÓPEZ-SERNA, R.; PÉREZ, S.; GENEBREDA, A.; PETROVIC, M.; BARCELÓ, D. Fully automated determination of 74 pharmaceuticals in environmental and waste by online solid phase extradition-liquid chromatography-electrospraytandem mass spectrometry. Talanta, v. 83, p. 410-424, 2010.

MADIGAN T. M.; MARTINKO, M. J.; PARKER, J. Microbiologia de Brock, Ed. 10, Editora Prentice-Hall, São Paulo. 2004.

MAGALHÃES, D. P.; FERRÃO FILHO, A. S. A ecotoxicologia como ferramenta no biomonitoramento de ecossistemas aquáticos. Oecologia Nrasiliensis, v.12, n.3, p. 355-381, 2008.

MALDANER, L. E JARDIM, I. C. S. F. O estado da arte da cromatografia líquida de ultra eficiência. Química Nova, v. 32, n. 1,p. 214-222, 2009.

MASSARO, F. C. Estudos ecológicos e ecotoxicológicos de espécies nativas de Hydra (Cnidaria: Hydrozoa). 2011. Tese (Doutorado em Ciências) - Escola 
de Engenharia de São Carlos, Universidade de São Paulo, São Carlos. 502 p. Disponível em: < http://www.teses.usp.br/teses/disponiveis/18/18139/tde25042011-092531/pt-br.php > Acesso em: 18 de março de 2016.

MENDES, F. R.; MOREIRA, B. S. S.; CORTEZ, F. S.; SANTOS, A. R.; CÉSAR, A. Avaliação do efeito agudo dos fármacos ibuprofeno e diclofenaco através de teste de toxicidade com Daphnia similis. Revista Ceciliana, v. 2, n. 2, p. 9-12, 2010.

MÉNDEZ-ARRIAGA. F.; OTSU, T.; OYAMA, T.; GIMENEZ, J.; ESPLUGAS, S.; HIDAKA, H.; SERPONE, N. Photooxidation of the antidepressant drug Fluoxetine $\left(\operatorname{Prozac}^{\circledR}\right.$ ) in aqueous media by hybrid catalytic/ozonation processes. Water research, n. 45, p. 2782-2794, 2011.

MORAIS, A. V.; Avaliação da toxicidade e remoção de cor de um efluente têxtil tratado com feixe de elétrons. 2015. Dissertação (Mestrado) - Instituto de Pesquisas Energéticas e Nucleares - Universidade de São Paulo, São Paulo. Disponível em: < http://www.teses.usp.br/teses/disponiveis/85/85131/tde22042014-155700/en.php > Acesso em: 18 de março de 2016.

MULROY, A. Monitoring and analysis of water and wastes. Water Environmental \& Technology, v.13, n. 2, p. 32-36, 2001.

NIPPER, M. Testes estatistitcos para a analise de resultados de testes de toxicidade com amostras liquidas e sedimentos. In: NASCIMENTO, I.A; SOUSA, E.C.P.N.; NIPÉR, M (Ed). Metodos em ecotoxicologia marinha: aplicacoes no Brasil. São Paulo: Artes Gráficas, Cap. 21, p. 245-259. 2002.

OLIVEIRA, L. L. D. Biomarcadores enzimáticos e testes ecotoxicológicos na avaliação da toxicidade de fármacos em invertebrados aquáticos. 2014. Tese (Doutorado) - Escola de Engenharia de São Carlos, São Carlos. Disponivel em: < http://www.teses.usp.br/teses/disponiveis/18/18139/tde-09022015-110612/ptbr.php > Acesso em: 18 de março de 2016

OLLER, I.; MALATO, S.; SÁNCHEZ-PÉREZ, J. A. Combination of Advanced Oxidation Processes and biological treatments for wastewater decontaminationA review. Science of the Total Environment, v. 409, p. 4141-4166, 2011.

ORSI, C. Água de 20 capitais tem 'contaminantes emergentes'. O Jornal da Unicamp.C ampinas, 23 de setembro de 2013. Disponível em: < http://www.unicamp.br/unicamp/ju/576/agua-de-20-capitais-tem-contaminantesemergentes > Acesso em: 18 de março de 2016

PÉRY, A. R. R.; GUST, M.; VOLLAT, B.; MONS, R.; RAMIL, M.; FINK, G.; TERNES, T.; GARRIC, J. Fluoxetine effects assessment on the life cycle of aquatic invertebrates. Chemosphere, n. 73, p. 300-304, 2008.

PINHEIRO, A. S. Avaliação da toxicidade e genotoxicidade dos corantes azo reativos Remazol Preto B e Remazol Alaranjado $3 \mathrm{R}$ e da eficácia da radiação com feixe de elétrons na redução da cor e efeitos tóxicos. 2011. Tese (Doutorado) - Instituto de Pesquisas Energéticas e Nucleares - Universidade de São Paulo, São Paulo. Disponível em: < 
http://www.teses.usp.br/teses/disponiveis/85/85131/tde-02032012-135231/ptbr.php $>$. Acesso em: 18 de março de 2016.

QUINN. B.; SCHMIDT. W.; O'ROURKE. K.; HERNAN, R. Effects of the pharmaceuticals gemfibrozil and diclofenac on biomarker expression in the zebra mussel (Dreissena polymorpha) and their comparison with standardised toxicity tests. Chemosphere. v. 84, n. 5, p.657-63, 2011.

RAND, G.M. Fundamentals of aquatic toxicology: effects, environmental fate, and risk assessment. Ed Taylor \& Francis, p 1125, 1995.

RAUF, M. A.; ASHRA, S. S. Radiation induced degradation of dyes - An overview. Journal of Hazardous Material, v 166, n. 1, p 6-16, 2009.

RELA, C. S. Estudo da viabilidade técnica e econômica para implementação de uma unidade móvel para tratamento de efluentes industriais com feixe de elétrons. 2006. Dissertação (Mestrado) - Instituto de Pesquisas Energéticas e Nucleares - Universidade de São Paulo, São Paulo. Disponível em: < http://www.teses.usp.br/teses/disponiveis/85/85131/tde-16052012-091709/pt-

br.php > Acesso em: 18 de março de 2016.

RIBANI, M. BOTTOLI, C. B. G.; COLLINS, C. H.; JARDIM, I. C. S. F.; MELO, L. F. C. Validação em métodos cromatográficos e eletroforéticos. Química Nova, v. 27, n. 5, p. 771-780, 2004.

RISSI, N.C. Correlação entre estrutura e propriedades de sistemas líquidos cristalinos para a liberação prolongada de fármacos. 2013. Dissertação (Mestrado) - Universidade Estadual Paulista “Júlio de Mesquita Filho" , Araraquara

São Paulo. Disponível em: < http://www2.fcfar.unesp.br/Home/Posgraduacao/CienciasFarmaceuticas/NATHALIA\%20C.\%20RISSI\%20-\%20ME.pdf > Acesso em: 18 de março de 2016.

RIZZO, L. Bioassays as a tool for evaluating advanced oxidation processes in water and wastewater treatment. Water Research, n. 45, p. 4311-4340, 2011.

RIZZO, L.; MERIC, S.; KASSINOS, D.; GUIDA, M.; RUSSO, F.; BELGIORNO, V. Degradation of diclofenac by $\mathrm{TiO} 2$ photocatalysis: UV absorbance kinetics and process evaluation through a set of toxicity bioassays. Water Research, n. 43, p; 979-988, 2009.

ROCHA, M.A. Biodegradação de Diclofenaco de Sódio por Aspergillus sp. 2010. Dissertação (Mestrado) - Universidade de Santa Cruz do Sul - UNISC, Santa Cruz do Sul. Disponível em: < http://livros01.livrosgratis.com.br/cp153270.pdf > Acesso em: 18 de março de 2016.

ROMANELLI, M.F.; MORAES, M.C.F.; VILLAVICENCIO, A.L.C.H.; BORRELY, S.I. Evaluation of toxicity reduction of sodium dodecyl sulfate submitted to electron beam radiation, Radiation Physics and Chemistry, v.71, p.409-411, 2004.

SANTOS D. R. A. Avaliação ecotoxicológica do fármaco cloridrato de fluoxetina e do surfactante dodecil sulfato de sódio quando submetidos a 
tratamento por radiação ionizante. 2011. Dissertação (Mestrado) - Instituto de Pesquisas Energéticas e Nucleares, Universidade de São Paulo, São Paulo. Disponível em: < http://www.teses.usp.br/teses/disponiveis/85/85131/tde03042012-105630/en.php > Acesso em: 18 de março de 2016.

SCHWAIGER, J.; FERLING, H.; MALLOW, U.; WINTERMAYR, H.; NEGELE, R. D. Toxic effects of the non-steroidal anti-inflammatory drug diclofenac: Part I: histopathological alterations and bioaccumulation in rainbow trout. Aquatic Toxicology, v. 68, n. 2, p. 141-150, 2004.

SHIMADZU CORPORATION. Total Organic Carbon Analyzer TOC-L. 2014.

SIRTORI, C.; ZAPATA, A.; OLLER, I.; GERNJAK, W.; AGUERA, A.; MALATO, S. Decontamination industrial pharmaceutical wastewater by combining solar photoFenton and biological treatment. Water research v. 43, p. 661-668, 2009.

SELAMBAKKANU, S.; BAKAR, K. A.; TING, T. M.; SHARIF, J.; DAHLAN, K. Z. Effect of gamma and electron beam irradiation on textile waster water. 2011.

SILVA, V. H. O. Avaliação da toxicidade e da degradação do fármaco cloridrato de fluoxetina, em solução aquosa e em mistura com esgoto doméstico, empregando irradiação com feixe de elétrons. 2014. Dissertação (Mestrado) - Instituto de Pesquisas Energéticas e Nucleares - Universidade de São Paulo, São Paulo. Disponível em: < http://www.teses.usp.br/teses/disponiveis/85/85131/tde-22042014-155700/en.php > Acesso em: 18 de março de 2016.

SOARES, W. A. A. Estudo da distribuição de metais em águas, sedimentos e organismos aquáticos de rios e reservatórios pertencentes à rede de monitoramento da qualidade dos sedimentos do Estado de São Paulo. 2012. Dissertação (Mestrado) - Instituto de Pesquisas Energéticas e Nucleares Universidade de São Paulo, São Paulo. Disponível em: < http://pelicano.ipen.br/PosG30/TextoCompleto/Walace\%20Anderson\%20Almeida \%20Soares M.pdf > Acesso em: 18 de março de 2016

SOUSA, B. A. I. Avaliação toxicológica de misturas dos medicamentos veterinários (Monensina, Sulfametazina e Enrofloxacina) em Daphnia magna (Cladocera, Crustacea). 2013. Dissertação (Mestrado) - Centro de Energia Nuclear na Agricultura - Universidade de São Paulo, Piracicaba. Disponível em: < http://www.teses.usp.br/teses/disponiveis/64/64135/tde-28012014-160019/ptbr.php > Acesso em: 18 de março de 2016.

SOUSA, D. N. R. Ocorrência e distribuição de contaminantes emergentes na bacia hidrográfica do rio Jundiaí - São Paulo. 2015. Tese (Doutorado) da Universidade Federal De São Carlos. Disponível em: < http://www.bdtd.ufscar.br/htdocs/tedeSimplificado//tde busca/arquivo.php?codArq uivo $=8213>$ Acesso em: 18 de março de 2016.

SOUZA, R. M. G. L. PRINCÍPIOS E MÉTODOS UTILIZADOS EM SEGURANÇA DA ÁGUA PARA CONSUMO HUMANO. 2008. São Paulo. 
TAGGART, M.A.; SENACHA, K. R.; GREEN, R. E.; JHALA, Y. V.; RAGHAVAN, B.; RAHMANI, A. R.; CUTHBERT, R.; PAIN, D. J.; MEHARG, A. E. ; . Diclofenac residues in carcasses of domestic ungulates available to vultures in India. Environmental International. v. 33, n. 6, p. 759-765, 2007.

TELLES-CORREIA,D.; GUERREIRO, D. F.; COENTRE, R.; ZUZARTE, P.; FIGUEIRA, L. PSICOFÁRMACOS NA DOENÇA MÉDICA Cardiologia, Nefrologia, Hepatologia. Acta Med Port. v. 22, n. 6, p. 797-808, 2009.

TEXEIRA, C. P. A. B.; JARDIM, W. F. Processos Oxidativos Avançados. Conceitos Teóricos. Universidade Estadual de Campinas, Laboratório de Química Ambiental, 2004.

TORRES, N.H.; ROMANHOLO FERREIRA, L.F.; AMERICO, J. H. P.; FREGUGLIA, R. M. O. ;MOURA-ANDRADE, G. C. R.; TORNISIELO, V. L. Analysis and occurrence of residues of the hormones estriol, 17alphaethinylestradiol and 17beta-estradiol in urban water supply by HPLCDAD. Journal of Engineering, v. 2, p. 984-989, 2012.

TRUHAUT, R. Ecotoxicology: Objectives, Principles and Perspectives. Ecotoxicology and Environmental Safety, v. 1, p. 151-173, 1977.

UFPR, Universidade Federal do Paraná (Departamento de Estatística). Estatística II. 2009. Disponível em: < http://www.est.ufpr.br/ce003/material/apostilace003.pdf > Acesso em: 18 de março de 2016.

VAN HAANDEL, A. C.; MARAIS, G. O comportamento do sistema de lodo ativado. Campina Grande: epgraf, p. 472, 1999.

VERLICCHI, P.; GALLETTI, A.; PETROVIC, M.; BARCELO, D. Hospital effluents as a source of emerging pollutants: An overview of micropollutants and sustainable treatment options. Journal of Hydrology, v. 389, p. 416-428, 2010.

WEINBERGER II, J.; KLAPER, R. Environmental concentrations of the selective serotonina reuptake inhibitor fluoxetina impact specific behavior involved in reproduction, feeding and predator avoidance in the fish Pimephales promelas (fathead minnow). Aquatic Toxicology, Article in Press. 2014.

ZAGATTO, P. A., BERTOLETTI, E. Ecotoxicologia Aquática: Princípios e Aplicações, Ed. Rima: São Carlos, 2006.

ZAGATTO, P. A \& BERTOLETTI, E. Ecotoxicologia Aquática - Princípios e Aplicações. 2aㅡ ed. Rima Editora. São Carlos-SP. 2008.

ZWIENER, C. Frimmel, F. H. Short-term tests with a pilot sewage plant and biofilm reactors for the biological degradation of the pharmaceutical compounds clofibric acid, ibuprofen, and diclofenac. The Science of the Total Environment, n .309 p, 2003. 